UNIVERSITY OF SÃO PAULO

DEPARTMENT OF STRUCTURAL AND GEOTECHNICAL ENGINEERING

FELIPE AUGUSTO DA SILVA BARBOSA

Numerical Assessment of Concrete Flexural Members Reinforced by FRP Rebars

São Paulo

2020 


\section{Numerical Assessment of Concrete Flexural Members Reinforced by FRP} Rebars

\section{Revised Version}

Dissertation thesis submitted to the Department of Structural and Geotechnical Engineering in partial fulfillment of the requirements for the degree of Master's in Sciences.

Concentration Area: Structural Engineering

Advisor: Professor Dr. Túlio Nogueira Bittencourt

São Paulo 
Autorizo a reprodução e divulgação total ou parcial deste trabalho, por qualquer meio convencional ou eletrônico, para fins de estudo e pesquisa, desde que citada a fonte.

Este exemplar foi revisado e corrigido em relação à versão original, sob responsabilidade única do autor e com a anuência de seu orientador.

São Paulo, 22 de__Julho de 2020

Assinatura do autor: Telipe Augusto da Satva Darbosa

Assinatura do orientador:

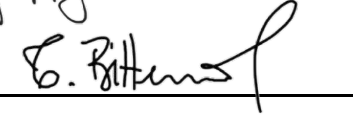

Catalogação-na-publicação

\section{Barbosa, Felipe}

Análise Numérica de Elementos de Concreto Armado com Barras de

PRF Sujeitos à Flexão / F. Barbosa -- versão corr. -- São Paulo, 2020.

$158 \mathrm{p}$.

Dissertação (Mestrado) - Escola Politécnica da Universidade de São Paulo. Departamento de Engenharia de Estruturas e Geotécnica.

1.Materiais Compósitos Poliméricos 2.Concreto Armado 3.Concreto Protendido 4.Dimensionamento de Estruturas I.Universidade de São Paulo. Escola Politécnica. Departamento de Engenharia de Estruturas e Geotécnica II.t. 


\section{ACKNOWLEDGMENTS - AGRADECIMENTOS}

Em primeiríssimo lugar, agradeço a Deus por todas as graças alcançadas no âmbito pessoal e profissional. Tenho a mais pura convicção de que, nos momentos mais difíceis, Ele se fez presente, dando-me forças para continuar lutando e não desistir jamais.

A minha família, meu bem maior: minha mãe Dalva, meu pai Marcos, meu irmão Arthur e minha avó Estelita pelo apoio incondicional, incentivando-me a sempre lutar pelos meus objetivos.

Ao Professor Túlio Nogueira Bittencourt pela paciência e boa vontade para comigo durante todo o desenvolvimento deste trabalho de mestrado. Agradeço por ter me dado a oportunidade de melhorar como profissional, visto que aprendi bastante durante este tempo.

A meus amigos e colegas de laboratório Gustavo Boriolo, Marcela Teixeira, Marcel Amaral, Marcos Barros, Yasmin Trindade, Ludmily Pereira, Malu Ribeiro, Paulo Víctor, Lívia Borges, André Peres, Tiago Marum e especialmente a Nathanaell Welter, Fernanda Ramos e Tarcísio Dias, amigos que levarei para além desta pós-graduação.

A todos do grupo de pesquisa GMEC - Grupo de Modelagem de Estruturas de Concreto - em especial a Juliana Fernandes, Rafael Petille, Osmar Manzoli e Alfredo Neto, pela oportunidade de aprendizado e crescimento profissional.

A Fellipe Rodrigues André, pela ajuda no desenvolvimento da interface gráfica referente ao programa de dimensionamento.

À USP - Universidade de São Paulo - pelo ensino de qualidade e excelente estrutura dos laboratórios, essencial para o desenvolvimento dos trabalhos de pesquisa.

À CAPES - Coordenação de Aperfeiçoamento de Pessoal de Nível Superior - pelo apoio financeiro concedido a esta pesquisa, Código de Financiamento 001.

À UFPB - Universidade Federal da Paraíba - instituição pela qual obtive o título de Bacharel em Engenharia Civil. Agradeço pelo ensino de qualidade sempre prezado pelos profissionais desta instituição.

A meus amigos Jéssica Carvalho, Bruno Fernandes, Larissa Suassuna, Rickson Carvalho, Daniel Félix, Esdras Queiroz, Alene Barbosa, Rogério Mota, Mariana Tavares, Priscila Almeida, Victor Mellia, Cristiane Silveira, Virgínia Dumont, Pedro Teodoro, Paula Bolelli, Karina Rocha, Matthew Danahy e demais. 


\begin{abstract}
The FRP - Fiber-Reinforced Polymer - reinforcement consists of an alternative material to replace the conventional steel in reinforced concrete structures. Besides being corrosion resistant, FRP is lightweight and has high tensile strength, being successively utilized in sea walls, magnetic resonance units, garage parks and bridges. However, the FRP stress-strain relationship is linear up to failure, not exhibiting a yielding plateau. It also has low elasticity modulus and presents sudden failure if subjected to high sustained stresses. Thus, this research evaluated the steps for the design of flexural members reinforced and prestressed with FRP rebars and strands, respectively. Their structural behavior was also numerically investigated and compared to that regarding the same members reinforced and prestressed with steel. Furthermore, the long-term behavior of one beam reinforced with different ratios of Glass FRP was evaluated from the short-term response to a period of one hundred years. The parameters for the long-term numerical assessment were based on design codes and experimental test results. Additionally, three axially loaded prismatic members and three simply supported beams were modeled to investigate the use of FRP in prestressing. The purpose was to obtain the axial force-strain and moment-curvature relationships, as well as to evaluate the cracking behavior and compare the performance of FRP prestressed members to those with steel. Finally, the equations for the design of rectangular and T/L cross-section shapes were developed through equilibrium and compatibility, considering the Navier's hypothesis. Those formulations were implemented to a code, which resulted in a design program that calculates the required FRP area for different concrete compressive strengths. For the cases in study, the results indicated that the creep rupture limit state usually governs the design of cross-sections reinforced with Aramid and Glass FRP, leading to over-reinforced cross-sections. In contrast, using Aramid and Carbon FRP in prestressing proved to be effective in comparison to the conventional steel. They exhibited higher flexural strengths and less intense cracking, with no need to overreinforce the cross-sections. Regarding the long-term behavior, changes in the concrete constitutive properties resulted in increases in the flexural strengths and changes in the failure mode. Moreover, deflections and crack widths exhibited the highest rate of increase during the first five years, stabilizing around the age of seventy years.
\end{abstract}

Keywords: non-metallic reinforcement, Fiber-reinforced polymer, FRP, long-term effects, design program, reinforced concrete, prestressed concrete. 


\section{RESUMO}

A armadura não metálica de PRF - Polímeros Reforçados por Fibras - constitui uma alternativa ao aço do concreto armado convencional, uma vez que é resistente à corrosão, apresenta baixo peso específico e alta capacidade de carga. Seu uso tem se mostrado eficiente em paredes marinhas, unidades de ressonância magnética, garagens e pontes. Diferentemente do aço convencional, a armadura de PRF não escoa, exibindo comportamento elástico-linear até a ruptura. Além disso, apresenta baixa rigidez e rompe por fluência quando sujeitas a elevadas cargas permanentes. Diante disso, esta pesquisa avaliou as etapas de dimensionamento e, através de análises numéricas, investigou o comportamento dos concretos armado e protendido com barras e cordoalhas de PRF, comparando-os com os concretos em aço convencional. Além disso, com base em parâmetros fornecidos por normas e ensaios, foram analisados os efeitos diferidos no tempo em uma viga armada com diferentes taxas de armadura de PRFV (vidro), para a qual estimaram-se os momentos resistentes, deflexões, abertura de fissuras e relações momento-curvatura, considerando-se a reposta imediata e períodos de cinco a cem anos. A fim de compreender o uso do PRF na protensão, foram modeladas três barras prismáticas e três vigas biapoiadas para as quais se avaliaram a relação normal-deformação e momento-curvatura, respectivamente, além da fissuração, comparando-os com os mesmos elementos protendidos em aço. Por fim, com base nas condições de equilíbrio e compatibilidade bem como nas hipóteses de Navier, foram desenvolvidas as formulações para o dimensionamento de vigas com seção retangular e T ou L. Estas formulações foram implementadas em um código, resultando em um programa computacional para cálculo da quantidade de armadura de PRF considerando diferentes classes de concreto. Para os casos em estudo, os resultados indicaram que o estado limite de ruptura à fluência geralmente governa o dimensionamento de seções armadas em PFRV e PRFA (aramida), acarretando em seções super-armadas. Em contrapartida, o uso de PRFA e PRFC (carbono) na protensão mostrou-se vantajoso em relação ao aço convencional, com elevados momentos resistentes, fissuração menos intensa e sem necessidade de super-armar as seções. Em relação ao comportamento a longo prazo, as mudanças nas propriedades constitutivas do concreto resultaram no aumento da capacidade resistente das seções e alteração do modo de falha. Além disso, as deflexões e abertura de fissuras cresceram em maior proporção nos primeiros cinco anos, estabilizando-se por volta dos setenta.

Palavras-chave: armadura não metálica, polímeros reforçados por fibras, PRF, efeitos diferidos no tempo, programa de dimensionamento, concreto armado, concreto protendido. 


\section{LIST OF FIGURES}

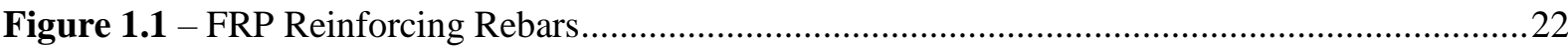

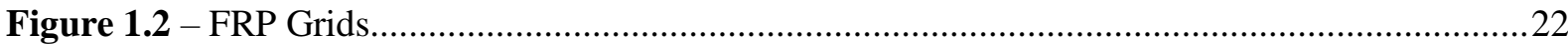

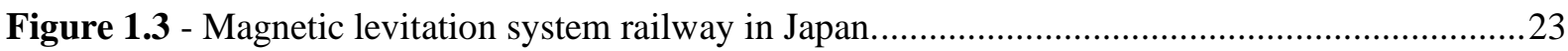

Figure 1.4 - GFRP reinforcing of the Emma Park Bridge, 2009 - Utah. ...........................................24

Figure 1.5 - Seawall protecting the Honoapiilani Highway in Maui, Hawaii. ......................................24

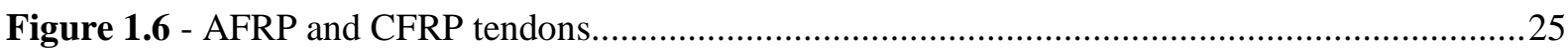

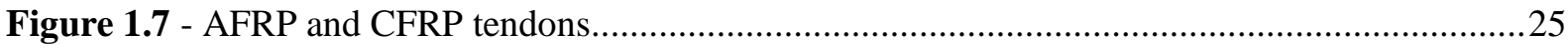

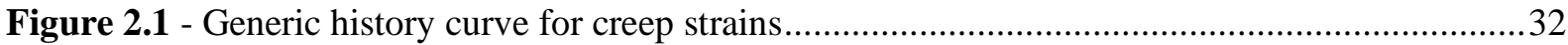

Figure 2.2 - Equilibrium and compatibility conditions for a balanced generic cross-section...............37

Figure 2.3 - Concrete stress-strain relationship for compression. ........................................................39

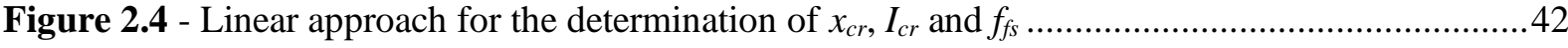

Figure 2.5 - Experimental bending moment-deflection relationship..................................................44

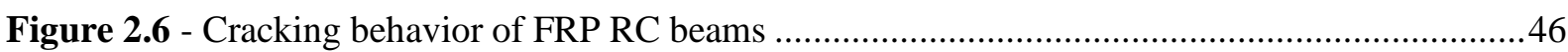

Figure 2.7 - Influence areas for the calculation of crack widths .....................................................47

Figure 2.8 - Different types of anchorage systems: a) Clamp; b) Plug and cone; c) straight sleeve; d)

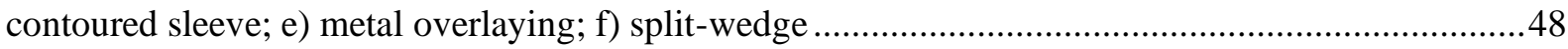

Figure 2.9 - Cross-section details of the flexural members ..................................................................

Figure 3.1 - Structural plan view - Lengths in $m$, cross-section dimensions in $\mathrm{cm}$.............................55

Figure 3.2 - Illustration of masonry walls supported by beams and slabs .........................................56

Figure 3.3 - Plastic hinges for the computing of linear distributed loads...........................................56

Figure 3.4 - Generic cross-section for the calculation of crack widths ...............................................60

Figure 4.1 - GFRP RC beam considered for the numerical analysis ...............................................69

Figure 4.2 - Cross-section equilibrium and compatibility conditions............................................... 70

Figure 4.3 - Chart for the determination of $k$, based on the volume to surface are ratio ....................72

Figure 4.4 - Shifting of concrete stress-strain curve due to the creep phenomenon ............................72

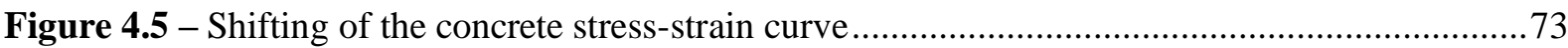

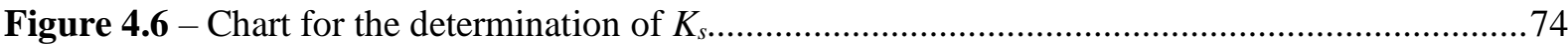

Figure 4.7 - Trend lines for the determination of $\beta$ as a function of $f_{f s} / f_{f u}$, obtained from experimental

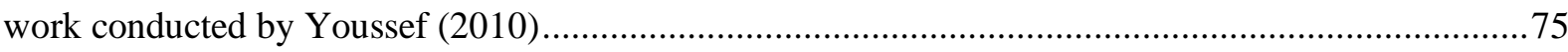

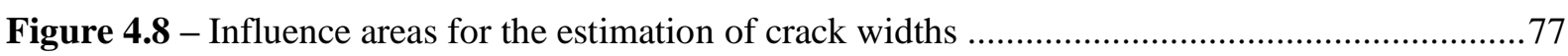

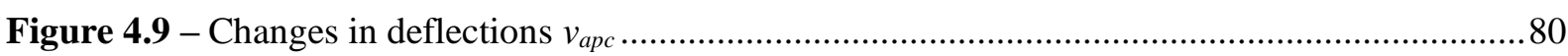

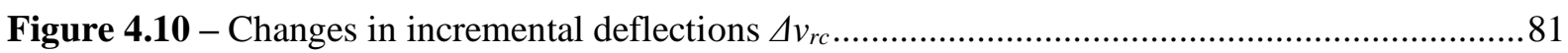

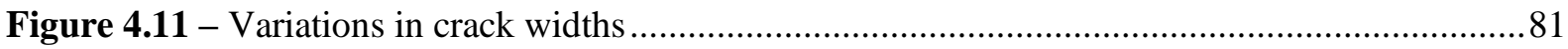

Figure 4.12 - Moment-curvature relationships for the Scenario I, whereby $\rho_{\mathrm{f}}=\rho_{\mathrm{fmin}} \ldots \ldots \ldots \ldots \ldots \ldots \ldots \ldots \ldots . . . . . . . . . . .82$ 
Figure 4.13 - Moment-curvature relationships for the Scenario II, whereby $\rho_{\mathrm{f}}=0.85 \rho_{\mathrm{fb}} \ldots \ldots \ldots \ldots \ldots \ldots . . . . . . . . . .22$

Figure 4.14 - Moment-curvature relationships for the Scenario III, whereby $\rho_{\mathrm{f}}=\rho_{\mathrm{fb}} \ldots \ldots \ldots \ldots \ldots \ldots \ldots \ldots . . . . . . . . . . . .82$

Figure 4.15 - Moment-curvature relationships for the Scenario IV, whereby $\rho_{\mathrm{f}}=1.5 \rho_{\mathrm{fb}} \ldots \ldots \ldots \ldots \ldots \ldots \ldots . . . . . . . . .83$

Figure 4.16 - Moment-curvature relationships for the Scenario V, whereby $\rho_{\mathrm{f}}=2.0 \rho_{\mathrm{fb}} \ldots \ldots \ldots \ldots \ldots \ldots \ldots . . . . . . . . . .83$

Figure 5.1 - Prismatic member subjected only to axial loads ........................................................... 87

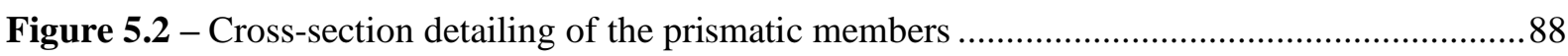

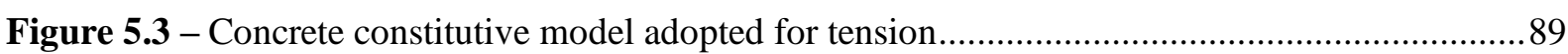

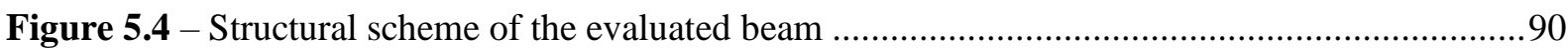

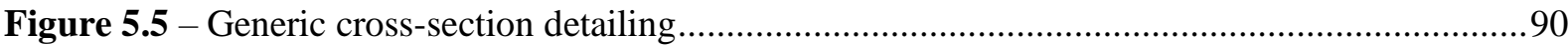

Figure 5.6 - Boundaries for the reinforcement positioning, considering concrete C30 ….................94

Figure 5.7 - Boundaries for the reinforcement positioning, considering concrete C70 ….................95

Figure 5.8 - Cross-section detailing with influence areas for the cracking evaluation ........................95

Figure 5.9 - Equilibrium and compatibility conditions of the prestressed beam ...............................98

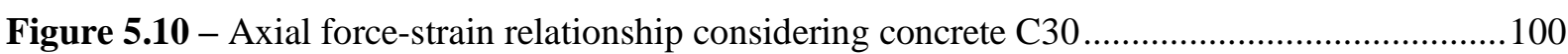

Figure 5.11 - Axial force-strain relationship considering concrete $\mathrm{C} 70$.......................................101

Figure 5.12 - Relationship between axial forces and crack widths, considering concrete C30 ........102

Figure 5.13 - Relationship between axial forces and crack widths, considering concrete C70 .........102

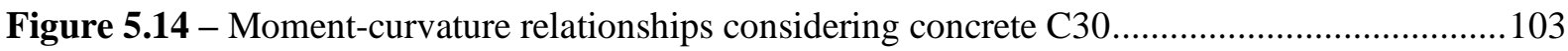

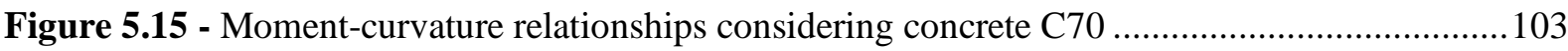

Figure 5.16 - Relationship between bending moments and crack widths for concrete C30 .............105

Figure 5.17 - Relationship between bending moments and crack widths for concrete C70 ….........106

Figure 6.1 - Balanced cross-section analysis for the stress block located on the flange. ...................109

Figure 6.2 - Balanced cross-section analysis for the stress block located on the web .......................109

Figure 6.3 - Tension-controlled section, neutral axis on the flange and concrete linear behavior ......111

Figure 6.4 - Tension-controlled section with stress block on the flange ….....................................112

Figure 6.5 - Tension-controlled section with stress block on the web..........................................114

Figure 6.6 - Tension-controlled section, neutral axis on the web and concrete linear behavior ........115

Figure 6.7 - Compression-controlled section with stress block on the flange ..................................117

Figure 6.8 - Compressed-controlled section with stress block on the web .....................................117

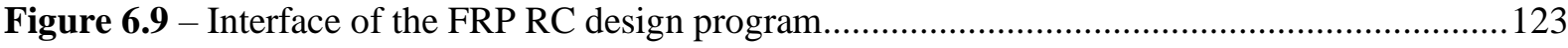

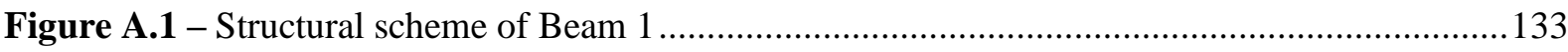

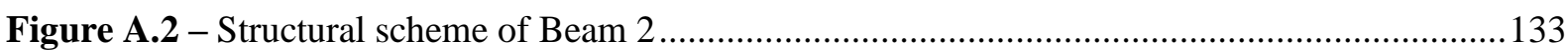

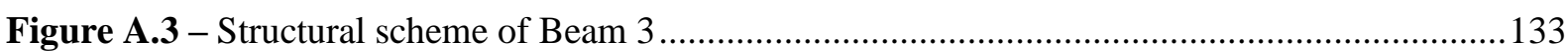

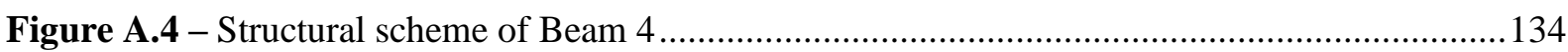

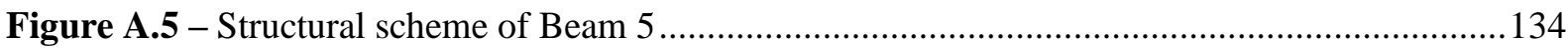

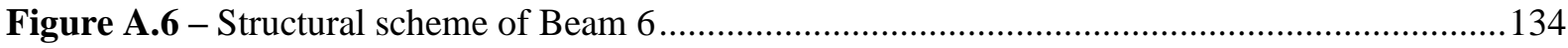

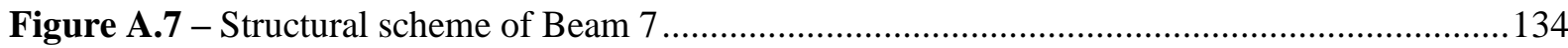


Figure A.8 - Structural scheme of Beam 8

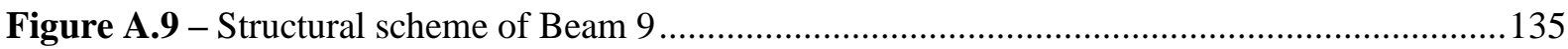

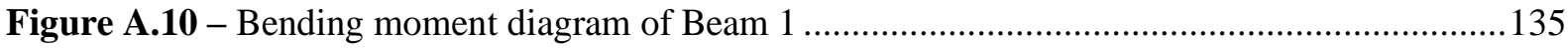

Figure A.11 - Bending moment diagram of Beam 2 …...........................................................136

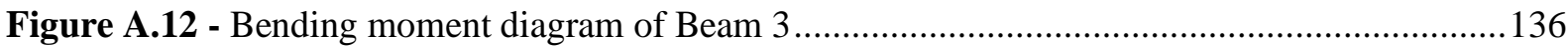

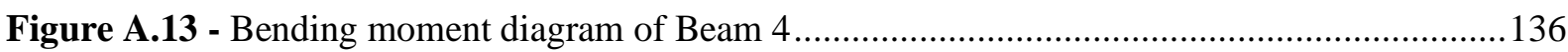

Figure A.14 - Bending moment diagram of Beam 5 …..........................................................136

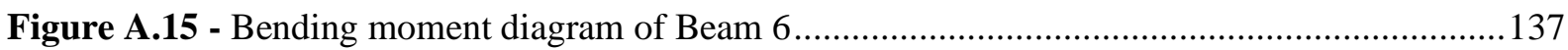

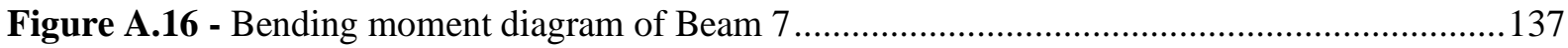

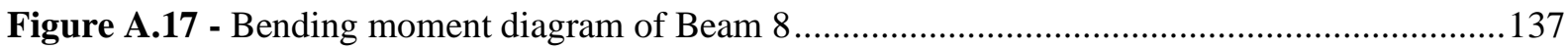

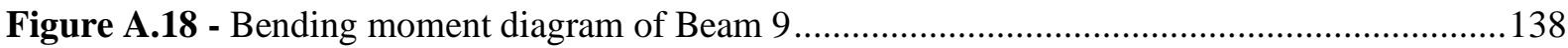

Figure B.1 - Example A: Balanced stress block on the flange, under-reinforced cross-section and concrete exhibiting linear behavior

Figure B.2- Example B: Balanced stress block on the flange, under-reinforced cross-section and concrete exhibiting non-linear behavior....

Figure B.3 - Example C: Balanced stress block on the flange, over-reinforced cross-section and actual stress block on the flange

Figure B.4 - Example D: Balanced stress block on the flange, over-reinforced cross-section and actual stress block on the web. 155

Figure B.5 - Example E: Balanced stress block on the web, under-reinforced cross-section, concrete exhibiting non-linear behavior and actual stress block on the flange 156

Figure B.6 - Example F: Balanced stress block on the web, under-reinforced cross-section, concrete exhibiting non-linear behavior and actual stress block on the web.

Figure B.7 - Example G: Balanced stress block on the web, under-reinforced cross-section, concrete exhibiting linear behavior and actual neutral axis on the flange

Figure B.8 - Example H: Balanced stress block on the web, under-reinforced cross-section, concrete exhibiting linear behavior and actual neutral axis on the web.

Figure B.9 - Example I: Balanced stress block on the web, over-reinforced cross-section and actual stress block on the web. 


\section{LIST OF TABLES}

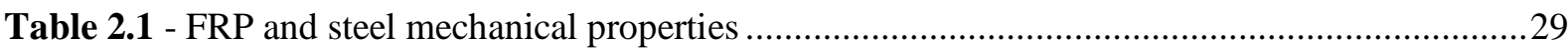

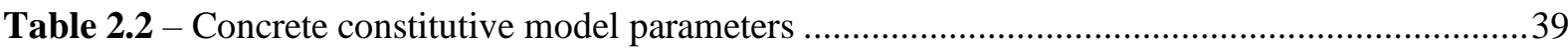

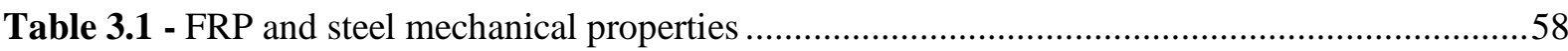

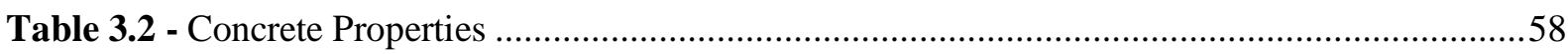

Table 4.1 - Description of different scenarios the beam was evaluated .............................................. 71

Table 4.2 - Determination of flexural strengths and applied loads .................................................... 71

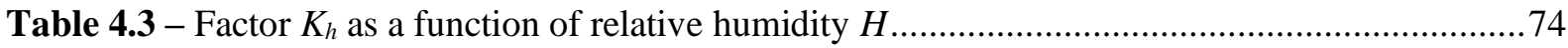

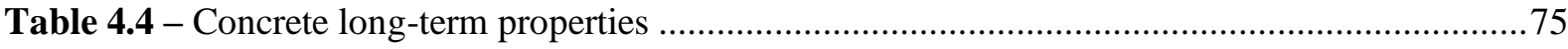

Table 4.5 - Changes in flexural strengths and balanced ratio for the scenarios I, II and III ................79

Table 4.6 - Changes in flexural strengths and balanced ratios for the scenarios IV and V..................79

Table 4.7 - Long term concrete and GFRP stresses for the scenarios I, II and III ..............................80

Table 4.8 - Long term concrete and GFRP stresses for the scenarios IV and V .................................80

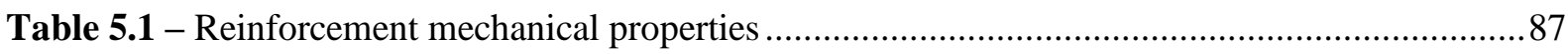

Table 5.2 - Concrete Properties according to ABNT NBR 6118 (2014) …...........................................87

Table 5.3 - Parameters for the calculation of time-dependent losses ...............................................93

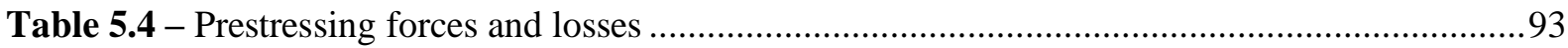

Table 5.5 - Checking for the ultimate limit state, considering concrete C30 ....................................97

Table 5.6 - Checking for the ultimate limit state, considering concrete $\mathrm{C} 70$....................................97

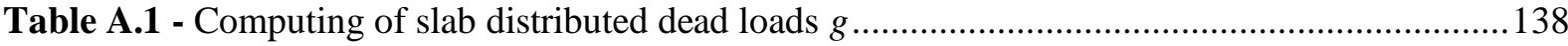

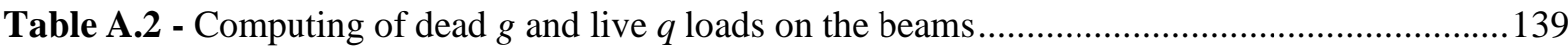

Table A.3 - Design for the ultimate limit state - AFRP and Concrete C25 .......................................140

Table A.4 - Checking for creep rupture, deflections and cracking - AFRP and Concrete C25.........141

Table A.5 - Design for the ultimate limit state - AFRP and Concrete C80 .......................................142

Table A.6 - Checking for creep rupture, deflections and cracking - AFRP and Concrete C80..........143

Table A.7 - Design for the ultimate limit state - CFRP and Concrete C25 .......................................144

Table A.8 - Checking for creep rupture, deflections and cracking - CFRP and Concrete C25 .........145

Table A.9 - Design for the ultimate limit state - CFRP and Concrete C80 .....................................146

Table A.10 - Checking for creep rupture, deflections and cracking - CFRP and Concrete C80 .......147

Table A.11 - Design for the ultimate limit state - GFRP and Concrete C25 ...................................148

Table A.12 - Checking for creep rupture, deflections and cracking - GFRP and Concrete C25 ........149

Table A.13 - Design for the ultimate limit state - GFRP and Concrete C80 ....................................150

Table A.14 - Checking for creep rupture, deflections and cracking - GFRP and Concrete C80........151

Table A.15 - Design for the ultimate limit state - Steel CA50 and Concrete C25 ............................152

Table A.16 - Design for the ultimate limit state - Steel CA50 and Concrete C80 ............................153 


\section{NOTATIONS}

\section{Symbols}

\section{Greek lower-case letters}

$\alpha$ - Parameter related to the width of the rectangular stress block;

$\alpha_{1}$ - Coefficient related to bonding between concrete and reinforcement for the evaluation of the tension-stiffening effect;

$\alpha_{2}$ - Coefficient related to the loading type for the evaluation of tension-stiffening;

$\alpha_{c}$ - Concrete thermal expansion coefficient;

$\alpha_{\text {eff }}$ - Parameter related to the width of the rectangular stress block accounting for creep effects;

$\alpha_{E}$ - Parameter related to the aggregate type;

$\alpha_{f}$ - Reinforcement thermal expansion coefficient;

$\alpha_{i}$ - Parameter related to the concrete grade for the calculation of the secant elasticity modulus;

$\alpha_{u l s}$ - Parameter $\alpha$ considering the crushing of the concrete;

$\alpha_{u l s, e f f}-$ Parameter $\alpha$ considering the crushing of the concrete and the creep effects;

$\beta$ - Parameter related to the depth of the rectangular stress block;

$\beta_{c}$ - Strain gradient;

$\beta_{c c}-$ FRP creep coefficient;

$\beta_{d}$ - Coefficient accounting for differences in tension-stiffening between steel and FRP;

$\beta_{\text {eff }}$ - Parameter related to the depth of the rectangular stress block accounting for creep effects;

$\beta_{u l s}$ - Parameter $\beta$ considering the crushing of the concrete;

$\beta_{u l s, \text { eff }}$ - Parameter $\beta$ considering the crushing of the concrete and the creep effects;

$\gamma_{c}$ - Concrete specific weight;

$r_{m w}$ - Specific weight of masonry walls;

$\gamma_{c t}$ - Coating specific weight;

$\Upsilon$ - ACI safety factor;

$\Upsilon_{f}-$ Reduction safety factors for prestressed FRP tendons;

$\varepsilon_{0}-$ Initial Elastic Strain;

$\varepsilon_{\infty}$ - Creep strain after a very long period of time, considered as infinite;

$\varepsilon_{c 50 \%}-$ Strain associated to the concrete linearity limit;

$\varepsilon_{c 2}-$ Strain at which concrete fails due to uniaxial compression; 
$\varepsilon_{c 2, e f f}-$ Strain at which concrete fails due to uniaxial compression, given the creep effects;

$\varepsilon_{c}$ - Concrete strain;

$\varepsilon_{c f}$ - Concrete strain due to stresses;

$\varepsilon_{c t h}-$ Concrete strain due to thermal variations;

$\varepsilon_{c t l i m}$ - Strain at which cracking occurs;

$\varepsilon_{c u}$ - Ultimate compressive strain of concrete due to flexure;

$\varepsilon_{c u, e f f}$ - Ultimate concrete compressive strain due to flexure, given the creep effects;

$\varepsilon_{f}$ - Non-prestressed reinforcement strain;

$\varepsilon_{f f}-$ Reinforcement strain due to stresses;

$\varepsilon_{f t h}-$ Reinforcement strain due to thermal variations;

$\varepsilon_{f u}$ - Ultimate reinforcement strain;

$\varepsilon_{f u, e f f}$ - Ultimate reinforcement strain considering the FRP creep effects;

$\varepsilon_{p i}-$ Prestressed reinforcement strain;

$\varepsilon_{p i}$ - Incremental strain with respect to the member decompression;

$\varepsilon_{p j}$ - Prestressing strain;

$\varepsilon_{p r e}$ - Prestressed reinforcement strain caused by the jacking force at long term;

$\varepsilon_{p u}$ - Ultimate strain of the prestressed reinforcement;

$\varepsilon_{\text {pud }}$ - Design ultimate strain of the prestressed reinforcement;

$\varepsilon_{p y d}$ - Design yield strain of prestressed steel;

$\varepsilon_{p y k}-$ Nominal yield strain of prestressed steel;

$\varepsilon_{s}-$ Steel strain at the ultimate limit state;

$\varepsilon_{s h}$ - Concrete strain due to shrinkage;

$\varepsilon_{t}-$ Strain at the most compressed fiber;

$\eta_{1}-$ Bond coefficient for the computing of crack widths;

$\eta_{f}-$ Modular ratio;

$\theta$ - Relative reinforcement slope at the direction of change location;

$\kappa$-Coefficient accounting for differences in stiffness throughout the flexural member;

$\lambda$ - Parameter for the computing of the cracking moment, depending on the cross-section shape;

$\xi$-Creep coefficient to compute long-term deflections;

$\rho_{f}^{\prime}$ - Compressive reinforcement ratio;

$\rho_{f}$ - Non-prestressed reinforcement ratio;

$\rho_{f b}-$ Balanced ratio for the non-prestressed reinforcement;

$\rho_{\min }-$ Minimum reinforcement ratio;

$\rho_{p}$ - Prestressed reinforcement ratio; 
$\rho_{p b}-$ Balanced ratio for the prestressed reinforcement;

$\rho_{r i}-$ Reinforcement ratio with respect to the influence area for the computing of crack widths;

$\sigma_{c}-$ Notation for the stress in concrete adopted by ABNT NBR 6118 (2014);

$\sigma_{c p}$ - Concrete compressive stress caused by the release of strands;

$\varphi$ - Cross-section curvature;

$\phi$ - Longitudinal bar diameter;

$\phi_{t}-$ Diameter of stirrups;

$\phi_{\text {max,agg }}$ - Maximum aggregate diameter;

$\psi_{1}-$ Frequent loading combination coefficient;

$\psi_{2}$ - Almost permanent loading combination coefficient;

\section{Greek capital-case letters}

$\Delta \varepsilon_{c r}$ - Concrete shortening due to the release of strands;

$\Delta M_{d}$ - Difference between the design bending moment and that related to the ductility limit;

$\Delta P_{f}$ - Percentual losses due to friction;

$\Delta P_{i}-$ Percentual initial losses;

$\Delta P_{s h}$ - Losses in the jacking stress due to the concrete shrinkage;

$\Delta t$ - Time interval counting from the application of the jacking stress and the strand release;

$\Delta v_{c r}$ - Incremental deflections due to rare loading combinations;

$\Phi$ - Concrete Creep coefficient;

$\Psi_{1000}$ - Steel relaxation after 1000 hours;

$\Psi$ - Reinforcement relaxation;

\section{Roman lower-case letters}

$b$ - Rectangular beam width;

$b_{f}$ - Flange width;

$b_{w}-$ Web width;

$c$ - reinforcement cover;

$d$ - Effective depth;

$d_{c}$ - Distance from the most tensioned fiber to the centroid of the closest bar;

$e_{m w}$ - Thickness of masonry walls;

$e_{p i}-$ Initial arbitrated eccentricity of strands; 
$f_{c}-$ Stress in concrete;

$f_{c d}$ - Concrete design compressive strength;

$f_{c k}$ - Concrete nominal compressive strength;

$f_{c t}$ - Concrete tensile strength;

$f_{\text {ctd }}$ - Concrete design tensile strength;

$f_{c t k}$ - Concrete nominal tensile strength;

$f_{c t k, \text { inf }}$ - Inferior concrete nominal tensile strength;

$f_{\text {ctm }}$ - Concrete average tensile strength;

$f_{c t k, \text { sup }}$ - Superior concrete nominal tensile strength;

$f_{f}-$ Stress in the reinforcement;

$f_{f s}$ - Sustained stress;

$f_{f s, l i m}-$ Maximum allowed sustained stress;

$f_{f u}$ - Reinforcement tensile strength;

$f_{\text {fud }}$ - Reinforcement design tensile strength;

$f_{p i}$ - Incremental stress with respect to the decompression of the member;

$f_{p j}$ - Jacking stress;

$f_{p u}$ - Tensile strength of prestressed reinforcements;

$f_{\text {pud }}$ - Design tensile strength of prestressed reinforcements;

$f_{p y k}$ - Nominal yield stress of prestressed steel;

$f_{t s}$ - Concrete contribution as regards the tension-stiffening effect;

$f_{y k}$ - Nominal yield stress of non-prestressed steel;

$g$ - Dead uniformly distributed load in $\mathrm{kN} / \mathrm{m}$;

$g_{c t}$ - Dead distributed load in $\mathrm{kN} / \mathrm{m}^{2}$ regarding the floor and ceiling coatings;

$g_{s}$ - Dead uniformly distributed load on the slabs in $\mathrm{kN} / \mathrm{m}^{2}$;

$h$ - Beam depth;

$h_{1}$ - Distance from the neutral axis to the least tensioned fiber of the cracking influence area;

$h_{2}-$ Thickness of the influence area;

$h_{c t}-$ Thickness of slab coatings;

$h_{f}$ - Flange thickness;

$h_{f f}$ - Floor-to-floor distance;

$h_{m w}$ - Height of masonry walls;

$h_{s}-$ Slab thickness;

$j$ - Auxiliary variable for the determination of rectangular block parameters;

$k$-Factor accounting for the volume to surface ratio to compute the concrete creep coefficient; 
$l$ - Beam theoretical span length;

$l_{x}$ - Smallest slab theoretical span;

$l_{y}$ - Largest slab theoretical span;

$n$-Parameter related to the concrete grade for the constitutive model determination;

$n_{b}-$ number of rebars;

$p$ - Uniformly distributed load;

$q$ - Live uniformly distributed load in $\mathrm{kN} / \mathrm{m}$;

$q_{\mathrm{s}}$ - Live uniformly distributed load on the slabs in $\mathrm{kN} / \mathrm{m}^{2}$;

$s$ - bar spacing;

$s_{h, \min }$ - Minimum horizontal bar spacing;

$s_{v, \min }-$ Minimum vertical bar spacing;

$t$ - Time-period considered for the numerical analysis;

$t_{i+1}$ - Upcoming time-period;

$t_{0}$ - Instant the load was applied;

$v_{a p c}-$ Deflections due to almost permanent loading combinations;

$v_{l t}$ - Long-term deflections;

$x$ - Neutral axis depth;

$x_{50 \%}$ - Neutral axis depth associated to the concrete linearity limit;

$x_{c r}-$ Neutral axis depth for the determination of the cracking moment of inertia;

$x_{b}$ - Neutral axis depth of a balanced cross-section;

$x_{i}-$ Initial neutral axis depth, based on the design bending moment $M_{d}$;

$x_{\text {lim }}$ - Neutral axis corresponding to the ductility limit imposed by ABNT NBR 6118 (2014);

$y$ - Axis originated in the neutral axis in direction to the tension region;

$\bar{y}-$ Center of the tension-stiffening force;

$\bar{y}_{50 \%}$ - Center of the resulting compressive force associated to the concrete linearity limit;

$\bar{y}_{c f}$ - Center of the resulting compressive force;

$\bar{y}_{t r i}-$ Center of the triangular stress block;

$\bar{y}_{\text {trp }}$ - Center of the trapezium stress block;

$y_{t}-$ Distance from the neutral axis to the most tensioned fiber;

$z$-Axis regarding the distance from the neutral axis to the most compressed fiber; 


\section{Roman capital-case letters}

$A_{50 \%}$ - Reinforcement area corresponding to the concrete limit of linearity;

$A_{\phi}-$ Cross-section area of one bar;

$A_{a d}$-Effective area adjusted for the commercially available rebars;

$A_{a d j}-$ Adjusted reinforcement area for the creep rupture limit state;

$A_{b}$ - Reinforcement area associated to the balanced bending moment;

$A_{c}-$ Concrete area in the cross-section;

$A_{c r i}$ - Influence area for the computing of crack widths;

$A_{f}-$ Non-prestressed reinforcement area;

$A_{f(f)}-$ Reinforcement area accounting for stresses on the flange;

$A_{f(w)}$ - Area accounting only for stresses on the web;

$A_{p}$ - Prestressed reinforcement area;

$E_{c i}$ - Initial elasticity modulus;

$E_{c t}-$ Concrete elasticity modulus defined by ABNT NBR 6118 (2014);

$E_{c t, e f f}$ - Concrete elasticity modulus adjusted for creep;

$E_{c s}-$ Concrete secant elasticity modulus;

$E_{c s 50 \%}$ - Concrete secant modulus corresponding to $50 \%$ of $0.85 f_{c d}$;

$E_{c s, e f f}-$ Concrete secant modulus after the creep effects;

$E_{f}-$ Reinforcement elasticity modulus;

$E_{f, e f f}-$ Reinforcement elasticity modulus considering the FRP creep effects;

$E_{p}-$ Elasticity modulus of the prestressed reinforcement;

$E_{p, e f f}-$ Elasticity modulus of the prestressed reinforcement considering the relaxation effects;

$F_{50 \%}$ - Resulting force associated to the concrete linearity limit;

$F_{c}$-Resulting compressive force for the neutral axis on the web and concrete behaving linearly;

$H$ - Relative humidity;

$I_{1}-$ Moment of inertia prior to cracking;

$I_{2}$ - Moment of inertia for the cracked cross-section;

$I_{c r}$ - Cracking moment of inertia;

$I_{\text {eff }}$ - Effective moment of inertia;

$I_{\text {eff }}-$ Effective moment of inertia related to the maximum positive bending moment;

$I_{\text {eff, 1- }}$ - Effective moment of inertia related to the maximum negative bending moment at the closest span end; 
$I_{\text {eff,2- }}$ - Effective moment of inertia related to the maximum negative bending moment at the farthest span end;

$I_{g}-$ Gross moment of inertia;

$K_{b}-$ Coefficient accounting for FRP and steel differences in bonding;

$K_{s}-$ Factor accounting for the volume to surface area ratio to estimate the concrete shrinkage;

$K_{h}$ - Factor relying on the environmental humidity to estimate the concrete shrinkage;

$M$ - Bending moment corresponding to the moment-curvature charts;

$M_{50 \%}$ - Bending moment associated to the concrete linearity limit;

$M_{a}$ - Applied Service Moment;

$M_{a p c}$ - Moment due to almost permanent loading combinations;

$M_{b(f)}$ - Balanced moment accounting for stresses on the flange;

$M_{b(w)}$ - Balanced moment accounting for stresses on the web;

$M_{d, \min }$ - Minimum design bending moment;

$M_{f_{c}}-$ Moment due to frequent loading combinations;

$M_{g}$ - Moment due to dead loads;

$M_{g 1}$ - Bending moment caused by the beam self-weight;

$M_{b}$ - Balanced bending moment;

$M_{d}$ - Design bending moment;

$M_{d(f)}$ - Bending moment accounting for stresses on the flange;

$M_{d(w)}$ - Bending moment accounting for stresses on the web;

$M_{k}$ - Maximum applied moment at mid-span;

$M_{\text {lim }}$ - Bending moment corresponding to the ductility limit of ABNT NBR 6118 (2014);

$M_{q}$ - Moment due to live loads;

$M_{q 1}$ - Moment due to the main live load;

$M_{q 2}-$ Moment due to secondary live loads;

$M_{r}-$ Flexural Strength;

$M_{r c}-$ Moment due to rare loading combinations;

$M_{u}$ - Ultimate bending moment;

$M_{u d}$ - Initial design bending moment computed by the FRP RC Design Program;

$N$ - Axial force in the prismatic members;

$N_{u}$ - Ultimate tensile force of the prismatic members;

$P_{0}-$ Effective load to be applied in the prestressing equipment;

$P_{1}$ - Jacking force after initial losses and shortening of the concrete member;

$P_{\infty}$ - Minimum jacking force after all losses; 
$P_{a}-$ Jacking force after the initial losses;

$P_{i, e s t}$ - Initial estimated load to be applied in the prestressing equipment;

$R_{c}$ - Resulting compressive force;

$R_{f}$ - Resulting tension force in the non-compressive reinforcement;

$R_{f u d}$ - Ultimate reinforcement load carried by the total area $A_{f}$,

$R_{f u d(f)}$ - Ultimate reinforcement load carried by the area $A_{f(f)}$;

$R_{f u d(w)}$ - Ultimate reinforcement load carried by the area $A_{f(w)}$;

$R_{p}$ - Resulting tension force in the prestressed reinforcement;

$R_{E L 3}-$ Relaxation of fibers;

$R_{t s}-$ Tension stiffening resulting force;

$W_{i n f}$ - Elastic section modulus with respect to the extreme inferior fiber;

$W_{\text {sup }}$ - The opposite number of the elastic section modulus with respect to the extreme superior fiber;

\section{Abbreviations}

ABNT - Associação Brasileira de Normas Técnicas - Brazilian Technical Standards Association;

ACI - American Concrete Institute;

AFRP - Aramid Fiber-reinforced Polymer;

AASHTO - American Association of State Highway and Transportation Officials;

BFRP - Basalt Fiber-reinforced Polymer;

CA50 - Steel for Reinforced Concrete, for which $\mathrm{f}_{\mathrm{yk}}=500 \mathrm{MPa}$;

CFCC - Carbon Fiber Composite Cables;

CFRP - Carbon Fiber-reinforced Polymer;

CP190 RB - Low Relaxation Steel for Prestressed Concrete, for which $\mathrm{f}_{\mathrm{pyk}}=1900 \mathrm{MPa}$;

GFRP - Glass Fiber-reinforced Polymer;

FRP - Fiber-reinforced Polymer;

MRI - Magnetic Resonance Imaging;

NBR - Norma Brasileira - Brazilian Technical Standard;

RC - Reinforced Concrete;

TP - Transfer of Prestress;

SL - Service Loads; 


\section{LIST OF CONTENTS}

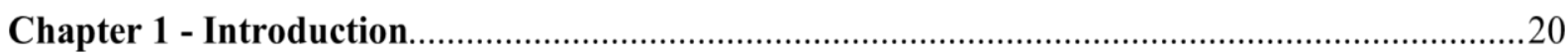

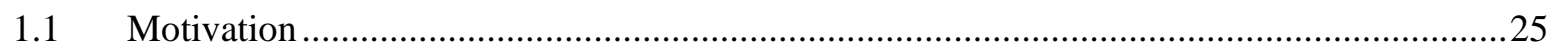

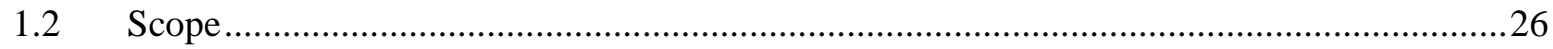

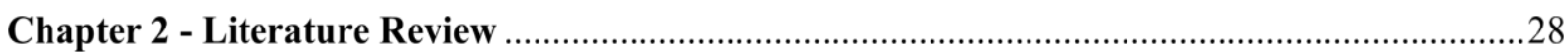

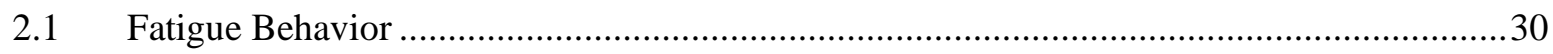

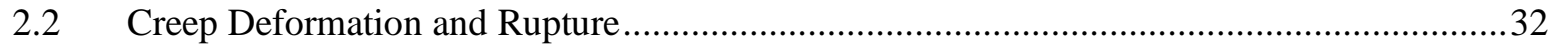

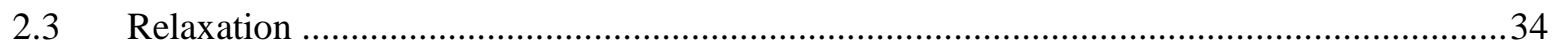

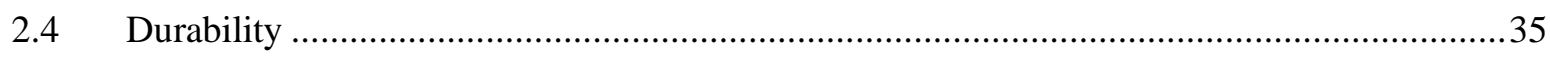

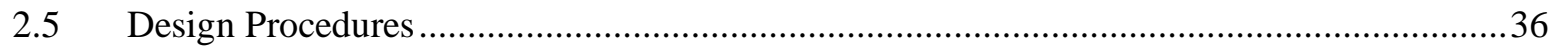

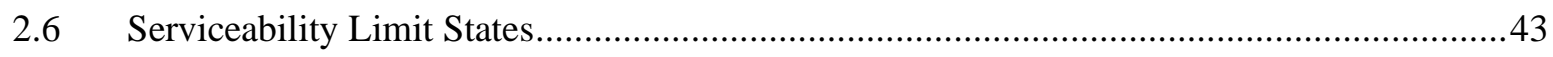

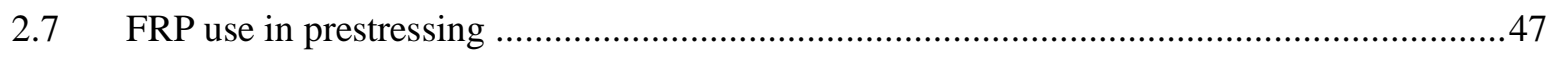

Chapter 3 - Comparative Design of FRP and Steel Reinforced Concrete......................................54

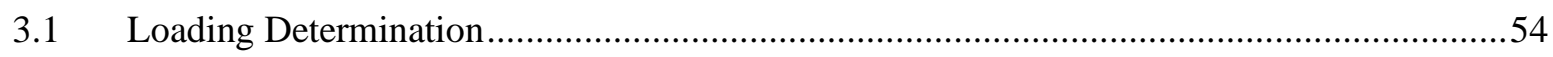

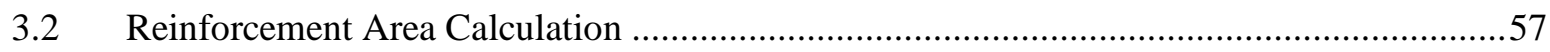

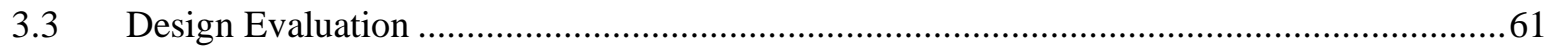

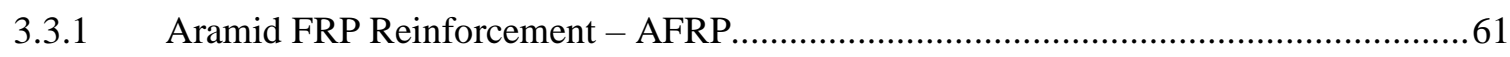

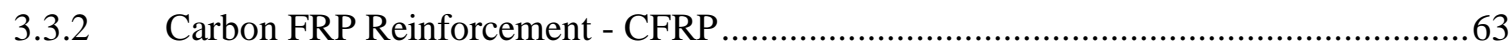

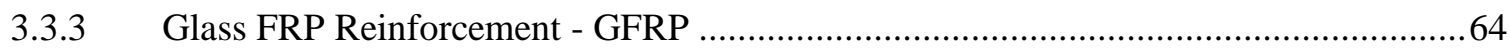

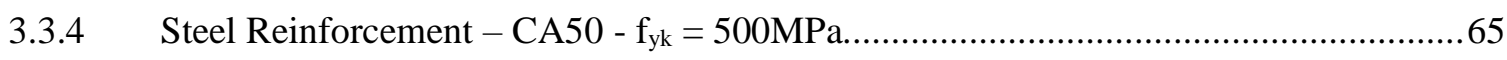

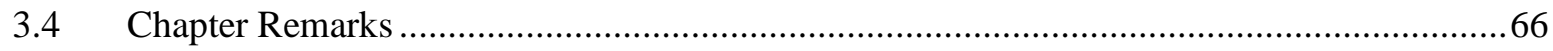

Chapter 4 - Long-term Assessment of GFRP Reinforced Concrete Beams..................................68

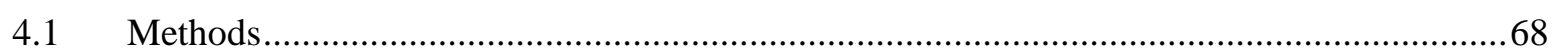

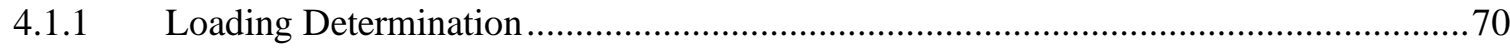

4.1.2 Determination of long-term performance parameters ............................................ 71

4.1.3 Compatibility conditions considering the long-term effects .......................................76

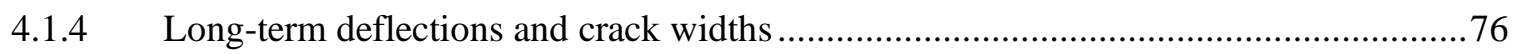

4.1.5 Long-term moment-curvature relationships .......................................................... 78 


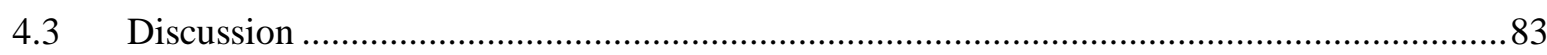

Chapter 5 - Numerical Assessment of FRP Prestressed Members .............................................86

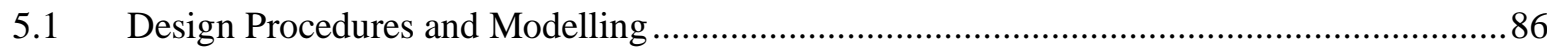

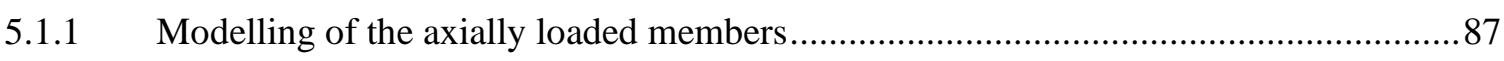

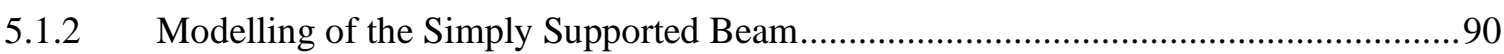

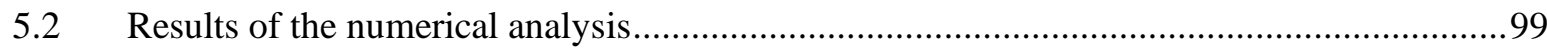

5.2.1 Results corresponding to the axially loaded member...............................................99

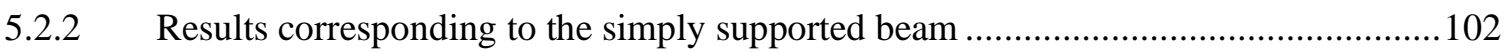

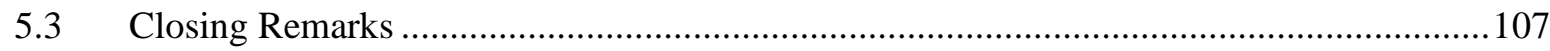

Chapter 6 - Development of the FRP RC Design Program......................................................... 108

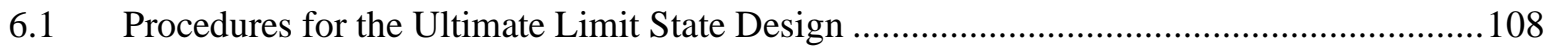

6.1.1 Tension-controlled sections and balanced stress block on the flange..........................110

6.1.2 Tension-controlled sections and balanced stress block on the web...........................113

6.1.3 Compression-controlled sections and balanced stress block on the flange..................116

6.1.4 Compression-controlled sections and balanced neutral axis on the web ....................117

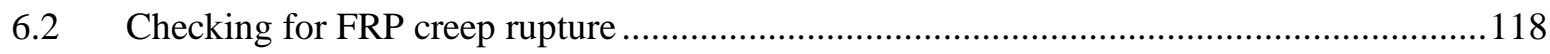

6.3 Determination of the Flexural Strength for the Adjusted Area .........................................118

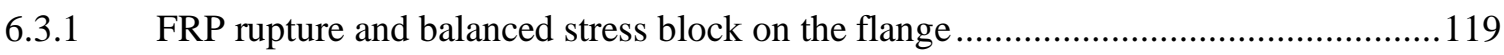

6.3.2 FRP Rupture and balanced stress block on the web ...............................................120

6.3.3 Concrete Crushing and balanced stress block on the flange.......................................121

6.3.4 Concrete Crushing and balanced stress block on the web ........................................122

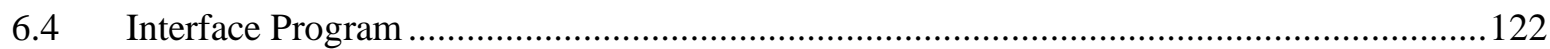

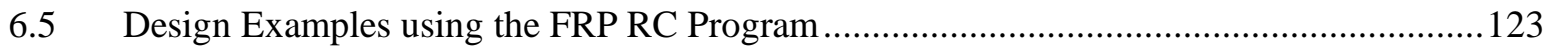

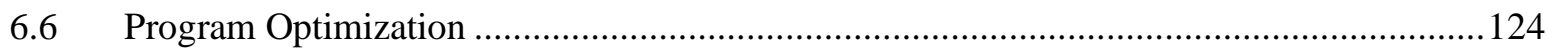

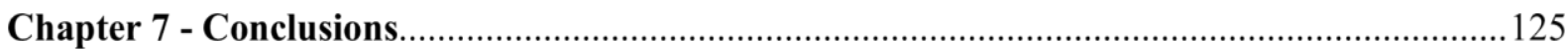

REFERENCES

Appendix A - Design of FRP and Steel Reinforced Concrete ...................................................... 133

Appendix B - Design Examples using the FRP RC Design Program.......................................154 


\section{Chapter 1 - Introduction}

Concrete is a construction material constituted by cement, water, fine aggregate, coarse aggregate, and eventually, quality improvement additives. Despite of the excellent compressive properties, the use of unreinforced concrete to resist flexure is not suitable for the most common civil structures. Therefore, it is necessary to use concrete in conjunction with a high tensile strength material, such as steel (CARVALHO and FIGUEIREDO FILHO, 2014).

However, steel undergoes corrosion, which significantly contributes to the life-span reduction of conventional reinforced concrete. The reinforcement initially protected by the concrete alkaline environment starts to corrode by virtue of the continuous exposition to humidity, temperature, chlorides, as well as deicing salts commonly used in bridges. Some measures such as, epoxy coating for steel and incorporation of additives to concrete have proved effective to slow down corrosion. Nonetheless, the oxidation process always begins and intensifies over the years (ACI 440 1R-06, 2006).

In order to avoid corrosion, FRP - Fiber-Reinforced-Polymer - rebars are an alternative to conventional steel, mainly in structures constantly subjected to aggressive environments. According to Urbanski, Lapko and Garbacz (2013), the expected service life of steel RC slabs is 25 years, whereas concrete panels reinforced with FRP last up to 75 years. Figures 1.1 and 1.2 illustrate the appearance of these materials, which are constituted by a tangle of aramid, carbon, glass or basalt fibers, impregnated in a low stiffness polymeric matrix. The longitudinal fibers are the strongest and stiffest elements of the composite, accounting for the FRP tensile strength and elasticity modulus. The polymeric resin, in turn, determines the reinforcement overall stress-strain relationship, as well as, binds the fibers together and protects them from damage. This fiber-resin combination makes the rebars anisotropic, with their properties varying from longitudinal to transversal directions; negatively affecting the shear strength, dowel action mechanisms and bonding to concrete (FIB BULLETIN 40, 2007).

Besides being corrosion resistant, they can also be utilized as flexural and shear reinforcement in MRI - Magnetic Resonance Imaging - unit structures, where the conventional steel may not be applicable. According to Brown and Bartholomew (1996, apud ACI 440 1R06, p.7, 2006), the construction of MRI units caused the demand for composite materials to considerably increase in the United States during the 1980's. As a result, FRP became an excellent alternative for the structural concrete and, as more researches were developed, it 
gained space in maritime constructions, substation reactor bases, airport runways and electronic laboratories.

FRP is also not as heavy as steel. Its specific weight ranges from $1 / 5$ to $1 / 4$ of that as regards the conventional steel (ACI 440 1R-15, 2015). This lightweight allows the FRP use in slender structural elements, where reinforcement congestion is more likely to occur.

In spite of the FRP non-corrosive and non-magnetic properties, its stress-strain relationship is linear until failure, which is fragile and not preceded by stress redistribution. Therefore, the use of FRP does not apply to structures requiring large plastic deformations at the ultimate limit state (URBANSKI, LAPKO and GARBACZ, 2013). In order to properly design flexural FRP RC members, the ultimate limit state should be defined by the crushing of the concrete rather than the FRP rupture. The main reason to choose this type of failure is that concrete presents some plastic behavior prior to crushing, providing some warning as regards the structural conditions. Therefore, the competent authorities are able to take proper measures to preserve the safety and integrity of structures (ACI 440 1R-06, 2006).

The design guidelines for conventional steel RC members served as basis for the development of FRP reinforcement codes. However, researchers and professionals in the field had to rethink the basic principles and assumptions, evaluating whether or not they applied for FRP RC members. There is some concern regarding the cross-section types of rupture, whether or not brittle failure modes should be accepted and if the adopted safety factors lead to acceptable reliability levels (FIB BULLETIN 40, 2007).

Furthermore, the FRP high tensile strength is associated to very large strains that negatively affect the structural functionality, which may result in excessive cracking and deflections under service loading conditions. According to Pilakoutas et al. (2009), if the serviceability requirements are not met, the designer may consider adding more reinforcement area. Yet, the cross-section may become over-reinforced, resulting in a cost increase and waste of FRP tensile properties. If the required reinforcement area is also too large, so will the shortterm deformations; likewise, the compressive stress in the concrete may exceed $45 \%$ of its nominal strength, leading to considerable creep deformations.

In addition, the designer must account the fact that FRP does not yield, assessing features to provide ductility to the structure (ACI 440 1R-06, 2006). Pilakoutas et al. (2009) describes some alternatives, already investigated by other authors: concrete confinement, use of hybrid FRP reinforcement or several FRP rebars with different types of fibers (BURGOYNE, 2001, HARRIS et al., 1998). Therefore, the structural elements can exhibit artificial ductile behavior when some of these rebars fail at different strains. Pseudo-ductility is also provided 
through plastic bond failure, as well as, by incorporating redundant elements that ruptures without causing the collapse of the structural member (FIB BULLETIN 14, 2001).

Figure 1.1 - FRP Reinforcing Rebars

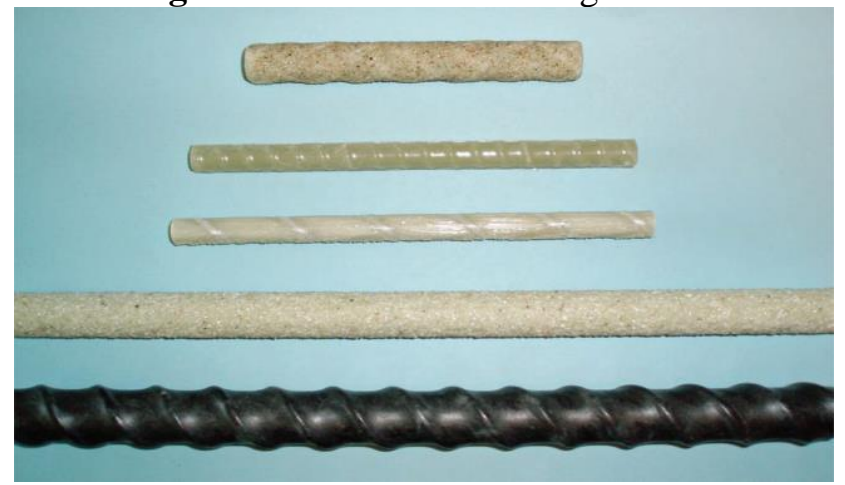

Source: ACI 440 1R-15, 2015

Figure 1.2 - FRP Grids

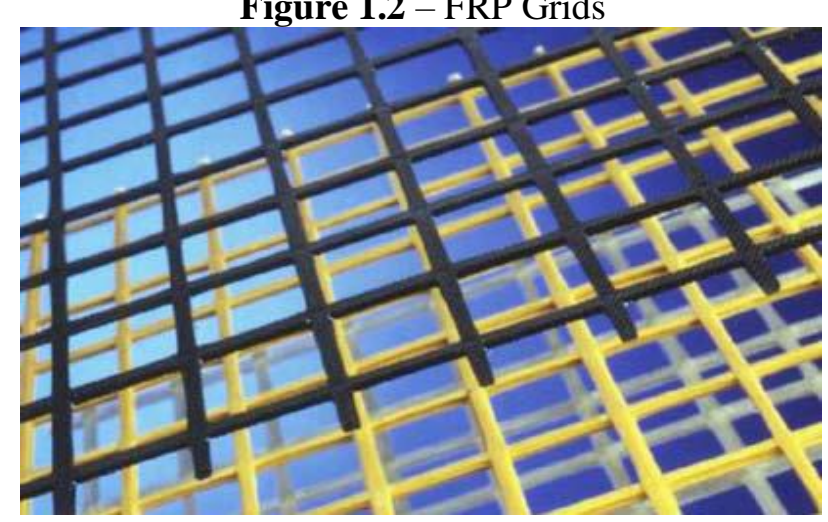

Source: FIB BULLETIN, 2007

Regarding the FRP use over the past years, Japanese were the most prominent in utilizing FRP as reinforcement for concrete, counting more than one-hundred commercial projects. Most of the initial researches were concentrated on the magnetic systems of railways, as shown in Figure 1.3 (FIB BULLETIN 40, 2007). As to the recent years, China has become the country that most used FRP in civil constructions, from bridges to even underground works (YE et al. 2003, apud ACI 440, p.7, 2006). According to Meier (1992, apud ACI 440, p.7, 2006), Germany was the pioneer in the FRP application as pre-tensioned reinforcement for road bridges in 1996. Thenceforth, several programs to encourage the use of FRP in Europe have been implemented.

Canada, in turn, leads the utilization of FRP rebars in road bridges, also possessing fiberoptic technology to remotely monitor strains (BENMOKRANE et al., 2004, apud ACI 440, p.7, 2006). The FRP incorporation approach into the Canadian Highway Bridge Design Code resulted in several applications of the non-metallic reinforcement, such as, the Headingley 
Bridge in Manitoba, reinforced with CFRP (carbon) and GFRP (glass) rebars; the Kent County Number 10 Bridge having the traffic barrier reinforced with GFRP rebars; and the deck slab with CFRP grids at negative bending moment spots. There is also the Joffre Bridge in Sherbrook, Quebec, reinforced with CFRP grids in the deck slab, and GFRP rebars in the trafficsidewalk partitions (ACI 440 1R-06, 2006).

Figure 1.3 - Magnetic levitation system railway in Japan.

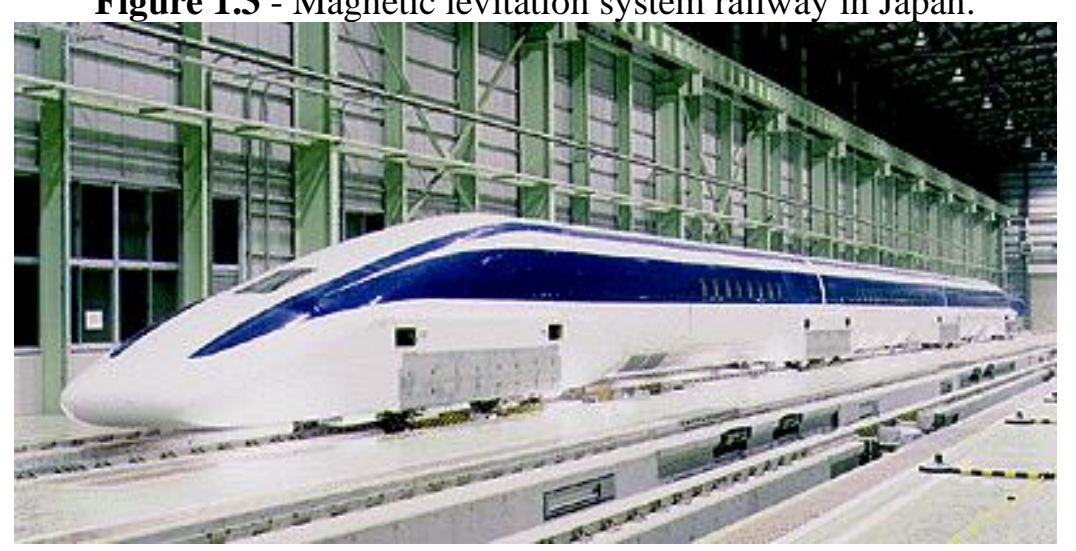

Source: FIB BULLETIN 40, 2007

In the United States, FRP has been applied in MRI units, ornamental and architectural works, bridge decks and precast concrete. Figure 1.4 shows an example of a huge structure reinforced with GFRP, the Emma Park Bridge located in Utah and built in 2009. Due to the GFRP lightweight, its application in the top and bottom mat of the precast bridge deck was quite successful to speed up construction. In Florida, GFRP was used in plinths of railways connecting the Earlington High Station to the Miami International Center. The main reason for the use lies on its non-conductive properties, essential for the rail electrical isolation (ACI 440 1R-15, 2015).

Another example is a bridge over the highway I-635, in Kansas, where a new deck reinforced with GFRP was incorporated. The cost to reinforce the deck was the same as if steel rebars had been epoxy-cotated. Moreover, Figure 1.5 shows a protection seawall of the Honoapiilani Highway, located in Hawaii. This structure was constructed in 2001, but needed repair in 2011 when the steel reinforcement was replaced by GFRP. The main objective was to provide longer service life in face of such an aggressive environment (ACI 440 1R-15, 2015).

Despite of all the successful applications of FRP as non-prestressed reinforcement, Barbosa, Bittencourt and Welter (2019) stress the importance of pre-tensioning to take greater advantages of the material high tensile strength, meeting the serviceability limit states with no need to over-reinforce the cross-sections. According to Leonhardt (1993, apud HANAI, 2005, p.38), the effectiveness of prestressing relies on both the material tensile strength and its 
capability to elongate before yielding or failing. Those are pre-requisites that FRP perfectly meets. Consequently, the loss in prestress will be smaller and so will the strains due to creep and shrinkage.

However, the design codes concerning the use of FRP as prestressed reinforcement are not fully applicable in comparison to conventional steel, requiring some research efforts to effectively investigate the behavior of the polymeric tendons. Experimental and analytical assessments can contribute to a better understanding of the FRP prestressed concrete under different loading conditions, also considering variations in parameters such as reinforcement ratio, concrete strength and prestressing levels (HUSAIN, FAWZY and NADA, 2015).

Figure 1.4 - GFRP reinforcing of the Emma Park Bridge, 2009 - Utah.

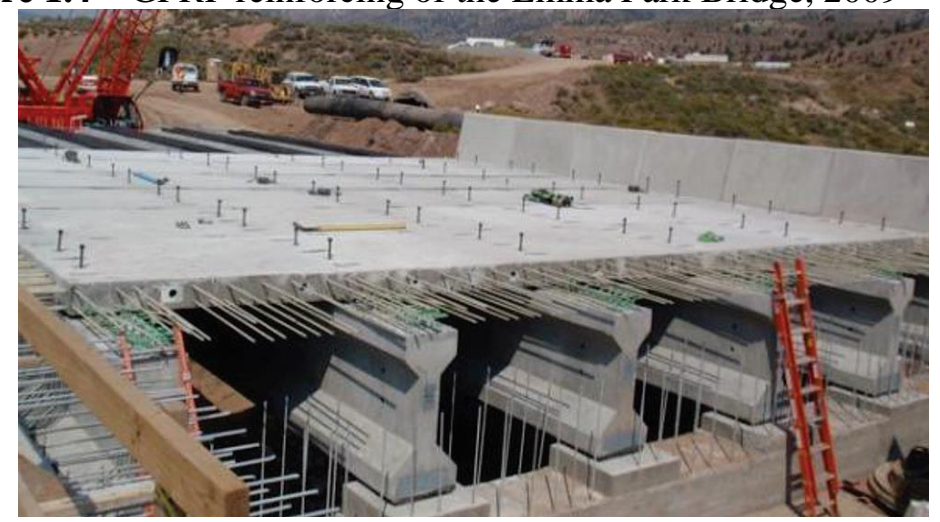

Source: ACI 440 1R-15, 2015

Figure 1.5 - Seawall protecting the Honoapiilani Highway in Maui, Hawaii.

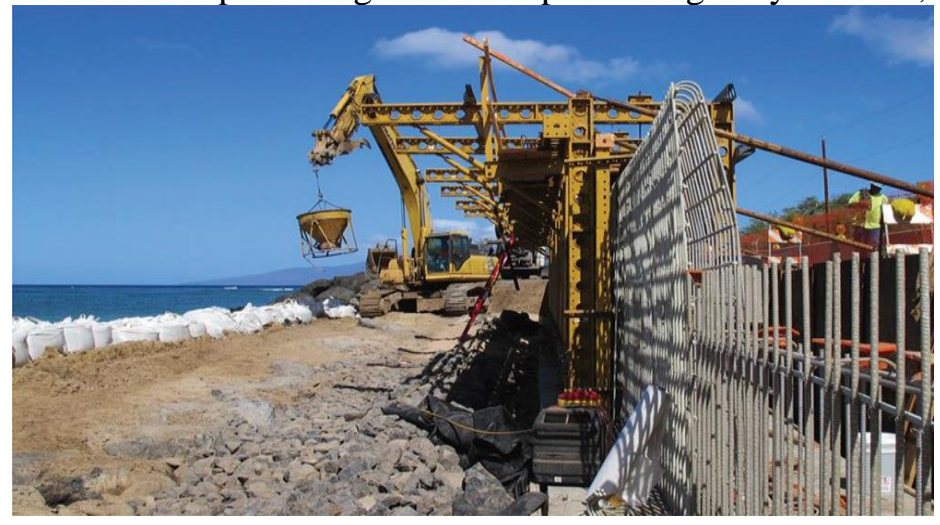

Source: ACI 440 1R-15, 2015

The most common fibers for FRP tendons are aramid, carbon and glass, as shown in Figures 1.6 and 1.7. Selecting one type or another depends on the provided strength, elasticity modulus and long-term performance. However, within the same fiber category, there is a wide range of these properties. AFRP tendons, for instance, have different stiffness grades, whereas the CFRP tensile strength varies from values smaller to multiples of the corresponding for steel (ACI 440 4R-04, 2004). ACI 440 4R-04 (2004) recommends the use of AFRP and CFRP 
tendons only. The application of GFRP is not addressed due to its low creep resistance under sustained loads as well as the vulnerability of glass fibers to alkaline environments.

Figure 1.6 - AFRP and CFRP tendons

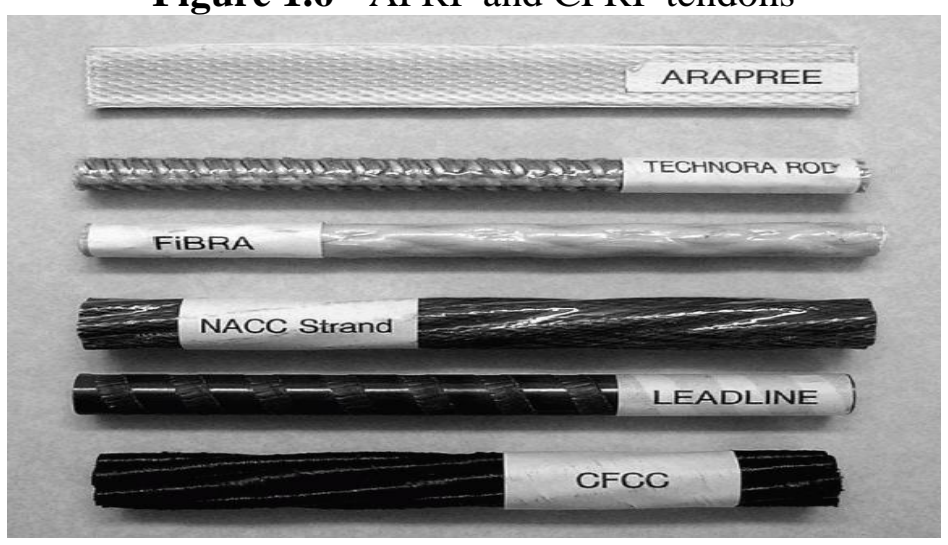

Source: ATUTIS and VALIVONIS, 2010

Figure 1.7 - AFRP and CFRP tendons

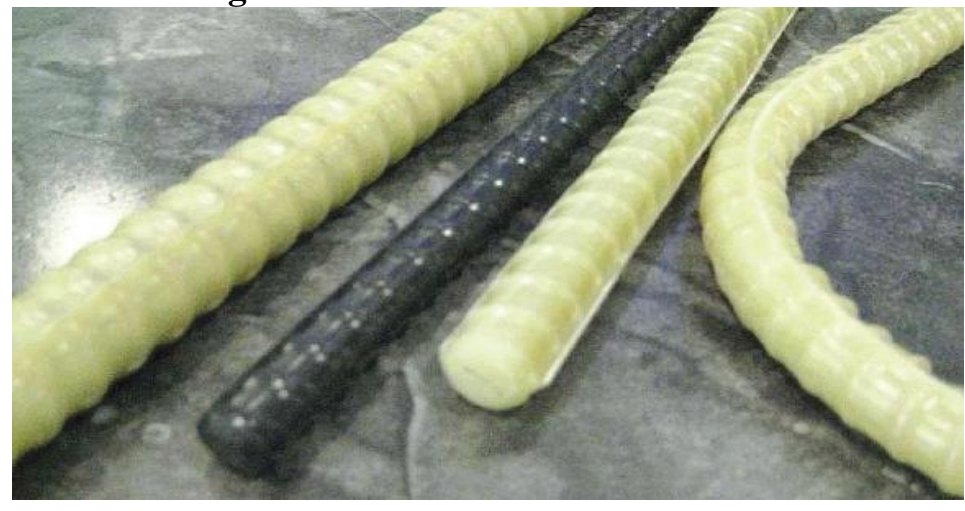

Source: ATUTIS and VALIVONIS, 2010

\subsection{Motivation}

The durability of a structure considerably affects its total cost, especially when the reinforcement corrosion compromises its functionality. In front of this, designers have been searching for durable materials such as FRP to replace steel. Researches on the field of FRP $\mathrm{RC}$ structures are still recent, and the design guidelines resemble the ones regarding conventional steel. Moreover, the design codes for conventional RC structures do not accept fragile failure modes, which implies that the concrete crushing occurs simultaneously to the yielding of steel. FRP RC members, in turn, present two types of fragile failure: concrete crushing and FRP rupture (RIBEIRO, 2009). 
Numerical models simulating the behavior of FRP RC structural members need to consider all these differences in mechanical properties. The designer should be able to compute the required amount of flexural FRP reinforcement in real time with the aid of computational mechanics and programming. Moreover, it is necessary to compare the behavior of structures reinforced with different types of FRP and steel, evaluating deflections, cracking and flexural strength. This comparison allows determining the material that best fits a particular structural system, in terms of serviceability requirements and ultimate limit state.

Investigating the long-term performance of FRP reinforced concrete is also necessary, especially for GFRP, extensively used for bridge decks due to its initial low cost compared to other types of non-metallic reinforcements (NKURUNZIZA et al. 2005). Therefore, experimental data on GFRP creep as well as concrete long-term properties could be used to numerically predict the long-term performance of GFRP RC flexural members. The designer would be able to determine the age at which these structures no longer meet the serviceability requirements, evaluating whether replacing steel by GFRP leads to improved structural functionality and cost reduction.

As previously mentioned, the FRP high tensile strength is associated to a low elasticity modulus and a large ultimate strain, which requires to increase the reinforcement areas so that all limit states are met; consequently, replacing steel by FRP may result in a very expensive solution. It is necessary to investigate the use of FRP as prestressed reinforcement, taking advantage of the material capability to elongate without rupturing, as well as checking if the design does not result in too over-reinforced cross-sections. Therefore, numerical simulations considering different types of FRP combined to normal and high strength concretes may provide the answer to this inquiry.

\subsection{Scope}

The primordial objective of this research was to develop a computational program that calculates the amount of FRP reinforcement for critical sections of one-dimension beams. The feature used to achieve this goal was the VISUAL BASIC.NET@ programming language, by which the design procedures of ACI 440 1R-15 (2015) and ABNT NBR 6118 (2014) were implemented.

This dissertation thesis also presents a literature review of the FRP mechanical properties, as well as its structural behavior compared to conventional steel. Some of 
experimental, numerical work and design procedures of ACI 440 1R-15 (2015) and ACI 440 4R-04 (2004) are described in a manner that numerical analyses are clearly comprehended.

Following this literature review, there is an example of a structural project whereby the design considerations of ACI 440 1R-15 (2015) and ABNT NBR 6118 (2014) are implemented for the design of FRP RC beams. Differences in reinforcement areas, deflections, crack widths and sustained stress are evaluated, considering the design meeting only the ultimate limit state for flexure and the one satisfying all limit states. The objective was to quantify how overreinforced the cross-sections became in order to meet all limit states.

The long-term performance of GFRP RC was also evaluated. The objective consisted of investigating how changes in concrete and GFRP properties affect the structural long-term performance. Thus, the flexural strength, deflections, crack widths and moment-curvature relationships were numerically analyzed for time-periods up to 100 years. The results concerning the deformability of the cross-sections also aimed to determine whether the procedures of ACI 440 and NBR 6118 lead to fragile or ductile failure modes.

Additionally, this research aimed to compare the behavior of FRP pre-stressed concrete beams to the same pre-tensioned with $1900 \mathrm{MPa}$ steel tendons. The axial force-strain, bending moment-curvature relationships and crack-widths were evaluated for different types of FRP combined to a normal strength and high-performance concretes. The objective is to outline the advantages and disadvantages of using a certain type of FRP in conjunction with a specified concrete grade, determining which combination is better in terms of serviceability and ultimate limit states. 


\section{Chapter 2 - Literature Review}

FRP rebars are constituted by high strength and stiffness fibers arranged longitudinally and embedded in a polymeric matrix. In addition to binding together and transferring stresses to the fibers, the resin works as a protection against damages from manufacturing and handling processes. However, the polymeric matrix has low fire resistance, softening at high temperatures, which compromises the FRP mechanical properties. Moreover, its high flexibility results in a composite material with low elasticity modulus (FIB BULLETIN 40, 2007).

The characterization of FRP reinforcement relies on its geometrical properties such as shape, size and surface texture, as well as its mechanical behavior regarding tension, fatigue, creep, relaxation and high temperatures. The bendability of the rebars, bond properties and long-term performance are also a criterion to specify the product (FIB MODEL CODE, 2010).

Fib Bulletin 40 (2007) outlines the required properties to use FRP efficiently in construction. First, its high tensile strength and low elasticity modulus must result in proper ductility at the ultimate limit state. Additionally, there must not be considerable variations in diameter, surface and tensile strength of fibers. The rebars also need to resist the manufacturing and handling processes, as well as, be available in applicable shapes at acceptable costs.

FRP tensile strength depends not only on the type of fiber but also on the bar bond characteristics. Consequently, if bond stresses around the cracks are too high, the rebars may lose adhesion, which violates the principle that plane sections remain plane. In addition, shear stresses on the bar surface compromises its tensile strength due to the incidence of lateral stresses. Such a fact causes the strength of bonded rebars to be lower in comparison to their uniaxial strength (PILAKOUTAS et al., 2009). In order to correctly determine this strength, Urbanski, Lapko and Garbacz (2013) utilized a proper mounting system at FRP bar ends, so that the material did not fail at the anchorage zone, allowing accurate determination of its tensile strength.

According to ACI 440 1R-15 (2006), there are three grades of FRP rebars, defined by the tensile strength:

a) Grade F60 whose tensile strength values range from 414 to $483 \mathrm{MPa}$;

b) Grade F70, ranging from 483 to $552 \mathrm{MPa}$;

c) Grade F290, from 1999 to $2069 \mathrm{MPa}$.

The most common elasticity modulus for AFRP, CFRP and GFRP are 68.9, 110.3 and 39.3 GPa. These values must be expressed in $10^{3} \mathrm{ksi}$ followed by the letter $\mathbf{E}$, characterizing 
the elasticity modulus groups provided by manufacturers (ACI 440 1R-15, 2015). In case the FRP mechanical properties are unknown, they can be obtained from the fiber and resin properties, as well as their volume proportion (FIB BULLETIN 40, 2007):

$$
\begin{gathered}
f_{f}=f_{f t}\left[V_{f}+\frac{E_{m}}{E_{f l}}\left(1-V_{f}\right)\right] \\
E_{f}=E_{f l} V_{f}+E_{m}\left(1-V_{f}\right)
\end{gathered}
$$

Table 2.1 presents intervals of tensile strength, elasticity modulus and ultimate tensile strain of FRP materials, considering fiber-proportions from $50 \%$ to $75 \%$.

Table 2.1 - FRP and steel mechanical properties

\begin{tabular}{ccccc}
\hline \multirow{2}{*}{ Mechanical Properties } & \multicolumn{4}{c}{ Material } \\
\cline { 2 - 5 } & Steel & GFRP & CFRP & AFRP \\
\hline Tensile Strength (MPa) & 450 to 700 & 450 to 1600 & 600 to 3500 & 1000 to 2500 \\
Young Modulus (GPa) & 200 & 35 to 60 & 100 to 580 & 40 to 250 \\
Ultimate Strain (\%) & 5 to 20 & 12 to 37 & 5 to 17 & 19 to 44 \\
\hline
\end{tabular}

Source: FIB BULLETIN 40, 2007

There is also the BFRP - Basalt Fiber-reinforced Polymer - rebars, which is relatively new in construction and have several advantages compared to steel and other types of FRP. Due to their varied chemical composition and production processes, the tensile strength of BFRP rebars ranges from 1500 to $2900 \mathrm{MPa}$ and the elasticity modulus from 78 to $90 \mathrm{GPa}$ (URBANSKI, LAPKO and GARBACZ, 2013).

The amount of flexural FRP reinforcement relies on its tensile strength and stiffness. These materials have strength-stiffness ratio ten times greater than steel. As a result, the depth of the neutral axis is generally smaller than the one for conventional RC. Such a fact leads to larger reinforcement strains, which makes anchorage difficult. Furthermore, a larger area of the cross-section is under tension, and the compressive zone subjected to high strain gradients. Therefore, FRP RC concrete exhibits larger deflections and intense cracking compared to conventional RC members (PILAKOUTAS et al., 2009).

Experimental work on BFRP RC beams by Urbanski, Lapko and Garbacz (2013) showed that the failure of these elements was not sudden, seeing that the beams were transformed into a tie system due to the fact the rebars did not collapse. Moreover, it was observed that the deflections were, approximately, three to four times larger than those of a steel RC beam. Such difference dropped to $40 \%$ by virtue of the plastic behavior exhibited by steel. Regarding crack widths, these were, in average, four times larger compared to the 
conventional members. Finally, this study concluded that the low elasticity modulus of BFRP rebars contributed to the large deformation and cracking of the alternative beams. The authors highlighted that the serviceability requirements would probably govern the design of BFRP RC beams.

Kassem, Farghaly and Benmokrane (2011) experimentally investigated the behavior of simply supported beams reinforced with CFRP, GFRP, AFRP and steel rebars, evaluating how the reinforcement ratio, position, configuration and surface texture would affect the flexural capacity. It was observed that beams reinforced with steel ruptured due to concrete crushing followed by steel yielding. Conversely, once cracking occurred on the FRP RC members, the relationship between bending-moment and reinforcement strains became non-linear. For most beams, the reinforcement strain was smaller than the maximum it could reach at failure. In addition, simultaneous failure of CFRP and concrete was also observed in only one CFRP RC beam, for which the ratio between the actual and balanced amount of reinforcement was 1.2. Increasing the reinforcement ratio and keeping the load level steady made the reinforcement strains drop, while the concrete most compressed fiber had its strain increased up to $3.2 \%$.

The experimental results also showed that the neutral axis depth did not exhibit considerable reductions after cracking occurred, being the service neutral axis close to that corresponding to failure. Moreover, the authors concluded that increasing the reinforcement ratio does not lead to great increments of flexural strength, for compression-controlled sections. It was found that some beams that had their reinforcement ratio increased by $50 \%$ and $100 \%$ obtained an increment of only 4 and $16 \%$ in their flexural capacity, respectively. Regarding the surface texture, the research concluded that it has no influence on the flexural capacity, but on deflections and crack widths (KASSEM, FARGHALY and BENMOKRANE 2011).

\subsection{Fatigue Behavior}

The fatigue behavior of FRP materials is characterized by the accumulation of damages due to cyclic loadings and exposition to aggressive environments. Those occur as a result of the polymeric resin cracking, rupture of fibers, cracks in the longitudinal direction, union of existing cracks and delamination growth. Therefore, the cause of fatigue failure is a combination of all these damage related events, and not the formation of just one macro-crack. Moreover, the fatigue failure may be considerably small compared to the short-term tensile strength, sometimes even smaller than stresses caused by service loads (SCHAFF, 2001). 
Fib Bulletin 40 (2007) stresses that it is difficult to establish endurance limits for any type of FRP. However, such technical report emphasizes that the fatigue limit is inversely proportional to the loading frequency. Moreover, the higher are the average stress and the ratio between maximum and minimum stress, the lower is the stress at failure for an infinite number of cycles.

Fib Model Code (2010) highlights the importance of using high modulus FRP rebars due to their great cyclic fatigue resistance. CFRP and AFRP, for instance, have their fatigue strength higher than the conventional pre-stressing steel, while the GFRP's is lower. Table 5.52 of Fib Model Code (2010) describes the maximum tensile stresses as a function of the shortterm strength considering $2.10^{6}$ load-cycles. According to this table, the tensile stress of CFRP and AFRP rods reaches $60 \%$ of their tensile strength, while GFRP, only 50\%. Moreover, the stress range at failure of CFRP rods may exceed $350 \mathrm{MPa}$, while the corresponding to AFRP rods, only $235 \mathrm{MPa}$. GFRP, in turn, fails at $50 \%$ of its short-term strength, with a stress range up to $75 \mathrm{MPa}$.

ACI 440 1R-15 (2015) also stresses the excellent capacity of CFRP to resist loadunloading cycles. The $\mathrm{S}-\mathrm{N}$ curve shows that the decrease in tensile strength ranges from 5 to $8 \%$ per decade of logarithmic life. Considering 1 million cycles, the stress at failure ranges from 50 to $70 \%$ of the short-term strength, being relatively not affected by moisture and temperature conditions as long as there are no damages on fibers or fiber-resin interfaces.

Regarding GFRP, the loss in strength due to loading cycles is quite associated to the environmental conditions due to their vulnerability to moisture, acid and alkaline solutions (ACI 440 1R-15, 2015). Experimental results conducted by Mandell and Meier (1983, apud ACI 440 1R-15, p.12, 2015) showed that very low humidity caused surface flaws to grow, inducing stress corrosion, which resulted in rupture of individual glass fibers. Mandell (1982, apud ACI 440 1R-15, p.12, 2015) observed a loss in GFRP tensile strength of 10\% per decade of logarithmic life for a composite with many glass fibers impregnated by a matrix. ACI 440 1R-15 (2015) concluded that the fatigue effect on GFRP rebars does not depend on the stress corrosion, but on the interaction between fibers.

According to Fib Bulletin 40 (2007), the tensile strength reduction of AFRP composites ranges from 5 to $6 \%$ per decade of logarithmic life. Values reported by Odagiri et al. (1997, 1983, apud FIB BULLETIN, p.29, 2007) indicate that the stress varies from 54 to $73 \%$ of the short-term strength, considering 2 million cycles. 


\subsection{Creep Deformation and Rupture}

Two main issues are related to creep in FRP reinforcement: the increasing strains (creep deformation) and the composite rupture (creep rupture) under sustained loads (FIB BULLETIN 40, 2007). The elastic fibers composing FRP are very resistant to creep. This is not the case of the resin, which exhibits considerable creep deformations. However, since FRP composite materials have a high-volume fraction of fibers, considerably stiffer than the polymeric matrix, FRP creep deformations are very slight (FIB MODEL CODE, 2010). Despite such negligible strains, the composite materials show significant creep under the application of high loads at temperatures exceeding $40 \%$ of their melting temperature (HULL and CLYNE, 1996, apud FIB BULLETIN 40, 2007, p.25).

Figure 2.1 illustrates three stages of creep deformations. The applied load causes the composite to elongate elastically, defining the initial elastic strain, which increases rapidly during the primary stage. A slight constant slope extending for a significant period defines the secondary stage of creep, which theoretically corresponds to the period the structure is in operation (BARBERO, 1999). In contrast, a high level of stresses characterizes the tertiary stage, for which there is a great accumulation of creep strain and material damage (FIB BULLETIN 40, 2007).

Figure 2.1 - Generic history curve for creep strains

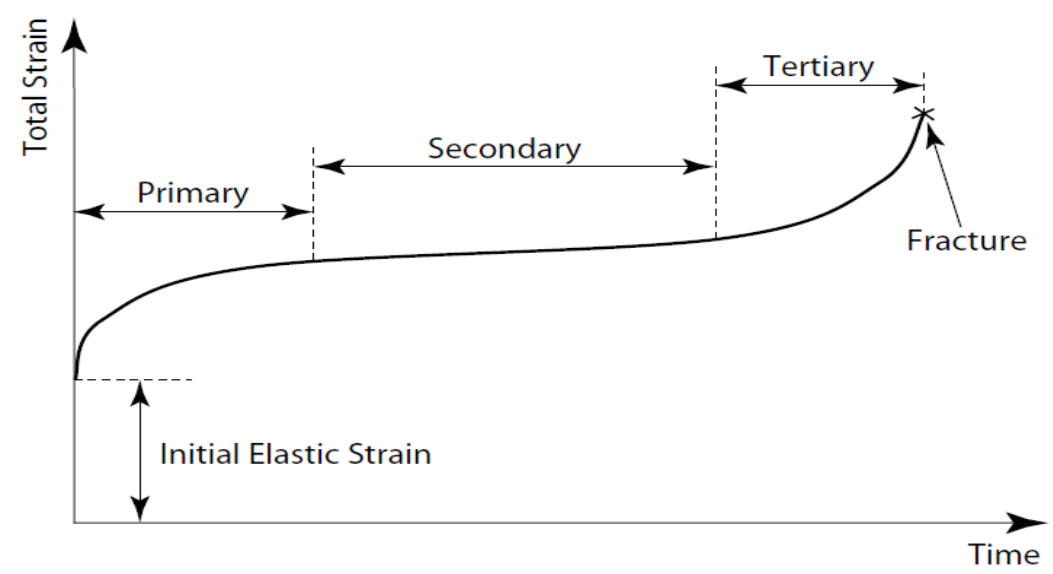

Source: FIB BULLETIN 40, 2007

The initial elastic strain $\varepsilon_{0}$ is obtained as the ratio between the applied stress and the elasticity modulus of the composite, which depends on the volume fraction of fibers and resin. Over time, creep develops in the polymeric matrix. As a result, greater partition of the load is carried out by the fibers. Thus, the composite strain after a long period time can be determined 
as the ratio between the applied stress and the elasticity modulus of the fibers (FIB BULLETIN 40, 2007).

Hollaway (1993) recommends plotting groups of history curves for creep strains, each one corresponding to a constant level of stress. Such author also advises to linearize the creep strain curve as a function of the logarithmic of time. Therefore, most of polymeric materials can exhibit a linear behavior through the following equation:

$$
\varepsilon(t)=\beta_{c c} \log (t)+\varepsilon_{0}
$$

In Equation 2.3, $\beta_{c c}$ corresponds to the creep coefficient, which depends on the composite stress level and characterizes the rate of creep. In turn, $\varepsilon_{0}$ is the short-term strain of the composite. The determination of $\beta_{c c}$ is very useful to compare the creep behavior of several polymeric materials; its value is directly proportional to the stress level, varying accordingly to different polymer manufacturing methods (HOLLAWAY, 1993).

Regarding creep rupture, FRP reinforcement may present sudden failure after a timeperiod denominated "endurance limit" (FIB BULLETIN 40, 2007). According to Fib Model Code (2010), the maximum allowed stress in the non-metallic reinforcement is a function of the fiber-resin system, fiber disposition as well as its volume fraction. The higher is the ratio between the sustained stress and the short-term strength, the lower is the endurance limit. Furthermore, environmental factors such as high alkalinity, moisture, ultra-violet exposition, freezing-and-thawing, as well as, wet and dry cycles contribute to early creep rupture due to sustained loads (ACI 440 1R-15, 2015).

According to Fib Model Code (2010), CFRP reinforcement is less prone to present creep rupture for tensile stresses up to $80 \%$ of its initial strength, whereas AFRP and GFRP, $50 \%$ and $30 \%$, respectively, for a time-period of 50 years. However, experimental results showed that FRP rebars do not fail due to sustained stresses lower than $60 \%$ of the short-term tensile strength (BUDELMAN and ROSTASY, 1993, apud FIB BULLETIN 40, p.27, 2007).

Yamaguchi et al. (1997) concluded from experimental results that the relationship between FRP creep strength and the logarithmic of time is linear for time-periods up to 100 hours. Moreover, if these results are extrapolated to 500,000 h (57 years), the creep rupture of GFRP, AFRP and CFRP is expected to occur at 29, 43 and $93 \%$ of their short-term tensile strength, respectively.

Nkurunziza et al. (2005) also investigated the creep behavior of GFRP rebars, focusing on the residual strength after the composite subjection to sustained loads under distinct environmental conditions. The time-period considered for the analysis was 10,000 hours (417 
days). Results showed that rebars immerged in de-ionized water presented, in average, residual tensile strengths of 97.1 and $100.8 \%$ of the guaranteed strength. Those were stressed at 25 and $38 \%$ of their guaranteed tensile strength, respectively. For specimens immerged in alkaline solutions, the residual tensile strengths were smaller: 88.5 and $68.6 \%$, respectively. The authors also highlighted that a stress level of $38 \%$ is considerably high for practical situations, corresponding to 4.3 times the maximum allowed by ACI 440 design guidelines. Furthermore, Nkurunziza et al. (2005) affirm that the surrounding environment has major influence on the tensile strength reduction compared to sustained stress levels. The authors also observed that the environmental conditions do not influence the residual tensile strength for low stress levels, since the resin strain is considerably smaller than its ultimate strain. Therefore, matrix microcracking does not occur, which prevents the alkaline or water medium from penetrating the composite and affecting the fibers.

Regarding the use of FRP in prestressing, polymeric tendons are commonly under stresses levels from 60 to $70 \%$ of their tensile strength. Although these stresses do not change significantly over time, creep rupture may occur under service load levels (SAYED-AHMED and SHRIVE, 1999). Slattery (1994, apud Sayed-Ahmed and Shrive, p.4, 1999) observed from experimental results, midterm failure of AFRP, CFRP and GFRP tendons at stresses levels of 55,80 and $33 \%$ of their ultimate tensile strength, respectively. The following equations developed by Nanni et al. (1996) can be used to estimate the stress levels at long term for AFRP, CFRP and GFRP tendons (SAYED-AHMED and SHRIVE, 1999):

$$
\begin{aligned}
& f_{f} / f_{f u}=79.8-5.67 \log t \\
& f_{f} / f_{f u}=102-1.92 \log t \\
& f_{f} / f_{f u}=79.2-8.29 \log t
\end{aligned}
$$

\subsection{Relaxation}

FRP materials subjected to constant strains over time also present stress losses. According to Fib Bulletin (2007), the relaxation of FRP strands can be depicted as the ratio between final and initial loads obtained experimentally, whereby the most common value is the one defined after 1 million hours. Such a phenomenon occurs due to the relaxation of resin and fibers associated to fiber straightening. Furthermore, losses in pre-stressing are a function of the ratio between the elasticity modules of resin and fibers, respectively, as well as the 
polymeric matrix volume fraction. The relaxation of the resin takes place after few days of prestressing and is intensified under the exposition to high temperatures (RYNGIER and ZDANOWICZ, 2015).

The type of fiber (carbon, aramid, glass or basalt) also contributes to the relaxation of the tendon as a whole. Ryngier and Zdanowicz (2015) recommends estimating the relaxation of fibers as $\mathrm{R}_{\mathrm{EL} 3}=0.231+0.345 \log (\mathrm{t})$, in accordance with Canadian guidelines, where $t$ is the time in days. Carbon fibers have low relaxation, differently from aramid, whose losses in stresses range from 1 to $3 \%$ per logarithmic decade. This considerable relaxation of aramid fibers is intimately related to its creep behavior (ACI 440 4R-04, 2004).

Since fibers are not parallel to each other, they penetrate into the resin during prestressing, phenomenon denominated as fiber straightening. The losses in stresses caused by this phenomenon depends on the manufacturing process, ranging from 1 to $2 \%$ of the prestressing stress (RYNGIER and ZDANOWICZ, 2015).

ACI 440 4R-04 (2004) recommends that over prestressing the FRP tendons can compensate losses due to the matrix relaxation. Nonetheless, this guideline highlights that tensile stresses must not exceed the limits established by Table 3.3 of the corresponding document, since such losses occur in the resin but not in the fibers, which would be definitely overstrained. To estimate the relaxation of AFRP and CFRP tendons, Sayed-Ahmed and Shrive (1999) recommend using the following equations (HOLTE, DOLAN and SCHMIDT, 1993), respectively:

$$
\begin{gathered}
\Psi(t)=3.88+2.88 \log (24 \Delta t) \\
\Psi(t)=0.231+0.345 \log (24 \Delta t)
\end{gathered}
$$

\subsection{Durability}

As previously mentioned, alkaline environments may negatively affect the FRP reinforcement properties. Once hydrated, the cement components are converted to chemical compounds that directly affect concrete properties. Solutions of calcium hydroxide, for instance, causes the concrete PH to reach 12.5, in average (ADHIKARI, 2009). Since the polymeric matrix resists well to strong alkalis, it protects both the fibers and interface region against the concrete and external aggressive environments. However, factors such as high PH, conditions and quality of composite (ends, voids, matrix homogeneity, surface texture, etc.), as 
well as, high stress levels and temperature compromise the effectiveness of this protection. Cut ends of FRP rebars, for example, expose the fibers and allow penetration of chemical agents through a wicking process. Therefore, it is necessary to properly seal the end surfaces of short rebars to avoid damages (FIB BULLETIN 40, 2007).

According to Fib Bulletin 40 (2007), alkali attack on FRP reinforcement has been extensively studied. The absence of standard durability test methods and the availability of uncountable FRP types of different manufacturers resulted in a wide variety of test data. Nonetheless, this technical report highlights that the mobility of $\mathrm{OH}^{-}$ions due to pore solution constitutes a more serious issue in terms of durability than the concrete environment itself. As a conclusion, a linear relationship between available test data and FRP resistance to the concrete environment must not be assumed.

Page 33 of Fib Bulletin 40 (2007) describes conclusions of experimental works regarding the effects of water on FRP reinforcement: Bank and Gentry (1995) concluded that the water molecules act as a resin plasticizer, disrupting Van-der-Walls bonds in polymer chains and deteriorating the polymeric matrix. As a result, changes in elasticity modulus, tensile strength and strain as well as swelling stresses and toughness cause the resin to crack and the fiber-matrix interface to undergo hydrolysis. Notwithstanding, those changes depend more on the type of fiber, being aggravated by temperatures higher than $60^{\circ} \mathrm{C}$ and the polymer potential to absorb moisture at saturation. Surprisingly, mechanical properties showed to be improved when FRP is immersed in water (HAYES et al., 1998).

Regarding the effects of chlorides, Fib Bulletin 40 (2007) mentions the difficulty to differentiate chloride attack and damages related to moisture diffusivity and alkali attack of the fibers. Generally, CFRP rebars do not show strength losses in time, exposure and temperature. AFRP and GFRP, in turn, can exhibit strength and stiffness losses up to $50 \%$ and stress relaxation up to $30 \%$ (FIB BULLETIN 40, 2007).

\subsection{Design Procedures}

The cross-section dimensions of flexural members can be determined with the aid of Table 7.3.2.1 of ACI 440 1R-15. For ABNT NBR 6118 (2014), continuous beams may have their thickness estimated as $1 / 10$ of the average span length.

In order to compute the amount of flexural FRP reinforcement, the first step is to determine the ultimate bending moment $M_{u}$ of a structural element. ABNT NBR 6118 (2014) 
applies a safety factor of 1.4 at the ultimate limit state, while ACI $4401 \mathrm{R}-15$ increases the bending moments due to dead and live loads by factors of 1.2 and 1.6, respectively.

Since FRP RC beams fail due to concrete crushing or FRP rupture, it is necessary to compare the factored moment $M_{d}$ with the balanced $M_{b}$, for which the two types of failure occur simultaneously. Given the equilibrium and compatibility conditions illustrated in Figure $8, M_{b}$ is:

$$
M_{b}=0.85 \alpha_{u l s} \beta_{u l s} f_{c d} b x_{b}\left(d-0.5 \beta_{u l s} x_{b}\right)
$$

For a normal strength concrete $\left(\mathrm{f}_{\mathrm{ck}} \leq 50 \mathrm{MPa}\right)$, the coefficients $\alpha_{u l s}$ and $\beta_{u l s}$ of the simplified rectangular stress block correspond to 1.0 and 0.8 , respectively, while the ultimate strain for a normal strength concrete $\varepsilon_{c u}$ corresponds to $-3.5 \%$. If a high-performance concrete $\left(50<\mathrm{f}_{\mathrm{ck}} \leq 90 \mathrm{MPa}\right)$ is used, these parameters vary from one grade to another (ABNT NBR 6118, 2014).

Equation 2.9 is compatible with the procedures of ABNT NBR 6118 (2014), which uses the parabolic rectangle model to represent stresses in concrete; in addition, it reduces the nominal strength $f_{c k}$ and $f_{f u}$ to the design values $f_{c d}$ and $f_{f u d}$. Since the Brazilian code neither addresses the application of FRP nor imposes reduction factors for its strength, the reduction factor of 1.25 provided by Fib Bulletin 40 (2007) may be applied.

Figure 2.2 - Equilibrium and compatibility conditions for a balanced generic cross-section

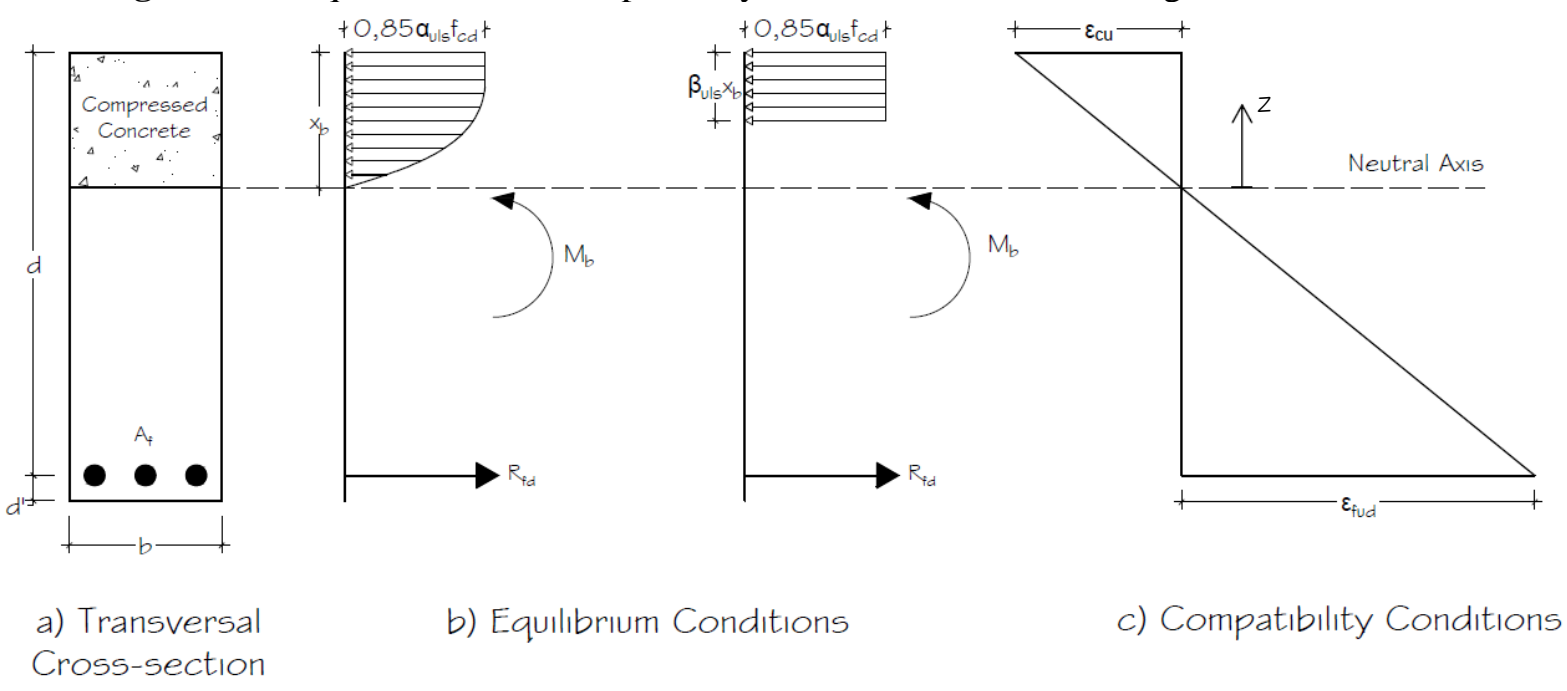

Source: Author

If $\mathrm{M}_{\mathrm{d}}<\mathrm{M}_{\mathrm{b}}$, the cross-section is under-reinforced and the failure at the ultimate limit state is attributed to the reinforcement rupture. Conversely, $M_{d}>M_{b}$ indicates over-reinforced cross-section, which fails due to concrete crushing, whereas $M_{d}=M_{b}$ denotes simultaneous 
failure. Therefore, the calculation of the reinforcement area $A_{f}$ relies on the equilibrium and compatibility equations for each failure mode.

For an over-reinforced cross-section, concrete crushes and the stress at reinforcement is smaller than its strength. Thus, the concrete stress-strain relationship is simplified to the rectangular block illustrated in Figure 2.2. Based on the equilibrium conditions, the neutral axis position $x$ is:

$$
x=\frac{d}{\beta_{u l s}}\left(1-\sqrt{1-\frac{M_{d}}{0.425 \alpha_{u l s} f_{c d} b d^{2}}}\right)
$$

Once $x$ is determined, the compatibility conditions allow to compute the reinforcement strain $\varepsilon_{f}$ and stress $f_{f}$ :

$$
f_{f}=E_{f} \varepsilon_{c u}\left(\frac{d-x}{x}\right)
$$

Therefore, upon imposing the equilibrium conditions, the amount of reinforcement $A_{f}$ as regards an over-reinforced cross-section is:

$$
A_{f}=\frac{M_{d}}{f_{f}\left(d-0,5 \beta_{u l s} x\right)}
$$

In case $\mathrm{M}_{\mathrm{d}}<\mathrm{M}_{\mathrm{b}}$, the FRP rebars reach its tensile strength before the concrete. Therefore, the simplified rectangular block of Figure 8 does not apply. Moreover, depending on the neutral axis depth, the stress-strain relationship in concrete may be linear or not (ACI 440 1R-15, 2015). In order to represent the stresses in concrete through a rectangular block, the values of $\alpha$ and $\beta$ must account that the compressive strength $0.85 f_{c d}$ as well as the ultimate strain $\varepsilon_{c u}$ were not reached. Collins and Mitchell (1987) present a method by which the strain at the most compressed fiber $\varepsilon_{t}$ is arbitrated and the compressive stresses turns to be known. Thenceforth, the resulting compressive force and its centroid are equal to the area and center of the simplified rectangular block, respectively:

$$
\begin{aligned}
& \int \sigma_{c d} b d z=0.85 \alpha f_{c d} \beta x b \\
& \frac{\int \sigma_{c d} b z d z}{\int \sigma_{c d} b d z}=x(1-0.5 \beta x)
\end{aligned}
$$


The section 8.2.10.1 of ABNT NBR 6118 (2014) defines the constitutive models for concrete grades up to $90 \mathrm{MPa}$, as shown in Figure 2.3 and Table 2.2:

Figure 2.3 - Concrete stress-strain relationship for compression.

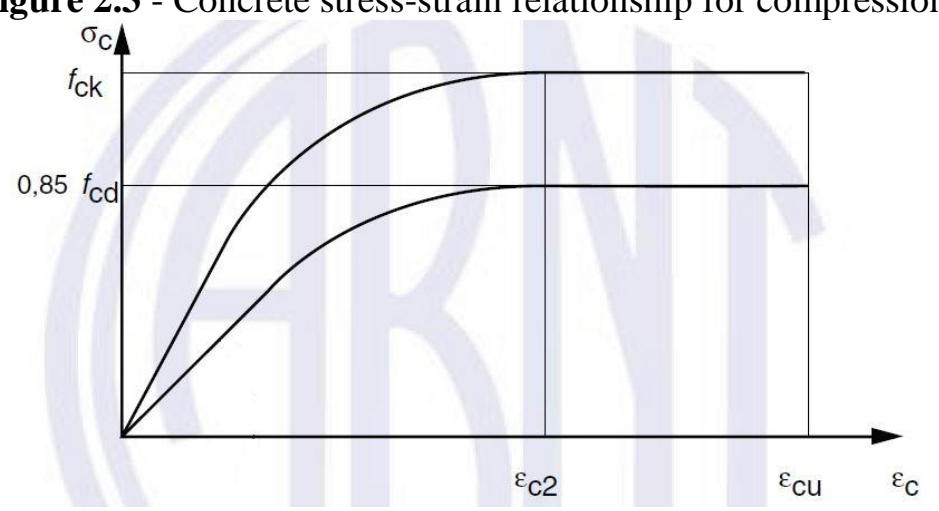

Source: ABNT NBR 6118, 2014

Table 2.2 - Concrete constitutive model parameters

\begin{tabular}{ccc}
\hline \multirow{2}{*}{ Parameters } & \multicolumn{2}{c}{ Concrete Compressive Strength Grades } \\
\cline { 2 - 3 } & Up to 50 MPa & From 50 to 90 MPa \\
\hline $\mathrm{n}$ & 2 & $1.4+23.4\left[\left(90-\mathrm{f}_{\mathrm{ck}}\right) / 100\right]^{4}$ \\
$\varepsilon_{\mathrm{c} 2}$ & $-2.0 \% \mathrm{o}$ & $-2.0 \% \mathrm{oo}-0.085 \% \mathrm{f}\left(\mathrm{f}_{\mathrm{ck}}-50\right)^{0.53}$ \\
$\varepsilon_{\mathrm{cu}}$ & $-3.5 \% \mathrm{o}$ & $-2.6 \% \mathrm{o}-35 \% \mathrm{o}\left[\left(90-\mathrm{f}_{\mathrm{ck}}\right) / 100\right]^{4}$ \\
\hline
\end{tabular}

The parameters above allow the determination of concrete constitutive equations:

$$
\begin{array}{cc}
\sigma_{c d}=0.85 f_{c d}\left[1-\left(1-\frac{\varepsilon_{c}}{\varepsilon_{c 2}}\right)^{n}\right] & \text { if } 0 \leq \varepsilon_{c}<\varepsilon_{c 2} \\
\sigma_{c d}=0.85 f_{c d} & \text { if } \varepsilon_{\mathrm{c} 2} \leq \varepsilon_{\mathrm{c}}<\varepsilon_{\mathrm{cu}}
\end{array}
$$

By imposing compatibility conditions, it is possible to write $\varepsilon_{c}$ as a function of the distance $z$, from neutral axis to the direction of the most compressed fiber. Therefore, $\alpha$ and $\beta$ are given as a function of $\varepsilon_{t}, \varepsilon_{c 2}$ and $n$. If the arbitrated strain $\varepsilon_{t}$ is smaller than $\varepsilon_{c 2}$, the parameters $\alpha$ and $\beta$ are calculated through:

$$
\begin{gathered}
j=\frac{1}{n+1}\left(\frac{\varepsilon_{c 2}}{\varepsilon_{t}}\right)\left[\left(1-\frac{\varepsilon_{t}}{\varepsilon_{c 2}}\right)^{n+1}-1\right]+1 \\
\beta=2-\frac{2}{j}\left(\frac{\varepsilon_{c 2}}{\varepsilon_{t}}\right)^{2}\left\{\frac{1}{n+2}\left[1-\left(1-\frac{\varepsilon_{t}}{\varepsilon_{c 2}}\right)^{n+2}\right]-\frac{1}{n+1}\left[1-\left(1-\frac{\varepsilon_{t}}{\varepsilon_{c 2}}\right)^{n+1}\right]+0.5\left(\frac{\varepsilon_{t}}{\varepsilon_{c 2}}\right)^{2}\right\} \\
\alpha=j / \beta
\end{gathered}
$$

If $\varepsilon_{t}$ is greater than $\varepsilon_{c 2}$, these parameters are given as follows: 


$$
\begin{gathered}
j=1-\left(\frac{\varepsilon_{c 2}}{\varepsilon_{t}}\right) \frac{1}{n+1} \\
\beta=2-\frac{2}{j}\left(\frac{\varepsilon_{c 2}}{\varepsilon_{t}}\right)^{2}\left\{\frac{1}{n+2}-\frac{1}{n+1}+0.5\left(\frac{\varepsilon_{t}}{\varepsilon_{c 2}}\right)^{2}\right\} \\
\alpha=j / \beta
\end{gathered}
$$

Once $\alpha$ and $\beta$ are found, the neutral axis depth $x$ is computed through Equation 2.10. Thus, it is possible to determine new values of $\varepsilon_{t}, \alpha$ and $\beta$, repeating this procedure until the strain at the most compressed fiber converges. Subsequently, the equilibrium conditions define the amount of reinforcement $A_{f}$.

$$
A_{f}=\frac{M_{d}}{f_{f u d}(d-0,5 \beta x)}
$$

Alternatively, the item 8.2.10.1 of ABNT NBR 6118 (2014) allows adopting a linear stress-strain relationship for concrete if the stress levels are lower than $50 \%$ of the compressive strength. Therefore, for the ultimate limit state, this limit corresponds to $0.5\left(0.85 f_{c d}\right)$, while for the serviceability limit, $0.5\left(0.85 f_{c k}\right)$, using the secant modulus of elasticity. According to the item 8.2.8 of the Brazilian code, the secant elasticity modulus can be estimated as:

$$
\begin{array}{cc}
E_{c s}=\alpha_{i} \alpha_{E} 5600 \sqrt{f_{c k}} & \text { for } 20 \leq f_{c k} \leq 50 \mathrm{MPa} \\
E_{c s}=21.5 * 10^{3} \alpha_{i} \alpha_{E}\left(\frac{f_{c k}}{10}+1.25\right)^{\frac{1}{3}} & \text { for } 50<f_{c k} \leq 90 \mathrm{MPa}
\end{array}
$$

The coefficient $\alpha_{E}$ depends on the aggregate type, which is 1.2 for basalt and diabase, 1.0 for granite and gneiss, 0.9 for limestone and 0.7 for sandstone. The coefficient $\alpha_{i}$ relies on the concrete compressive strength, being $\alpha_{\mathrm{i}}=0.8+0.2\left(\mathrm{f}_{\mathrm{ck}} / 80\right)$, but never higher than $1.0(\mathrm{ABNT}$ NBR 6118, 2014)

Since ABNT NBR 6118 (2014) does not apply for concrete compressive strengths higher than $90 \mathrm{MPa}$, the approach described in Equations 2.17 to 2.22 to calculate $\alpha$ and $\beta$ has to consider the constitutive models of the reference code. The approaches of Fib Model Code (2010), for instance, apply for concrete compressive strengths up to $120 \mathrm{MPa}$.

Furthermore, the factored bending moment may lead to the calculation of reinforcement areas smaller than the minimum established by Table 17.3 of ABNT NBR 6118 (2014), for each concrete grade. Therefore, the Brazilian code defines the minimum bending moment $M_{d \text {,min }}$ to compute $A_{f}$ and fulfill this requirement: 


$$
M_{d, \min }=\frac{0.8 f_{c t k, \text { sup }} I_{g}}{y_{t}}
$$

In the previous equation, $f_{c t k \text {,sup }}$ is the concrete tensile strength for which there is a $5 \%$ probability of the actual tensile strength being higher than such value $f_{c t k, s u p}$. In turn, $I_{g}$ is the gross moment of inertia and $y_{t}$ is the distance from the geometrical cross-section center to the most tensioned fiber.

Upon determining the amount of reinforcement and detailing the cross-section, it is necessary to check for creep rupture, deflections and crack widths. Since FRP has low modulus and high tensile strength, the serviceability limit states may govern the design of flexural members (ACI 440 1R-15, 2015). Therefore, the amount of reinforcement, concrete grade and cross-section dimensions are subjected to change.

In order to check for creep rupture, deflections and crack widths, the service load combinations have to be properly computed. Table 11.4 of ABNT NBR 6118 (2014) defines three types of load-combinations: almost permanent, frequent and rare. The almost permanent combination is defined as the sum of dead load and the factored live load considering the almost permanent load combination coefficient $\psi_{2}$. Thus, the almost permanent bending moment is: $\mathrm{M}_{\mathrm{apc}}=\mathrm{M}_{\mathrm{g}}+\psi_{2} M_{\mathrm{q}}$. Frequent combinations, in turn, are defined as the sum of dead loads, the main live load factored by the frequent load combination coefficient $\psi_{1}$, and the secondary live loads factored by $\psi_{2}$, as follows: $\mathrm{M}_{\mathrm{fc}}=\mathrm{M}_{\mathrm{g}}+\psi_{1} \mathrm{M}_{\mathrm{q} 1}+\psi_{2} \mathrm{M}_{\mathrm{q} 2}$. To compute the rare load combinations, the dead and main live loads are added to the frequent portion of secondary live loads: $\mathrm{M}_{\mathrm{rc}}=\mathrm{M}_{\mathrm{g}}+\mathrm{M}_{\mathrm{q} 1}+\psi_{1} \mathrm{M}_{\mathrm{q} 2}(\mathrm{ABNT}$ NBR 6118, 2014). Table 11.2 of ABNT NBR 6118 (2014) provides these loading combination coefficients.

According to ACI 440 1R-15 (2015), the stress levels under service loads must not exceed the limits of 30, 55 and 20\% for AFRP, CFRP and GFRP, respectively. They are based on the bending moment $M_{\text {sus }}$ resulted from dead loads as well as the permanent portion of live loads. For the purposes of this research, the almost permanent combination $M_{a p c}$ defined by ABNT NBR 6118 (2014) is used. The linear approach adopted by ACI to estimate the sustained stress $f_{f s}$ for FRP reinforcement is:

$$
f_{f s}=M_{a p c} \eta_{f} \frac{\left(d-x_{c r}\right)}{I_{c r}}
$$

The parameter $\eta_{f}$ corresponds to the modular ratio $E_{f} / E_{c s}$, while $x_{c r}$ and $I_{c r}$ depicts the neutral axis and the cracked moment of inertia, which depend on the material and geometrical cross-section properties, as shown in Figure 2.4: 
Figure 2.4 - Linear approach for the determination of $x_{c r}, I_{c r}$ and $f_{f s}$

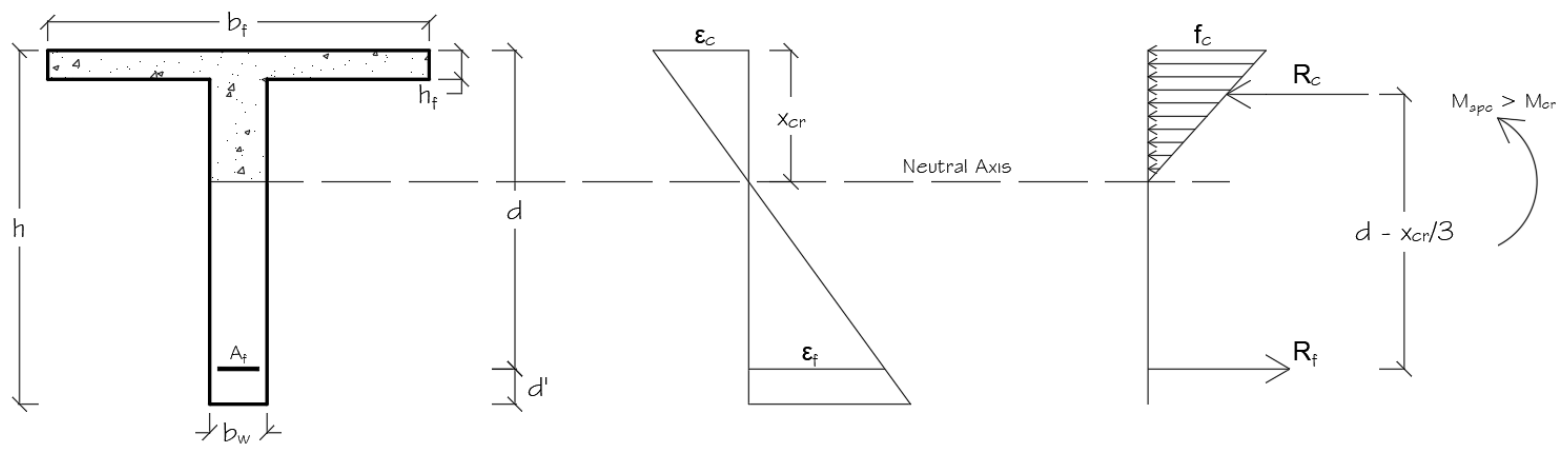

Source: CARVALHO and FIGUEIREDO FILHO, 2014 - Adapted

Carvalho and Figueiredo Filho (2014) recommend using the equations developed by Ghali and Favre (1986) to calculate $x_{c r}$ and $I_{c r}$ for a T-section:

$$
\begin{gathered}
a_{I} x_{c r}^{2}+a_{2} x_{c r}+a_{3}=0 \\
a_{1}=\frac{b_{w}}{2} \\
a_{2}=h_{f}\left(b_{f}-b_{w}\right)+\eta_{f} A_{f} \\
a_{3}=-d \eta_{f} A_{f}-\frac{h_{f}^{2}}{2}\left(b_{f}-b_{w}\right) \\
x_{c r}=\frac{-a_{2}+\sqrt{a_{2}^{2}-4 a_{1} a_{3}}}{2 a_{1}}
\end{gathered}
$$

Once $x_{c r}$ is computed, the equations to calculate $I_{c r}$ depend on the location of the neutral axis. According to Carvalho and Figueiredo Filho (2014), Equations 2.33 and 2.34 apply for the neutral axis on the flange and web, respectively:

$$
\begin{gathered}
I_{c r}=\frac{b_{f} x_{c r}^{3}}{3}+\eta_{f} A_{f}\left(x_{c r}-d\right)^{2} \\
I_{c r}=\frac{\left(b_{f}-b_{w}\right) h_{f}{ }^{3}}{12}+\frac{b_{w} x_{c r}^{3}}{3}+\left(b_{f}-b_{w}\right)\left(x_{c r}-\frac{h_{f}}{2}\right)^{2}+\eta_{f} A_{f}\left(x_{c r}-d\right)^{2}
\end{gathered}
$$

The above equations for $x_{c r}$ and $I_{c r}$ are valid for rectangular, T and $\mathrm{L}$ sections without compression reinforcement. For rectangular cross-sections, $b_{f}=b_{w}$ and $h_{f}=0($ CARVALHO and FIGUEIREDO FILHO, 2014). 


\subsection{Serviceability Limit States}

In order to verify the serviceability limit states regarding deflections and crack widths, the first step is the determination of the service moments related to almost permanent and frequent load combinations.

The deflections of FRP RC members are larger in comparison to conventional reinforced concrete since FRP has low elasticity modulus, behaves linear until failure and bonds to concrete in a different manner than steel (ACI 440 1R-15, 2015). According to Pilakoutas et al. (2009), steel rebars bonds to concrete due to the interlock of bar lugs, whereas the FRP bonding mechanism is attributed to the friction between the materials interface. Moreover, the author emphasizes that the loss in bonding between concrete and steel occurs due to concrete crushing in the surroundings of steel lugs. FRP, in turn, detaches as a result of the concrete failure in the surrounding of the rebars, as well as damage on the surface of both materials. Therefore, FRP RC members are more sensitive to variables affecting displacements, which requires a different approach to estimate their deflections.

Kassem, Farghaly and Benmokrane (2011) assessed the deflections of FRP RC beams, observing that the relationship between deflections at mid-span and service moment was linear before cracking. Thenceforth, the corresponding slope to this relationship progressively dropped as the cracking process took place. Figure 2.5 shows that the decrease in slope is greater for the FRP reinforcement, while for steel, the curve is trilinear by virtue of its yielding plateau. The letters C, G, AR and ST denotes carbon, glass, aramid and steel, respectively, whereas the first number following the letter indicates the surface type; the second, in turn, refers to the reinforcement ratio and configuration as defined by Kassem, Farghaly and Benmokrane (2011).

Additionally, increasing the reinforcement ratio by 50 and $100 \%$ reduced the deflections from $16 \%$ to $36 \%$ for sand coated CFRP RC beams, while for those with ribbed-deformed rebars, this reduction ranged from $25 \%$ to $36 \%$. The deflections of ribbed deformed GFRP RC beams, in turn, were less sensitive to a $33 \%$ increase in the reinforcement ratio, decreasing by 20\%. Regarding the ones with GFRP and AFRP sand coated deformed rebars, the deflections dropped by $27 \%$ and $15 \%$, respectively. Difference in surface texture did not seem to cause discrepancies between beams reinforced with the same type of FRP and reinforcement ratio under applied loads smaller than the service ones. Moreover, even though ribbed deformed rebars had larger elasticity modulus, the beams reinforced with sand coated CFRP rebars presented smaller deflections at failure, which possibly infers better bond behavior of sand coated rebars in comparison to ribbed-deformed. 
Figure 2.5 - Experimental bending moment-deflection relationship
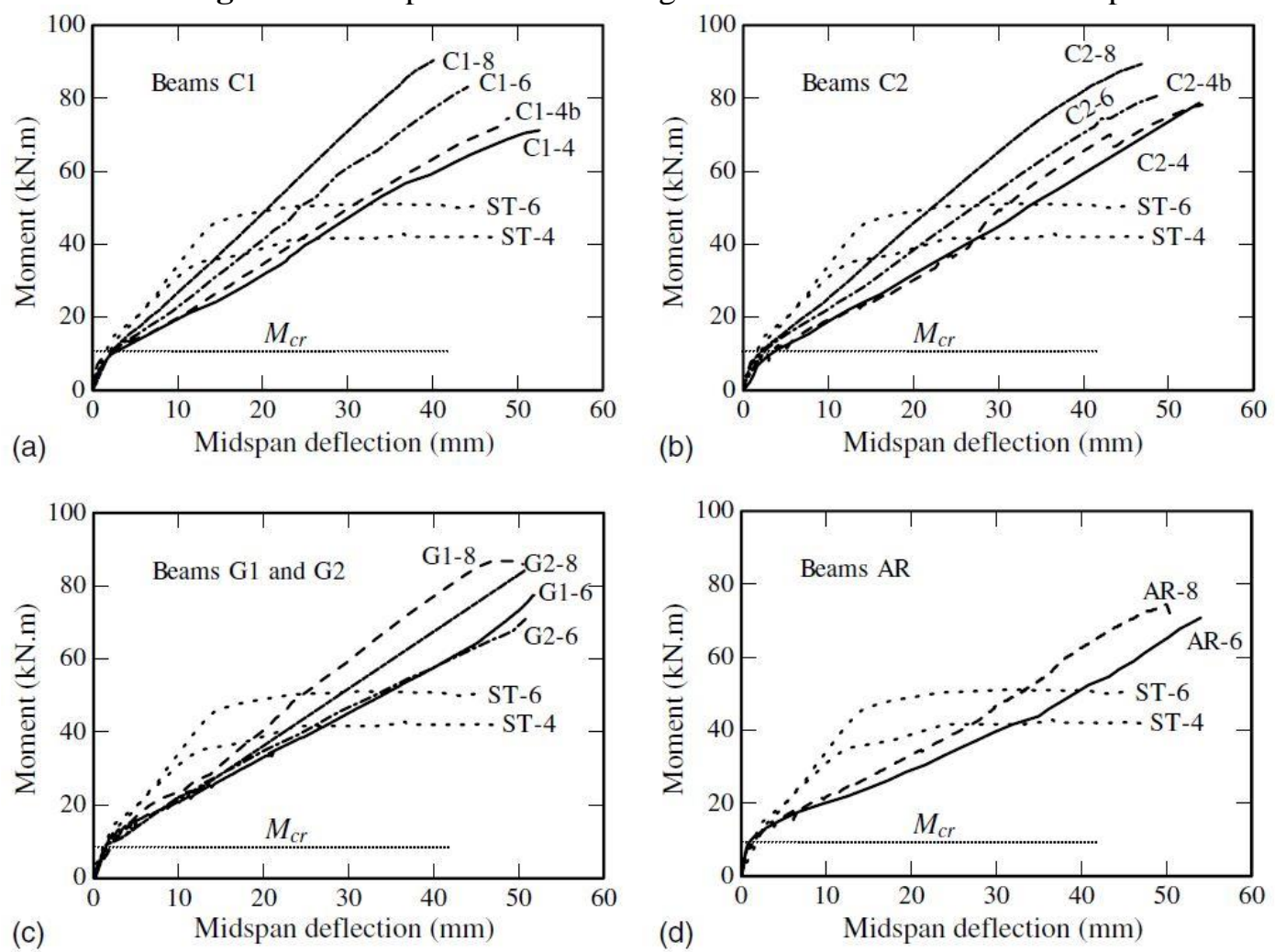

Source: KASSEM, FARGHALY and BENMOKRANE, 2011

ABNT NBR 6118 (2014) adopts the Branson's Equation to compute deflections steel reinforced concrete, the same as ACI 440 1R-15 (2015). In contrast, ACI 440 (2006) incorporated the parameter $\beta_{d}$, accounting for differences in tension stiffening between steel and FRP. This parameter is calculated as $\beta_{\mathrm{d}}=0.2 \rho_{\mathrm{f}} / \rho_{\mathrm{fb}}$, where $\rho_{f b}$ is the balanced reinforcement ratio. Therefore, the modified Branson's Equation is:

$$
I_{e f f}=\left(\frac{M_{c r}}{M_{a}}\right)^{3} \beta_{d} I_{g}+\left[1-\left(\frac{M_{c r}}{M_{a}}\right)^{3}\right] I_{c r}
$$

ACI 440 1R-15 (2015) uses the Bischoff modified Equation to compute the effective moment of inertia $I_{\text {eff }}$.

$$
I_{e f f}=\frac{I_{c r}}{1-\kappa\left(\frac{M_{c r}}{M_{a}}\right)\left[1-\left(\frac{I_{c r}}{I_{c g}}\right)\right]} \leq I_{g}
$$

The cracking moment defined by ACI $4401 \mathrm{R}-15(2015)$ is $\mathrm{M}_{\mathrm{cr}}=0.62 \lambda \sqrt{f_{c k}} \mathrm{I}_{\mathrm{g}} / \mathrm{y}_{\mathrm{t}}$, where $\lambda$ is factor that depends on the cross-section shape. ABNT NBR 6118 (2014) defines this 
moment as $\mathrm{M}_{\mathrm{cr}}=\lambda \mathrm{f}_{\mathrm{ct}} \mathrm{I}_{\mathrm{g}} / \mathrm{y}_{\mathrm{t}}$, establishing that the tensile strength $f_{c t}$ equals the average tensile strength $f_{c t m}$ for the serviceability limit state regarding excessive deflections.

Equations 2.35 and 2.36 are valid if $\mathrm{M}_{\mathrm{cr}} \leq \mathrm{M}_{\mathrm{a}}$, otherwise the gross moment of inertia $I_{g}$ is used. The coefficient $\kappa$ accounts for the load type, boundary conditions and length of uncracked regions. It can be calculated as $\kappa=1.72-0.72\left(\mathrm{M}_{\mathrm{cr}} / \mathrm{M}_{\mathrm{a}}\right)$, resulted from the integration of the curvature on the span length of a simply supported beam. Regarding continuous beams, the effective moment of inertia corresponds to the weighted average of those corresponding to positive and negative moment locations. For both-end continuous spans, $\mathrm{I}_{\mathrm{eff}}=0.70 \mathrm{I}_{\mathrm{eff}+}+$ $0.15\left(\mathrm{I}_{\mathrm{eff}, 1-}+\mathrm{I}_{\mathrm{eff}, 2-}\right)$, while for one-end continuous spans, $I_{\text {eff }}$ is calculated based on the maximum service bending moment (DESIMONE, 2009, apud ACI 440 1R-15, 2015).

The calculation of deflections must account for the concrete long-term performance, as regards creep and shrinkage. Thus, ACI 440 1R-15 (2015) uses Equation 2.37 to compute longterm deflections, where $\xi$ refers to the creep coefficient and $\rho_{\mathrm{f}}^{\prime}$ to the compression reinforcement ratio.

$$
v_{l t}=\frac{\xi}{1+50 \rho_{f}^{\prime}}
$$

Table 13.3 of ABNT NBR 6118 (2014) establishes the maximum allowable displacements, depending on the effect they cause in terms of sensorial acceptability, damages in non-structural elements and structural functionality. The maximum visible displacement in structural elements, for instance, must not be larger than 1/250 of its span.

In relation to crack widths, Kassem, Farghaly and Benmokrane (2011) investigated the behavior of the same beams subjected to bending moments ranging from 0.3 to 0.67 of the nominal flexural strength. As the load was increased, the first cracks appeared in the pure bending zone, perpendicular to the reinforcement direction, while inclined cracks were observed in the shear area, as shown in Figure 2.6. Moreover, it was observed that the number of cracks as well as their depth were inversely proportional to the reinforcement ratio.

The experimental work developed by Kassem, Farghaly and Benmokrane (2011) also indicated that beams reinforced with bundled rebars showed fewer cracks in comparison to those with single rebars. In contrast, the distance between cracks were larger, inferring better bond quality with respect to the single rebars. Nonetheless, these differences were negligible and do not exclude the possibility of using bundled rebars (ALY et al. 2006). 
Figure 2.6 - Cracking behavior of FRP RC beams
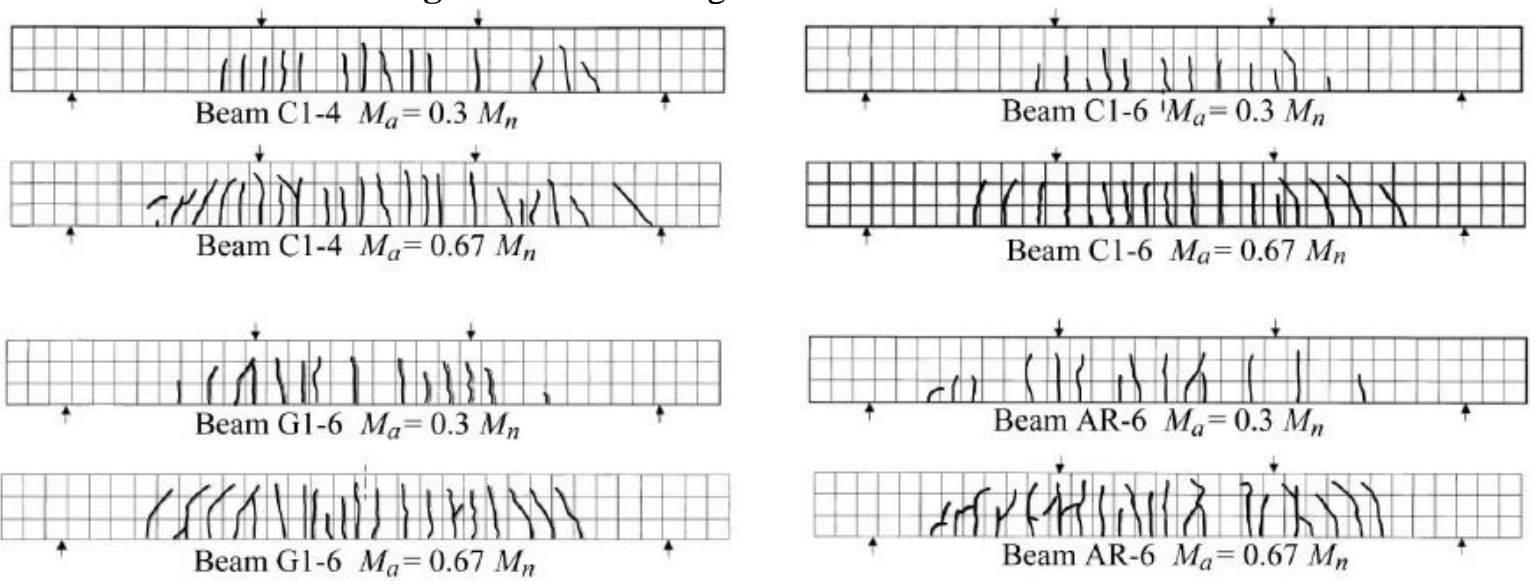

Source: KASSEM, FARGHALY and BENMOKRANE, 2011

In order to numerically predict crack widths, ACI 440 1R-06 (2006) recommends using the modified Frosch model described in Equation 2.38. Such formula was not determined empirically, but based on physical models, applying to both steel and FRP reinforcement. However, ACI 440 1R-06 (2006) establishes that this model needs to account for differences in FRP bond quality compared to steel through a correction coefficient $K_{b}$. This coefficient is determined experimentally and its value ranges from 0.60 to 1.72. If the FRP rebars have bond quality similar to steel, $K_{b}$ is equal to 1.0 . In case no experimental data is available, ACI 440 1R-06 (2006) suggests a conservative value of 1.4, which does not apply for smooth rebars and grids.

$$
w=2 \frac{f_{f}}{E_{f}} \beta_{c} K_{b} \sqrt{d_{c}^{2}+\left(\frac{s}{2}\right)^{2}}
$$

The tensile stress $f_{f}$ depends on the service moment the design code establishes for the prediction of crack widths. The item 11.8.3.1 of ABNT NBR 6118 (2014) states that frequent load combinations can be considering when checking for crack widths. Therefore, $f_{f}$ is determined from $M_{f c}$. The term $\beta_{c}$ corresponds to the strain gradient, defined as $\beta_{c}=\frac{h-x_{c r}}{d-x_{c r}}$, whereas $d_{c}$ refers to the distance between the most tensioned fiber and the closest bar center; $s$ is the bar spacing.

The cracking model of ABNT NBR 6118 (2014) applies for steel reinforced and pretensioned members. Crack widths are estimated as:

$$
w=\frac{\phi_{i}}{12,5 \eta_{1}} \frac{f_{f}}{E_{f}} \min \left[3 \frac{f_{f}}{f_{c t m}} ;\left(\frac{4}{\rho_{r i}}+45\right)\right]
$$


The coefficient $\eta_{1}$ accounts for differences in bond, corresponding to 1.0, 1.4 and 2.25 for smooth, plain and ribbed-deformed rebars (ABNT NBR 6118, 2014). In turn, $\phi_{i}$ designates the bar diameter while $f_{c t m}$, the average concrete tensile strength, computed as $f_{c t m}=0.3 f_{c k}^{2 / 3}$, in accordance to the Brazilian code. Finally, $\rho_{r i}$ corresponds to the reinforcement ratio with respect to the concrete area $A_{c r i}$. This is defined by a distance up to $7.5 \phi_{i}$ from the center of the bar, as shown in Figure 2.7:

Figure 2.7 - Influence areas for the calculation of crack widths

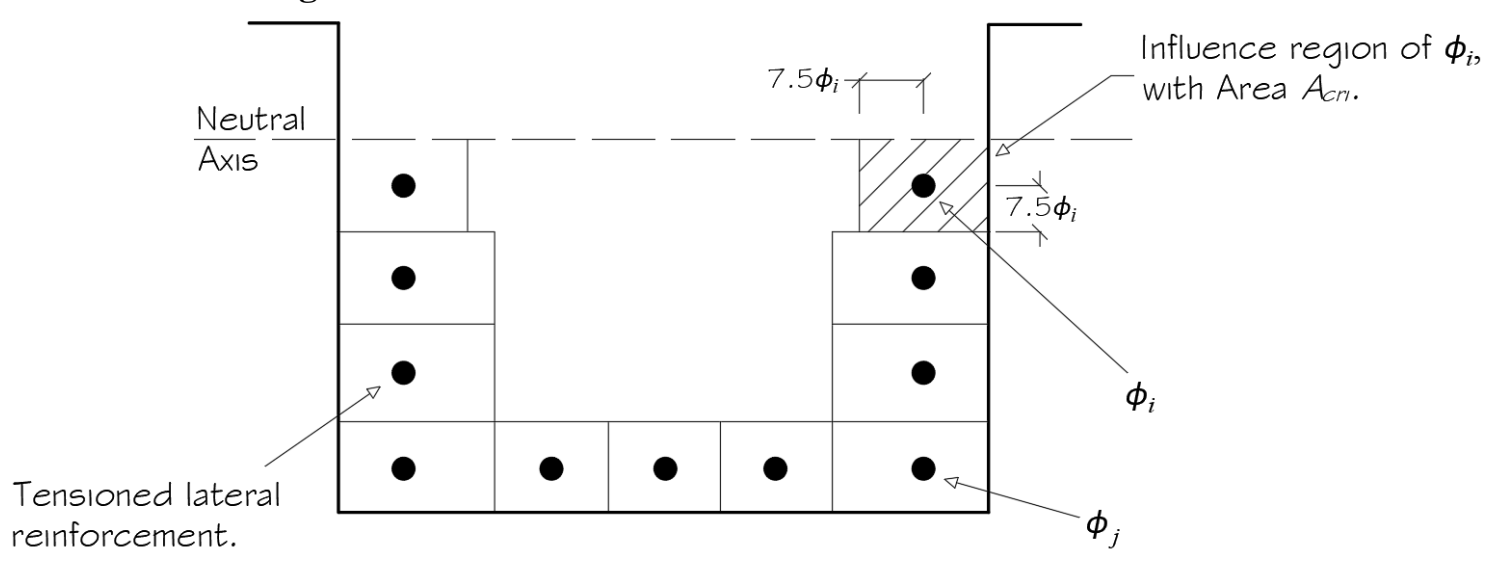

Source: ABNT NBR 6118, 2014 - Adapted

Regarding prestressing members, $f_{f}$ refers to the additional stress in the reinforcement center with respect to the decompression of the member. Its value relies on the service moment related to the type of prestressing: partial, limited or total. ABNT NBR 6118 (2014) highlights that its cracking model does not provide precise results since crack widths vary due to restrained volume changes and depend on construction conditions.

\section{7 $\quad$ FRP use in prestressing}

Regarding the use of FRP in pre-stressing, the guideline ACI 440 4R-04 (2004) addresses only the use of AFRP and CFRP tendons. The utilization of GFRP is not recommended by virtue of its vulnerability to creep rupture and degradation in alkaline environments. Moreover, the manufacturing of FRP tendons depends on the specified type of anchorage. Therefore, if an alternative anchorage is utilized for a certain type of tendon, the functionality of the system as a whole may be compromised. (ACI $4404 \mathrm{R}-04,2004$ ).

Provided that CFRP, for instance, is an anisotropic material, the shear stresses cannot be calculated in the same manner as that for steel prestressed concrete members: based on the normal stress acting in the reinforcement orthogonal direction. Moreover, CFRP has a low 
compressive strength in the transverse direction of the fibers, which makes difficult to define an anchorage system. Therefore, the development of anchor systems must rely on experimental data, considering the short and long-term behavior of prestressed members, so that they can become reliable and commercially competitive (SCHMIDT and TÄLJSTEN, 2009)

Figure 2.8 illustrates different types of anchorages for FRP tendons, followed by a brief description of each type.

Figure 2.8 - Different types of anchorage systems: a) Clamp; b) Plug and cone; c) straight sleeve; d) contoured sleeve; e) metal overlaying; f) split-wedge

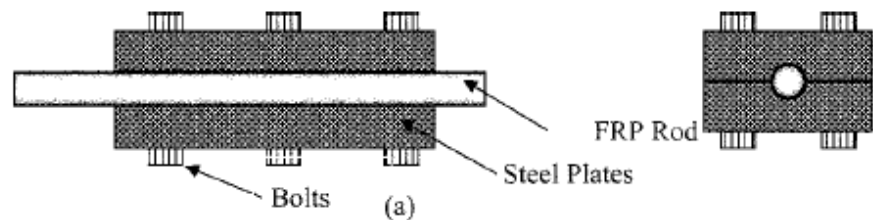

(a)
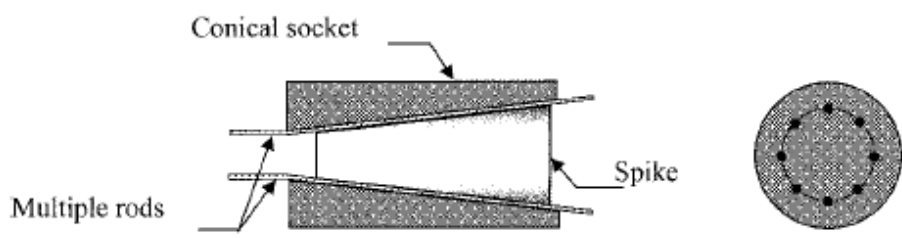

(b)
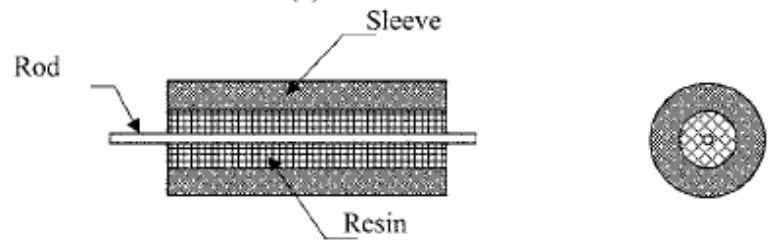

(c)
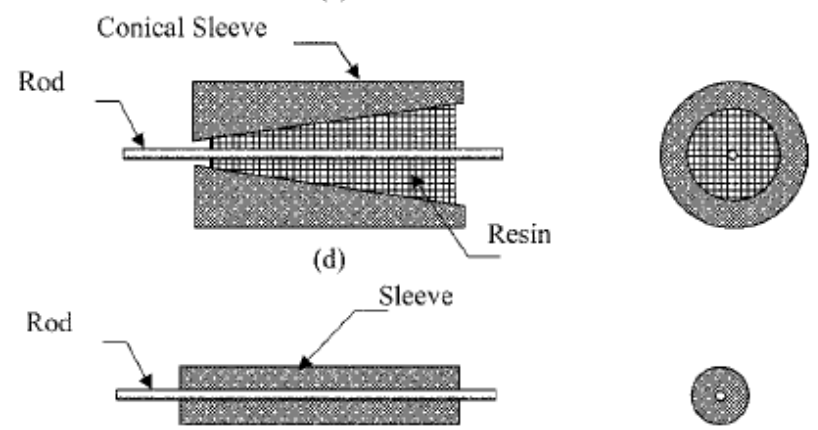

(e)
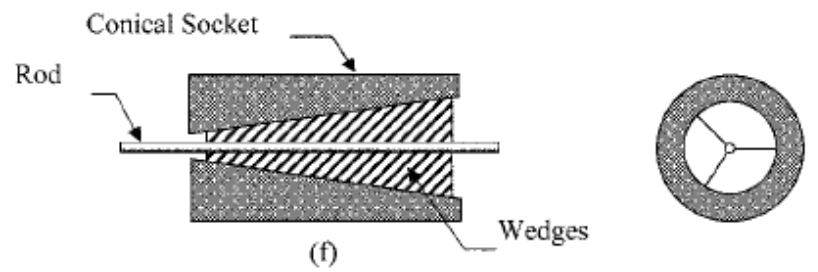

Source: ACI 440 4R-04, 2004

The clamp anchorage system illustrated in Figure 2.8.a is characterized by two steel plates connected by bolts and involving the FRP tendons. The prestressing force transfer to the anchorage occurs due to the shear-friction mechanism, depending on the surface roughness 
between the FRP and the plates, as well as the load applied by the bolts. The plug and cone system, in turn, consists of a socket encasement and a conical spike, as shown in Figure 2.8.b Such system is suitable for AFRP tendons, for which the fibers are fixed by an exterior protective sheath. Moreover, the force applied by the conical socket to the spike in conjunction with the friction between the tendons and the spike ensures proper anchorage (ACI 440 4R-04, 2004).

The straight sleeve-anchorage consists of a metallic tube filled with a resin that involves the FRP tendon, as shown in Figure 2.8.c. The load transfer mechanism occurs by virtue of the bonding between the FRP rod and the resin, as well as the resin and the metallic tube. The contoured sleeve anchorage illustrated in Figure 2.8.d is similar to the straight one. The difference lies on the shape of the sleeve, which can be conical or parabolical. The load transfer occurs due to shear stresses on the tendon-resin interface and radial stresses caused by the change in the resin profile. The failure mode corresponding to this type of anchorage is often characterized by the pullout of FRP from the potting material instead of the reinforcement rupture (ACI 440 4R-04, 2004).

Regarding the metal overlaying anchorage type illustrated in Figure 2.8.e, it is necessary to define the length of the FRP tendon priorly to the cast of the tube, which is placed onto the tendons at a predefined location. The compressive stresses in the radial direction as well as the friction at the interface surface prevent the FRP tendon from slipping. Finally, the split-wedge anchorage shown in Figure 2.8.f is characterized by a system where the steel wedges or plastic are directly fixed to the FRP tendons. There is also a variation incorporating a sleeve between those materials. Unlike steel, the lengths of the FRP tendons have to be longer in order to reduce transversal stresses. Conversely, the rugosity of the wedges must be limited in order to avoid tendon notching. The load transfer occurs due to friction and compressive forces between the tendons, wedges and the conical socket (ACI 440 4R-04, 2004).

In addition to the difficulty to define a proper anchorage system for FRP tendons, it is important to evaluate their behavior under different temperature conditions. Sayed-Ahmed and Shrive (1999) affirm that some types of FRP have positive thermal coefficient, while other variations, negative. Furthermore, the authors highlight that the FRP exposition to low temperature levels increases the minimum temperature it can be exposed. The authors found that exposing the tendons to temperatures ranging from -60 to $100^{\circ} \mathrm{C}$ did not apparently affect their physical properties. However, CFRP tendons under temperatures of 200,300 and $400^{\circ} \mathrm{C}$ had their strength reduced by 10,37 and $74 \%$, respectively, exhibiting darker appearance, which denotes evaporation of the resin and loosening of the fibers. 
The exposition to high temperatures also compromised the anchorage of the tendons. Due to the evaporation of the resin, loads could not be transferred to the fibers, resulting in the anchorage failure rather than FRP rupture at $400^{\circ} \mathrm{C}$. Regarding the specimen subjected to $500^{\circ} \mathrm{C}$, the total evaporation of the resin made the reinforcement gripping impossible (SAYEDAHMED and SHRIVE, 1999).

Grace et al. (2008) experimentally assessed the flexural behavior of three bridge boxes with same cross-section dimensions and prestressed with CFCC - Carbon Fiber Composite Cables. It was found that deflections at the ultimate limit state decreased as the prestressing forces increased, meaning that the compressive force applied by the FRP released tendons improved the structural serviceability. Moreover, high prestressing levels slowed down the development of cracks, reducing not only their number but also their width.

Upon subjecting the flexural members to the ultimate load test, the initial prestressing strain of $4.2 \%$ did not seem to increase prior to cracking. In contrast, as the cracks appeared and the cross-sections lost stiffness, the reinforcement strains exhibited a significant linear increase, resulting in the collapse of the members. Strains of 11.8 and $15.8 \%$ at rupture were observed for an over and under-reinforced member, respectively. Those were smaller than the value provided by the manufacturer, which was 17\%. (GRACE et al., 2008).

Grace et al. (2008) also observed that high prestressing levels resulted in sudden failure modes, with no warning regarding the structural conditions. Over-reinforcing the cross-sections by reducing the prestressing levels led to progressive failure modes with considerable dissipation of inelastic energy. In spite of this ductility related to compression-controlled sections, the authors observed that low prestressing levels may result in large residual deflections due to loading-unloading cycles.

Husain, Fawzy and Nada (2015) numerically investigated how changes in prestressed reinforcement ratio, concrete strength and prestressing levels affect the structural behavior of FRP prestressed flexural members. Three specimens of CFRP were modelled and detailed as shown in Figure 2.9. By keeping the concrete strength and prestressing levels equal to $35 \mathrm{MPa}$ and $70 \%$ of the strand tensile capacity, the authors considered three reinforcement ratios: 0.63 , 0.494 and $0.293 \%$. It was found that, in spite of the great flexural strength related to the ratio of $0.63 \%$, the member presented low deformability and sudden failure. However, the balanced ratio of $0.494 \%$ increased the deformation capacity by $50 \%$ compared to the previous evaluation. The authors also observed that reducing the amount of reinforcement provided a slight increase in the strength factor, defined as the ratio between the ultimate load capacity and the one corresponding to the linearity limit. Additionally, the lowest reinforcement ratio 
resulted in an under-reinforced cross-section, which failure is defined by the CFRP rupture. This member exhibited the highest deformability capacity and energy absorption index, which corresponds to the ratio between the total area under the load-deformation curve and that corresponding to the linear portion of the curve.

Figure 2.9 - Cross-section details of the flexural members

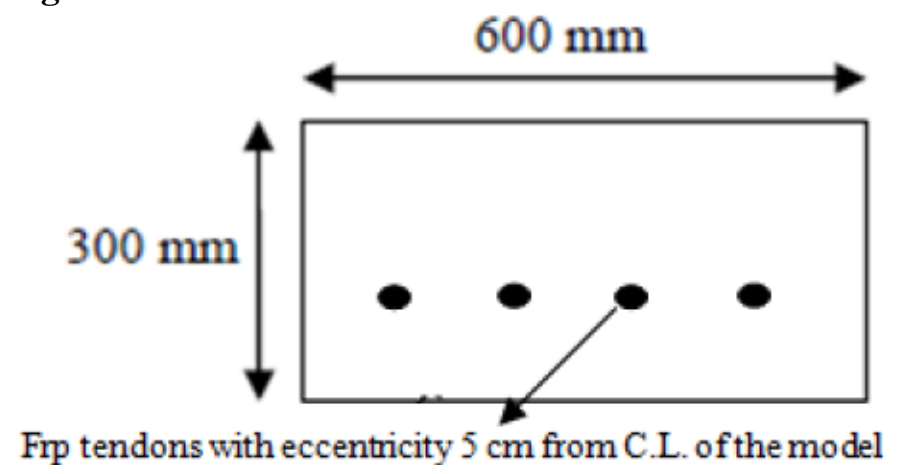

Source: HUSAIN, FAWZY and NADA, 2015

Husain, Fawzy and Nada (2015) also evaluated how changes in the concrete compressive strength affected the structural behavior of four CFRP pre-tensioned members. The reinforcement ratio and prestressing levels remained constant and equal to $0.56 \%$ and $60 \%$ of the strand capacity, respectively. The lowest concrete strength of $35 \mathrm{MPa}$ resulted in great deformability and low flexural strength; however, it was observed that increasing the concrete strength led to low deformability and slight increases in flexural capacity, considering the strengths of 50 and $60 \mathrm{MPa}$. The authors also found that the use of high strength concretes reduces the deformability and energy absorption indexes by $25 \%$ and $15 \%$, respectively. They concluded that, for this particular situation, the proper concrete compressive strength corresponds to $45 \mathrm{MPa}$, which best conciliates high flexural strength and serviceability requirements.

Finally, the concrete compressive strength and the reinforcement ratio were kept constant and equal to $35 \mathrm{MPa}$ and $0.63 \%$, respectively. Only the prestressing levels for three CFRP flexural members varied: 70, 60 and 50\% of the strand capacity. Despite the great flexural strength related to the highest prestressing level, the member presented low deformability and sudden failure, whereas for levels of 60 and $50 \%$, the deformability increased and the flexural strength slightly decreased. Furthermore, the load-deflection curve was very sensitive to changes in prestressing levels. It was observed that the energy absorption index regarding the level of $50 \%$ is $25 \%$ and $45 \%$ higher compared to the levels of 60 and $70 \%$, 
respectively. The deformability, in turn, is approximately 20 and 50\% higher in comparison to the same levels, respectively (HUSAIN, FAWZY and NADA, 2015).

The design of prestressed members is governed by the serviceability limit states, which are defined in accordance with the proper prestressing level for a particular structural system. ABNT NBR 6118 (2014) defines three prestressing levels: partial, limited and complete, which are related to the environmental aggressivity as regards the steel corrosion. Therefore, depending on the structural system, cracks have their widths limited or must even be avoided for a particular loading combination. In some cases, tensile stresses are not allowed in any crosssection fiber.

The partial prestressing or the prestressing level 1 applies for rural and submerged environments, where the risk of deterioration is insignificant. The only serviceability limit state refers to the crack widths, which must not exceed $0.2 \mathrm{~mm}$ for frequent load combinations (ABNT NBR 6118, 2014). Hanai (2005) highlights that the tensile stresses for the computing of crack widths are based only on the bending moment, not considering the contribution of shear forces, especially in the anchorage zone. Therefore, not only this limit state but also others involving tensile stresses might not be fully met.

The limited prestressing, also named as prestressing level 2 applies for urban environments, where the risk of deterioration is low. This becomes lower as the air humidity decreases, especially in regions that it rarely rains and the structure is protected from the water. For this level, two limit states must be met: the decompression limit state and the cracking formation limit state. The first one establishes that there must not be tensile stresses in the crosssection, considering the almost permanent load combination. Thus, the stress at the extreme fiber most susceptible to tension has to be lower than zero, since compressive stresses are usually considered as negative. The second one imposes that cracks must be avoided for a frequent load combination. Consequently, the stress at the most tensioned fiber must not exceed that related to the formation of cracks, which corresponds to 1.2 and 1.5 of the nominal tensile strength for T-sections and rectangular sections, respectively (ABNT NBR 6118, 2014).

The complete prestressing or the prestressing level 3 applies for structural systems located in marine and industrial environments where the risk of deterioration is high. For chemically aggressive structural environments or those subjected to splashes of the sea water, the risk of steel corrosion is even higher, considered as elevated. Therefore, to protect the reinforcement, the same limit states as the level 2 must be met, but for different loading combinations. For the level 3, there must not be tensile stresses in the cross-section due to 
frequent load combinations. Moreover, the cracking formation must be avoided considering rare load combinations (ABNT NBR 6118, 2014).

There is also the total prestressing, which is not exactly the same as the complete prestressing defined by ABNT NBR 6118 (2014). The total prestressing does not allow tensile stresses for even rare load combinations, which theoretically discards the possibility of cracking formation. This type of prestressing is necessary only for situations at which cracking must be avoided at any cost, such as reservoir walls. In contrast, the Brazilian code establishes that tensile stresses must be avoided for frequent combinations. As a result, small cracks may occur due to rare load combinations. Once such loads cease, the cracks close and the concrete at crack locations no longer resists to tensile stresses. Thus, the occurrence of frequent load combinations reopens these cracks, which are very small, making the calculation of their widths unnecessary (HANAI, 2005).

Since FRP does not undergo corrosion, it could be expected that the limits regarding tensile stresses and crack widths would be less strict. However, ACI 440 4R-04 (2004) imposes the same allowable stresses as regards the conventional steel prestressed concrete structures in accordance with the AASHTO - American Association of State Highway and Transportation Officials - Standard Specification for Highway bridges. According to ACI 440 4R-04 (2004), such values are more restrictive than those imposed by the American Code ACI 318-02, which also addresses the design of steel reinforced and prestressed concrete. Therefore, the allowable compressive and tensile stresses imposed by ABNT NBR 6118 (2014) could apply for the design of FRP prestressed concrete structures provided that the tensile stress at jacking does not exceed the limits imposed by Table 3.3 of ACI 440 4R-04 (2004).

Furthermore, for any type of prestressing, the designer needs to evaluate the structural behavior of the flexural member considering only the compressive force due to prestressing and the permanent loads, not accounting for other types of load combinations. Therefore, the designer verifies if the prestressing force causes excessive compressive stresses in concrete or cracking formation in the most tensioned fiber. Hanai (2005) recommends that the stress at the most compressed concrete fiber does not exceed $60 \%$ of the nominal concrete compressive strength $f_{c k}$, while the tensile stress in the extreme opposite fiber should not exceed 1.2 and 1.5 of the nominal tensile stress $f_{c t k}$ for T-shape and rectangular cross-sections, respectively.

Further details on the design of FRP prestressed concrete members based on the serviceability limit states and the verification for the ultimate limit states are described in Chapter 5. 


\section{Chapter 3 - Comparative Design of FRP and Steel Reinforced Concrete}

This chapter presents a structural project of a residential building, where 16 beams were designed considering four types of reinforcement: AFRP, CFRP, GFRP and conventional steel CA-50 $\left(f_{\mathrm{yk}}=500 \mathrm{MPa}\right)$, combined to a normal strength concrete $(\mathrm{C} 25)$ and a high-performance concrete (C80). The initial stage of this research aimed to compare the amount of each type of reinforcement to, simultaneously, resists the factored ultimate bending moment, avoids creep rupture and meets the serviceability requirements regarding maximum allowable deflections and cracking. Therefore, this part of the research investigated:

a) changes in reinforcement areas $A_{f}$, seeing that they need to be adjusted for the commercially available rebars with diameters $\phi$ in addition to meeting the limit states for creep rupture, deflections and crack widths;

b) changes in flexural strengths $M_{r}$, curvatures $\varphi$, sustained stress levels $f_{f s} / f_{f u}$, deflections $v_{l t}$ and crack widths $w$. Initially, the beams are designed to meet only the ultimate limit state for flexure. In order to meet all limit states, the reinforcement areas need to be readjusted, which inevitably modifies all these variables;

c) changes in the adopted areas $A_{d}$, flexural strengths $M_{r}$, curvatures $\varphi$, sustained stress levels $f_{f} \triangleleft f_{f u}$, deflections $v_{l t}$, crack widths $w$ and failure mode when the concrete C25 is replaced by the concrete $\mathrm{C} 80$.

Figure 3.1 illustrates a symmetrical structural project with 22 columns (C), 13 slabs (S) and 16 beams (B). The dimensions of columns and slabs, as well as the beam widths $b$ had already been previously provided. The depth of the beams $h$, in turn, were determined based on their span lengths. Della Bella (2018) recommends that the depth of a simply supported beam situates in the interval of $1 / 25$ to $1 / 10$ of its span length, whereas continuous beams with comparable spans - adjacent spans whose lengths ranges from 0.67 to 1.5 of each other - should have their depth based on the average span length.

\subsection{Loading Determination}

Prior to computing the amount of reinforcement, it is necessary to determine the dead and live loads acting on each beam. The dead loads are composed by the weight of beams, slabs, masonry walls and coatings, while the accidental loads were determined according to Table 2 
of the Brazilian code ABNT NBR 6120:1980 - Determination of Loads for Building Structural Projects.

Figure 3.1 - Structural plan view - Lengths in $m$, cross-section dimensions in $\mathrm{cm}$

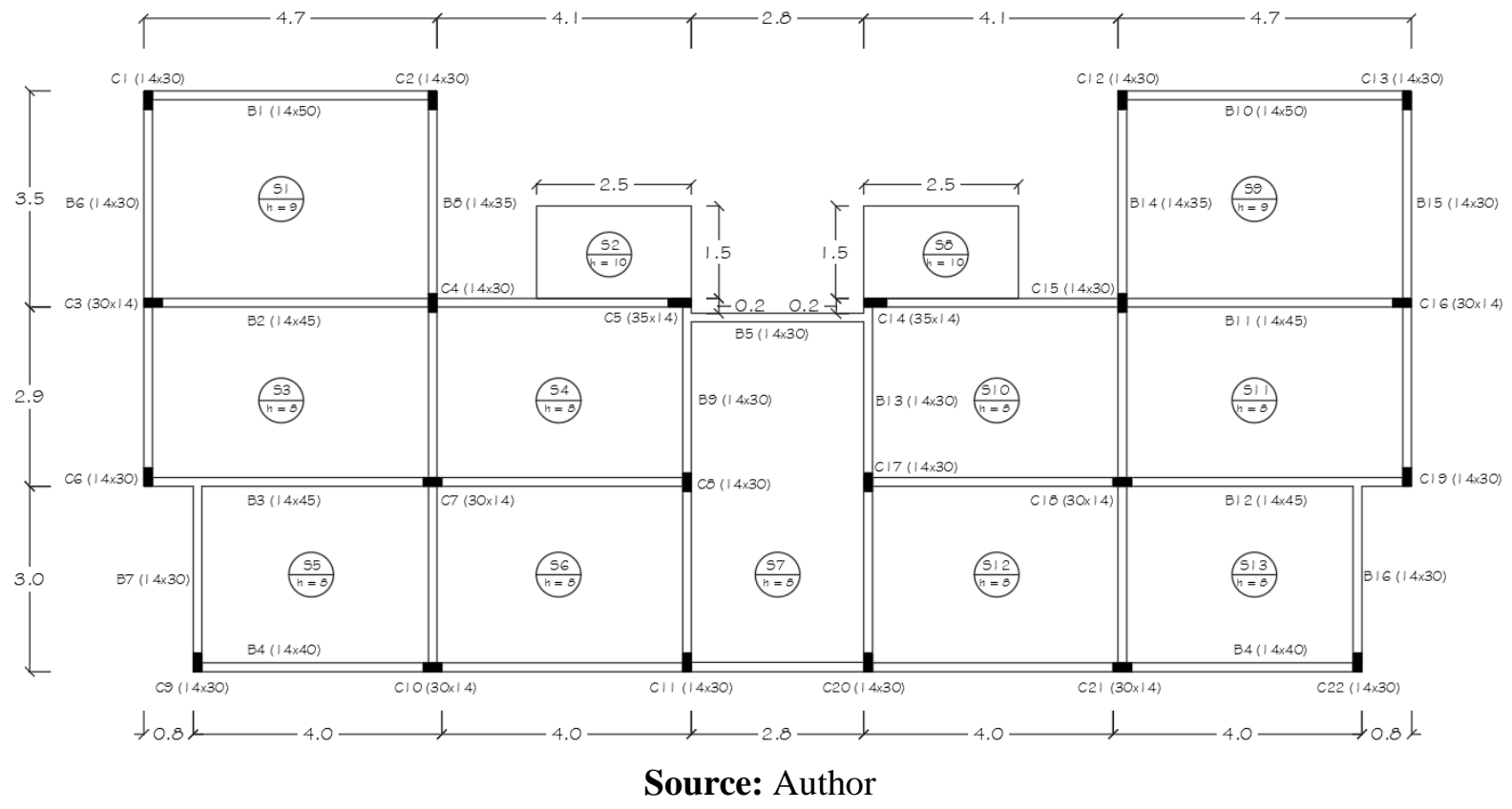

The specific weight adopted for reinforced concrete was $\Upsilon_{c}=25 \mathrm{kN} / \mathrm{m}^{3}$, in accordance with ABNT NBR 6120:1980, while for masonry walls, it was $\Upsilon_{\mathrm{mw}}=13 \mathrm{kN} / \mathrm{m}^{3}$ (DELLA BELLA, 2018). Regarding the accidental loads for residential building beams, Table 2 of ABNT NBR 6120 (1980) establishes a range of 1.5 to $2.0 \mathrm{kN} / \mathrm{m}^{2}$. The most conservative value of $\mathrm{q}_{\mathrm{s}}=2 \mathrm{kN} / \mathrm{m}^{2}$ was chosen. The distributed live load $g_{s}$ in $\mathrm{kN} / \mathrm{m}^{2}$ acting on each slab is:

$$
g_{s}=h_{s} \gamma_{c}+h_{c t} \gamma_{c t}+\frac{\gamma_{m w}\left(h_{f f}-h_{s}\right)}{l_{x} l_{y}}
$$

In Equation 3.1, $\gamma_{c t}$ corresponds to the coating specific weight, whereas $h_{f f}$ is the floorto-floor distance. The weight of masonry walls is uniformly distributed on the slab area for the purposes of the loading determination. The product $l_{x} l_{y}$ corresponds to the theoretical slab area, for which $l_{y}$ is the longest theoretical span and $l_{x}$, the shortest. Figure 3.2 illustrates how to determine the wall heights over slabs and beams.

Once the slab dead $g_{s}$ and live $q_{s}$ loads in $\mathrm{kN} / \mathrm{m}^{2}$ are determined, it is assumed that the slabs fail due to the formation of plastic hinges at the ultimate limit state, as shown in Figure 3.3. Thenceforth, $g_{s}$ and $q_{s}$ are multiplied by the areas delimited by the plastic hinges. The resulting load is divided by the slab theoretical span length, which can be $l_{x}$ or $l_{y}$, providing the dead and live uniformly distributed loads carried by the beams. Finally, the dead loads are added 
to weight of the beam and its supported masonry wall, which leads to the total dead uniformly distributed load. Both load types are primordial to compute the FRP and steel reinforcement area, as well as, check for the compliance of serviceability limit states.

Figure 3.2 - Illustration of masonry walls supported by beams and slabs

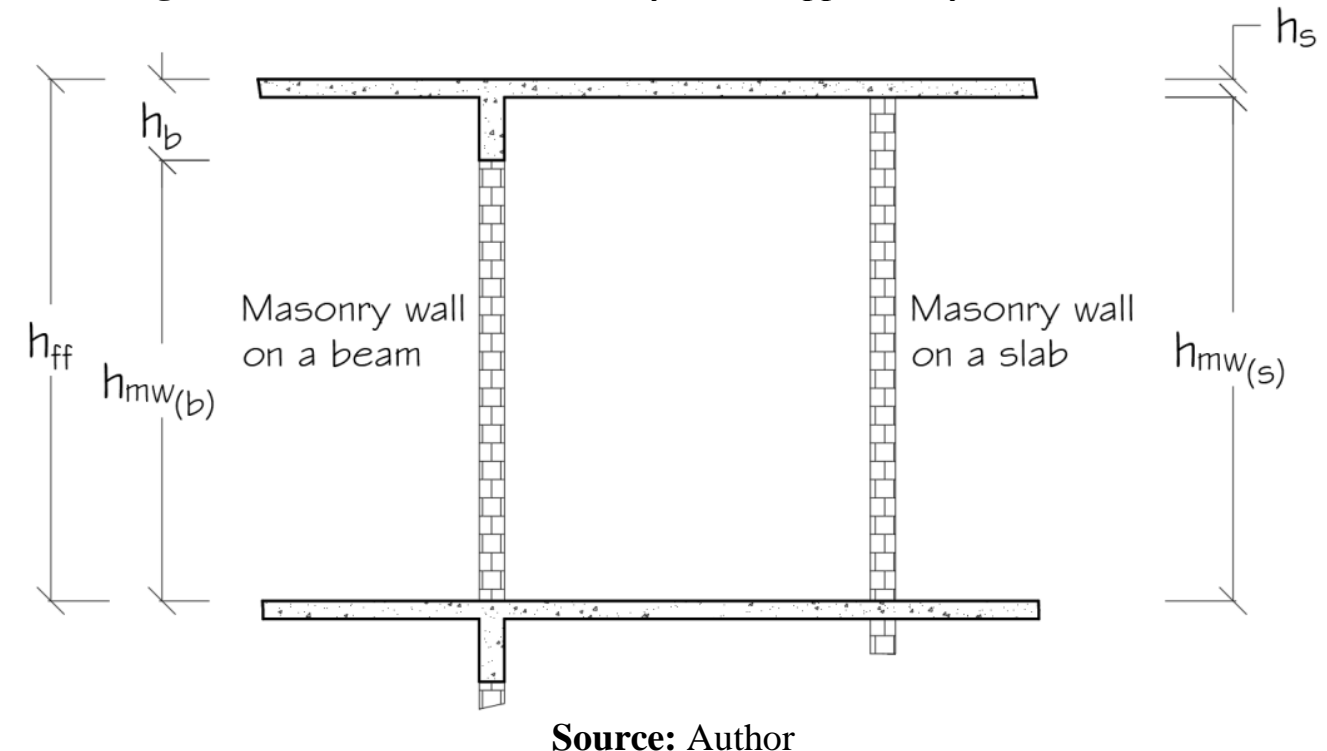

Figure 3.3 - Plastic hinges for the computing of linear distributed loads
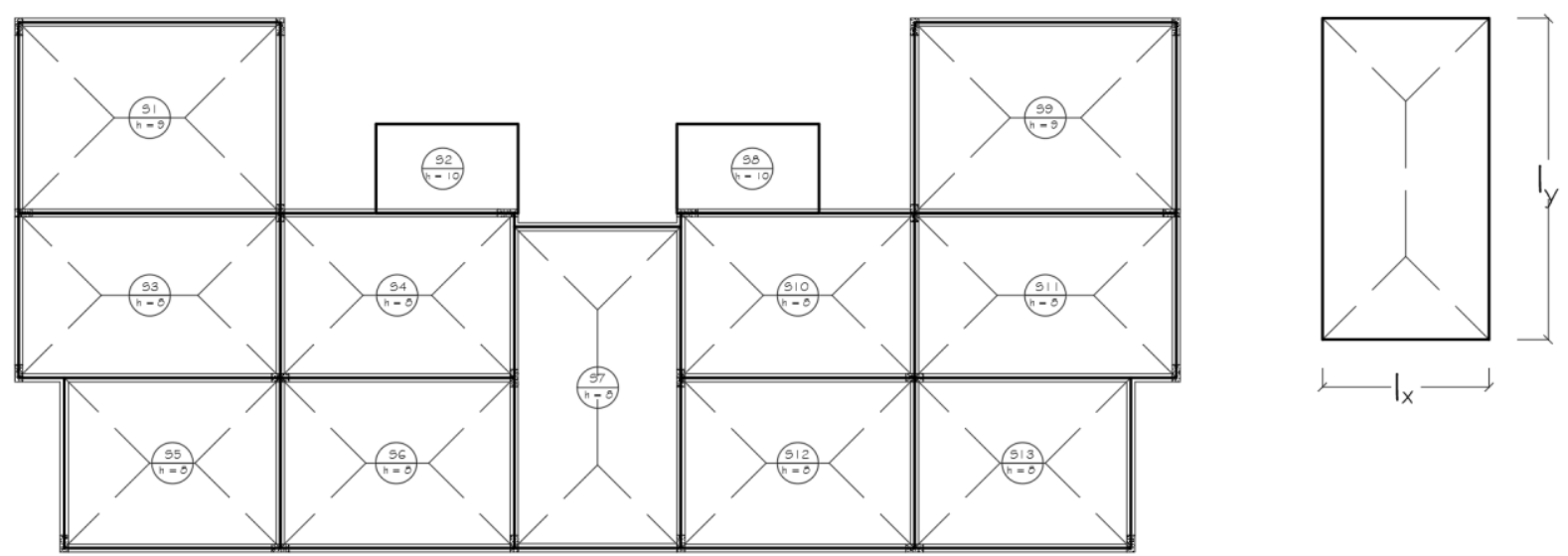

Source: Author

In Appendix A, Table A.1 shows the theoretical spans and depths of all slabs, as well as the thicknesses $e_{m w}$, lengths $l_{m w}$ and heights $h_{m w}$ of their masonry walls. Accordingly, dead loads corresponding to the weight of slabs $g_{s w}$ and masonry walls $g_{m w}$ were determined. Dead loads concerning floor and ceiling coatings were assumed as $\mathrm{g}_{\mathrm{ct}}=2 \mathrm{kN} / \mathrm{m}^{2}$.

Subsequently, the uniformly distributed dead loads in $\mathrm{kN} / \mathrm{m}$ are added to the beam and its supported masonry wall self-weights. Even though not all beams support masonry walls, the 
resulting distributed dead loads include their weight because the residence owner may require some architectural modifications, removing or including masonry walls.

Figures A.1 to A.9, also in Appendix A, illustrate the structural schemes of all beams, showing not only dead and live loads coming from slabs but also the beam and masonry wall self-weights. Figures A.10 to A.18, in turn, display their frame models, with the bending moment diagrams computed by the software Ftool@ .

Supports located at corners or edges were modeled as 2D frames due to the moment transfer and rotations associated to these supports. In order to compute the required amount of reinforcement, dead and live loads were increased by safety factors of 1.4 , in accordance to Table 11.1 of ABNT NBR 6118 (2014). Table A.2 describes linear dead and live loads distributed on each beam, as well as, their theoretical span $l$ corresponding to the distance between support centers.

\subsection{Reinforcement Area Calculation}

In order to compute the reinforcement area considering AFRP, CFRP, GFRP and Steel, Tables 3.1 and 3.2 display the reinforcement and concrete properties considered for the design. The FRP properties are in accordance with Table 7.2.1 of ACI 440 1R-15, whereas the item 8.3.5 of ABNT NBR 6118 (2014) recommends an elasticity modulus of $210 \mathrm{GPa}$ for nonprestressed steel. Regarding the material safety factors, the values of 1.25 and 1.15 were adopted for FRP and steel, in accordance with Fib Bulletin 40 (2007) and ABNT NBR 6118 (2014), respectively.

Since the cross-sections may fail due to either concrete crushing or FRP rupture, it is necessary to determine the balanced moment $M_{b}$ and compare it to the factored bending moment $M_{d}$ for a particular cross-section. If $\mathrm{M}_{\mathrm{d}}<\mathrm{M}_{\mathrm{b}}$, the cross-section failure is tension-controlled, requiring iterative processes described by Equations 2.17 to 2.22 to compute the rectangular block parameters and find the neutral axis position $x$. The required area $A_{f}$ is computed through Equation 2.23, seeing that the strain at the extreme compressed fiber is smaller than the ultimate concrete strain $\varepsilon_{c u}$, and the stress in the reinforcement reaches the FRP design tensile strength $f_{\text {fud }}$. Regarding compressed-controlled sections, $M_{d} \geq M_{b}$ and the most compressed fiber strain reaches $\varepsilon_{c u}$. The neutral axis position, FRP tensile stress and the required area are determined through Equations 2.10, 2.11 and 2.12, respectively. 
Tables A.3 to A.16, in Appendix A, summarize the design of all beams reinforced with FRP and steel, combined to concretes C25 and C80.

Table 3.1 - FRP and steel mechanical properties

\begin{tabular}{ccccccccc}
\hline Material & $\mathbf{f}_{\mathbf{f u}}(\mathbf{M P a})$ & $\mathbf{E}_{\mathbf{f}}(\mathbf{G P a})$ & $\boldsymbol{\varepsilon}_{\mathbf{f u}}(\mathbf{\% o})$ & $\mathbf{\Upsilon}_{\mathbf{f}}$ & $\mathbf{\varepsilon}_{\mathbf{y k}}(\mathbf{\%})$ & $\mathbf{f}_{\text {fud }}(\mathbf{M P a})$ & $\boldsymbol{\varepsilon}_{\mathbf{f u d}}(\mathbf{\% o})$ & $\boldsymbol{\varepsilon}_{\mathbf{y d}}(\mathbf{\% o})$ \\
\hline AFRP & 1172 & 82.7 & 14.17 & 1.25 & - & 937.6 & 10.67 & - \\
CFRP & 2070 & 152 & 13.62 & 1.25 & - & 1656 & 10.89 & - \\
GFRP & 552 & 41.4 & 13.33 & 1.25 & - & 441.6 & 10.67 & - \\
Steel CA-50 & $500^{*}$ & 210 & 10.00 & 1.15 & 2.38 & $434.78^{*}$ & 10.00 & 2.07 \\
\hline \multicolumn{8}{c}{ *Steel yielding stress $\left(f_{y k}\right.$ or $\left.f_{\text {yd }}\right)$ or strain $\left(\varepsilon_{y k}\right.$ or $\left.\varepsilon_{y d}\right)$}
\end{tabular}

Sources: ABNT NBR 6118 (2014), ACI 440 1R-15 (2015), FIB BULLETIN 40 (2007)

Table 3.2 - Concrete Properties

\begin{tabular}{cccccccccc}
\hline Grade & $\mathbf{f}_{\text {ck }}(\mathbf{M P a})$ & $\mathbf{f}_{\text {cd }}(\mathbf{M P a})$ & $\mathbf{n}$ & $\boldsymbol{\varepsilon}_{\mathrm{c} 2} \mathbf{( \% )}$ & $\boldsymbol{\varepsilon}_{\mathrm{cu}}(\mathbf{\% o})$ & $\boldsymbol{\alpha}_{\text {uls }}$ & $\boldsymbol{\beta}_{\text {uls }}$ & $\boldsymbol{\alpha}_{\mathbf{i}}$ & $\mathbf{E}_{\text {cs }}(\mathbf{G P a})$ \\
\hline $\mathrm{C} 25$ & 25 & 17.86 & 2.00 & 2.00 & 3.50 & 1.00 & 0.800 & 0.86 & 24.15 \\
$\mathrm{C} 80$ & 80 & 57.14 & 1.40 & 2.52 & 2.60 & 0.85 & 0.725 & 1.00 & 45.13 \\
\hline
\end{tabular}

Source: ABNT NBR 6118, 2014

In order to always respect the minimum amount of reinforcement established by ABNT NBR 6118 (2014) for each concrete grade, sections with factored moments smaller than the minimum $M_{d, \min }$ had their reinforcement area computed for $M_{d, \min }$. Thus, $M_{d}$ in Tables A.3 to A.16 corresponds to the highest between these two values.

Initially, the effective depth $d$ was taken as $90 \%$ of the beam depth $h$. Tables A.3, A.5, A.7, A.9, A.11 and A.13 describe the initial neutral axis position $x_{i}$, the failure mode and the required area $A_{f}$ to resist $M_{d}$, for $\mathrm{C} 25$ and C80 concrete grades. Some of the computed areas were too small in comparison to those of commercial rebars described in Table B1 of ABNT NBR 7480 (2007) - Steel for the Reinforcement in Concrete Structures - Specification; only diameters of $8,10,12.5,16,20$ and $25 \mathrm{~mm}$ were utilized. Moreover, the calculation of the new effective depth $d$ accounted for the concrete cover $c$, diameter of stirrups $\phi_{t}$ and the adopted longitudinal rebars $\phi$, considering $c$ and $\phi_{t}$ as $3.0 \mathrm{~cm}$ and $5.0 \mathrm{~mm}$, respectively. As a result, the neutral axis depth $x_{r}$ and the flexural strength $M_{r}$ changed, modifying the failure modes of some cross-sections.

In Tables A.3 to A.16, the letters $\mathbf{B}$ and $\mathbf{S}$ designate the beam and its cross-section, respectively, while the terms $\mathbf{S P}$ and $\mathbf{S U}$ refer to the location of cross-section: mid-span or support, respectively. The numbers following $\mathbf{S P}$ and $\mathbf{S U}$ define the spans and supports, from left to right, in accordance to Figures A.10 to A.18. The terms $\mathbf{F}$ and $\mathbf{F}_{\mathbf{r}}$, in turn, defines the type of failure (Tension $\mathbf{T}$ or Compression Controlled $\mathbf{C}$ ) for the required $A_{f}$ and effective area $\mathrm{A}_{\mathrm{ad}}=\mathrm{n}_{\mathrm{b}} \mathrm{A}_{\phi}$, respectively, where $n_{b}$ is the number of rebars and $A_{\phi}$, the section area of one bar. 
Once the reinforcement areas are defined, it is necessary to check for creep rupture, long-term excessive deflections and crack widths. Hence, the reinforcement areas may considerably change to comply with all these requirements. Consequently, the neutral axis position $x_{r}$ and the flexural capacity $M_{r}$ increase, as described in Tables A.4, A.6, A.8, A.10, A.12 and A.14 for the three types of FRP combined with concrete grades of C25 and C80.

Upon defining the diameter and the number of rebars, the first step was to check for creep rupture, calculating the sustained stress for the service moment $M_{a p c}$, regarding the almost permanent loading combination. In accordance with Table 11.2 of ABNT NBR 6118 (2014), $M_{a p c}$ was defined as $\mathrm{M}_{\mathrm{apc}}=\mathrm{M}_{\mathrm{g}}+\psi_{2} \mathrm{M}_{\mathrm{q}}$, where $\psi_{2}=0.3$ for residential buildings. Therefore, the sustained stress $f_{f s}$ is found through Equation 2.27, which allows to calculate the stress level in the reinforcement, determining whether or not creep rupture occurs. As previously mentioned, the sustained stresses must not exceed 30, 55 and 20\% of the AFRP, CFRP and GFRP tensile strengths, respectively (ACI $4401 \mathrm{R}-15,2015)$. In case $\mathrm{f}_{\mathrm{fs}}>\mathrm{f}_{\mathrm{fs}}$,lim, the areas are increased to reduce the stress levels. Consequently, the failure mode $F_{r}$, flexural strength $M_{r}$, long-term deflections $v_{l t}$ and crack widths $w$ are determined for the adjusted area.

In order to check for excessive deflections, the values provided by Ftool@ are corrected by the effective moment of inertia $I_{\text {eff, }}$ calculated through Branson's Equation, described by Equation 2.35. Since there is no compression reinforcement, the ratio $\rho_{f}^{\prime}$ is zero. Furthermore, for periods up to 70 months, the coefficient $\xi$ to compute long-term deflections equals two, in accordance to Table 17.1 of ABNT NBR 6118 (2014). The values are compared to the limit of l/250 established by the Brazilian code. If necessary, the reinforcement areas are increased to fulfill this requirement.

Crack widths, in turn, are determined through the Frosch model described in Equation 2.38. The tensile stress $f_{f}$ is calculated through Equation 2.27, except that the service moment to consider is $M_{f c}$, for a frequent loading combination, leading to $\mathrm{M}_{\mathrm{fc}}=\mathrm{M}_{\mathrm{g}}+\psi_{1} \mathrm{M}_{\mathrm{q}}$, where $\psi_{1}=$ 0.4, in accordance with Table 11.2 of ABNT NBR 6118 (2014). Figure 3.4 illustrates a generic detailing of a cross-section, with the geometrical parameters $h, d, x_{c r}, d_{c}$, and $s$.

For this particular situation, $d$ is the distance between the most tensioned bar to the most compressed fiber, not necessarily the effective depth. However, since all cross-sections have just one reinforcement layer, they have the same values. Equation 3.2 defines the horizontal bar spacing $s$, respecting the horizontal $s_{h, \text { min }}$ and vertical $s_{v, \text { min }}$ limits established by the item 18.3.2.2 of ABNT NBR 6118 (2014) and defined in Equations 3.3 and 3.4, respectively: 


$$
\begin{gathered}
s=\frac{b-2\left(c+\phi_{t}\right)}{n_{b}-1} \\
s_{h, \min }=\max \left(2, \phi, 1.2 \phi_{\text {max }, a g g}\right) \\
s_{v, \text { min }}=\max \left(2, \phi, 0.5 \phi_{\text {max }, a g g}\right)
\end{gathered}
$$

The coefficient $K_{b}$ regarding differences in bonding between steel and FRP assumed the values of 1.27, 0.86 and 1.04 for AFRP, CFRP and GFRP, respectively. Such values were obtained experimentally from tests on FRP RC sections similar to the ones numerically evaluated in this research (KASSEM, FARGHALY and BENMOKRANE, 2011).

Figure 3.4 - Generic cross-section for the calculation of crack widths

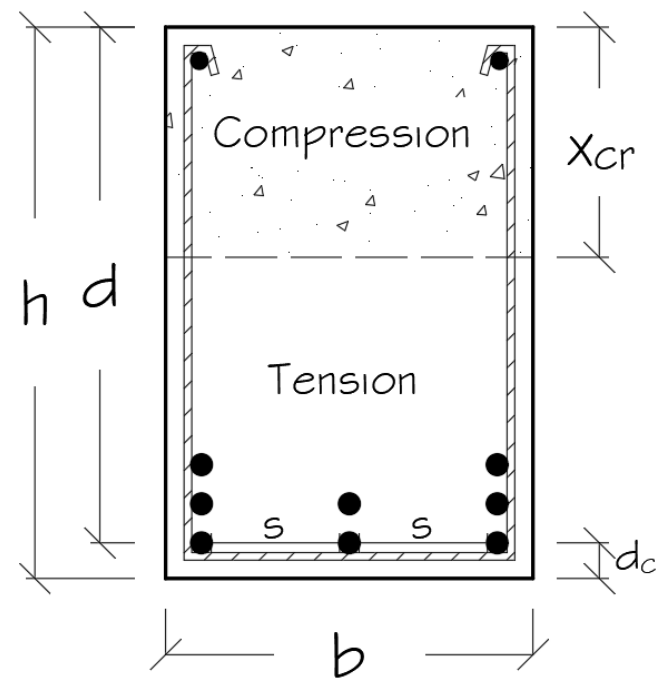

Source: Author

Tables A.15 and A.16, in turn, report the design considering steel CA50. The bending moment $M_{\text {lim }}$ refers to the position of the neutral axis $x_{\text {lim }}$, defined as the ductility limit. If $\mathrm{M}_{\mathrm{d}}>$ $\mathrm{M}_{\text {lim }}$, the designer must impose $\mathrm{x}=\mathrm{x}_{\mathrm{lim}}$, using compressive reinforcements to resist the difference $\Delta M_{d}=M_{d}-M_{l i m}$. Since steel yields for $x=x_{l i m}$, the ultimate limit state is defined by concrete crushing and steel yielding, characterizing a ductile failure mode. The item 14.6.4.3 of ABNT NBR 6118 (2014) establishes that $\mathrm{x}_{\lim }=0.45 \mathrm{~d}$ for normal strength and $0.35 \mathrm{~d}$ for high performance concretes. The term $\varepsilon_{s}$ refers to the steel strain at the ultimate limit state.

The cross-sections reinforced with steel also had the required areas $A_{f}$ adjusted for the commercially available rebars, modifying the effective depth $d$, neutral axis position $x$ and consequently, the flexural strength $M_{r}$. Therefore, the failure mode also changes from steel yielding with a $10 \%$ reinforcement strain to concrete crushing and steel yielding with a strain smaller than 10\%o (ABNT NBR 6118, 2014). 
According to ACI 440 1R-15 (2015), creep rupture is not an issue for conventional steel reinforcement, except under high temperatures, such as in a fire. Thus, checking for creep rupture of steel rebars was not necessary. Once presented these tables, the design of each type of FRP and steel is evaluated.

\subsection{Design Evaluation}

Tables A.3 to A.16 analyses allow evaluating changes in the reinforcement area $A_{f}$ and mechanical properties of all cross-sections, accounting for different types of FRP and steel combined to $\mathrm{C} 25$ and $\mathrm{C} 80$ concrete grades.

\subsubsection{Aramid FRP Reinforcement - AFRP}

Regarding the combination of AFRP and concrete C25, the results on Tables A.3 and A.4 indicate that the final adopted area was in average $23 \%$ larger than the one calculated to resist only the design bending moment $M_{d}$, with a maximum value of $64 \%$ for the section B2SUP2. Such need to increase the amount of reinforcement lies on the maximum allowable sustained stress $f_{f s}$ for AFRP, which is limited to $30 \%$ of its nominal tensile strength, as previously mentioned. Since $45 \%$ of the cross-sections did not meet this requirement for the adjusted area considering only the ultimate limit state for flexure, those changes were necessary. Additionally, it was observed that once the reinforcement areas were readjusted for the creep rupture limit state, the serviceability limit states for deflections and crack widths were automatically met for the majority of sections.

Given this increase in reinforcement area, the flexural strength $M_{r}$ became, in average, $32 \%$ higher, while the curvature $\varphi$ decreased by $2.3 \%$. However, increases of $50 \%$ and $9 \%$ in $M_{r}$ and $\varphi$ were observed for B2-SP1, resulting in greater ductility compared to the initial area. Moreover, $53 \%$ of the cross-sections with changes in reinforcement area had their failure mode switched from tension to compression-controlled. Such changes are followed by reductions up to $18 \%$ in curvature, compromising the ductility of the cross-sections due to the increase of the neutral axis depth $x_{r}$ and the decrease in the reinforcement strains $\varepsilon_{f}$. In turn, the reductions in stress levels, deflections and crack widths corresponded to 32,35 and 40\%, in average.

Regarding the combination of AFRP and Concrete C80, the increase in the reinforcement areas was, in average, 53\%. Tables A.4 and A.5 showed that a high strength concrete results in smaller required areas $A_{f}$ to resist the design moment $M_{d}$. Consequently, the 
ratio between the area adjusted for commercial rebars $A_{d}$ and $A_{f}$ is considerably higher for the combination with concrete $\mathrm{C} 80$. As a result, fewer cross-sections fail due to creep rupture, $36 \%$ only. However, the curvatures at the ultimate limit state increase, in average, $3 \%$, since a high strength concrete contributes to the reduction of the neutral axis depth and increases in the reinforcement strain, suggesting larger curvatures. Regarding changes in the failure mode, only the cross-section B2-SUP2 became compression-controlled after adjustments in area due to creep rupture. For this cross-section, the reinforcement area increased 64\%, reducing the sustained stress level by $38 \%$. Such reduction was, in average, $34 \%$ for the cross-sections whose areas were readjusted.

In relation to the deflections, no changes were observed for the combination AFRP and concrete C80. Since the service moment corresponding to almost permanent loading combinations is smaller than the cracking moment for concrete C80, the moment of inertia theoretically did not change, and the gross moment $I_{g}$ is used to compute deflections. Because it does not depend on the amount of reinforcement, the deflections did not change.

Furthermore, increasing the concrete strength did not effectively reduce the final reinforcement area. Only two cross-sections, B3-SP2 and B3-SP1, had a reduction of 33\% in comparison to the same cross-sections with concrete $\mathrm{C} 25$. The flexural strength was, in average, $8 \%$ higher considering the $\mathrm{C} 80$ grade, given the increase in the moment arm $d-0.5 \beta x$. The curvature reduced, in average, 5\% compared to concrete C25 due to the very small strains at the most compressed concrete fiber and large reinforcement strains, since most cross-sections fail due to the FRP rupture rather than concrete crushing. Concerning stress levels due to the almost permanent loading combination, the reduction was, in average, 1\%, which had been already expected, seeing that the only parameter changing was the concrete secant modulus $E_{c s}$, which slightly modifies the neutral axis position $x_{c r}$ and, consequently, the cracked moment of inertia $I_{c r}$ and the sustained stress $f_{f s}$.

Regarding deflections, the reduction was $60 \%$. Since the cracking moment $M_{c r}$ is higher for this concrete grade, some cross-sections that showed cracking for concrete $\mathrm{C} 25$, theoretically did not for concrete $\mathrm{C} 80$, allowing the computing through the gross moment of inertia $I_{g}$, resulting in smaller deflections. The higher tensile strength of Concrete C80 caused the crack widths to be smaller. Additionally, some cross-sections showing cracking for concrete $\mathrm{C} 25$ did not for $\mathrm{C} 80$. The sections still exhibiting cracking had the widths reduced by $3 \%$, in average. 


\subsubsection{Carbon FRP Reinforcement - CFRP}

Tables A.7 to A.10 describes the design of CFRP RC cross-sections. Unlike AFRP, the majority of cross-sections are compression-controlled, given the normal strength concrete C25 and the higher CFRP tensile strength and elasticity modulus, compared to AFRP and GFRP. Furthermore, since the maximum allowed sustained stress established by ACI $4401 \mathrm{R}-15$ is $55 \%$, the required adjusted areas to meet the ultimate limit state for flexure automatically met the limit state for creep rupture. The only cross-section that had its area readjusted was B2-SP2, which did not meet the serviceability limit state for excessive deflections. Thus, its reinforcement area increased by $50 \%$, which resulted in a flexural strength $16 \%$ higher. The curvature, sustained stress, deflection and crack width decreased by 16, 33, 32 and 43\%, respectively. Deflections and crack widths are smaller in comparison to AFRP, given the higher elasticity modulus of CFRP.

Considering the C80 concrete grade, all cross-sections are tension-controlled. Alike concrete $\mathrm{C} 25$, no cross-section had its area readjusted for the creep rupture limit state, but B2SP2 had its area increased by $50 \%$ to meet the limit state for excessive deflections. The flexural strength increased by $49 \%$ and, unlike concrete C25, the curvature increased by $4 \%$. Such increase relates to the failure mode, characterized by the CFRP rupture, which exhibits an ultimate design strain of $10.9 \%$, resulting in larger curvatures.

The high-performance concrete did not effectively change the final reinforcement area compared to concrete C25. Only the cross-sections B2-SP2 and B2-SUP2 had their amount of reinforcement reduced by 33 and 4\%, respectively. However, the average flexural strength increased by $20 \%$ and curvatures decreased by $0.6 \%$. It is important to highlight that the crosssections related to Beam 1 to Beam 4 showed smaller curvatures, whereas Beam 5 to Beam 9 , larger curvatures in comparison to the combination of CFRP and concrete C25.

The sections that were already tension-controlled for concrete $\mathrm{C} 25$ and did not have their reinforcement area changed exhibited smaller curvatures for concrete $\mathrm{C} 80$, since the strain at the reinforcement remained equal to $\varepsilon_{f u d}$, but the distance from the CFRP layer to the neutral axis increased, which reduced the inclination of the cross-section. Regarding the compressioncontrolled sections that became tension-controlled, both increases and decreases in curvature were observed. That depended on how over-reinforced the cross-section was. If the reinforcement area for concrete $\mathrm{C} 25$ is much larger than the balanced area $A_{b}$ and the section becomes under-reinforced for concrete $\mathrm{C} 80$, the strain at the reinforcement $\varepsilon_{f}$ jumps from very small values to its ultimate design strain $\varepsilon_{f u d}$, in a higher proportion compared to the increase in 
distance from the FRP layer to the neutral axis. As a result, the curvatures are larger and so are the flexural strengths.

Conversely, if the cross-section is not too much over-reinforced for concrete $\mathrm{C} 25$, the increments in reinforcement strains when the concrete grades changes to $\mathrm{C} 80$ are not enough to cause increases in curvature because the distance from neutral axis to the FRP layer expands in a higher proportion. The flexural strengths are also higher, but not as much compared to very over reinforced cross-sections that became under-reinforced.

Alike AFRP, the reductions in sustained stress levels were only $0.3 \%$ and the deflections reduced by $60 \%$. The cross-sections that did not have the reinforcement area readjusted for concrete $\mathrm{C} 80$ and still exhibited cracking showed an average reduction of $3 \%$ in crack widths. However, the section B2-SP2, which had its area reduced, showed an increase of $49 \%$ in the crack widths, since its configuration switched from $3 \phi 8 \mathrm{~mm}$ to $2 \phi 8 \mathrm{~mm}$, reducing the reinforcement area and increase the tensile stresses. Moreover, the larger space between rebars also contributed to wider cracks.

\subsubsection{Glass FRP Reinforcement - GFRP}

As previously mentioned, GFRP reinforcement is very susceptible to creep rupture, which explains why ACI 440 1R-15 (2015) established a maximum sustained stress level of only $20 \%$ of the nominal tensile strength. The design described in Tables A.11 and A.12 show that the majority of cross-sections initially did not meet this requirement for Concrete C25, which resulted in considerable increases in the reinforcement area, 132\% in average. Consequently, half of all cross-sections became over-reinforced, with increments of $89 \%$ in average regarding flexural strengths. Moreover, reductions of up to $32 \%$ and increments of up $16 \%$ in curvatures were observed. The design analysis showed that, if the sustained stress is much higher than the maximum allowed, a very large amount of area is necessary to make $\mathrm{f}_{\mathrm{fs}} / \mathrm{f}_{\mathrm{fu}}$ $\leq 0.2$, especially for tension-controlled cross-sections. Thus, the more area is added, the deeper the neutral axis becomes, resulting in larger strains at the most compressed concrete fiber and smaller strains in the reinforcement, leading to larger curvatures for tension-controlled sections that did not have their failure mode changed.

However, reductions in curvature were also observed when more area was added for cross-sections that were already over-reinforced. Incrementing more area increased the neutral axis depth, not changing the most compressed fiber strain $\varepsilon_{c u}$ but reducing the reinforcement strain $\varepsilon_{f}$, which resulted in smaller curvatures. 
Regarding the stress levels, they were reduced by $52 \%$, while deflections, by $60 \%$ and crack widths for the sections that remained cracked, 57\%. The reductions in deflections are attributed to the higher cracking moment of inertia $I_{c r}$ and the ratio $\beta_{d}$ for the adjusted area, which consequently increases the effective moment of inertia $I_{\text {eff. }}$ Crack widths, in turn, exhibited smaller values by virtue of the considerable increase in the neutral axis depth, reducing the reinforcement stresses.

Considering the combination of GFRP and concrete $\mathrm{C} 80$, the increase in reinforcement areas to meet the limit state for creep rupture corresponded to $113 \%$, with an increment of $103 \%$ in the flexural strength. The curvatures increase, in average, by $5 \%$. Since most cross-sections were already tension-controlled and adding more area did not change the failure mode, the neutral axis depths increased but the reinforcement strains remained equal to $\varepsilon f u d$, which means increases in curvatures while the section remained under-reinforced.

The deflections, in turn, did not increase due to readjustments in reinforcement areas, which is explained by the fact that, theoretically, the cross-sections had not exhibited cracks before increases in areas, since $\mathrm{M}_{\mathrm{apc}}<\mathrm{M}_{\mathrm{cr}}$. Therefore, the moment of inertia used to compute deflections is the gross moment of inertia $I_{g}$, regardless of the reinforcement area.

By switching the concrete $\mathrm{C} 25$ to $\mathrm{C} 80$, flexural strengths showed an average increase of $24 \%$, but some sections reached $62 \%$, with no change in the reinforcement area from one grade to another. The moment arm, in turn, became considerably longer, contributing to a high flexural strength. Because some sections are compression-controlled for both concrete strengths, changing grades from C25 to C80 made the neutral axis depths decrease in a high proportion compared to the strains at the most compressed fibers, making the cross-sections more inclined and, consequently, improving their ductility. The sections B9-SUP1 and B9SUP2, for instance, exhibited curvatures $22 \%$ higher for the grade C80. On the other hand, tension-controlled sections for both concrete grades exhibited reductions in curvatures from $\mathrm{C} 25$ to $\mathrm{C} 80$. The fact that the reinforcement strains remained constant and the neutral axis depths decreased led to reductions in curvatures. Deflections and crack widths were reduced by 58 and $3.5 \%$, respectively, while sustained stresses by $2.5 \%$, in average.

\subsubsection{Steel Reinforcement - CA50 $-\mathbf{f}_{\mathbf{y k}}=500 \mathrm{MPa}$}

Unlike FRP, the required steel areas $A_{f}$ were adjusted only for the commercial rebars. Tables A.15 and A.16 show that the design for the ultimate limit state automatically met the serviceability states for excessive deflections and crack widths, with no need to increase areas. Furthermore, replacing concrete $\mathrm{C} 25$ by $\mathrm{C} 80$ did not effectively increase the flexural strength 
for the same reinforcement areas. Tables A.15 and A.16 also indicate that the ultimate limit state for all sections is characterized by the yielding of steel with a strain of 10\%. Using a highperformance concrete only makes the neutral axis depth and concrete strains decrease, reducing the cross-section curvatures by $8 \%$, in average. The deflections were reduced by $48 \%$, and the sections that still showed cracking for a C80 grade had the crack widths reduced by $10 \%$.

\subsection{Chapter Remarks}

Unlike steel, the required areas to resist the ultimate bending moment do not meet the serviceability limit states and, mainly, result in high tensile stresses that overcome the maximum allowed to avoid creep rupture of FRP rebars. Moreover, since the neutral axis depth is directly proportional to the FRP elasticity modulus, the reinforcement layer tends to be distant from the neutral axis, resulting in high tensile stresses and, consequently, large strains that contribute to excessive deflections and crack widths. Such a fact was more visible for the GFRP reinforcement, which has a very low elasticity modulus compared to steel, but a higher tensile strength. Therefore, using GFRP as non-prestressed reinforcement may lead to very costive solutions due to the large areas required to meet all limit states, especially for the residential building beams evaluated, where the ultimate bending moment $M_{d}$ is considerably smaller than the balanced moment $M_{b}$, resulting in too under-reinforced cross-sections.

In addition to its high cost, large FRP areas may force the cross-sections to become overreinforced, which increases the flexural strength but reduces curvatures at the ultimate limit state, leading to fragile failure modes, especially if high strength concretes are used. Therefore, to avoid large FRP areas, its use in prestressing could result in better utilization of its mechanical properties. The high tensile strength and deformability could lead to high prestressing forces and low percentual losses, respectively.

Conversely, the greater stiffness of CFRP makes the design similar to those regarding members reinforced with conventional steel. Since CFRP has higher modulus than AFRP and GFRP, the reinforcement layer is closer to the neutral axis, which makes it difficult to exhibit excessive deflections and cracking, as well as, creep rupture. Furthermore, using CFRP in conjunction with a high-performance concrete showed excellent results. It was not necessary to readjust areas to meet the limit states regarding creep rupture, excessive deflections and crack widths; additionally, the curvatures at the ultimate limit state are larger, which is great in terms of ductility, providing some warning with respect to the structural conditions. 
Even though the use of CFRP as non-prestressed reinforcement showed great results, it does not exclude the possibility of utilizing it in prestressing, since its tensile strength is four times higher than the yielding of steel, and its elasticity modulus lower. The elevated ratio strength to modulus suggests that the prestressing losses would still be low, compared to the strain due to pre-tensioning. Moreover, since CFRP is not as vulnerable to creep rupture as AFRP and GFRP, a high stress level is allowed during prestressing (ACI 440 4R-04, 2004). Therefore, its use as prestressed reinforcement has the potential to yield excellent results. 


\section{Chapter 4 - Long-term Assessment of GFRP Reinforced Concrete Beams}

Although corrosion does not constitute an issue for FRP in general, physical and environmental factors may negatively affect the structural functionality of GFRP reinforced concrete. Losses in strength due to sustained stresses, as well as, creep effects associated to thermal variations and concrete alkalinity may considerably preclude the use of GFRP as nonprestressed reinforcement, leading to fragile failure modes. Therefore, it is not by chance that the serviceability requirements usually govern the design of GFRP RC flexural members (YOUSSEF, 2010).

This chapter describes a numerical analysis in regards to the long-term performance of a simply supported GFRP RC beam, considering different reinforcement ratios. The numerical assessment accounted for FRP losses in stiffness due to the creep phenomenon, vulnerability to sudden failure by virtue of sustained stresses, and changes in concrete properties due to creep, shrinkage and thermal variations. The deflections due to almost permanent and rare loading, as well as, the crack widths due to frequent loading combinations were computed for time periods ranging from zero to one-hundred years. Furthermore, the bending moment-curvature relationships were determined for different reinforcement ratios and time-periods, so that the deformability of members could be investigated, determining whether or not the design procedures lead to fragile or ductile failure modes. The results corresponding to this part of the research were published at the $61^{\circ}$ Brazilian Concrete Conference with the title Service Life Assessment of Concrete Reinforced with Glass Fiber-reinforced Polymer Bars (BARBOSA and BITTENCOURT, 2019).

\subsection{Methods}

Figure 4.1 illustrates the GFRP RC simply supported beam, with a span length of $5 \mathrm{~m}$ and cross-section dimensions of $15 \times 45 \mathrm{~cm}^{2}$, subjected to a uniformly distributed load $p$. For the purposes of this numerical analysis, it was imposed that the dead load $g$ corresponded to $2 / 3$ of the total $p$, whereas the live load to $1 / 3$. Moreover, five different reinforcement ratios were considered, including the minimum value $\rho_{\min }$, determined to resist the minimum bending moment $M_{d, \min }$, calculated through Equation 2.26. The other ratios corresponded to $0.85,1.0$, 1.4 and 2.0 of the balanced ratio $\rho_{f b}$, for which the concrete crushing occurs simultaneously to 
the FRP rupture. For each ratio $\rho_{f}$, it is possible to obtain the flexural strength $M_{r}$ at mid-span, computing, therefore, the maximum values for $g$ and $q$.

In addition, concrete $f_{c k}$ and GFRP $f_{f u}$ nominal strengths were not decreased by safety factors for the calculation of flexural strengths $M_{r}$. Such a decision was taken in order to avoid confusions regarding safety factors provided by ABNT NBR 6118 (2014) and ACI 440 1R-15 (2015), seeing that uncertainties regarding steel and FRP are quite different. Furthermore, whereas ABNT NBR 6118 (2014) decreases material strengths, ACI 440 1R-15 (2015) reduces the flexural strength by safety factors that depend on the failure mode. Since FRP does not yield, the ACI safety factor for tension-controlled sections corresponds to $\Upsilon=0.55$, which is more conservative compared to that for compression-controlled sections, which is $\Upsilon=0.65$. Because this is a numerical analysis to evaluate changes in flexural strength, deflections and crack widths over time, not a structural project, the safety factors of 1.4 and 1.25 were not used to reduce concrete and FRP strengths.

Figure 4.1 - GFRP RC beam considered for the numerical analysis

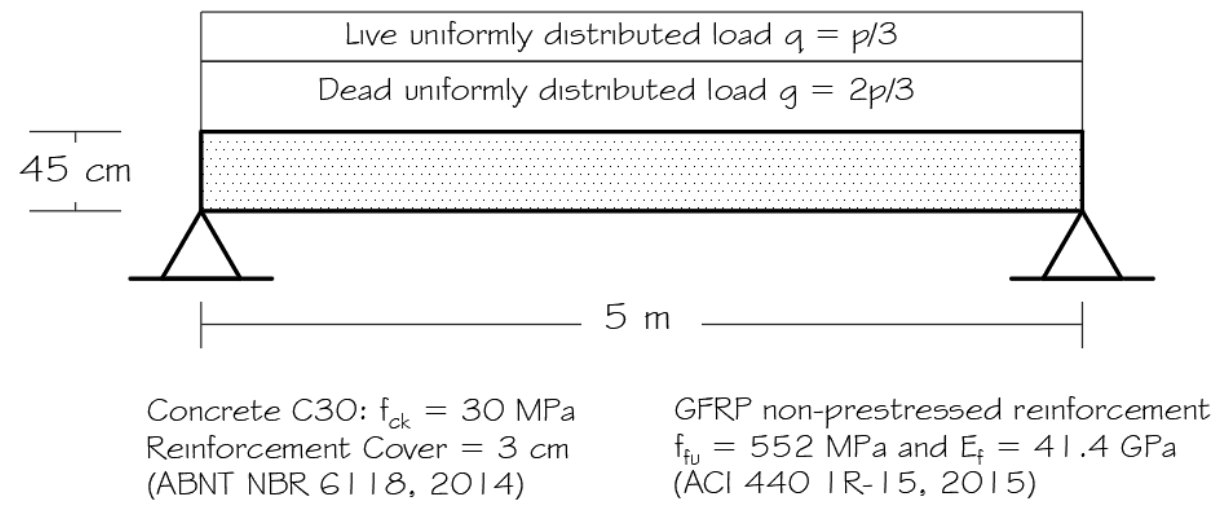

Source: BARBOSA and BITTENCOURT, 2019

Nonetheless, the flexural strength $M_{r}$ was reduced by the ACI safety factors $Y$, as a function of the failure mode. Because the bending moment increased by a safety factor of 1.4 must not exceed the flexural strength reduced by $\Upsilon$, the maximum applied moment $M_{k}$ at midspan is:

$$
M_{k}=\frac{\gamma M_{r}}{1.4}
$$

Therefore, the maximum service loads $g$ and $q$ are directly determined for each reinforcement ratio, allowing numerical evaluations for deflections, crack widths and sustained stresses considering different load combinations. 


\subsubsection{Loading Determination}

First, it is necessary to determine the balanced reinforcement ratio $\rho_{f b}$, for the period $\mathrm{t}=$ 0 , for which the long-term effects are not considered. Figure 4.2 illustrates the equilibrium and compatibility conditions for the cross-section at mid-span.

Figure 4.2 - Cross-section equilibrium and compatibility conditions

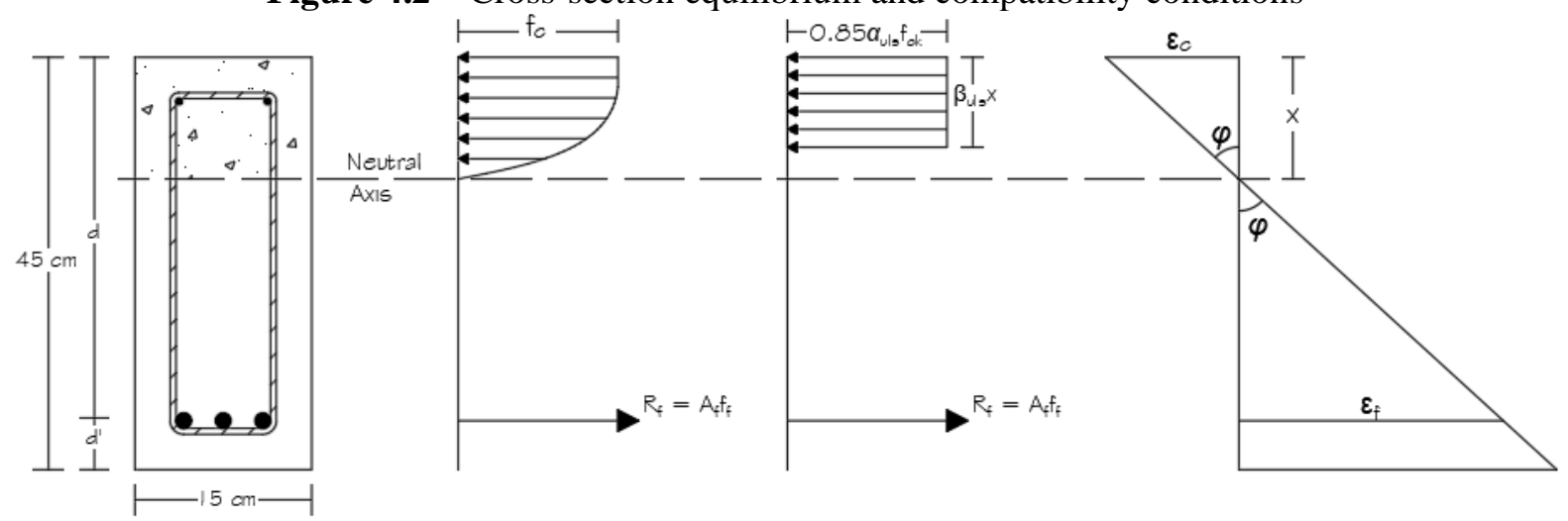

Source: BARBOSA and BITTENCOURT, 2019

The balanced reinforcement ratio $\rho_{f b}$ is calculated establishing that the strain at the most concrete compressed fiber reaches $\varepsilon_{c u}$, whereas the reinforcement strain arrives at $\varepsilon_{f u}$, meaning that both materials fail simultaneously. Thus, by establishing that the resulting force on the concrete compressed area equals the reinforcement tension force, $\rho_{f b}$ is:

$$
\rho_{f b}=0.68 \frac{f_{c k}}{f_{f u}}\left(\frac{E_{f} \varepsilon_{c u}}{E_{f} \varepsilon_{c u}+f_{f u}}\right)
$$

Equation 4.2 corresponds to Equation 7.2.1.b of ACI 440 1R-15 (2015), adjusted for the concrete parameters of ABNT NBR 6118 (2014). The term 0.68 comes from the product $0.85 \alpha_{u l s} \beta_{u l s}$ for a normal strength concrete when it reaches the maximum strain value $\varepsilon_{c u}$, still not considering the creep effects on the concrete stiffness. Since $\mathrm{f}_{\mathrm{ck}}=30 \mathrm{MPa}, \mathrm{f}_{\mathrm{fu}}=552 \mathrm{MPa}$ and $\mathrm{E}_{\mathrm{f}}=41.4 \mathrm{GPa}$, the ratio $\rho_{f b}$ for the beam in analysis is $0.76 \%$. Table 4.1 defines the reinforcement ratios $\rho_{f}$, areas $A_{f}$, number of rebars $n_{b}$ and the non-commercial diameters $\phi$ best fitting the reinforcement area $A_{f}$, given that $n_{b}$ is integer. The bar spacing $s$, in turn, was determined considering $n_{b}$, a $3 \mathrm{~cm}$ reinforcement cover $c$ and a $5 \mathrm{~mm}$ diameter $\phi_{t}$ for the stirrups.

The cross-sections with $\rho<p_{\mathrm{fb}}$ are tension-controlled, for which $\varepsilon_{\mathrm{c}}<\varepsilon_{\mathrm{cu}}$ and $\varepsilon_{\mathrm{f}}=\varepsilon_{\mathrm{fu}}$, requiring an iterative process to compute not only the strain at the most compressed fiber $\varepsilon_{c}$ but also the constitutive parameters $\alpha$ and $\beta$ described by Equations 2.17 to 2.22. First, $\varepsilon_{c}$ was taken as $\varepsilon_{c u}$, leading to values of $\alpha, \beta$ and $x$ that do not satisfy the compatibility conditions, because $\varepsilon_{f}$ 
$\neq \varepsilon_{\mathrm{fu}}$, which is false. Therefore, with the initial neutral axis depth $x$ in hands and imposing that $\varepsilon_{\mathrm{f}}=\varepsilon_{\mathrm{fu}}$, a new value for $\varepsilon_{c}$ is found, which allows computing new parameters $\alpha$ and $\beta$ through Equations 2.17 to 2.19 or 2.20 to 2.22, as well as the new neutral axis depth $x$ through Equation 2.10. This iterative process continued until the reinforcement strain $\varepsilon_{f}$ converged to the ultimate strain $\varepsilon_{f u}$, satisfying the equilibrium and compatibility conditions.

Table 4.1 - Description of different scenarios the beam was evaluated

\begin{tabular}{cccccccc}
\hline Scenario & Description & $\boldsymbol{\rho}_{\mathbf{f}}(\boldsymbol{\%})$ & $\mathbf{A}_{\mathbf{f}}\left(\mathbf{c m}^{2}\right)$ & $\mathbf{n}_{\mathbf{b}}$ & $\boldsymbol{\phi}(\mathbf{m m})$ & $\mathbf{d}(\mathbf{c m})$ & $\mathbf{s}(\mathbf{c m})$ \\
\hline I & $\rho_{\mathrm{f}}=\rho_{\min }$ & 0.08 & 0.48 & 3 & 4.5 & 41.27 & 3.32 \\
II & $\rho_{\mathrm{f}}=0.85 \rho_{\mathrm{fb}}$ & 0.65 & 4.00 & 3 & 13 & 40.85 & 2.05 \\
III & $\rho_{\mathrm{f}}=\rho_{\mathrm{fb}}$ & 0.76 & 4.68 & 2 & 17.3 & 40.64 & 4.55 \\
IV & $\rho_{\mathrm{f}}=1.4 \rho_{\mathrm{fb}}$ & 1.05 & 6.53 & 2 & 20.4 & 40.48 & 3.92 \\
V & $\rho_{\mathrm{f}}=2.0 \rho_{\mathrm{fb}}$ & 1.50 & 9.29 & 2 & 24.3 & 40.28 & 3.14 \\
\hline
\end{tabular}

Source: BARBOSA and BITTENCOURT, 2019

Table 4.2 describes the strains $\varepsilon_{c}$ and $\varepsilon_{f}$, the constitutive parameters $\alpha$ and $\beta$, the type of failure and the flexural strength $M_{r}$ for the five scenarios. The maximum applied moment $M_{k}$, as well as, the loads $g$ and $q$ are also shown.

Table 4.2 - Determination of flexural strengths and applied loads

\begin{tabular}{ccccccccccc}
\hline Scenario & $\begin{array}{c}\boldsymbol{\varepsilon}_{\mathbf{c}} \\
(\mathbf{\% o})\end{array}$ & $\mathbf{0 . 8 5} \boldsymbol{\alpha}_{\text {uls }}$ & $\boldsymbol{\beta}_{\text {uls }}$ & $\begin{array}{c}\mathbf{x} \\
(\mathbf{c m})\end{array}$ & $\begin{array}{c}\boldsymbol{\varepsilon}_{\mathbf{f}} \\
(\mathbf{\%})\end{array}$ & Failure & $\begin{array}{c}\mathbf{M}_{\mathbf{r}} \\
(\mathbf{k N . m})\end{array}$ & $\begin{array}{c}\mathbf{M}_{\mathbf{k}} \\
(\mathbf{k N . m})\end{array}$ & $\begin{array}{c}\mathbf{g} \\
(\mathbf{k N} / \mathbf{m})\end{array}$ & $\begin{array}{c}\mathbf{q} \\
(\mathbf{k N} / \mathbf{m})\end{array}$ \\
\hline I & 0.74 & 0.69 & 0.40 & 2.2 & 13.3 & Tension & 10.9 & 4.3 & 0.9 & 0.5 \\
II & 2.97 & 0.81 & 0.82 & 7.4 & 13.3 & Tension & 83.5 & 32.8 & 7.0 & 3.5 \\
III & 3.5 & 0.85 & 0.80 & 8.4 & 13.3 & Balanced & 96.3 & 44.7 & 9.5 & 4.8 \\
IV & 3.5 & 0.85 & 0.80 & 9.7 & 11.0 & Compression & 109.1 & 50.7 & 10.8 & 5.4 \\
V & 3.5 & 0.85 & 0.80 & 11.3 & 9.0 & Compression & 123.6 & 57.4 & 12.2 & 6.1 \\
\hline
\end{tabular}

Source: BARBOSA and BITTENCOURT, 2019

\subsubsection{Determination of long-term performance parameters}

Once the loads $g$ and $q$ are computed, the step ahead was the evaluation of the flexural member structural performance. For different time periods considered in the analysis, it was necessary to establish new constitutive parameters for concrete, based on the creep coefficient $\Phi$. This coefficient was computed through the simplified model described on Chapter 3 Material Properties, of the book Prestressed Concrete Basis (COLLINS and MITCHELL, 1987), which defines $\Phi$ as:

$$
\Phi\left(t, t_{0}\right)=3,5 k\left(1,58-\frac{H}{120}\right) t_{0}{ }^{-0,118} \frac{\left(t-t_{0}\right)^{0,6}}{10+\left(t-t_{0}\right)^{0,6}}
$$

The parameter $k$ accounts for the structural member volume to surface area ratio, determined according to Figure 4.3, while $H$ is the relative humidity, taken as $70 \%$ for the case 
in study. Finally, $t$ and $t_{0}$ refer to the time period considered for the analysis and the instant the load was applied, respectively; both in days.

Figure 4.3 - Chart for the determination of $\mathrm{k}$, based on the volume to surface are ratio

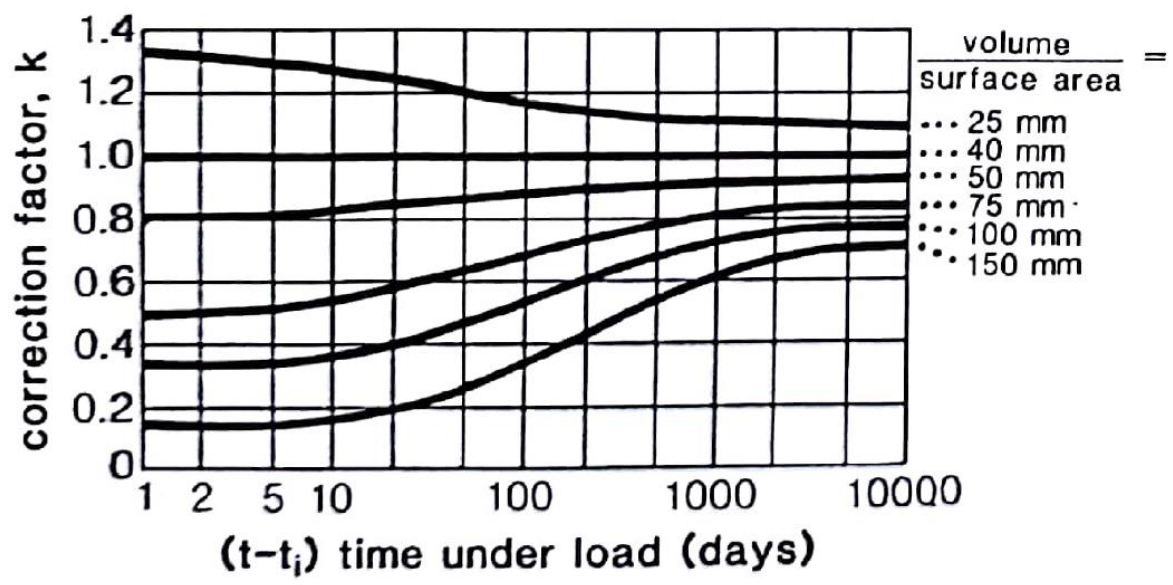

Source: COLLINS and MITCHELL, 1987

Once the creep coefficient $\Phi$ is determined, the concrete secant modulus $E_{c s}$ as well as the strains $\varepsilon_{c 2}$ and $\varepsilon_{c u}$ are modified for the changes in stiffness due to creep effects. According to Collins and Mitchell (1987), the effective secant modulus after considering the creep effects is:

$$
E_{c s, e f f}=\frac{E_{c S}}{1+\Phi}
$$

Figure 4.4 depicts how creep affects the concrete stress-strain relationship, shifting the curve to the right and reducing the slope of straight lines tangent to the curve, which means, reducing the stiffness.

Figure 4.4 - Shifting of concrete stress-strain curve due to the creep phenomenon

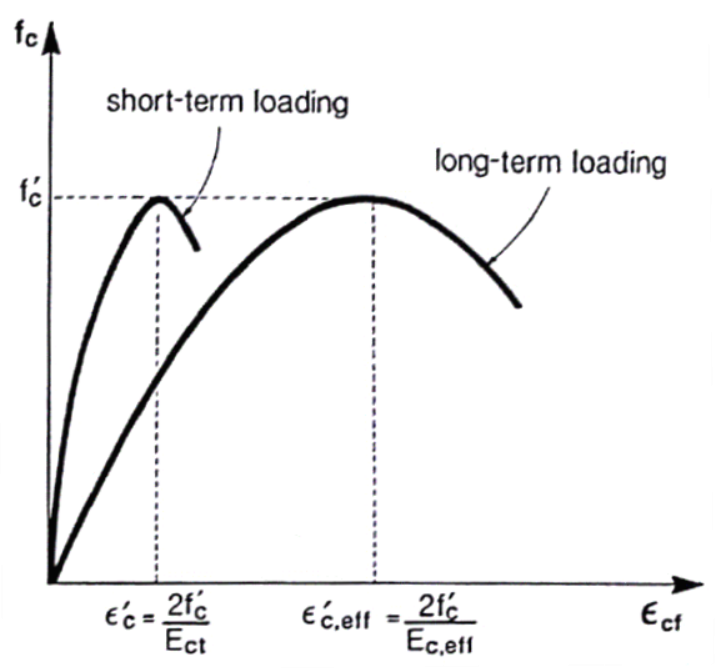

Source: COLLINS and MITCHELL, 1987 
The creep phenomenon illustrated in Figure 4.4 was adapted to the constitutive models of ABNT NBR 6118 (2014), for the purposes of this research. The Brazilian code defines the secant elasticity modulus as $\mathrm{E}_{\mathrm{cs}}=\alpha_{\mathrm{i}} \mathrm{E}_{\mathrm{ci}}$, for which $E_{c i}$ corresponds to the initial modulus, defined as the slop of the line tangent to the curve for $\varepsilon_{\mathrm{c}}=0$. Thus, $E_{c s}$ can be obtained by deriving Equation 2.15 , imposing $\varepsilon_{\mathrm{c}}=0$ and multiplying by $\alpha_{i}$. Therefore, isolating $\varepsilon_{c 2}$ leads to:

$$
\varepsilon_{c 2}=\frac{0.85 n f_{c k} \alpha_{i}}{E_{c s}}
$$

Since the creep phenomenon reduces the secant modulus, the effective strain $\varepsilon_{c 2 \text {,eff }}$ accounting for creep is:

$$
\varepsilon_{c 2, e f f}=(1+\Phi) \varepsilon_{c 2}
$$

Therefore, different constitutive models for concrete are obtained, replacing only the

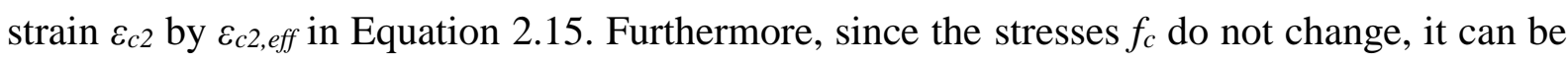
proven that any strain $\varepsilon_{c, \text { eff }}$ equals $(1+\Phi) \varepsilon_{c}$ given $\varepsilon_{\mathrm{c}} \leq \varepsilon_{\mathrm{c} 2}$, for the ABNT NBR 6118 (2014) constitutive model. Because, there is a plateau for $\varepsilon_{\mathrm{c} 2}<\varepsilon_{\mathrm{c}} \leq \varepsilon_{\mathrm{cu}}$, this expression does not mathematically apply. Nonetheless, the ultimate concrete strain considering the creep effects was computed as $\varepsilon_{\mathrm{cu}, \mathrm{eff}}=(1+\Phi) \varepsilon_{\mathrm{cu}}$, as if the parabolic curve applied from zero to the ultimate strain. Figure 4.5 shows the shifting of the concrete stress-strain curve for ABNT NBR 6118 (2014) constitutive model:

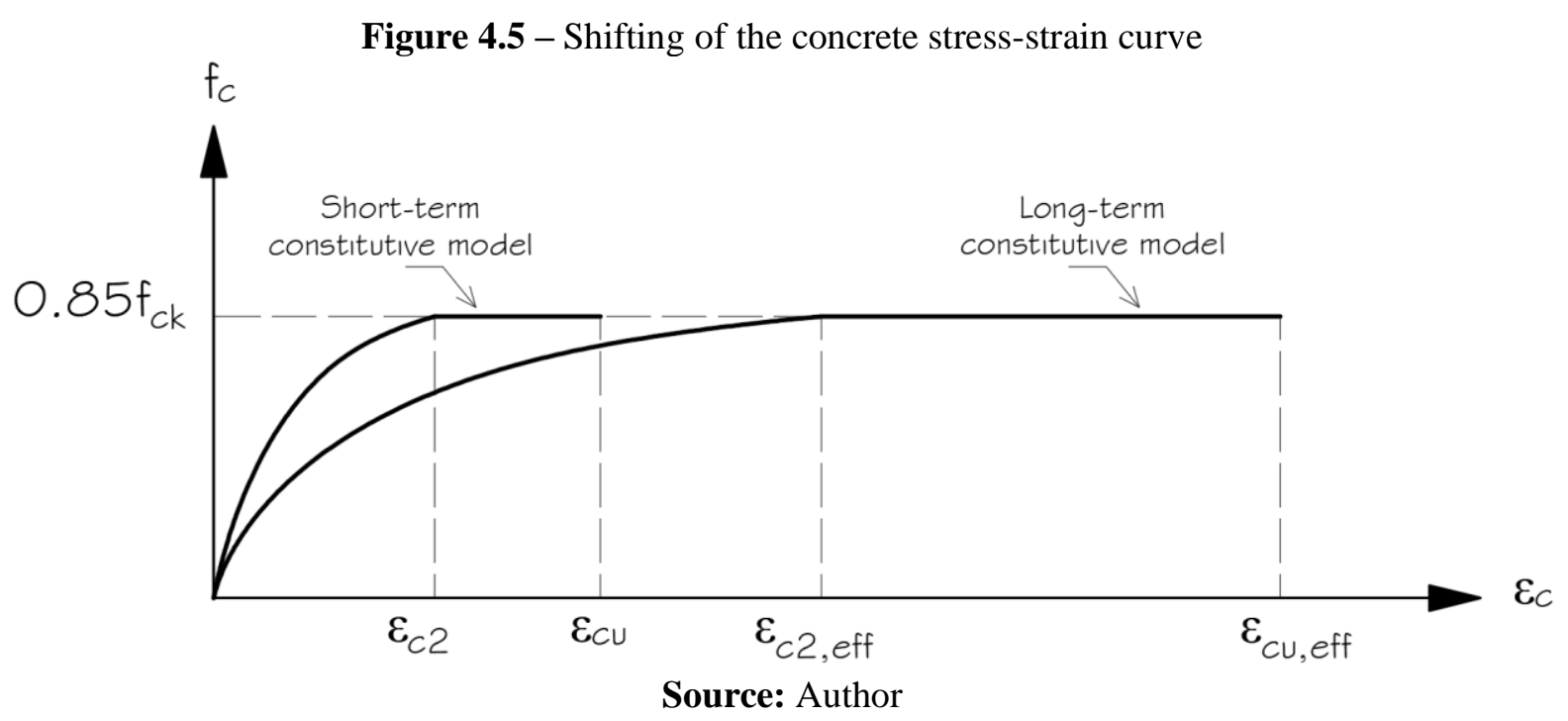

Besides the creep effects, the concrete shrinkage was also considered for the numerical analysis. Nonetheless, this does not modify the concrete constitutive model, being included in 
the compatibility equations, as shown further. The shrinkage equation was determined in accordance to Equation 3-10 of the book Prestressed Concrete Basis (COLLINS and MITCHELL, 1987):

$$
\varepsilon_{s h}=-K_{s} K_{h}\left(\frac{t}{35+t}\right) 0,51 * 10^{-3}
$$

In the equation above, $K_{s}$ depends on the volume to surface area ratio, obtained through Figure 4.6, whereas $K_{h}$ relies on the environmental humidity, obtained through Table 4.3.

Figure 4.6 - Chart for the determination of $K_{s}$

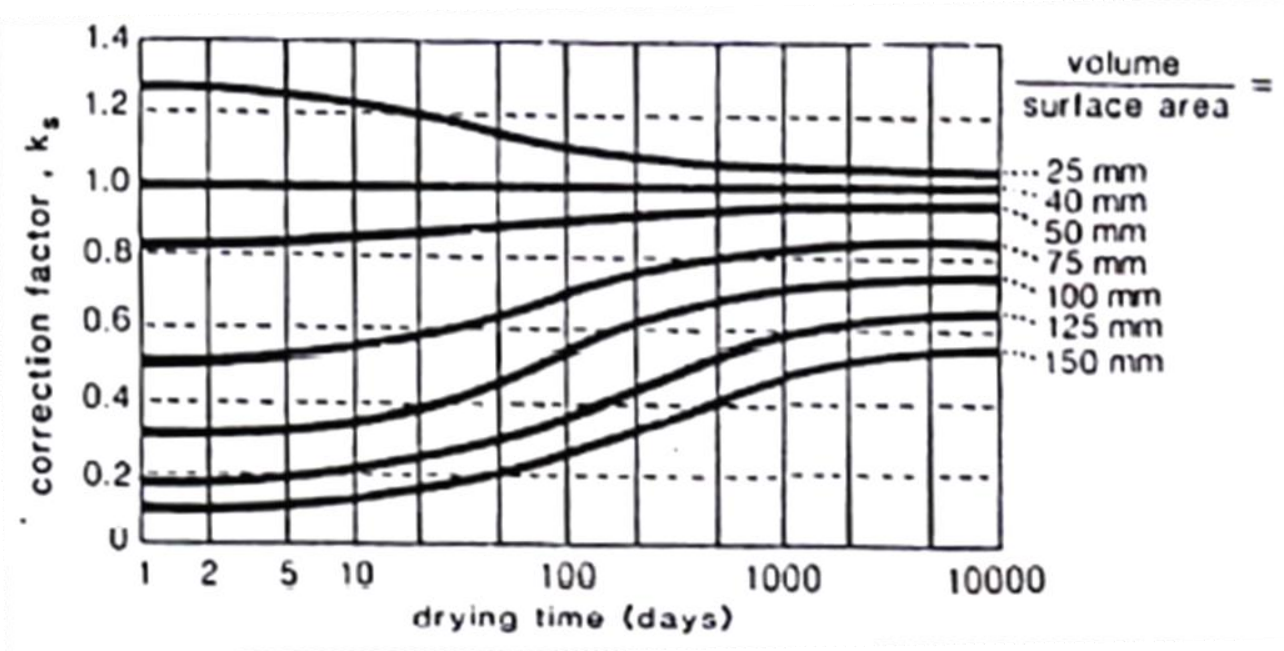

Source: COLLINS and MITCHELL, 1987

Table 4.3 - Factor $K_{h}$ as a function of relative humidity $H$

\begin{tabular}{cccccccc}
\hline $\mathbf{H}(\boldsymbol{\%})$ & $\mathbf{4 0}$ & $\mathbf{5 0}$ & $\mathbf{6 0}$ & $\mathbf{7 0}$ & $\mathbf{8 0}$ & $\mathbf{9 0}$ & $\mathbf{1 0 0}$ \\
\hline $\mathbf{K}_{\mathbf{h}}$ & 1.43 & 1.29 & 1.14 & 1.00 & 0.86 & 0.43 & 0.00 \\
\hline \multicolumn{8}{c}{ Source: COLLINS and MITCHELL, 1987}
\end{tabular}

The effects of increase in temperature were also considered for the numerical evaluation. In accordance with ABNT NBR 6118 (2014) and ACI 440 1R-15 (2015), the thermal expansion coefficient considered for concrete $\alpha_{c}$ and GFRP $\alpha_{f}$ were $10^{-5}$ and $8^{*} 10^{-6}{ }^{\circ} \mathrm{C}^{-1}$, respectively. Hence, for a temperature increase of $15^{\circ} \mathrm{C}$, the concrete $\varepsilon_{c t h}$ and GFRP $\varepsilon_{f t h}$ thermal elongations corresponded to 0.15 and $0.12 \%$, respectively.

Considering that the loading application took place after 28 days the concrete was cast, Table 4.4 describes the long-term properties for the grade $\mathrm{C} 30$, regarding time-periods ranging from five to one-hundred years. In relation to the GFRP rebars, the creep phenomenon was accounted as a reduction of the GFRP elasticity modulus $E_{f}$, whereas the effects of thermal variations were addressed through the compatibility conditions. The sustained stress $f_{f s}$ due to 
almost permanent load combinations, was also evaluated in order to verify if there is creep rupture of GFRP rebars. Budelman and Rotasy (1993) (apud Youssef, 2010, p.14) concluded from experimental work that creep rupture does not occur if the sustained stresses in GFRP rebars do not exceed $60 \%$ of the material tensile strength $f_{f u}$. Therefore, this was the criteria to numerically determine if there is a chance for creep rupture in case $f_{f s} \geq 0.6 f_{f u}$.

Table 4.4 - Concrete long-term properties

\begin{tabular}{ccccccccc}
\hline & \multicolumn{4}{c}{ Creep } & \multicolumn{4}{c}{ Shrinkage } \\
\hline Time (years) & $\mathbf{k}$ & $\mathbf{\Phi}$ & $\mathbf{E}_{\mathbf{c s}, \text { eff }}\left(\mathbf{k N / \mathbf { c m } ^ { 2 }}\right)$ & $\mathbf{\varepsilon}_{\mathbf{c} 2 \text {,eff }}(\mathbf{\% o})$ & $\boldsymbol{\varepsilon}_{\text {cu,eff }}(\mathbf{\%})$ & $\mathbf{K}_{\mathbf{s}}$ & $\mathbf{K}_{\mathbf{h}}$ & $\boldsymbol{\varepsilon}_{\text {sh }}$ \\
$\mathbf{5}$ & 0.83 & 1.76 & 945.30 & 5.52 & 9.65 & 0.77 & 1 & 0.39 \\
$\mathbf{1 0}$ & 0.85 & 1.86 & 910.13 & 5.73 & 10.03 & 0.78 & 1 & 0.39 \\
$\mathbf{2 0}$ & 0.88 & 1.98 & 875.92 & 5.95 & 10.42 & 0.79 & 1 & 0.40 \\
$\mathbf{3 0}$ & 0.9 & 2.04 & 857.13 & 6.08 & 10.65 & 0.8 & 1 & 0.41 \\
$\mathbf{4 0}$ & 0.9 & 2.05 & 853.80 & 6.11 & 10.69 & 0.8 & 1 & 0.41 \\
$\mathbf{5 0}$ & 0.9 & 2.06 & 851.58 & 6.12 & 10.72 & 0.81 & 1 & 0.41 \\
$\mathbf{7 0}(\mathbf{t} \rightarrow \infty)$ & 0.9 & 2.12 & 835.63 & 6.24 & 10.92 & 0.81 & 1 & 0.41 \\
$\mathbf{1 0 0}(\mathbf{t} \rightarrow \infty)$ & 0.9 & 2.12 & 835.63 & 6.24 & 10.92 & 0.81 & 1 & 0.41 \\
\hline
\end{tabular}

Source: BARBOSA and BITTENCOURT, 2019

The long-term reinforcement strain due to creep is defined by Equation 2.3, according to Fib Bulletin 40 (2007). The determination of GFRP creep coefficient $\beta$ was based on the stresses levels $f_{f s} / f_{f u}$, obtained from experimental work conducted by Youssef (2010) considering two types of GFRP. The chart on Figure 4.7 illustrates the results for both GFRP types, whereby the coefficients $\beta$ were determined from the trend line corresponding to the GFRP type 2, the most prone to exhibit large strains due to creep.

Figure 4.7 - Trend lines for the determination of $\beta$ as a function of $f_{f s} / f_{f u}$, obtained from experimental work conducted by Youssef (2010)

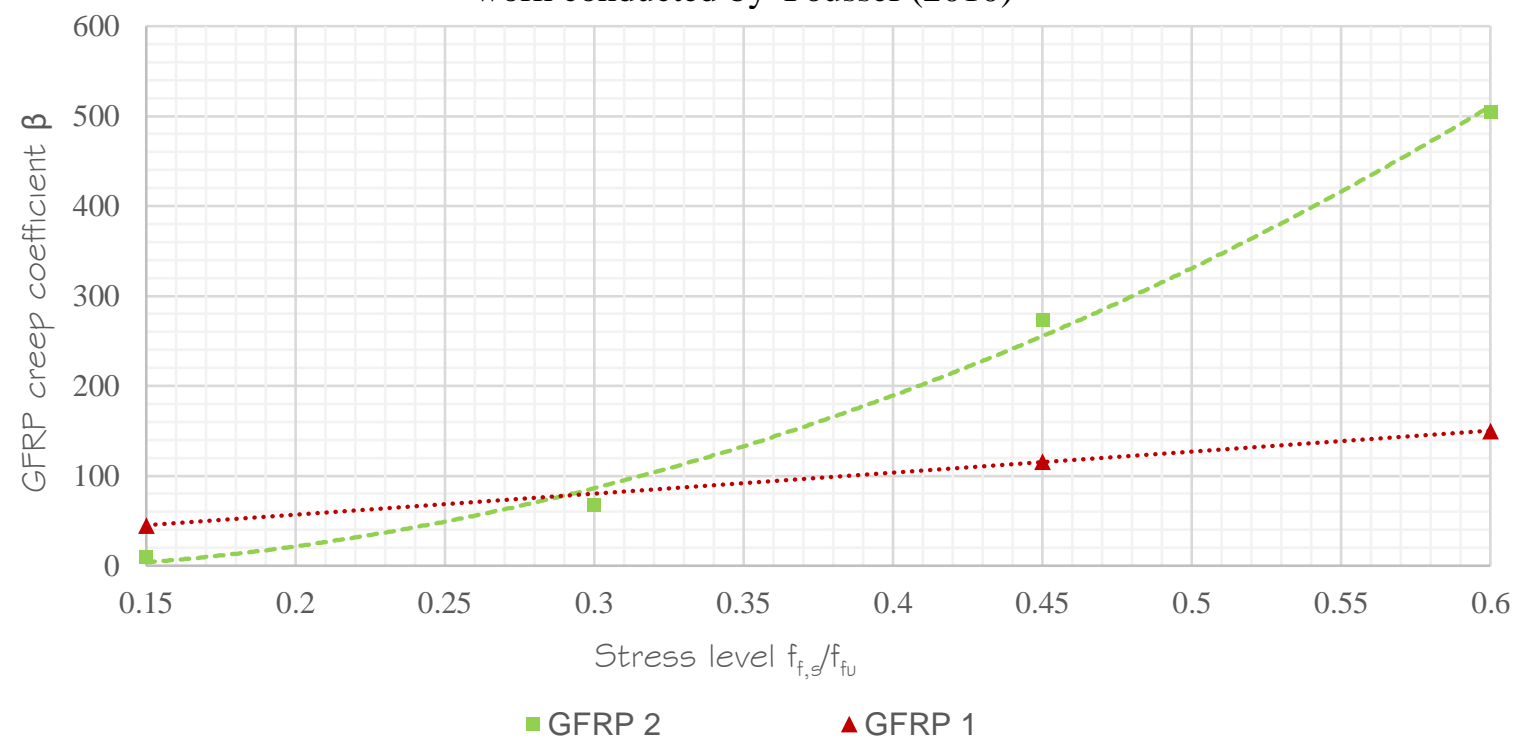

Source: BARBOSA and BITTENCOURT, 2019 
First of all, the short-term strain $\varepsilon_{0}$ and stress level $f_{f s} / f_{f u}$ are computed, allowing to determine $\beta_{c c}$ from Figure 4.7. Thenceforth, the strain due to creep for a time-period $t_{i}$ was determined through Equation 2.3. The effective elasticity modulus $E_{f, e f f}$ after this period was computed as the ratio between the sustained stress $f_{f s}$ and the adjusted strain $\varepsilon\left(t_{i}\right)$, with $t$ in days. Therefore, considering all changes in concrete and GFRP properties, a new stress level and strain were computed for the upcoming period $t_{i+1}$, and consequently, the creep coefficient $\beta$ and strain $\varepsilon_{f}$ to calculate $E_{f, e f f}$ for $t_{i+2}$, and so forth.

\subsubsection{Compatibility conditions considering the long-term effects}

Since the evaluation of long-term structural behavior incorporates strains due to shrinkage, thermal variations and reduction in stiffness due to creep, the compatibility conditions shown in Figure 4.2 must account for all these strains. The total concrete strain $\varepsilon_{c}$ turns to be $\varepsilon_{\mathrm{c}}=\varepsilon_{\mathrm{cf}}+\varepsilon_{\mathrm{sh}}-\varepsilon_{\mathrm{cth}}$, whereas the total for the reinforcement is $\varepsilon_{\mathrm{f}}=\varepsilon_{\mathrm{ff}}+\varepsilon_{\mathrm{fth}}$ (COLLINS and MITCHELL, 1987). The strains $\varepsilon_{c f}$ and $\varepsilon_{f f}$ were obtained from the concrete and GFRP constitutive equations, modified by the creep phenomenon.

The balanced reinforcement ratio calculated through Equation 4.2 has now to account for such strains and modifications in concrete and GFRP constitutive equations. Consequently, the cross-section failure mode may change over time from compression to tension-controlled or vice-versa. The effective balanced ratio becomes:

$$
\rho_{f b, e f f}=0.85 \alpha_{u l s, e f f} \beta_{u l s, e f f} \frac{f_{c k}}{f_{f u}}\left(\frac{\left|\varepsilon_{c u, e f f}+\varepsilon_{s h}-\varepsilon_{c t h}\right|}{\left|\varepsilon_{c u, e f f}+\varepsilon_{s h}-\varepsilon_{c t h}\right|+\left|\varepsilon_{f u, e f f}+\varepsilon_{f t h}\right|}\right)
$$

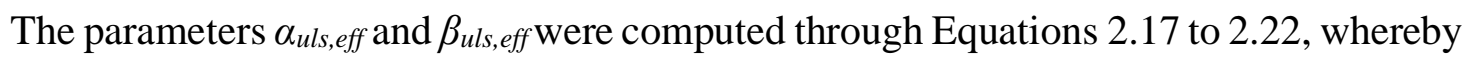
the most compressed strain $\varepsilon_{t}$ is equal to the effective ultimate strain $\varepsilon_{c u \text {,eff }}$ and $\varepsilon_{c 2}$ is replaced by its long-term value $\varepsilon_{c 2, e f f}$. The GFRP ultimate strain $\varepsilon_{f u, e f f}$ was obtained through the ratio between $f_{f u}$ and the effective GFRP modulus $E_{f, e f f}$ for the reference period.

\subsubsection{Long-term deflections and crack widths}

Deflections due to almost permanent load combinations $v_{a p c}$ were computed in accordance with the item 17.3.2.1.1 of ABNT NBR 6118 (2014), by which the effective moment of inertia $I_{\text {eff }}$ is calculated through Equation 4.9. For this numerical analysis, it was assumed that the GFRP bonding properties are similar to the steel's; thus, the parameter $\beta_{d}$ is considered as one: 


$$
I_{e f f}=\left(\frac{M_{r}}{M_{a p c}}\right)^{3} I_{1}+\left[1-\left(\frac{M_{c r}}{M_{a p c}}\right)^{3}\right] I_{2}
$$

Additionally, instead of using the gross moment of inertia $I_{g}$, Equation 4.9 considers the adjusted moment of inertia $I_{l}$ prior to cracking, which accounts for the concrete and GFRP areas and stiffness. In turn, $I_{2}$ corresponds to $I_{c r}$, the cracking moment of inertia defined by ACI. Due to changes in concrete and GFRP elasticity modulus, both $I_{1}$ and $I_{2}$ were modified for each period $t_{i}$. The loading combination factors $\psi_{1}$ and $\psi_{2}$ considered for the analysis were 0.4 and 0.3 , respectively, in compliance with Table 11.2 of the Brazilian code. Therefore, the bending moments due to almost permanent and frequent load combinations were defined as $\mathrm{M}_{\mathrm{apc}}=\mathrm{Mg}_{\mathrm{g}}$ $+0.3 \mathrm{M}_{\mathrm{q}}$ and $\mathrm{M}_{\mathrm{fc}}=\mathrm{M}_{\mathrm{g}}+0.4 \mathrm{M}_{\mathrm{q}}$, respectively.

This numerical analysis also aimed to compute the incremental deflections $\Delta v_{r c}$ due to rare loading combinations $M_{r c}$, determined as $\mathrm{M}_{\mathrm{rc}}=\mathrm{M}_{\mathrm{g}}+\mathrm{M}_{\mathrm{q}}$. First, the effective moment of inertia $I_{\text {eff }}$ was calculated for $M_{r c}$ instead of $M_{a p c}$ through Equation 4.9, which led to the deflection $v_{r c}$. The difference between $v_{r c}$ and $v_{a p c}$ corresponds to the incremental deflection $\Delta v_{r c}$, which must not exceed $l / 350$ in accordance to ABNT NBR 6118 (2014) regarding deflections due to accidental loads.

Regarding crack widths, those were calculated through the ABNT NBR 6118 (2014) cracking model described in Equation 2.38 and Figure 2.7, considering the tensile stresses $f_{f}$ caused by the bending moment $M_{f c}$, and the elasticity modulus $E_{f, e f f}$ for the period $t_{i}$. In relation to bonding, the rebars were considered as smooth, for which the parameter $\eta_{1}$ equals one. Figure 4.8 illustrates the cross-section influence areas with different reinforcement ratios:

Figure 4.8 - Influence areas for the estimation of crack widths
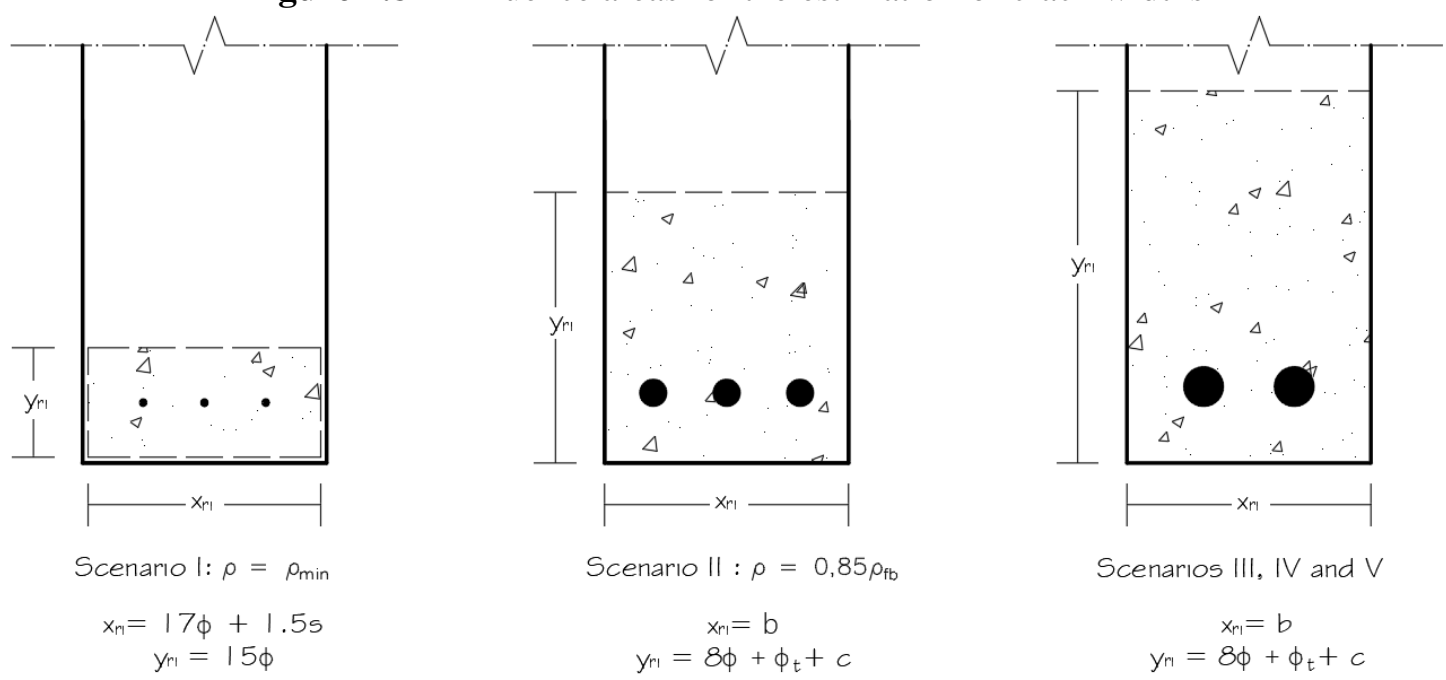

Source: BARBOSA and BITTENCOURT, 2019 - Adapted 


\subsubsection{Long-term moment-curvature relationships}

Upon calculating the deflections and crack widths, the next step was to determine the moment-curvature relationships for time-periods of 10,20 and 50 years after the application of the permanent load. First, it was necessary to check if the cross-section was tension or compression-controlled through Equation 4.8 for the reference period. In case of compressioncontrol, the strain at the most compressed fiber due to stresses $\varepsilon_{c f}$ ranges from 0 to $\varepsilon_{c u \text {,eff. }}$ Therefore, for every single strain at the top $\varepsilon_{c f}$, the simplified rectangular parameters $\alpha_{\text {eff }}$ and $\beta_{\text {eff }}$ are computed for the strains $\varepsilon_{c f}$ and $\varepsilon_{c 2, e f f}$, through Equations 2.17, 2.18 and 2.19 if $\varepsilon_{\mathrm{cf}}<\varepsilon_{\mathrm{c} 2 \text {,eff }}$ or through Equations 2.20, 2.21 and 2.22 if $\varepsilon_{\mathrm{c} 2, \text { eff }} \leq \varepsilon_{\mathrm{cf}} \leq \varepsilon_{\mathrm{cu}, \mathrm{eff}}$. It is important to highlight that $\varepsilon_{c f}$ is not the total concrete strain, but the one as regards the long-term stress-strain relationship.

By imposing equilibrium conditions, establishing that the resulting compression force $R_{c}$ equals the reinforcement tension force $R_{f}$, two unknown variables showed up: the neutral axis depth $x$ and the reinforcement strain $\varepsilon_{f f}$.

$$
0.85 \alpha_{e f f} \beta_{e f f} b x=A_{f} E_{f, e f f} \varepsilon_{f f}
$$

The long-term compatibility conditions illustrated in Figure 4.2 allowed writing $\varepsilon_{f f}$ as a function of $x$ as follows:

$$
\varepsilon_{f f}=\left(\varepsilon_{c f}+\varepsilon_{s h}-\varepsilon_{c t h}\right)\left(\frac{d-x}{x}\right)-\varepsilon_{f t h}
$$

Thus, replacing $\varepsilon_{f f}$ in Equation 4.10 by the expression given in 4.11 allows calculating the neutral axis depth $x$, the total strain in the most compressed fiber $\varepsilon_{c}$ as well as the total reinforcement strain $\varepsilon_{f}$. Therefore, the cross-section curvature $\varphi$ is obtained dividing $\varepsilon_{c}$ by $x$. Finally, the bending moment associated to this curvature is:

$$
M=0.85 \alpha_{e f f} \beta_{e f f} f_{c k} b x\left(d-0,5 \beta_{e f f} x\right)=A_{f} E_{f e f f} \varepsilon_{f f}\left(d-0,5 \beta_{e f f} x\right)
$$

Regarding under-reinforced cross-sections, the procedure to calculate $\varphi$ and $M$ were interrupted when the strain $\varepsilon_{f f}$ due to stresses in reinforcement reached its effective ultimate value $\varepsilon_{f u, e f f}$, indicating that the flexural member failed due to GFRP rupture. Finally, the charts relating $\varphi$ and $M$ were plotted for different time periods. 


\subsection{Results}

Tables 4.5 and 4.6 describe changes in the flexural strength from $t_{i}=0$ to 100 years, considering all five scenarios concerning the mid-span cross-section. The reinforcement ratio $\rho_{f b}$ is shown in $\%$ and the flexural strength $M_{r}$ in $\mathrm{kNm}$. The failure mode is also defined as tension, compression-controlled or balanced.

Table 4.5 - Changes in flexural strengths and balanced ratio for the scenarios I, II and III

\begin{tabular}{cccccccccc}
\hline \multirow{2}{*}{$\mathbf{t}$} & \multicolumn{3}{c}{ Scenario I } & \multicolumn{3}{c}{ Scenario II } & \multicolumn{3}{c}{ Scenario III } \\
\cline { 2 - 10 } & $\boldsymbol{\rho}_{\mathbf{f b}, \mathbf{e f}}$ & Failure & $\mathbf{M}_{\mathbf{R}}$ & $\boldsymbol{\rho}_{\mathbf{f b}, \mathbf{e f}}$ & Failure & $\mathbf{M}_{\mathbf{r}}$ & $\boldsymbol{\rho}_{\mathbf{f b}, \mathbf{e f}}$ & Failure & $\mathbf{M}_{\mathbf{r}}$ \\
\hline $\mathbf{0}$ & 0.77 & Tension & 10.9 & 0.77 & Tension & 83.5 & 0.77 & Balanced & 96.3 \\
$\mathbf{5}$ & 1.50 & Tension & 10.9 & 1.51 & Tension & 82.8 & 1.48 & Tension & 95.0 \\
$\mathbf{1 0}$ & 1.46 & Tension & 10.9 & 1.47 & Tension & 82.8 & 1.42 & Tension & 95.1 \\
$\mathbf{2 0}$ & 1.42 & Tension & 10.9 & 1.43 & Tension & 82.8 & 1.37 & Tension & 95.2 \\
$\mathbf{3 0}$ & 1.37 & Tension & 10.9 & 1.39 & Tension & 82.9 & 1.31 & Tension & 95.2 \\
$\mathbf{4 0}$ & 1.31 & Tension & 10.9 & 1.33 & Tension & 82.9 & 1.24 & Tension & 95.3 \\
$\mathbf{5 0}$ & 1.26 & Tension & 10.9 & 1.28 & Tension & 82.9 & 1.18 & Tension & 95.4 \\
$\mathbf{7 0}$ & 1.22 & Tension & 10.9 & 1.25 & Tension & 83.0 & 1.13 & Tension & 95.5 \\
$\mathbf{1 0 0}$ & 1.16 & Tension & 10.9 & 1.20 & Tension & 83.0 & 1.08 & Tension & 95.6 \\
\hline
\end{tabular}

Source: BARBOSA and BITTENCOURT, 2019 - Adapted

Table 4.6 - Changes in flexural strengths and balanced ratios for the scenarios IV and V

\begin{tabular}{ccccccc}
\hline \multirow{2}{*}{$\mathbf{t}$} & \multicolumn{3}{c}{ Scenario IV } & \multicolumn{3}{c}{ Scenario $\mathbf{~}$} \\
\cline { 2 - 7 } & $\boldsymbol{\rho}_{\mathbf{f b}, \mathbf{e f}}$ & Failure & $\mathbf{M}_{\mathbf{r}}$ & $\boldsymbol{\rho}_{\mathbf{f b}, \mathbf{e f}}$ & Failure & $\mathbf{M}_{\mathbf{r}}$ \\
\hline $\mathbf{0}$ & 0.77 & Compression & 109.1 & 0.77 & Compression & 123.6 \\
$\mathbf{5}$ & 1.51 & Tension & 127.4 & 1.54 & Balanced & 171.4 \\
$\mathbf{1 0}$ & 1.48 & Tension & 127.5 & 1.53 & Compression & 171.4 \\
$\mathbf{2 0}$ & 1.44 & Tension & 127.5 & 1.52 & Compression & 171.5 \\
$\mathbf{3 0}$ & 1.40 & Tension & 127.7 & 1.50 & Compression & 171.6 \\
$\mathbf{4 0}$ & 1.35 & Tension & 127.8 & 1.46 & Compression & 171.8 \\
$\mathbf{5 0}$ & 1.30 & Tension & 127.9 & 1.43 & Compression & 171.9 \\
$\mathbf{7 0}$ & 1.27 & Tension & 128.0 & 1.41 & Compression & 172.0 \\
$\mathbf{1 0 0}$ & 1.22 & Tension & 128.2 & 1.37 & Compression & 172.2 \\
\hline
\end{tabular}

Source: BARBOSA and BITTENCOURT, 2019 - Adapted

Tables 4.7 and 4.8, in turn, display the stresses $f_{f}$ and $f_{c}$ in MPa, referring to the tensile stress in the reinforcement and the highest concrete compressive stress, respectively. The GFRP creep coefficient $\beta$ and the effective modulus $E_{f, e f f}$ in GPa for the period $t_{i+1}$ are also displayed. If $\mathrm{f}_{\mathrm{f}}>0.6 \mathrm{f}_{\mathrm{fu}}$, GFRP is vulnerable to sudden creep rupture, assumption based on the experimental work conducted by Budelman and Rotasy (1993), as previously described. Thus, if $\mathrm{f}_{\mathrm{f}}>0.6 \mathrm{f}_{\mathrm{fu}}$, its value will be marked with a strikethrough. The same applies if $f_{c}>0.5\left(0.85 f_{c k}\right)$, suggesting that concrete exhibits non-linear behavior for the momenr $M_{a p c}$. Figure 4.9 illustrates changes in permanent deflections $v_{a p c}$ over the years, while Figure 4.10 shows variations in deflections caused by accidental loads, also modified by the long-term effects: 
Table 4.7 - Long term concrete and GFRP stresses for the scenarios I, II and III

\begin{tabular}{ccccccccccccc}
\hline \multirow{2}{*}{$\mathbf{t}$} & \multicolumn{4}{c}{ Scenario I } & \multicolumn{4}{c}{ Scenario II } & \multicolumn{4}{c}{ Scenario III } \\
\cline { 2 - 13 } & $\mathbf{f}_{\mathbf{f}}$ & $\mathbf{f}_{\mathbf{c}}$ & $\boldsymbol{\beta}$ & $\mathbf{E}_{\mathbf{f}, \text { eff }}$ & $\mathbf{f}_{\mathbf{f}}$ & $\mathbf{f}_{\mathbf{c}}$ & $\boldsymbol{\beta}$ & $\mathbf{E}_{\mathbf{f}, \text { fff }}$ & $\mathbf{f}_{\mathbf{f}}$ & $\mathbf{f}_{\mathbf{c}}$ & $\boldsymbol{\beta}$ & $\mathbf{E}_{\mathbf{f}, \text { fff }}$ \\
\hline $\mathbf{0}$ & 165.0 & 5.1 & 85.3 & 37.7 & 157.6 & 13.6 & 74.4 & 38.0 & 186.6 & 16.9 & 120.8 & 36.8 \\
$\mathbf{5}$ & 165.0 & 2.5 & 85.5 & 34.5 & 157.7 & 8.7 & 74.6 & 35.0 & 186.8 & 11.4 & 121.2 & 33.1 \\
$\mathbf{1 0}$ & 165.0 & 2.6 & 85.2 & 31.7 & 157.6 & 8.8 & 74.5 & 32.4 & 186.7 & 11.7 & 121.0 & 30.0 \\
$\mathbf{2 0}$ & 165.0 & 2.6 & 85.2 & 29.4 & 157.7 & 9.0 & 74.6 & 30.1 & 186.6 & 12.0 & 120.9 & 27.3 \\
$\mathbf{3 0}$ & 165.0 & 2.7 & 85.3 & 27.3 & 157.6 & 9.2 & 74.4 & 28.1 & 186.6 & 12.3 & 120.8 & 25.1 \\
$\mathbf{4 0}$ & 165.0 & 2.8 & 85.3 & 25.5 & 157.7 & 9.5 & 74.6 & 26.4 & 186.6 & 12.7 & 120.9 & 23.3 \\
$\mathbf{5 0}$ & 165.0 & 2.9 & 85.3 & 23.9 & 157.7 & 9.7 & 74.6 & 24.8 & 186.6 & 13.1 & 120.9 & 21.6 \\
$\mathbf{7 0}$ & 165.0 & 3.0 & 85.3 & 22.4 & 157.7 & 9.9 & 74.6 & 23.3 & 186.6 & 13.4 & 120.8 & 20.0 \\
$\mathbf{1 0 0}$ & 165.0 & 3.1 & 85.3 & 21.1 & 157.7 & 10.2 & 74.6 & 22.0 & 186.6 & 13.8 & 120.9 & 18.7 \\
\hline
\end{tabular}

Source: BARBOSA and BITTENCOURT, 2019 - Adapted

Table 4.8 - Long term concrete and GFRP stresses for the scenarios IV and V

\begin{tabular}{ccccccccc}
\hline \multirow{2}{*}{$\mathbf{t}$} & \multicolumn{4}{c}{ Scenario IV } & \multicolumn{5}{c}{ Scenario $\mathbf{~}$} \\
\cline { 2 - 9 } & $\mathbf{f}_{\mathbf{f}}$ & $\mathbf{f}_{\mathbf{c}}$ & $\boldsymbol{\beta}$ & $\mathbf{E}_{\mathbf{f}, \text { eff }}$ & $\mathbf{f}_{\mathbf{f}}$ & $\mathbf{f}_{\mathbf{c}}$ & $\boldsymbol{\beta}$ & $\mathbf{E}_{\mathbf{f}, \text { eff }}$ \\
\hline $\mathbf{0}$ & 153.0 & 16.7 & 68.0 & 38.1 & 123.2 & 16.4 & 33.1 & 39.4 \\
$\mathbf{5}$ & 153.1 & 11.2 & 68.1 & 35.4 & 123.4 & 11.0 & 33.3 & 37.5 \\
$\mathbf{1 0}$ & 153.0 & 11.3 & 68.0 & 32.8 & 123.3 & 11.0 & 33.2 & 35.7 \\
$\mathbf{2 0}$ & 153.0 & 11.5 & 68.1 & 30.6 & 123.3 & 11.1 & 33.3 & 34.1 \\
$\mathbf{3 0}$ & 153.0 & 11.7 & 68.1 & 28.7 & 123.4 & 11.2 & 33.3 & 32.6 \\
$\mathbf{4 0}$ & 153.0 & 12.0 & 68.1 & 27.0 & 123.2 & 11.4 & 33.1 & 31.3 \\
$\mathbf{5 0}$ & 153.0 & 12.3 & 68.1 & 25.4 & 123.2 & 11.5 & 33.1 & 30.0 \\
$\mathbf{7 0}$ & 153.0 & 12.5 & 68.1 & 23.9 & 123.3 & 11.6 & 33.2 & 28.7 \\
$\mathbf{1 0 0}$ & 153.0 & 12.8 & 68.1 & 22.6 & 123.2 & 11.8 & 33.1 & 27.5 \\
\hline
\end{tabular}

Source: BARBOSA and BITTENCOURT, 2019 - Adapted

Figure 4.9 - Changes in deflections $v_{a p c}$

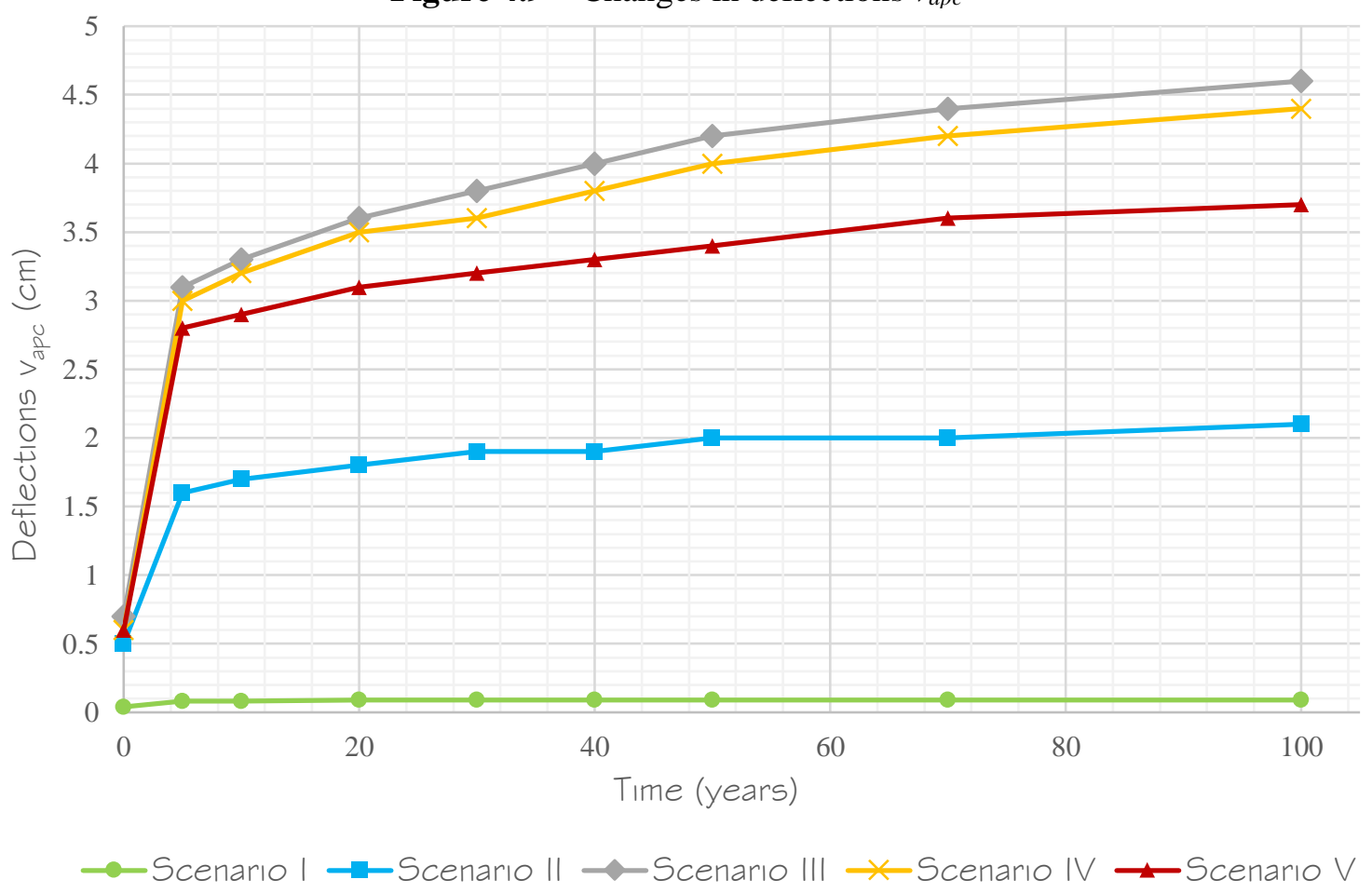

Source: BARBOSA and BITTENCOURT, 2019 


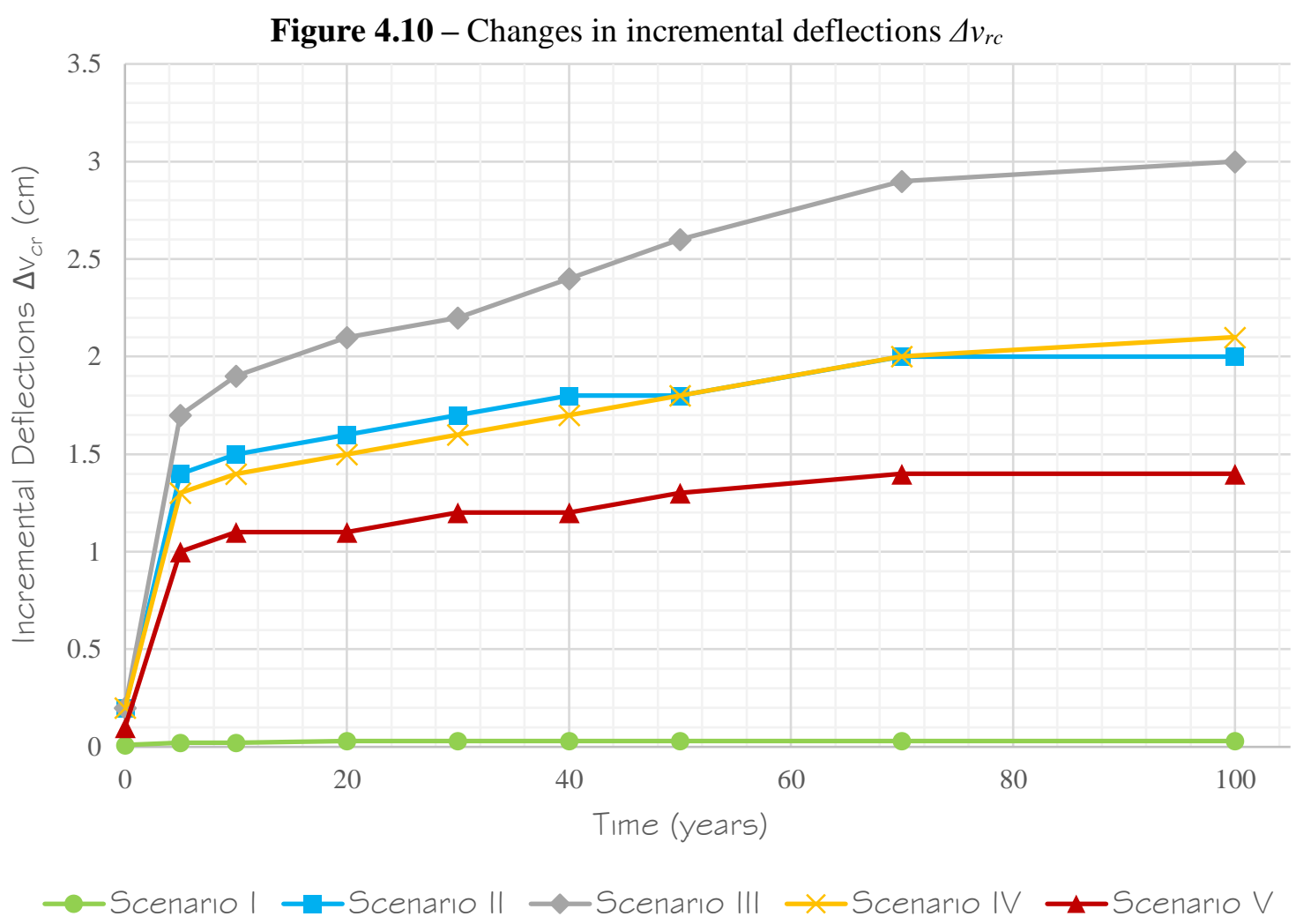

Source: BARBOSA and BITTENCOURT, 2019

Figure 4.11, in turn, shows the variations in crack widths, considering all changes in concrete and GFRP properties estimated for all reference periods:

Figure 4.11 - Variations in crack widths

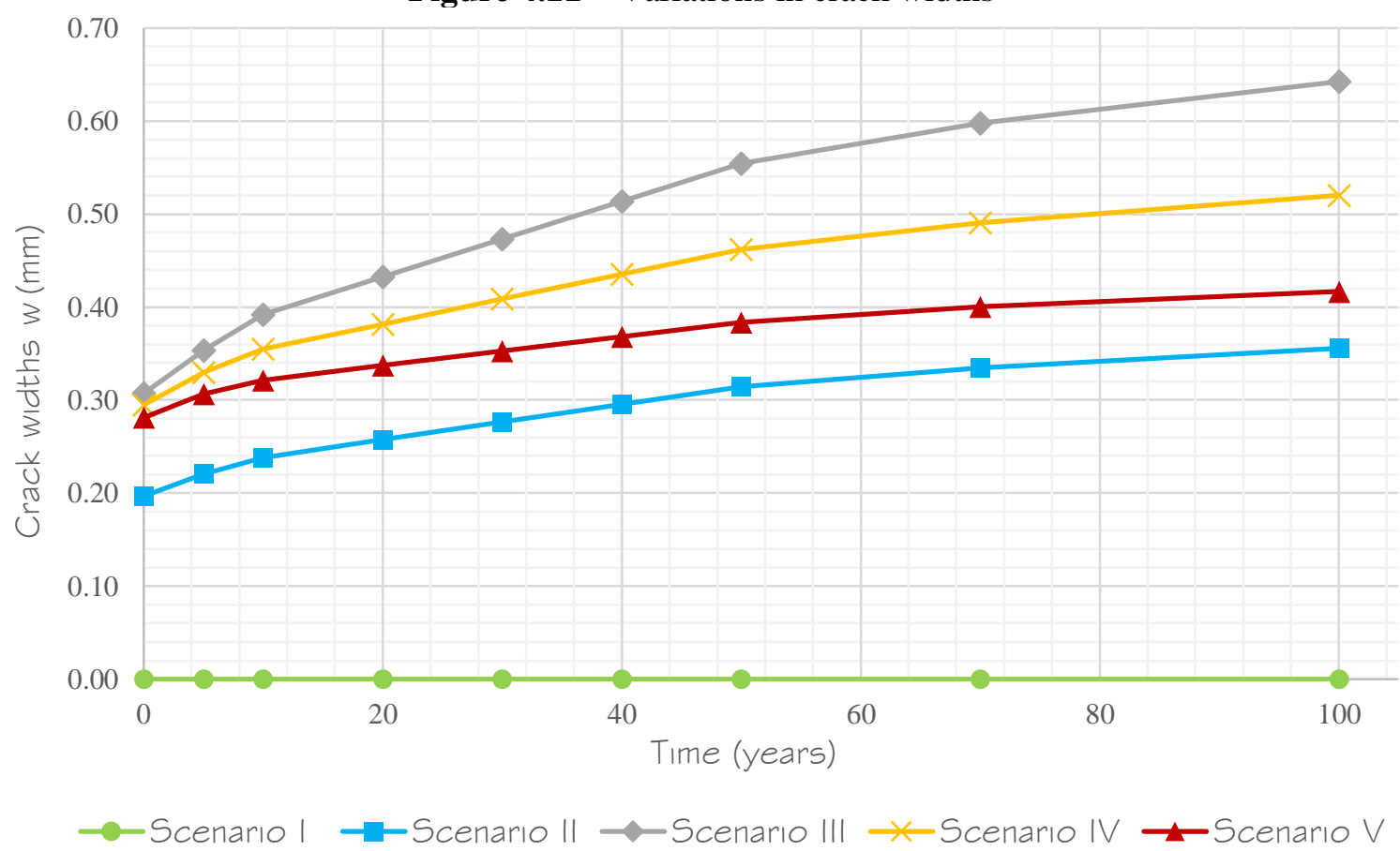

Source: BARBOSA and BITTENCOURT, 2019 
Finally, Figures 4.12 to 4.16 illustrate changes in the moment-curvature relationships, for the short-term response and reference periods of 10, 20 and 50 years:

Figure 4.12 - Moment-curvature relationships for the Scenario I, whereby $\rho_{f}=\rho_{\mathrm{fmin}}$

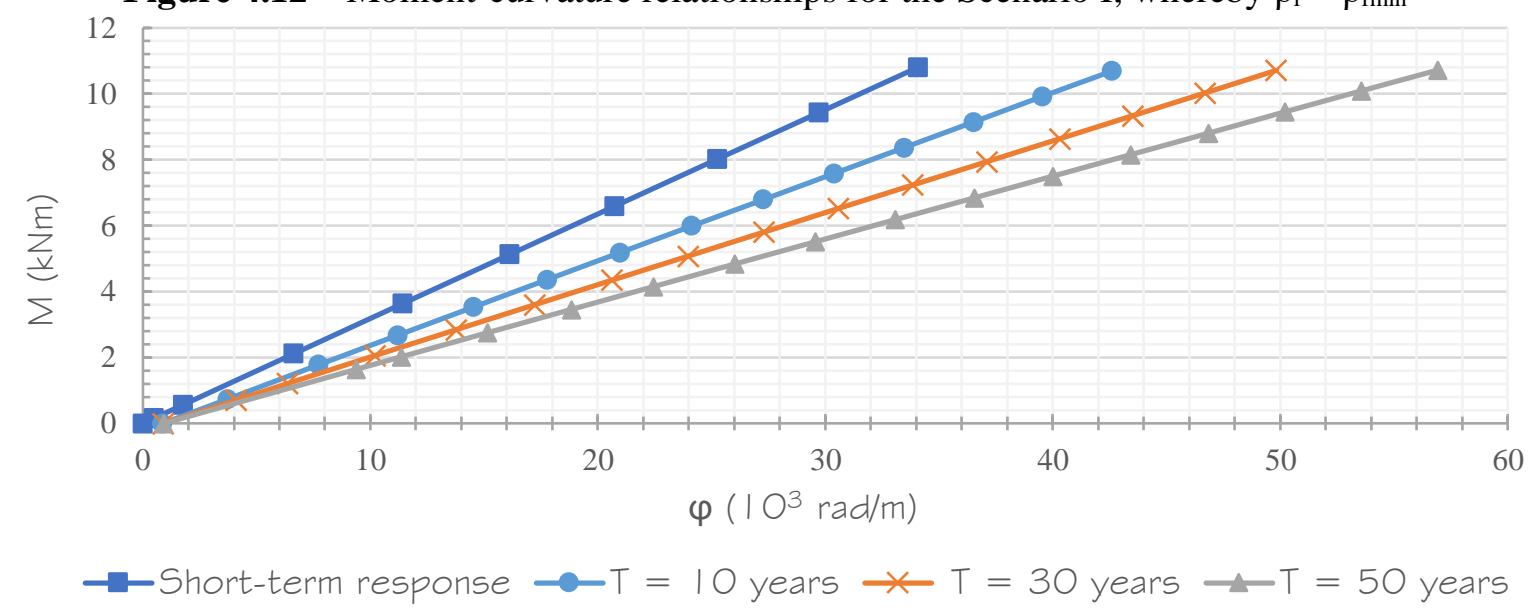

Source: BARBOSA and BITTENCOURT, 2019

Figure 4.13 - Moment-curvature relationships for the Scenario II, whereby $\rho_{\mathrm{f}}=0.85 \rho_{\mathrm{fb}}$

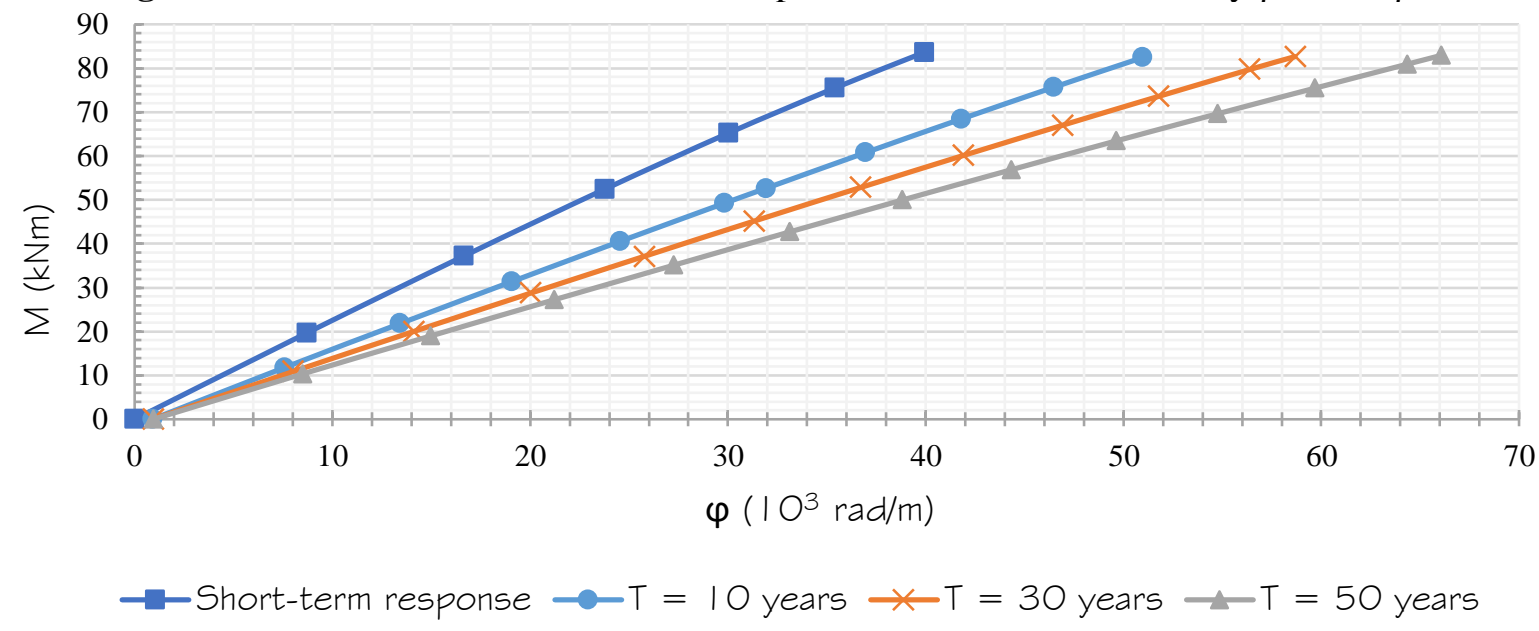

Source: BARBOSA and BITTENCOURT, 2019

Figure 4.14 - Moment-curvature relationships for the Scenario III, whereby $\rho_{\mathrm{f}}=\rho_{\mathrm{fb}}$

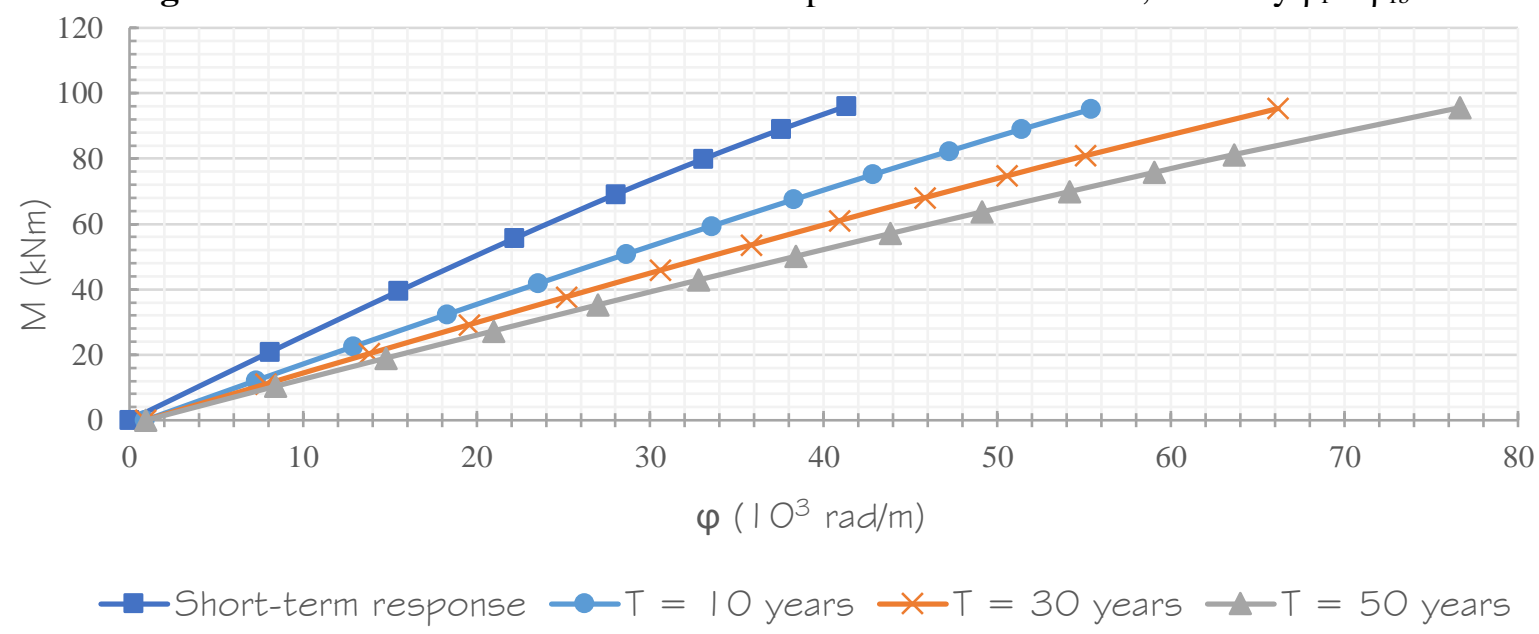

Source: BARBOSA and BITTENCOURT, 2019 
Figure 4.15 - Moment-curvature relationships for the Scenario IV, whereby $\rho_{\mathrm{f}}=1.5 \rho_{\mathrm{fb}}$

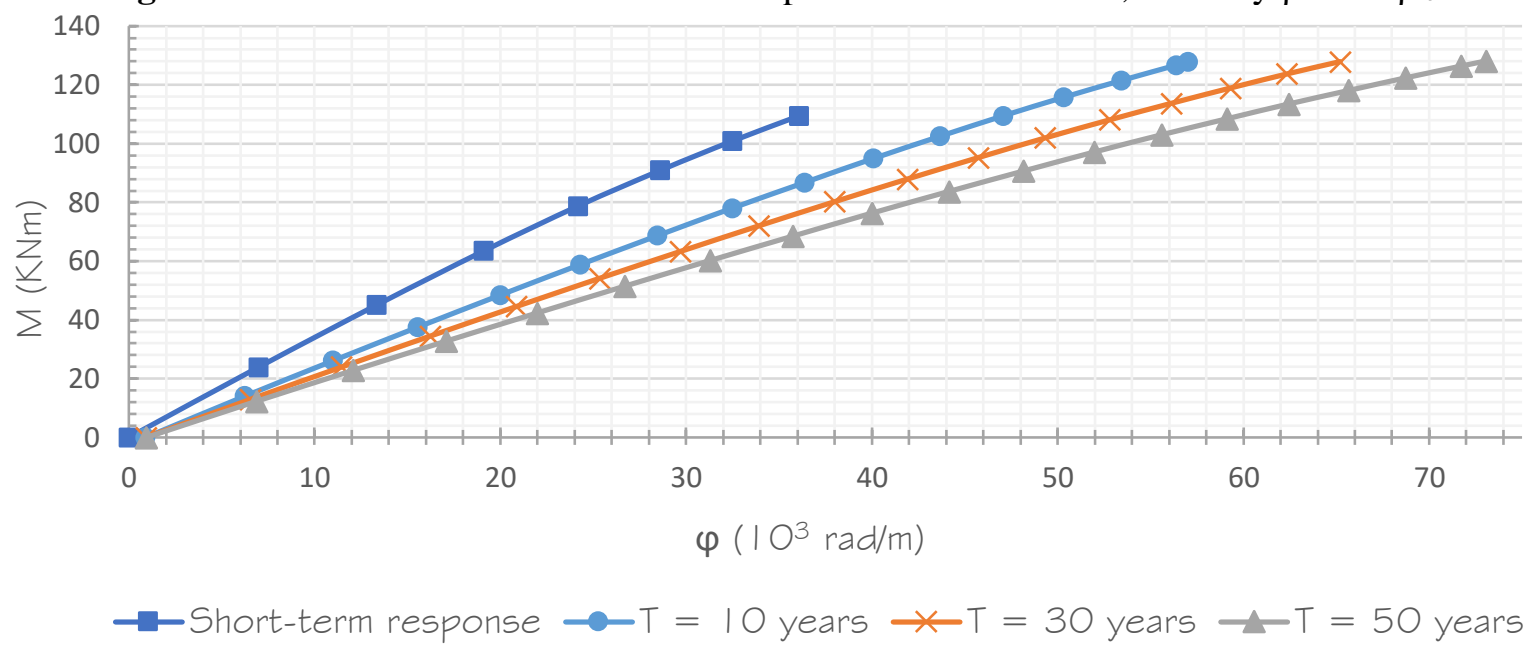

Source: BARBOSA and BITTENCOURT, 2019

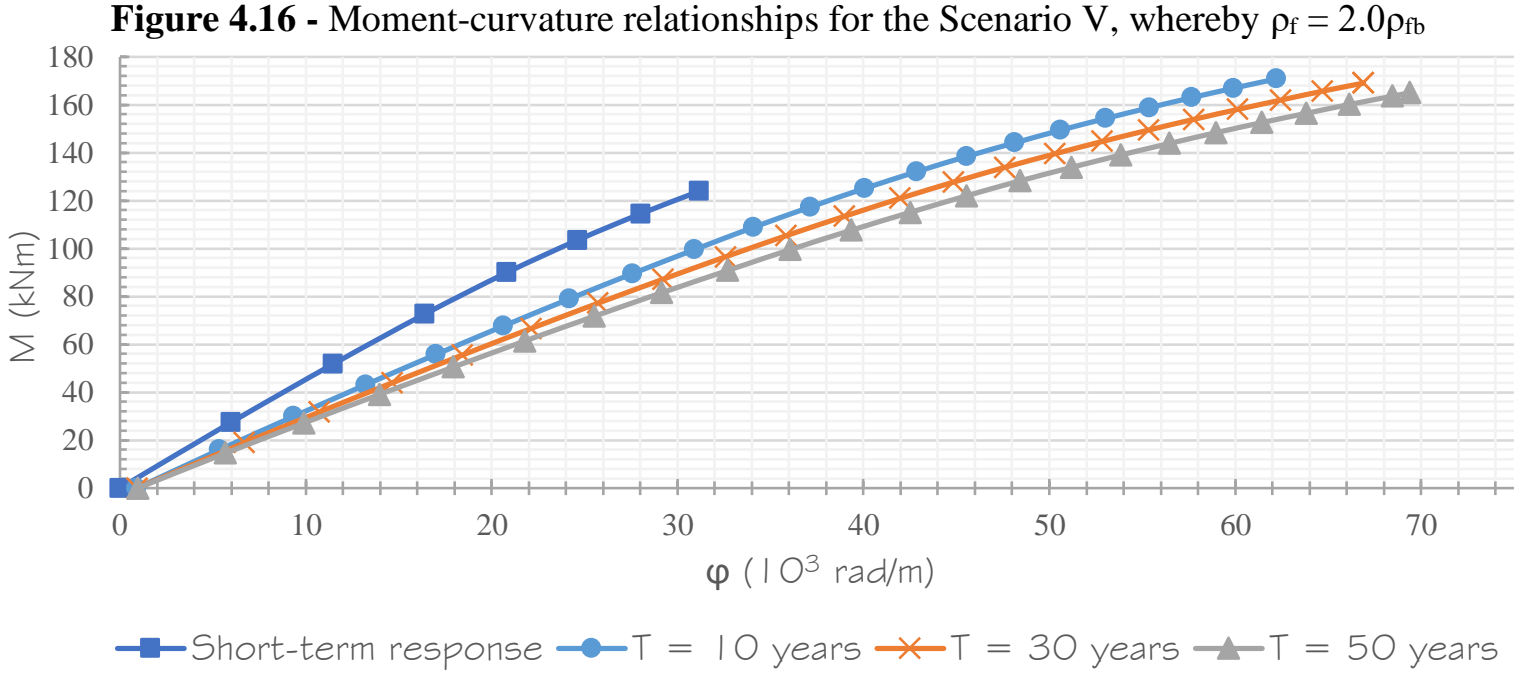

Source: BARBOSA and BITTENCOURT, 2019

\subsection{Discussion}

Regarding flexural strengths, the results showed considerable increases during the first five years, as shown in Tables 4.5 and 4.6. Additionally, there is a $63.74 \%$ decrease in the concrete elasticity modulus due to creep effects. As a result, the concrete strains $\varepsilon_{c 2, e f f}$ and $\varepsilon_{c u, e f f}$ increased in a higher proportion compared to the GFRP ultimate strain $\varepsilon_{f u, e f f}$, also modified by the creep properties of the non-metallic reinforcement. Therefore, cross-sections that were initially compression-controlled for $t_{i}=0$ became tension-controlled after the long-term effects took place, exhibiting higher flexural strengths and larger curvatures, as illustrated in Figures 4.15 and 4.16 (BARBOSA and BITTENCOURT, 2019). 
Furthermore, the strains due to shrinkage and thermal variations contributed for the increase of the balanced reinforcement ratio $\rho_{f b}$,eff during the first five years. Thenceforth, it started to decrease since these strains remain constant for the purposes of this numerical analysis, whereas the strains $\varepsilon_{c 2, \text { eff }}$ and $\varepsilon_{c u \text {,eff }}$ continued to increase, resulting in small neutral axis depths, overstressing the GFRP rebars and keeping the compressive stresses low (BARBOSA and BITTENCOURT, 2019).

Considering reference periods longer than five years, flexural strengths did not show significant increases; however, the structural member failure is preceded by very large curvatures compared to the short-term response. According to Shield (2009), previous versions of ACI 440 (2006) considered that compression-controlled cross-sections were preferable for design purposes since, unlike FRP, concrete exhibits some plateau, providing ductility to the structural element. Thus, only the cross-sections corresponding to the scenarios III, IV and IV would be ductile, considering the short-term response. However, since the long-term effects made the cross-sections III and IV become under-reinforced, they turned out to be fragile, since the GFRP rebars fail before the concrete reaches its ultimate strain. This concept of ductility is controversial because the cross-sections III and IV exhibited excessive deflections and cracking prior to failure, providing some warning with respect to the structural conditions. Moreover, for all numerical analyses, the relative neutral axis depth $x / d$ remained under the ductility limit of 0.45 established by ABNT NBR 6118 (2014) as regards conventional steel combined to a normal strength concrete (BARBOSA and BITTENCOURT, 2019).

Regarding the sustained tensile stress in the reinforcement, the numerical analysis showed that creep rupture is unlikely to occur because all the stresses levels $f_{f s} / f_{f u}$ remained under $60 \%$ considering all the scenarios and reference periods. In contrast, only the crosssection corresponding to the Scenario I did not show a concrete compressive stress higher than $50 \%$ of $0.85 f_{c k}$ for the short-term response. Nonetheless, once the long-term effects were considered, the compressive stress levels fell below the limit of linearity, increasing again only for the scenario III, as regards the reference periods of 50, 70 and 100 years; and for the scenario II, at 100 years. It is important to check if the compressive stresses remain under $50 \%$ of $0.85 f_{c k}$, since higher stresses indicate concrete non-linear behavior, which means the analysis to calculate deflections, crack widths and FRP sustained stresses may no longer apply. (BARBOSA and BITTENCOURT, 2019).

In turn, Figures 4.9 and 4.10 show that deflections due to almost permanent load combinations $v_{a p c}$ increased in a range of 100 to $400 \%$, while incremental deflections due to accidental loads $v_{c r}$, in a range of 100 to $950 \%$ during the first five years, considering different 
reinforcement ratios. The numerical evaluation also showed that, for $t_{i}=5$ years, the deflections $v_{p a c}$ regarding the scenarios III, IV and V exceeded the maximum allowed of L/250, established by the Brazilian code. Moreover, the deflections $v_{r c}$ concerning the scenarios II, III and IV exceeded the maximum of L/350, for the same reference period. Since the service moment $M_{a p c}$ regarding the Scenario I is smaller than the cracking moment $M_{c r}$, the cross-sections did not exhibit cracking, which means that, numerically, the effective moment of inertia remained the same for the entire structural life, leading to small variations in deflections compared to the other scenarios (BARBOSA and BITTENCOURT, 2019).

Regarding variations in crack widths, only the cross-section for the Scenario I did not show cracking, which is reflected in its moment-curvature relationship, essentially linear for all reference periods. Conversely, the other cross-sections showed higher increase ratio of their crack widths during the first ten years, followed by a steady and slighter growth ratio from ten to fifty years. Finally, this rate decreases seeing that concrete stops losing stiffness; therefore, the stress in the reinforcement tends to increase in a lower ratio or even, decrease, contributing to the cracking stabilization (BARBOSA and BITTENCOURT, 2019). 


\section{Chapter 5 - Numerical Assessment of FRP Prestressed Members}

The design analysis described in Chapter 3 showed that computing the FRP reinforcement area to meet only the ultimate limit state for flexure results in elevated sustained stresses, as well as, excessive deflections and crack widths. Therefore, in order to meet the creep rupture and the serviceability limit states, the reinforcement areas had to be increased. Consequently, some cross-sections became over-reinforced, which means that only a small portion of the FRP tensile strength is utilized, characterizing waste of its material mechanical properties. Moreover, over-reinforcing cross-sections resulted in smaller curvatures regarding the ultimate limit state, inferring poor ductility of the structural member.

In order to avoid over-reinforced cross-sections with poor ductility and waste of FRP mechanical properties, using the non-metallic reinforcement in pre-tensioning could yield better results since its high tensile strength would lead to high compressive forces in concrete, while the low elasticity modulus to large strains compared to relaxation losses, concrete creep and shrinkage, etc.

This chapter presents a comparative numerical analysis regarding the structural behavior of AFRP, CFRP and steel CP 190 RB prestressed concrete members, combined to a normal strength concrete with grade C30 and a high-performance concrete with grade C70. For each combination, two structural members were modeled: a prismatic concrete bar subjected only to axial forces, and a simply supported beam subjected to uniformly distributed loads. The results corresponding to this part of the research were published at the $61^{\circ}$ Brazilian Concrete Conference with the title Structural Behavior Analysis of Prestressed Concrete Reinforced with Fiber-Reinforced Polymer Tendons (BARBOSA, BITTENCOURT and WELTER, 2019).

\subsection{Design Procedures and Modelling}

Initially, three prismatic concrete members were modelled with dimensions $30 \times 30 \mathrm{~cm}^{2}$, considering AFRP, CFRP and steel CP190 RB for both concrete grades. The simply supported beam with dimensions $15 \times 70 \mathrm{~cm}^{2}$ and span length of $8 \mathrm{~m}$ also had their reinforcement areas and jacking loads computed for all reinforcement-concrete grade combinations. The design and numerical analysis considered the ABNT NBR 6118 (2014) constitutive models for concrete, while for steel CP190 RB and FRP, the constitutive equations and parameters were obtained from ABNT NBR 7483 (2008) and ACI 440 4R-04 (2004), respectively. 
Tables 5.1 and 5.2 present the mechanical properties of reinforcement and concrete grades considered for the analysis, where $E_{p}$ and $E_{c t}$ refer to the reinforcement and concrete elasticity modules, respectively. The terms $f_{p u}$ and $\varepsilon_{p u}$, in turn, correspond to the FRP tensile strength and ultimate strain, respectively, whereas the steel yield stress and strain are designated by $f_{p y k}$ and $\varepsilon_{p y k}$, respectively. For the purposes of this numerical analysis, the concrete and steel strengths were reduced by safety factors of 1.4 and 1.15 , respectively; in compliance with ABNT NBR 6118 (2014). Regarding AFRP and CFRP tendons, the reduction safety factors $\Upsilon_{f}$ were 1.43 and 1.18, respectively, in accordance with ACI 440 4R-04 (2004).

Table 5.1 - Reinforcement mechanical properties

\begin{tabular}{ccccccccc}
\hline Reinforcement & $\begin{array}{c}\mathbf{E}_{\mathbf{p}} \\
(\mathbf{G P a})\end{array}$ & $\begin{array}{c}\mathbf{f}_{\mathbf{p u}} \\
(\mathbf{M P a})\end{array}$ & $\begin{array}{c}\mathbf{f}_{\text {pyk }} \\
(\mathbf{M P a})\end{array}$ & $\boldsymbol{\Upsilon}_{\mathbf{f}}$ & $\begin{array}{c}\mathbf{f}_{\text {pud }} \\
(\mathbf{M P a})\end{array}$ & $\begin{array}{c}\mathbf{f}_{\text {pyd }} \\
(\mathbf{M P a})\end{array}$ & $\begin{array}{c}\boldsymbol{\varepsilon}_{\text {pyd }} \\
(\mathbf{\%})\end{array}$ & $\begin{array}{c}\boldsymbol{\varepsilon}_{\text {pud }} \\
(\%)\end{array}$ \\
\hline Steel & 200 & 1900 & 1710 & 1.15 & 1652.2 & 1487.0 & 7.43 & 30.4 \\
AFRP & 70 & 1430 & - & 1.43 & 1001.0 & - & - & 14.3 \\
CFRP & 137 & 2220 & - & 1.18 & 1887.0 & - & - & 13.8 \\
\hline
\end{tabular}

Source: BARBOSA, BITTENCOURT and WELTER, 2019

Table 5.2 - Concrete Properties according to ABNT NBR 6118 (2014)

\begin{tabular}{ccccccccc}
\hline \multirow{2}{*}{ Grade } & $\begin{array}{c}\mathbf{f}_{\text {ck }} \\
(\mathbf{M P a})\end{array}$ & $\begin{array}{c}\mathbf{E}_{\text {ct }} \\
(\mathbf{G P a})\end{array}$ & $\begin{array}{c}\mathbf{f}_{\text {ctk }} \\
(\mathbf{M P a})\end{array}$ & $\begin{array}{c}\mathbf{f}_{\text {cd }} \\
(\mathbf{M P a})\end{array}$ & $\begin{array}{c}\mathbf{f}_{\text {ctd }} \\
(\mathbf{M P a})\end{array}$ & $\begin{array}{c}\boldsymbol{\varepsilon}_{\text {c2 }} \\
\mathbf{( \% o )}\end{array}$ & $\begin{array}{c}\boldsymbol{\varepsilon}_{\text {cu }} \\
(\mathbf{\% o})\end{array}$ & $\begin{array}{c}\boldsymbol{\varepsilon}_{\text {ctlim }} \\
(\mathbf{\% o})\end{array}$ \\
\hline $\mathbf{C 3 0}$ & 30 & 30.67 & 2.03 & 21.43 & 1.45 & 2.00 & 3.50 & 0.15 \\
$\mathbf{C 7 0}$ & 70 & 43.44 & 3.21 & 50.00 & 2.29 & 2.42 & 2.66 & 0.15 \\
\hline
\end{tabular}

Source: BARBOSA, BITTENCOURT and WELTER, 2019 - Adapted

\subsubsection{Modelling of the axially loaded members}

Figure 5.1 illustrates the axially loaded member, for which the prestressing reinforcement was calculated in order to provide the same ultimate tensile force $N_{u}$ for all six combinations of reinforcement and concrete grades. Furthermore, it was assumed that concrete is completely cracked at the ultimate limit state, not contributing to the prismatic member capacity. The jacking stress $f_{p j}$, in turn, was determined so that the prestressing strains $\varepsilon_{p j}$ were the same for all combinations, without exceeding the stress limits imposed by ABNT NBR 6118 (2014) and ACI 440 4R-04 (2004) for steel and FRP, respectively.

Figure 5.1 - Prismatic member subjected only to axial loads

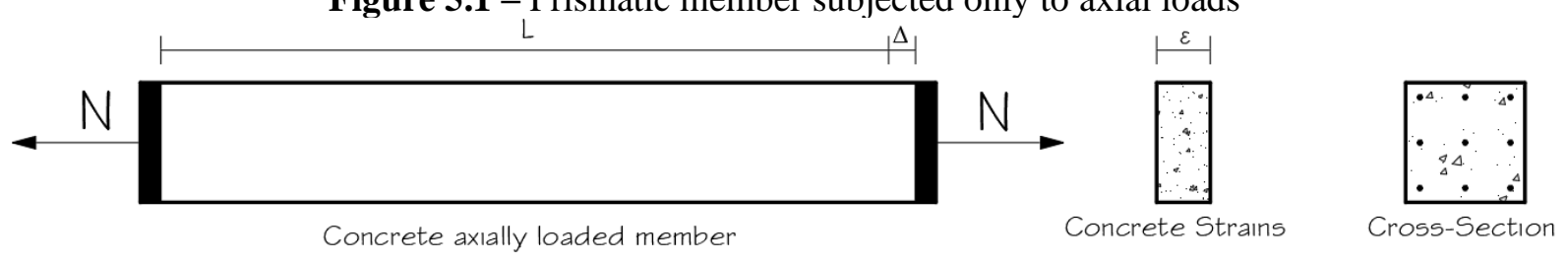

Source: COLLINS and MITCHELL, 1987 - Adapted 
The calculation of AFRP and CFRP areas was based on the imposed area for the steel CP $190 \mathrm{RB}$ RC member, consisting of nine strands of $12.5 \mathrm{~mm}$ in diameter each. Therefore, the ultimate tensile capacity $N_{\mathrm{u}}$ of this section is given by the product of the reinforcement area $A_{p}$ and the steel design tensile strength $f_{\text {pud. }}$. Since all combinations must have the same capacity, the AFRP and CFRP areas are determined dividing $N_{u}$ by their respective design strengths. Figure 5.2 illustrates the cross-section detailing for each reinforcement type:

Figure 5.2 - Cross-section detailing of the prismatic members

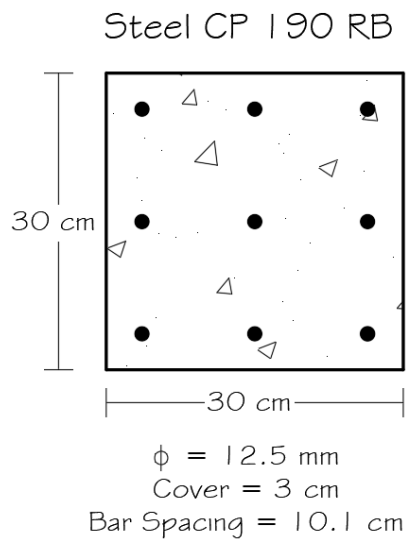

AFRP (Aramid)

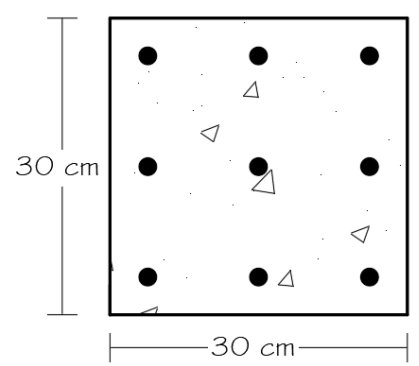

$\phi=16 \mathrm{~mm}$

Cover $=3 \mathrm{~cm}$

Bar spacing $=9.6 \mathrm{~cm}$
CFRP (Carbon)

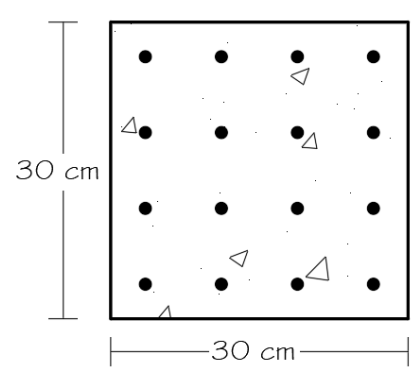

$\phi=10 \mathrm{~mm}$

Cover $=3 \mathrm{~cm}$

Bar spacing $=6.7 \mathrm{~cm}$

Source: BARBOSA, BITTENCOURT and WELTER, 2019

The step ahead was to compute the jacking force $P_{0}$. According to ACI $4404 \mathrm{R}-04$ (2004), steel is commonly subjected to jacking stresses $f_{p j}$ of $85 \%$ of its yield stress, while for AFRP and CFRP, $f_{p j}$ must not exceed 50 and $65 \%$ of the tensile strength, respectively. By imposing the steel jacking stress of $0.85 f_{p y d}$, the prestressing strain $\varepsilon_{p j}$ corresponds to $6.32 \%$. Therefore, for the AFRP and CFRP strands to present this elongation, the stresses at jacking must be 442.4 and $865.8 \mathrm{MPa}$, respectively, which are lower than the maximum allowed.

By imposing compatibility conditions, the strain in the reinforcement $\varepsilon_{p}$ corresponds to the sum of the concrete strain $\varepsilon_{c}$ and the prestressing strain $\varepsilon_{p j}$ :

$$
\varepsilon_{p}=\varepsilon_{c}+\varepsilon_{p j}
$$

Therefore, Equation 5.2 defines the axial force $N$ for each arbitrated strain $\varepsilon_{c}$ as the sum relating to the contributions of both materials. Compressive stresses and strains are entered with negative values, whereas for tension, they are positive.

$$
N=f_{c} A_{c}+f_{p} A_{p}
$$

In Equation 5.2, the stresses in concrete $f_{c}$ were obtained from three different constitutive models. If $\varepsilon_{\mathrm{c} 2} \leq \varepsilon_{c} \leq 0$, the compressive stresses were determined according to Equation 2.15. 
Conversely, the constitutive model defined by the item 8.2.10.2 of ABNT NBR 6118 (2014) and described by Equations 5.3 and 5.4 is used to determine the tensile stresses. This model is valid only for tensile strains smaller than $\varepsilon_{c t l i m}$, at which cracking begins. Therefore, according to the Brazilian code, the tensile stresses $f_{c}$ prior to cracking are computed as follows:

$$
\begin{array}{cc}
f_{c}=E_{c t} \varepsilon_{c} & \text { if } 0<\varepsilon_{c} \leq 0.9 \frac{f_{c t d}}{E_{c t}} \\
f_{c}=f_{c t d}\left[0.9+0.1\left(\frac{\varepsilon_{c}-0.9 f_{c t d} / E_{c t}}{\varepsilon_{c t l i m}-0.9 f_{c t d} / E_{c t}}\right)\right] & \text { if } 0.9 \frac{f_{c t d}}{E_{c t}}<\varepsilon_{c} \leq \varepsilon_{c t l i m}
\end{array}
$$

According to Collins and Mitchell (1987), once concrete reaches its tensile strength, the first crack appears. Thenceforth, as other cracks develop, the contribution of concrete between cracks on the axial force $N$ gradually decreases. In order to account for the strength of concrete between cracks, the tension-stiffening model developed by Vecchio and Collins (1986) was used to compute the concrete contribution to tension $f_{t s}$ for $\varepsilon_{\mathrm{c}}>\varepsilon_{\mathrm{ctlim}}$ :

$$
f_{t s}=\frac{\alpha_{1} \alpha_{2} f_{c t d}}{1+\sqrt{500 \varepsilon_{c}}}
$$

In Equation 5.5, the parameter $\alpha_{1}$ accounts for bonding between concrete and reinforcement, corresponding to 0.7 for prestressing, whereas $\alpha_{2}$ relies on the load type, adopted as 1.0 for short-term monotonic loads (COLLINS and MITCHELL, 1987).

Figure 5.3 shows the concrete constitutive model adopted for this numerical analysis, which incorporates the stress-strain relationships defined by the Brazilian Code and the tensionstiffening model of Vecchio and Collins (1986):

Figure 5.3 - Concrete constitutive model adopted for tension

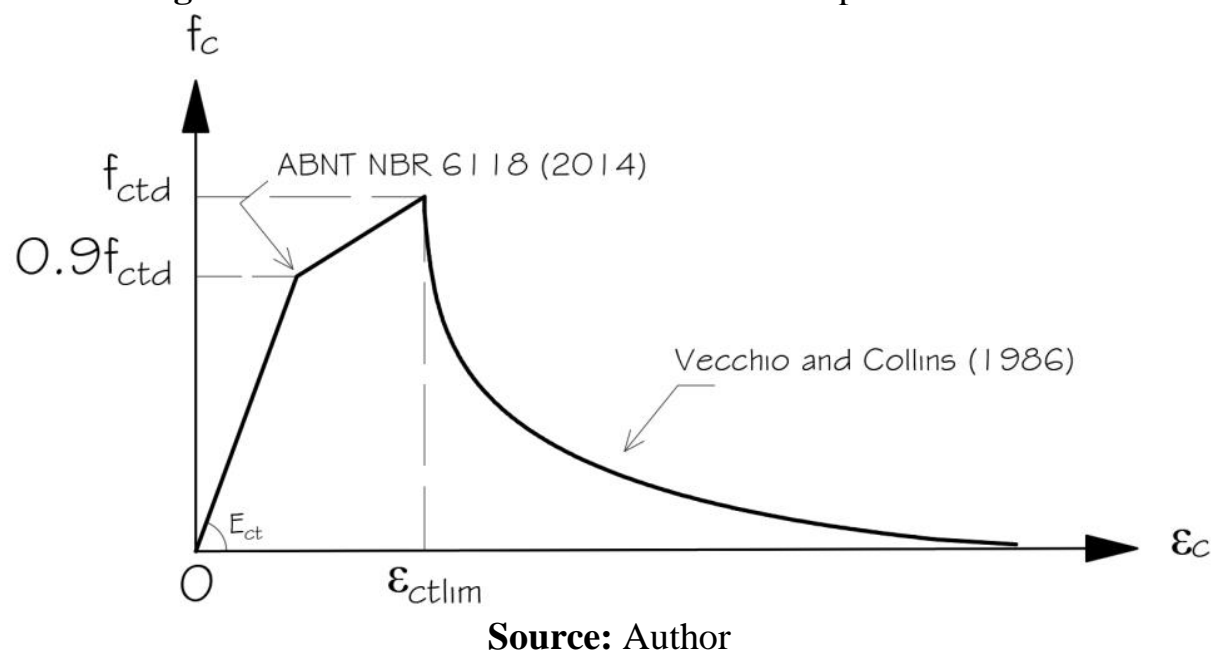


To compute crack widths $w$, the cracking model of ABNT NBR 6118 (2014) is used:

$$
w=\frac{\phi_{i}}{12,5 \eta_{1}} \varepsilon_{p i} \min \left[3 \frac{f_{p i}}{f_{c t m}} ;\left(\frac{4}{\rho_{r i}}+45\right)\right]
$$

In Equation 5.6, $\varepsilon_{p i}$ and $f_{p i}$ correspond to the incremental strain and stress, respectively, in relation to the member decompression. Furthermore, it was assumed for this numerical analysis that steel and FRP have similar bond properties. Therefore, for three to seven wire strands bonding well to concrete, the coefficient $\eta_{1}$ was taken as 1.2 in accordance with the item 9.3.2.2 of ABNT NBR 6118 (2014). Finally, charts relating the axial force $N$ and crack widths $w$ were plotted for the six reinforcement-concrete combinations.

\subsubsection{Modelling of the Simply Supported Beam}

The simply supported beam was also modelled for the six combinations of reinforcement types and concrete grades. Figures 5.4 and 5.5 illustrate the structural scheme of the beam and a generic detailing for its cross-section, respectively:

Figure 5.4 - Structural scheme of the evaluated beam

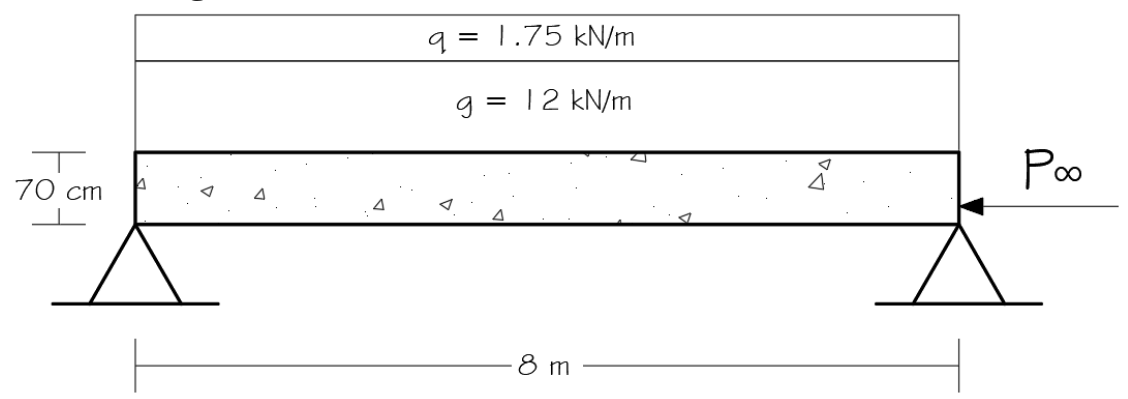

Source: BARBOSA, BITTENCOURT and WELTER, 2019

Figure 5.5 - Generic cross-section detailing

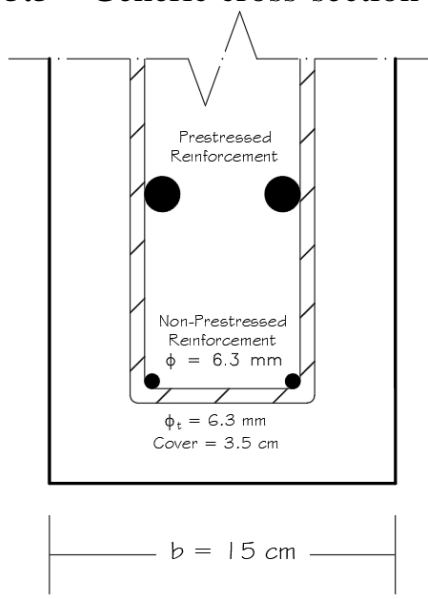

Source: BARBOSA, BITTENCOURT and WELTER, 2019 
Considering that the flexural member is located in an urban area, ABNT NBR 6118 (2014) establishes that the risk of deterioration due to steel corrosion is moderate, limiting prestressing to the Level 2, as imposed by Table 13.3 of the reference code. Thus, the design must meet the serviceability limit states regarding the crack formation for frequent load combinations, and decompression for almost permanent combinations.

The first step for the design was to estimate the force $P_{i, e s t}$, applied by the prestressing equipment. The initial eccentricity $e_{p i}$ was arbitrated as half of the beam depth $0.5 \mathrm{~h}$ minus the sum of the concrete cover $c$, diameter of stirrups $\phi_{t}$ and half of the flexural reinforcement diameter $\phi$, resulting in $\mathrm{e}_{\mathrm{pi}}=30.1 \mathrm{~cm}$. Moreover, the total prestressing losses were initially assumed as $30 \%$ of the jacking force $P_{i, \text { est }}$, as recommended by HANAI (2005). Equations 5.7 and 5.8 determine the minimum jacking force after losses $P_{\infty}$, required to meet the limit states for crack formation and decompression, respectively:

$$
\begin{gathered}
P_{\infty}=\left(1.5 f_{c t k}-\frac{M_{f c}}{W_{\text {inf }}}\right)\left(\frac{1}{A_{c}}+\frac{e_{p}}{W_{\text {inf }}}\right)^{-1} \\
P_{\infty}=-\frac{M_{a p c}}{W_{\text {inf }}}\left(\frac{1}{A_{c}}+\frac{e_{p}}{W_{\text {inf }}}\right)^{-1}
\end{gathered}
$$

The value of $P_{\infty}$ that met both limit states was chosen to proceed with the design. To compute the service bending moments $M_{a p c}$ and $M_{f c}$, the load combination coefficients $\psi_{1}$ and $\psi_{2}$ were 0.4 and 0.3, respectively, as recommended by ABNT NBR 6118 (2014) for residential building beams. Thus, at mid-span, $\mathrm{M}_{\mathrm{apc}}=100.2 \mathrm{kNm}$ and $\mathrm{M}_{\mathrm{fc}}=101.6 \mathrm{kNm}$. The cross-section geometrical properties $A_{c}$ and $W_{i n f}$ are $1050 \mathrm{~cm}^{2}$ and $12250 \mathrm{~cm}^{3}$, respectively. Accordingly, for concrete $\mathrm{C} 30, P_{\infty}$ corresponds to -154 and $-239.8 \mathrm{kN}$ as regards the crack formation and decompression limit state, whereas for concrete C70, these values are -102 and $-239.8 \mathrm{kN}$, respectively. Since the decompression limit state governs the design for both grades, the concrete mechanical properties did not affect the calculation of $P_{\infty}$, which assumed the same value for both concrete grades. Subtracting the total losses from $\left|P_{\infty}\right|$, the jacking load $P_{i, e s t}$ was found, corresponding to $342.65 \mathrm{kN}$.

If seven wire strands with $15.2 \mathrm{~mm}$ in diameter are used, the tensile strength $f_{p u}$ of steel $\mathrm{CP} 190 \mathrm{RB}$ corresponds to $1818 \mathrm{MPa}$ and the strand nominal area to $1.43 \mathrm{~cm}^{2}$. Moreover, the yield stress $f_{p y k}$ corresponds to approximately $0.9 f_{p u}$ (ABNT NBR 7483, 2008). The AFRP and CFRP tensile properties are described in Table 5.1. Following the ACI 440 4R-04 (2004) recommendations for jacking stresses $f_{p j}$, those were adopted as 0.5 and 0.65 of the AFRP and 
CFRP tensile strengths $f_{p u}$, respectively, and 0.85 of $f_{p y k}$ for steel. Thus, the reinforcement areas $A_{p}$ were determined dividing $P_{i, e s t}$ by $f_{p j}$ and adjusting for the nominal area of the strands. For steel and CFRP, two strands were used, totalizing an effective area $A_{p}$ of $2.87 \mathrm{~cm}^{2}$, while for AFRP, four strands were necessary, corresponding to an area of $5.74 \mathrm{~cm}^{2}$.

Once these areas are defined, it was necessary to adjust the jacking load so that the maximum jacking stresses $f_{p j}$ allowed by ACI could be applied. Therefore, the adjusted jacking load $P_{0}$ corresponds to the product of the effective area $A_{p}$ and the stress $f_{p j}$.

The next step was to compute the immediate losses due to anchoring displacements, friction and relaxation. For all reinforcement types, it was assumed that the anchoring displacements correspond to $6 \mathrm{~mm}$. According to Hanai (2005), the percentual loss due to anchoring movements is defined as the ratio between such displacement and the strand elongation. Regarding friction due to changes in strand slopes, Thomaz (2005) defines this percentual loss as $\Delta \mathrm{P}_{\mathrm{f}}=100\left(1-\mathrm{e}^{-0.21 \theta}\right)$, where $\theta$ is the reinforcement slope at the direction change location. In relation to the relaxation losses, Equations 2.7 and 2.8 determined the initial percentual losses for AFRP and CFRP, respectively, while for steel CP $190 \mathrm{RB}$, those losses were computed in accordance with the item 9.6.3.4.5 of ABNT NBR 6118 (2014), for which:

$$
\Psi(\Delta t)=\Psi_{1000}(0.024 \Delta t)^{0.15}
$$

In Equation 5.9, $\Psi_{1000}$ corresponds to the relaxation after 1000 hours at a $20{ }^{\circ} \mathrm{C}$ temperature, obtained from Table 8.4 of ABNT NBR 6118 (2014). Since this numerical analysis considered a low relaxation steel whose jacking stress $f_{p j}$ corresponds to $76.5 \%$ of the ultimate strength $f_{p u}, \Psi_{1000}=3.5$. Furthermore, considering a period $\Delta t$ of 30 days between the jacking stress application and the release of the strands, the initial relaxation losses were computed for the three reinforcement types. Therefore, the initial total loss $\Delta P_{i}$ is the sum of the three types of losses described above.

Therefore, it was possible to compute the jacking force $P_{a}$ after the initial losses. Since the application of the compressive force $-P_{a}$ causes an elastic strain in the concrete, this is deducted from the pre-existing reinforcement strain, characterizing more losses in prestressing (HANAI, 2005). Therefore, the compressive force $P_{l}$ after such losses was calculated through:

$$
P_{1}=P_{a} E_{c t}\left[A_{c}\left(\frac{1}{A_{p} E_{p}}-\frac{e_{p i}{ }^{2}}{I_{g}}\right)-1\right]
$$

Once $P_{1}$ was determined, the step ahead was the calculation of long-term losses, considering a life-span of fifty years. This numerical analysis accounted for concrete creep and 
shrinkage as well as reinforcement relaxation, for the reference period of $50 * 365-30=18,220$ days.

To estimate the creep coefficient $\Phi$, the Collins and Mitchell (1987) model described in Equation 4.3 was implemented. Considering $\mathrm{H}=75 \%, k$ is directly obtained from Figure 4.3, corresponding to 0.68 for the volume to surface area ratio of 6.2 related to the evaluated structural member. Therefore, the creep coefficient $\Phi$ is 1.48 . Losses due to shrinkage were assumed as $0.0006 E_{p}$, as recommended by ACI $4404 \mathrm{R}-04$ (2004). Table 5.3 describes the calculation of time-dependent parameters for all six reinforcement-concrete combinations, while Table 5.4 summarizes the determination of all losses and forces $P_{\infty}$.

Table 5.3 - Parameters for the calculation of time-dependent losses

\begin{tabular}{ccccccc}
\hline \multirow{2}{*}{ Parameters } & \multicolumn{2}{c}{ Steel CP 190 RB } & \multicolumn{2}{c}{ AFRP } & \multicolumn{2}{c}{ CFRP } \\
\cline { 2 - 7 } & $\mathbf{C 3 0}$ & $\mathbf{C 7 0}$ & $\mathbf{C 3 0}$ & $\mathbf{C 7 0}$ & $\mathbf{C 3 0}$ & $\mathbf{C 7 0}$ \\
\hline $\boldsymbol{\Delta} \mathbf{P}_{\text {sh }}(\mathbf{M P a})$ & 120 & 120 & 42 & 42 & 82.2 & 82.2 \\
$\boldsymbol{\Psi}(\mathbf{\%})$ & 8.71 & 8.71 & 19.6 & 19.6 & 2.18 & 2.18 \\
$\mathbf{E}_{\mathbf{p}, \text { eff }}(\mathbf{M P a})$ & 182.57 & 182.57 & 134.01 & 134.01 & 56.26 & 56.26 \\
$\mathbf{E}_{\text {ct,eff }}(\mathbf{M P a})$ & 12.36 & 17.51 & 12.36 & 17.51 & 12.36 & 17.51 \\
$\boldsymbol{\sigma}_{\mathbf{c p}}(\mathbf{M P a})$ & 3.0 & 3.0 & 3.4 & 3.4 & 4.8 & 4.8 \\
$\boldsymbol{\Delta} \boldsymbol{\varepsilon}_{\text {cr }}(\mathbf{\% o})$ & 0.14 & 0.10 & 0.23 & 0.16 & 0.16 & 0.11 \\
\hline
\end{tabular}

In Table 5.3, $\Delta P_{s h}$ corresponds to the jacking stress loss due to concrete shrinkage, while $E_{p, e f f}$ refers to the reinforcement elasticity modulus adjusted for relaxation and $E_{c t, e f f}$, to the concrete modulus adjusted for creep. The concrete stress $\sigma_{c p}$ accounts for the long-term strain $\Delta \varepsilon_{c r}$ caused by the compressive force $P_{a}$ and the permanent bending moment $M_{g l}$ due to the beam self-weight. However, this strain was computed considering the effective concrete elasticity modulus $E_{c t, e f f}$.

Table 5.4 - Prestressing forces and losses

\begin{tabular}{|c|c|c|c|c|c|c|c|c|c|c|}
\hline \multirow[b]{2}{*}{ Reinforcement } & \multirow[b]{2}{*}{$\begin{array}{c}\mathbf{P}_{\mathbf{0}} \\
(\mathbf{k N})\end{array}$} & \multirow[b]{2}{*}{$\underset{(\mathbf{k N})}{\mathbf{P}_{\mathbf{a}}}$} & \multicolumn{4}{|c|}{ Concrete C30 } & \multicolumn{4}{|c|}{ Concrete C70 } \\
\hline & & & $\begin{array}{l}\Delta \mathbf{P}_{i} \\
(\%)\end{array}$ & $\begin{array}{c}-\mathbf{P}_{1} \\
(\mathbf{k N})\end{array}$ & $\begin{array}{l}\Delta \mathbf{P}_{\mathbf{p}} \\
(\%)\end{array}$ & $\begin{array}{c}-\mathbf{P}_{\infty} \\
(\mathbf{k N})\end{array}$ & $\begin{array}{l}\Delta \mathbf{P}_{i} \\
(\%)\end{array}$ & $\begin{array}{c}-\mathbf{P}_{1} \\
(\mathbf{k N})\end{array}$ & $\begin{array}{l}\Delta \mathbf{P}_{\mathrm{p}} \\
(\boldsymbol{\%})\end{array}$ & $\begin{array}{c}-\mathbf{P}_{\infty} \\
(\mathbf{k N})\end{array}$ \\
\hline Steel & 375.4 & 318.7 & 15.1 & 300.9 & 22.7 & 232.7 & 15.1 & 306.0 & 21.7 & 239.6 \\
\hline AFRP & 410.1 & 331.1 & 19.3 & 318.0 & 28.3 & 226.2 & 19.3 & 321.7 & 28.4 & 230.8 \\
\hline CFRP & 413.9 & 378.1 & 8.6 & 363.5 & 11.1 & 323.1 & 8.6 & 367.7 & 10.3 & 329.8 \\
\hline
\end{tabular}

Source: BARBOSA, BITTENCOURT and WELTER, 2019

Once the prestressing forces $P_{1}$ and $P_{\infty}$ were computed, the next step was to define the boundaries for the location of the prestressing reinforcement, so that all the limit states as regards the transfer of prestress TP and under services loads SL could be met. Therefore, $P_{1}$ must neither cause excessive compressive stresses at the cross-section bottom nor crack formation at the top. Moreover, the position of $P_{\infty}$ in relation to the cross-section center must 
be defined in a manner that the cross-section is entirely under compressive stresses and crack formation free for the bending moments $M_{a p c}$ and $M_{f c}$, respectively. Therefore, Equations 5.11, 5.12, 5.13 and 5.14 define the intervals of eccentricities $e_{p}$ meeting each of the limit states described above, following the order they were mentioned:

$$
\begin{gathered}
e_{p} \leq-\frac{W_{\text {inf }}}{P_{1}}\left(\frac{P_{1}}{A_{c}}+\frac{M_{g 1}}{W_{\text {inf }}}+0.6 f_{c k}\right) \\
e_{p} \leq-\frac{W_{\text {sup }}}{P_{1}}\left(\frac{P_{1}}{A_{c}}+\frac{M_{g 1}}{W_{\text {sup }}}-1.5 f_{c t k}\right) \\
e_{p} \geq-\frac{W_{\text {inf }}}{P_{\infty}}\left(\frac{P_{\infty}}{A_{c}}+\frac{M_{\text {apc }}}{W_{\text {inf }}}\right) \\
e_{p} \geq-\frac{W_{\text {inf }}}{P_{\infty}}\left(\frac{P_{\infty}}{A_{c}}+\frac{M_{f c}}{W_{\text {inf }}}-1.5 f_{c t k}\right)
\end{gathered}
$$

In Equations 5.11 and 5.12, $M_{g 1}$ corresponds to the bending moment caused by the beam self-weight considering $\Upsilon_{\mathrm{c}}=25 \mathrm{kN} / \mathrm{m}^{3}$ for concrete. The chosen interval is the one that meet both limit states regarding the transfer of prestress. The same applies for Equations 5.13 and 5.14 with respect to the application of service loads. Therefore, for each combination of reinforcement and concrete, there are two boundaries, one corresponding to the transfer of prestress and other accounting for the service loads. To compute the intervals for $e_{p}$ and determine the reinforcement position, the bending moments $M_{g l}, M_{a p c}$ and $M_{f c}$ were entered as a function of the cross-section position along the beam, ranging from 0 to $8 \mathrm{~m}$. Figures 5.6 and 5.7 define such intervals for all reinforcements combined to the C30 and C70 concrete grades, respectively, as well as the position chosen for each grade.

Figure 5.6 - Boundaries for the reinforcement positioning, considering concrete C30

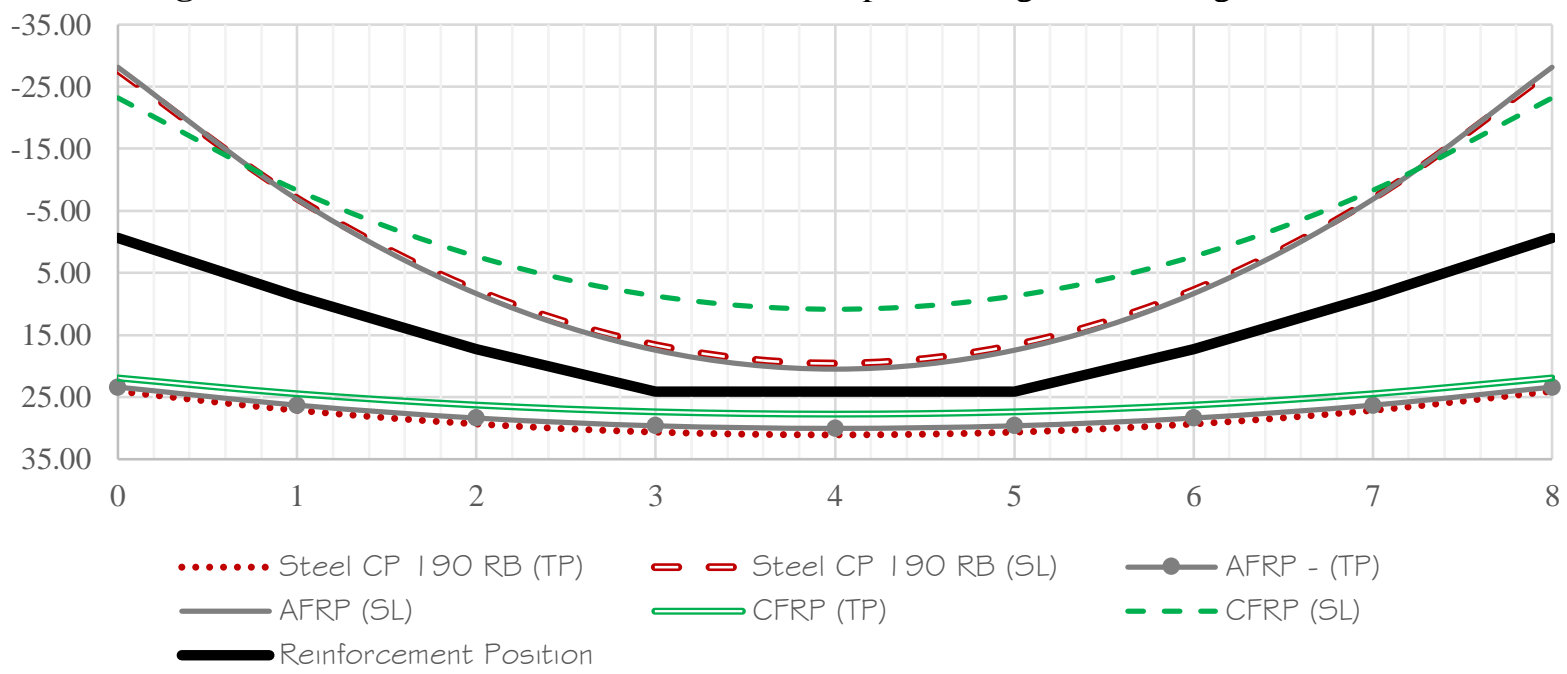

Source: BARBOSA, BITTENCOURT and WELTER, 2019 
Figure 5.7 - Boundaries for the reinforcement positioning, considering concrete C70

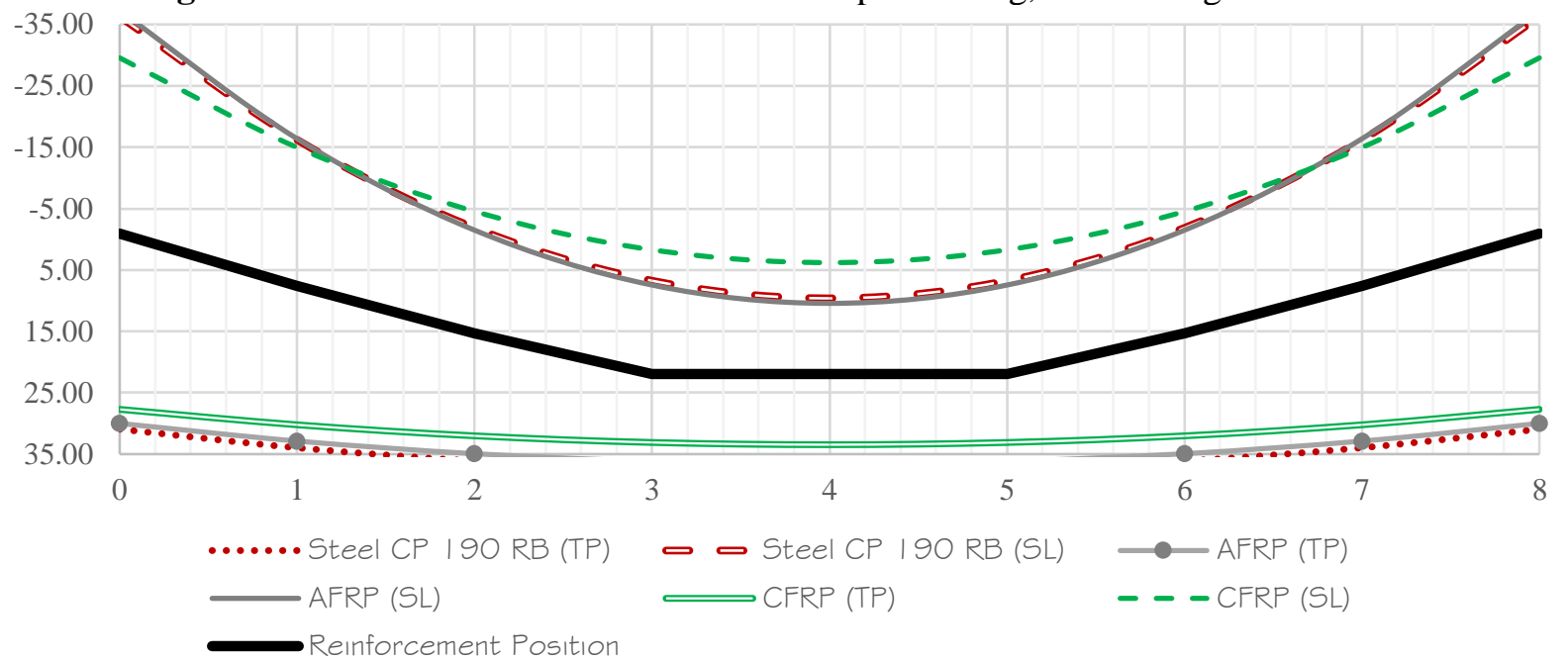

Source: BARBOSA, BITTENCOURT and WELTER, 2019

Conventionally, the adopted eccentricities $e_{p}$ at mid-span were 24.1 and $21.9 \mathrm{~cm}$, as regards concretes $\mathrm{C} 30$ and $\mathrm{C} 70$, respectively. The eccentricities on the supports, in turn, correspond to $-0.64 \mathrm{~cm}$ for the normal strength concrete and -0.9 , for the high-performance concrete. Figure 5.8 illustrates the detailing of the cross-sections at mid-span, for which the moment-curvature relationships and crack widths were numerically evaluated.

Figure 5.8 - Cross-section detailing with influence areas for the cracking evaluation
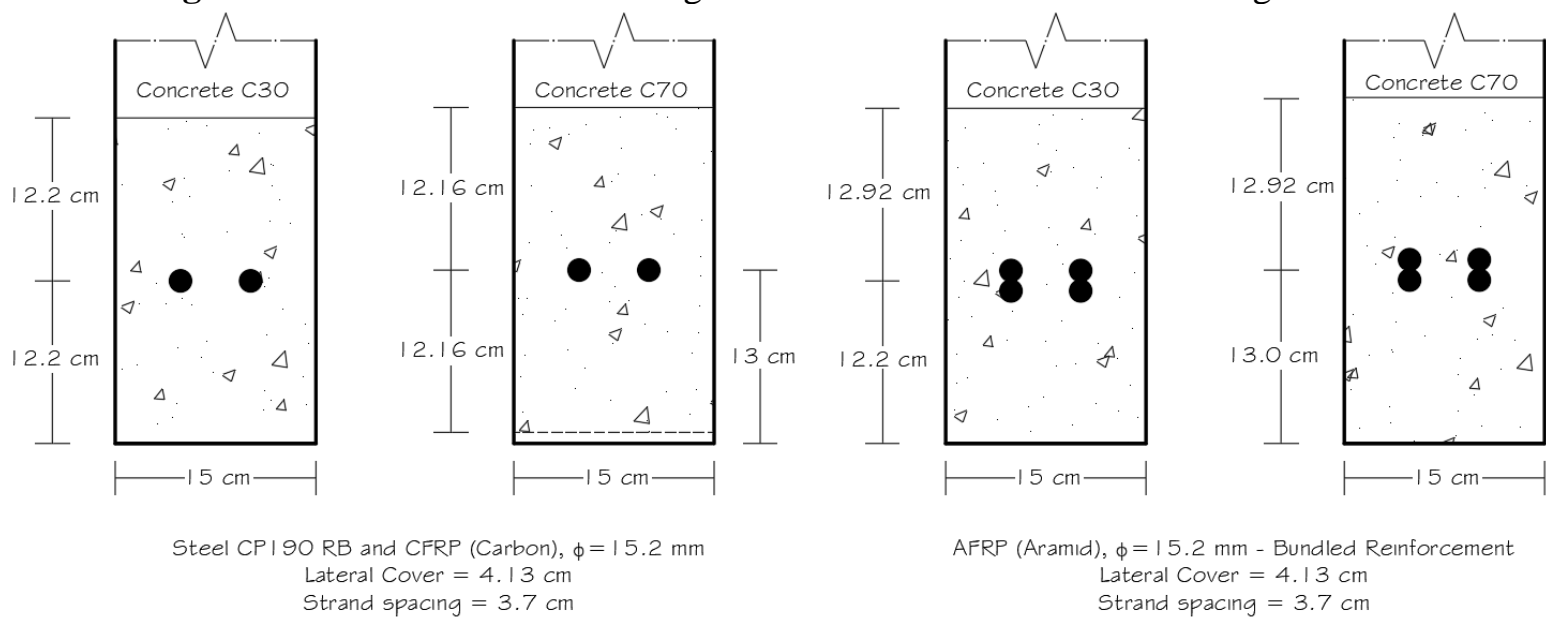

Source: BARBOSA, BITTENCOURT and WELTER, 2019

Once the reinforcement areas and eccentricities at mid-span were determined, it was necessary to check if the design meets the ultimate limit state for flexure, related to the factored bending moment $\mathrm{M}_{\mathrm{d}}=154 \mathrm{kNm}$. If the flexural strength $M_{r}$ is lower than $M_{d}$, it is necessary to utilize non-prestressed reinforcements to resist the difference between $M_{r}$ and $M_{d}$, so that all limit states are met. 
Prior to computing the flexural strength $M_{r}$, the FRP reinforcement ratio $\rho_{p}$ was compared to the balanced $\rho_{p b}$ in order to identify the type of failure: compression or tensioncontrolled. Thus, Equation 3.6 of ACI 440 4R-04 (2004) was adapted for the constitutive models of ABNT NBR 6118 (2014):

$$
\rho_{p b}=0.85 \alpha_{u l s} \beta_{u l s} \frac{f_{c d}}{f_{p u d}}\left(\frac{\varepsilon_{c u}}{\varepsilon_{c u}+\varepsilon_{p u d}-\varepsilon_{p r e}}\right)
$$

The pre-stressing strain for the ultimate limit state $\varepsilon_{\text {pre }}$ was calculated based on the longterm prestressing force $\left|P_{\infty}\right|$ reduced by the safety factor of 0.9 , in accordance with Table 11.1 of ABNT NBR 6118 (2014). Since the three types of reinforcement behave linear during prestressing, $\varepsilon_{\text {pre }}$ is determined as follows:

$$
\varepsilon_{\text {pre }}=\frac{0.9\left|P_{\infty}\right|}{A_{p} E_{p}}
$$

Regarding steel, the balanced reinforcement ratio $\rho_{p b}$ was defined as the one causing strains of $\varepsilon_{\mathrm{p}}=10 \% \mathrm{o}+\varepsilon_{\mathrm{pre}}$ and $\varepsilon_{\mathrm{c}}=\varepsilon_{\mathrm{cu}}$ in the reinforcement and concrete, respectively. This indicates that the crushing of the concrete occurs simultaneously to the yielding of steel for the maximum allowed cross-section strain at the reinforcement position, established as $10 \%$ by ABNT NBR 6118 (2014). Therefore, the balanced ratio for steel is:

$$
\rho_{p b}=0.85 \alpha_{u l s} \beta_{u l s} \frac{f_{c d}}{f_{p y d}}\left(\frac{\varepsilon_{c u}}{\varepsilon_{c u}+\varepsilon_{p r e}+10 \% 0}\right)
$$

By imposing equilibrium conditions, the flexural strength $M_{r}$ was computed through:

$$
M_{r}=0.85 \alpha \beta f_{c d} b x(d-0.5 \beta x)=A_{p} f_{p}(d-0.5 \beta x)
$$

Concerning AFRP and CFRP, for $\rho_{\mathrm{p}} \geq \rho_{\mathrm{pb}}$, the cross-section is compression-controlled, which means the strain at the top $\varepsilon_{t}$ reaches the concrete ultimate value $\varepsilon_{c u}$. The simplified rectangle parameters $\alpha$ and $\beta$ assumed the values of $\alpha_{u l s}$ and $\beta_{u l s}$, related to $\varepsilon_{c u}$. The reinforcement strain $\varepsilon_{p}$, in turn, was written as a function of the neutral axis position $x$, found by imposing equilibrium and compatibility conditions. Finally, the flexural strength $M_{r}$ was computed through Equation 5.18.

If $\rho_{p}<\rho_{p b}$, the cross-section is tension-controlled. The values of $\alpha$ and $\beta$ were determined from Equations 2.17 to 2.22 through iterative processes by which different strains $\varepsilon_{t}$ at the most compressed fiber were arbitrated. The strains $\varepsilon_{t}$ that made $\varepsilon_{p}$ match the ultimate value $\varepsilon_{p u d}$ 
satisfied both the equilibrium and compatibility conditions; thus, the parameters $\alpha$ and $\beta$ related to this strain were used to compute the flexural strength $M_{r}$ through Equation 5.18.

Regarding the combination of steel and concrete C30, it was found that $\rho_{\mathrm{p}} \geq \rho_{\mathrm{pb}}$. Thus, the neutral axis $x$ was calculated by imposing equilibrium conditions and assuming yielding of steel. To check if steel effectively yielded, the reinforcement strain $\varepsilon_{p}$ was computed by imposing compatibility conditions, which confirmed such assumption. Regarding the grade $\mathrm{C} 70$, it was found that $\rho_{\mathrm{p}}<\rho_{\mathrm{pb}}$; therefore, the reinforcement strain $\varepsilon_{p}$ corresponds to $10 \%_{0}+\varepsilon_{\mathrm{pre}}$, which is larger than $\varepsilon_{p y d}$, confirming the assumption of steel yielding.

Table 5.5 and 5.6 describe the checking for the ultimate limit state as regards the combinations of reinforcement and concrete grades C30 and C70, respectively. All the computed flexural strengths $M_{r}$ are greater than the factored applied moment $M_{d}$, indicating that non-prestressed reinforcements are not necessary.

Table 5.5 - Checking for the ultimate limit state, considering concrete C30

\begin{tabular}{cccccccccc}
\hline Reinforcement & $\begin{array}{c}\boldsymbol{\varepsilon}_{\text {pre }} \\
(\mathbf{\%})\end{array}$ & $\begin{array}{c}\boldsymbol{\rho}_{\mathbf{p}} \\
(\boldsymbol{\%})\end{array}$ & $\begin{array}{c}\boldsymbol{\rho}_{\mathbf{p b}} \\
(\boldsymbol{\%})\end{array}$ & Failure & $\begin{array}{c}\mathbf{x} \\
(\mathbf{c m})\end{array}$ & $\begin{array}{c}\boldsymbol{\varepsilon}_{\mathbf{t}} \\
(\mathbf{\% o})\end{array}$ & $\begin{array}{c}\boldsymbol{\varepsilon}_{\mathbf{p}} \\
(\mathbf{\% o})\end{array}$ & $\begin{array}{c}\mathbf{M}_{\mathbf{r}} \\
(\mathbf{k N m})\end{array}$ & ULS \\
\hline Steel & 3.65 & 0.32 & 0.27 & Compression & 18.7 & 3.50 & 11.22 & 210.8 & OK \\
AFRP & 5.07 & 0.65 & 0.40 & Compression & 21.0 & 3.50 & 11.42 & 232.7 & OK \\
CFRP & 7.40 & 0.32 & 0.27 & Compression & 23.1 & 3.50 & 12.85 & 251.9 & OK \\
\hline
\end{tabular}

Table 5.6 - Checking for the ultimate limit state, considering concrete $\mathrm{C} 70$

\begin{tabular}{cccccccccc}
\hline Reinforcement & $\begin{array}{c}\boldsymbol{\varepsilon}_{\text {pre }} \\
(\mathbf{\% )})\end{array}$ & $\begin{array}{c}\boldsymbol{\rho}_{\mathbf{p}} \\
(\boldsymbol{\%})\end{array}$ & $\begin{array}{c}\boldsymbol{\rho}_{\mathbf{p b}} \\
(\boldsymbol{\%})\end{array}$ & Failure & $\begin{array}{c}\mathbf{x} \\
(\mathbf{c m})\end{array}$ & $\begin{array}{c}\boldsymbol{\varepsilon}_{\mathbf{t}} \\
(\mathbf{\% o})\end{array}$ & $\begin{array}{c}\boldsymbol{\varepsilon}_{\mathbf{p}} \\
(\mathbf{\% o})\end{array}$ & $\begin{array}{c}\mathbf{M}_{\mathbf{r}} \\
(\mathbf{k N m})\end{array}$ & ULS \\
\hline Steel & 3.76 & 0.33 & 0.36 & Tension & 9.5 & 2.00 & 13.76 & 217.8 & OK \\
AFRP & 5.17 & 0.67 & 0.65 & Compression & 13.1 & 2.67 & 14.05 & 293.5 & OK \\
CFRP & 7.55 & 0.33 & 0.45 & Tension & 15.1 & 2.26 & 13.80 & 279.3 & OK \\
\hline
\end{tabular}

Once the cross-sections were designed, detailed and checked for the ultimate limit state, the next step was to plot the bending moment-curvature relationships, considering the tensionstiffening effect described in Equation 5.5, but applied for a flexural member where the strains $\varepsilon_{c}$ change over the cross-section. Figure 5.9 illustrates the equilibrium and compatibility conditions considered for the determination of moment-curvature relationships.

The neutral axis position $x$ was found by imposing such conditions, for which the resulting concrete compressive force equals the resulting tension force, composed by the reinforcement tensile stress times its area, and the contribution of concrete to tension.

$$
0.85 \alpha \beta f_{c d} b x=A_{p} f_{p}(x)+\int_{h_{1}}^{h_{1}+h_{2}}\left(\frac{\alpha_{1} \alpha_{2} f_{c t d}}{1+\sqrt{500 \varepsilon_{c}(y)}}\right) b d y
$$


In Equation 5.19, the reinforcement stress $f_{p}$ is written as a function of $x$. The axis $y$ has its origin in the neutral axis position and the strain $\varepsilon_{c}$ is written as a function of $y$, leading to $\varepsilon_{c}(y)=\varepsilon_{t} \frac{y}{x}$. The coordinates $h_{1}$ and $h_{1}+h_{2}$ define the influence area for the computing of the tension force in concrete. If the term $\frac{500 \varepsilon_{t}}{x}$ is written as $u$, the integral in Equation 5.19 defining the tension stiffening force $R_{t s}$ becomes:

$$
R_{t s}=\frac{\alpha_{1} \alpha_{2} f_{c t d} b x}{250 \varepsilon_{t}}[\sqrt{u y}-\ln (1+\sqrt{u y})]_{h_{1}}^{h_{1}+h_{2}}
$$

For each imposed strain at the top $\varepsilon_{t}$, there is just one value for $x$ that satisfies both the equilibrium and compatibility conditions. If the found neutral axis $x$ locates in the influence area, $h_{1}$ is taken as zero and a new value of $x$ is calculated. This avoided errors in Equations 5.20 and 5.21 due to negative values of $h_{1}$. Moreover, applying the tension-stiffening model to compressed areas would be unreasonable.

Figure 5.9 - Equilibrium and compatibility conditions of the prestressed beam
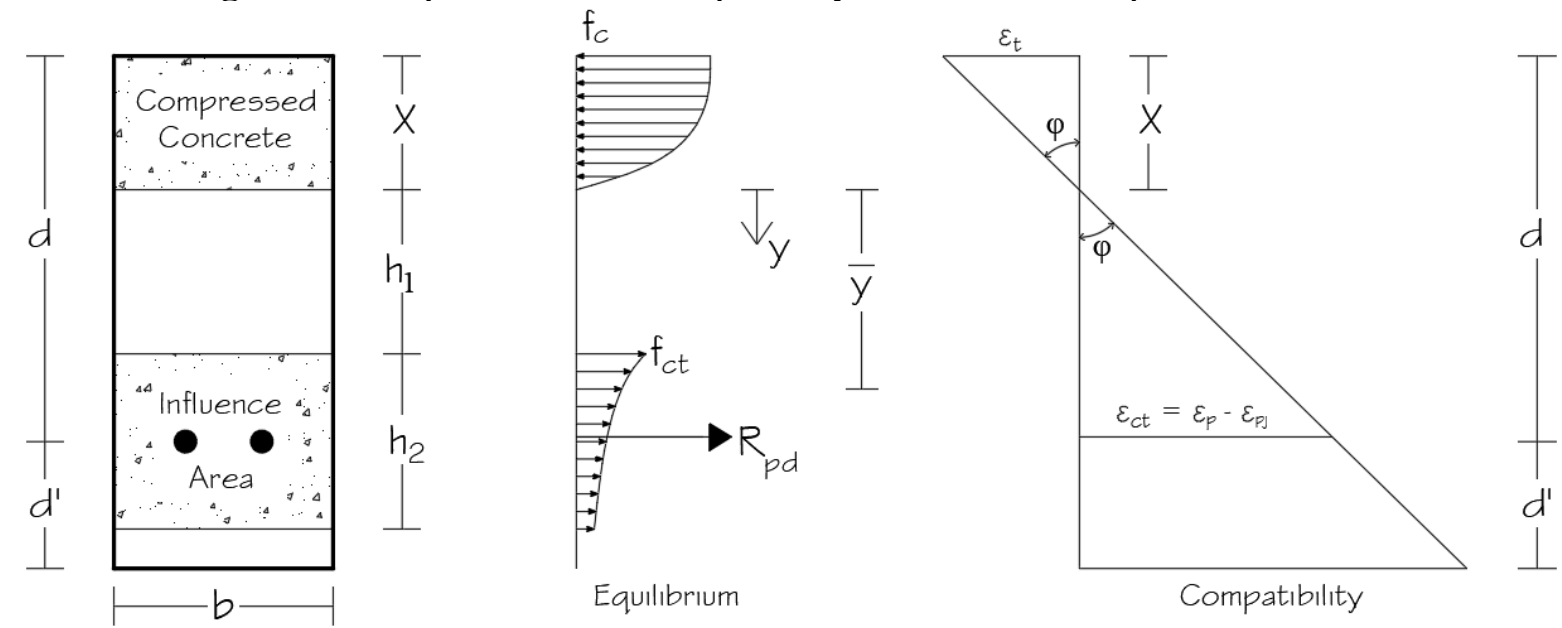

Source: BARBOSA, BITTENCOURT and WELTER, 2019 - Adapted

In Figure 5.9, $\bar{y}$ refers to the center of the tension-stiffening force. This force corresponds to the right side of Equation 5.19. Therefore, the moment arm is not $d-0.5 \beta x$, but the distance between the resulting compression and tension forces. The distance $\bar{y}$ as shown in Figure 5.9 is calculated as follows:

$$
\bar{y}=\frac{\int_{h_{1}}^{h_{1}+h_{2}} y f_{t s}(y) d y}{\int_{h_{1}}^{h_{1}+h_{2}} f_{t s}(y) d y}=\frac{1}{u}\left\{\frac{0.33(u y)^{1.5}-0.5(u y)+(u y)^{0.5}-\ln \left[1+(u y)^{0.5}\right]}{(u y)^{0.5}-\ln \left[1+(u y)^{0.5}\right]}\right\}_{h_{1}}^{h_{1}+h_{2}}
$$


The moment-curvature relationships were also determined without considering the tension-stiffening effect, seeing that, at the crack location, the contribution of concrete to tension is zero (COLLINS and MITCHELL, 1987). Therefore, cracked cross-sections have lower strength, governing the failure of the cross-section member. Faced with this, the momentcurvature curve for between-cracks cross-sections had their plotting interrupted at the coordinates corresponding to the failure of the cracked section, which defines the ultimate limit state of the flexural member.

Regarding cracking widths, those were calculated through Equation 5.6, considering the strain $\varepsilon_{p i}$ related to a cracked cross-section. The influenced areas corresponds to the ones illustrated in Figure 5.8, and the coefficient $\eta_{1}$ was taken as 1.2 in compliance with the item 9.3.2.2 of ABNT NBR 6118 (2014). Finally, the charts relating the service bending moment $M$ and crack widths were plotted for the six combinations of reinforcement and concrete grades.

\subsection{Results of the numerical analysis}

This section presents the results of the numerical analysis as regards the axially loaded member and the simply supported beam. The first subsection presents the axial strain-force relationship and the charts relating the axial force to the crack widths with respect to the axially loaded member. The second subsection, in turn, presents the moment-curvatures and crackingmoment relationships for the simply supported beam.

\subsubsection{Results corresponding to the axially loaded member}

Figures 5.10 and 5.11 illustrate the axial force-strain relationship for the three types of reinforcement combined to the concrete grade C30 and C70, respectively. The numbers 1, 2 and 3 refer to the reinforcement type, while the letters $a, b, c$ and $d$ denote the FRP rupture, beginning of cracking, concrete crushing and yielding of steel, respectively. It is important to highlight that the ultimate limit state as regards tension is defined by the rupture of strands at the crack location, where the concrete contribution $f_{c}$ is zero. Therefore, at those locations, the reinforcement stress $f_{p}$ is higher than those regarding between-cracks cross-sections.

The results showed that the benefits of prestressing are more evident for steel CP190 RB. The required load $N$ to initialize cracking is approximately $65 \%$ higher in comparison to the non-metallic reinforcements combined to concrete C 30 . This difference drops to $60 \%$ for the grade C70. Regarding the decompression of the members, the required load to make the 
strain $\varepsilon_{c}$ higher than zero corresponds to $75 \%$ and $70 \%$ compared to the AFRP and CFRP prestressed members, respectively (BARBOSA, BITTENCOURT and WELTER, 2019).

This advantage of steel CP190 RB over the non-metallic reinforcement is attributed to the fact that the same jacking strain $\varepsilon_{p j}$ was imposed for all reinforcement types. Since steel has the highest elasticity modulus, its jacking stress $f_{p j}$ is also the highest, corresponding to $85 \%$ of the steel design yielding stress $f_{p y d}$. AFRP and CFRP, in turn, were subjected to jacking stresses of 44.2 and $45.9 \%$ of their design tensile strength, respectively. Thus, to improve the performance of the non-metallic strands, their jacking stresses needs to be increased to the maximum limits imposed by ACI 440 4R-04 (2004), so that there is no waste of their mechanical properties (BARBOSA, BITTENCOURT and WELTER, 2019).

If the AFRP jacking stress is increased to the ACI limit of 50\%, the required load to decompress the member jumps from 800.5 to $905.7 \mathrm{kN}$, still lower than the decompression force of the steel prestressed member, which is $1396 \mathrm{kN}$. The required load to initialize cracking, in turn, have an increase of $11 \%$ for the grade $\mathrm{C} 30$ and $10.3 \%$ for the grade C70. Regarding CFRP, for a jacking stress of $65 \%$ of the tensile strength, the decompression load jumps from 816 to $1156 \mathrm{kN}$, an increase of $41.7 \%$, but still inferior to steel. The cracking load, in turn, increases by 35.3 and $32.7 \%$ for the grades C30 and C70, respectively (BARBOSA, BITTENCOURT and WELTER).

Figure 5.10 - Axial force-strain relationship considering concrete C30

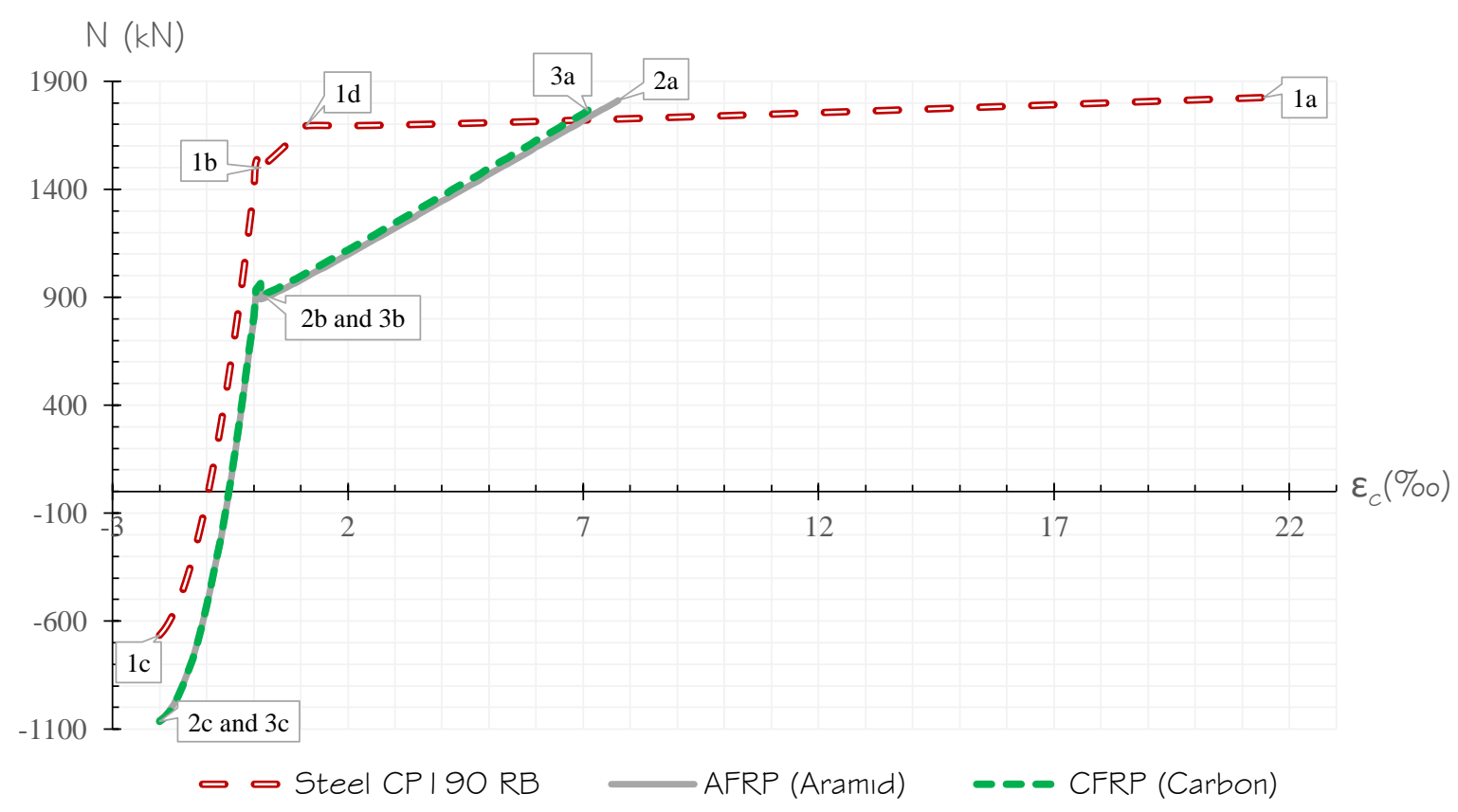

Source: BARBOSA, BITTENCOURT and WELTER, 2019 
Figure 5.11 - Axial force-strain relationship considering concrete C70

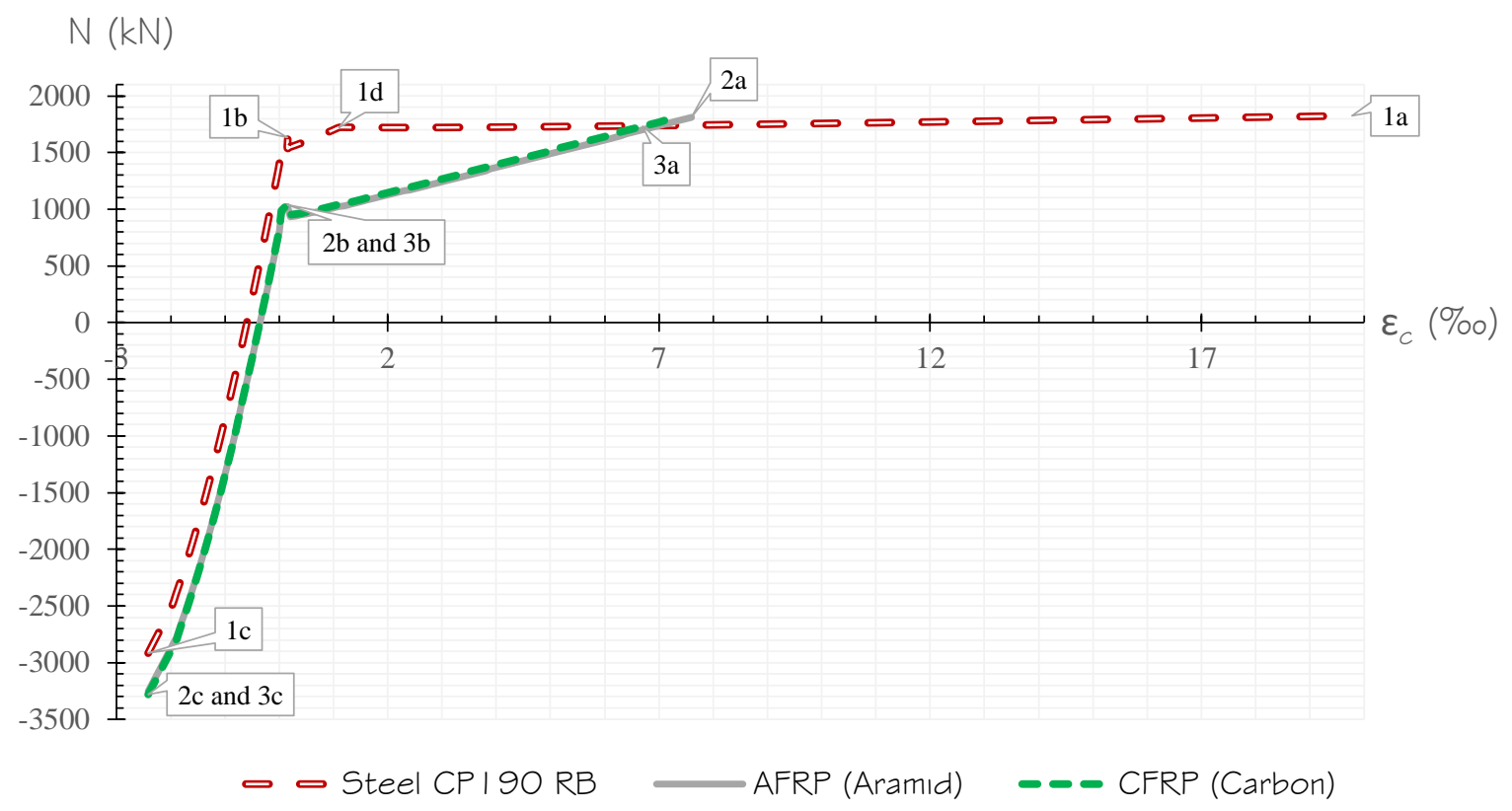

Source: BARBOSA, BITTENCOURT and WELTER, 2019

Regarding cracking, Figures 5.12 and 5.13 illustrate the relationship between the axial force and crack widths for the three types of reinforcement combined to the concrete grades C30 and C70, respectively. The results showed that the non-metallic reinforcement exhibited wider cracks compared to steel CP190 RB, above the maximum allowed by ABNT NBR 6118 (2014) for the prestressing level 1, which is $0.2 \mathrm{~mm}$. Although FRP does not undergo corrosion, ACI 440 1R-15 (2015) highlights that crack widths must be limited for aesthetic reasons and to avoid percolation of water, which can potentially damage the concrete. The Japanese Society of Civil Engineers, for instance, imposes the maximum limit of $0.5 \mathrm{~mm}$, whereas the Canadian code for the design of bridges CAN/CSA S6-06 allows that the FRP reinforcement area is adjusted so that the computed crack widths do not exceed $0.7 \mathrm{~mm}$ (BARBOSA, BITTENCOURT and WELTER, 2019).

The cracking-load relationship as regards steel presents three stages that characterizes it as ductile. The first one corresponds to the material linear behavior, whereas the second to the beginning of the yielding plateau. The third stage, in turn, is characterized by an accelerated growing of crack widths, which no longer depends on the concrete tensile strength but on the incremental strain $\varepsilon_{p i}$ and the reinforcement ratio $\rho_{r i}$ related to the influence area. Concerning the AFRP and CFRP prismatic members, there is only one stage, whereby the material behaves linear and the crack widths depends on the incremental strain and the concrete tensile strength, but not on the reinforcement ratio $\rho_{r i}$, considering the cracking model of ABNT NBR 6118 (2014) (BARBOSA, BITTENCOURT and WELTER, 2019). 
Figure 5.12 - Relationship between axial forces and crack widths, considering concrete C30

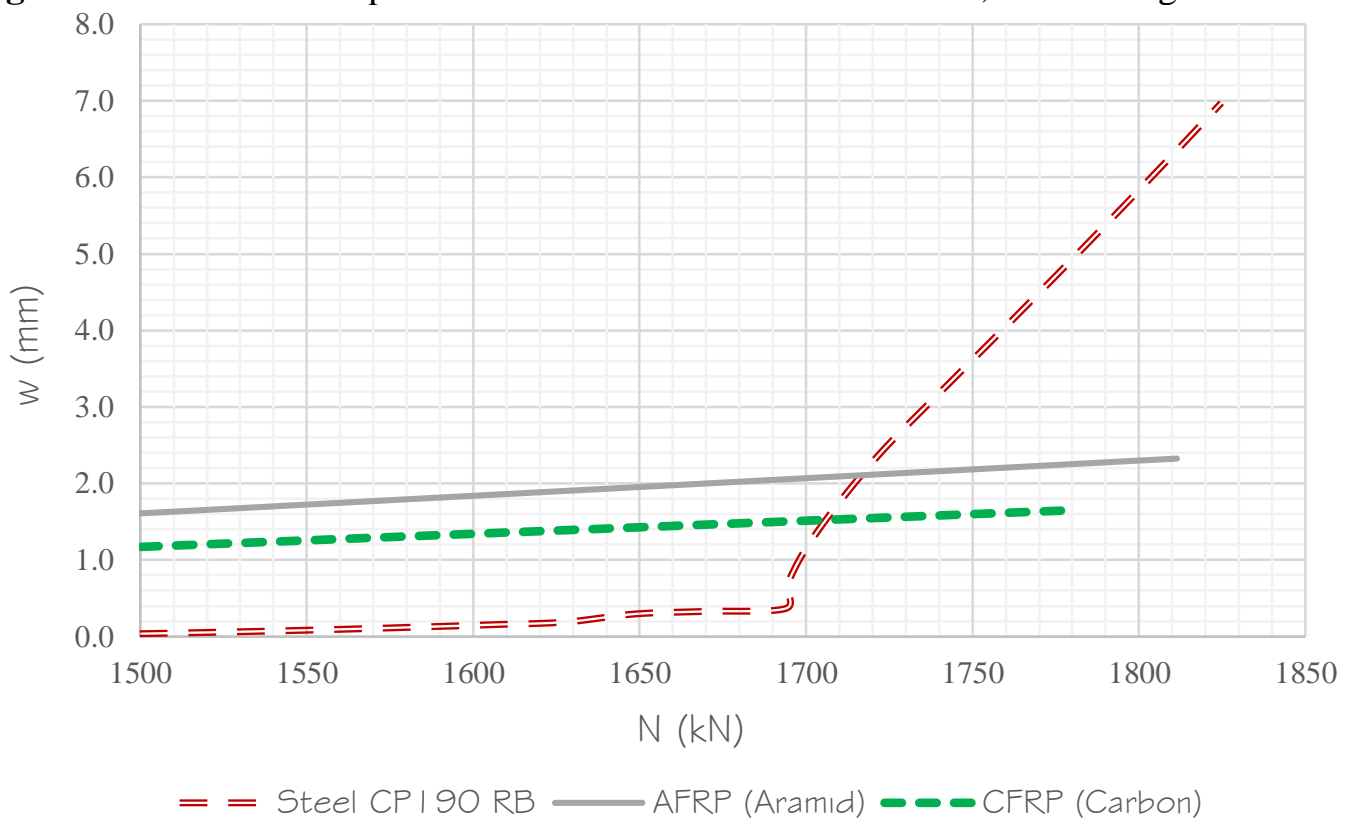

Source: BARBOSA, BITTENCOURT and WELTER, 2019

Figure 5.13 - Relationship between axial forces and crack widths, considering concrete C70

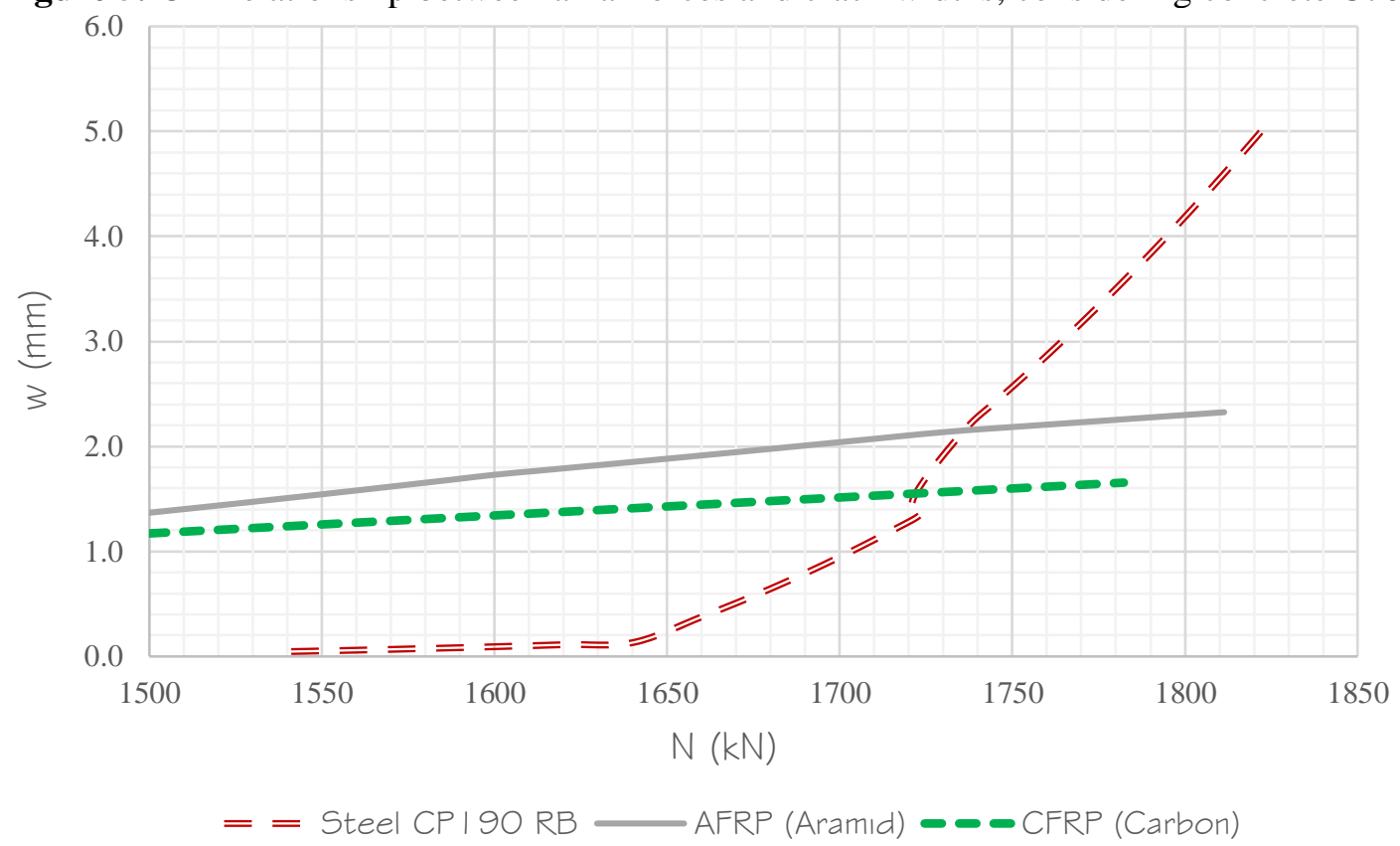

Source: BARBOSA, BITTENCOURT and WELTER, 2019

\subsubsection{Results corresponding to the simply supported beam}

The moment-curvature relationships as regards the reinforcement combinations with concrete $\mathrm{C} 30$ and C70 are shown in Figure 5.14 and 5.15, respectively. Alike the axially loaded members, the ultimate limit state is characterized by the failure of the cracked cross-section. The letters $a$ and $b$ refer to the rupture due to service loads and transfer of prestress, respectively. 


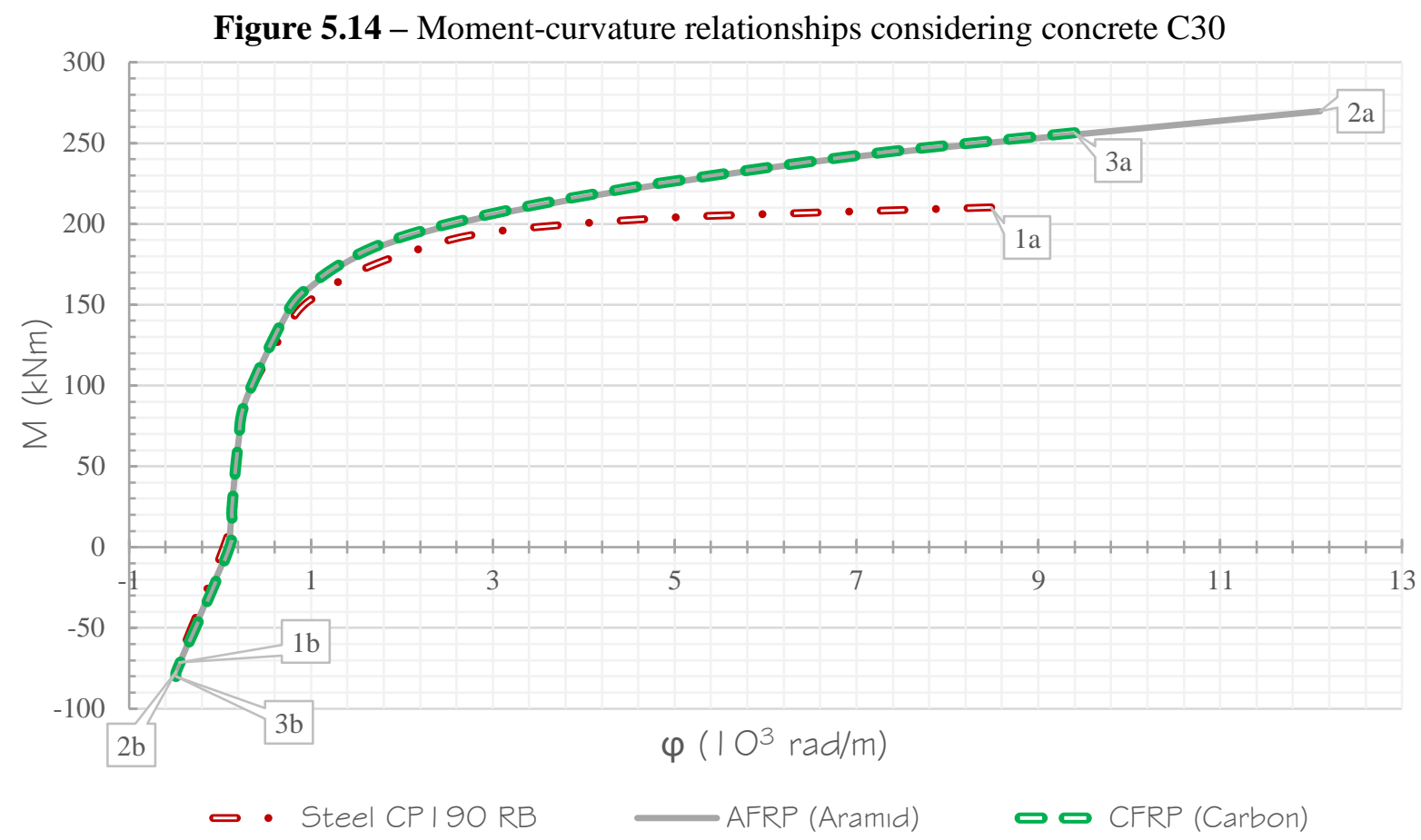

Source: BARBOSA, BITTENCOURT and WELTER, 2019 - Adapted

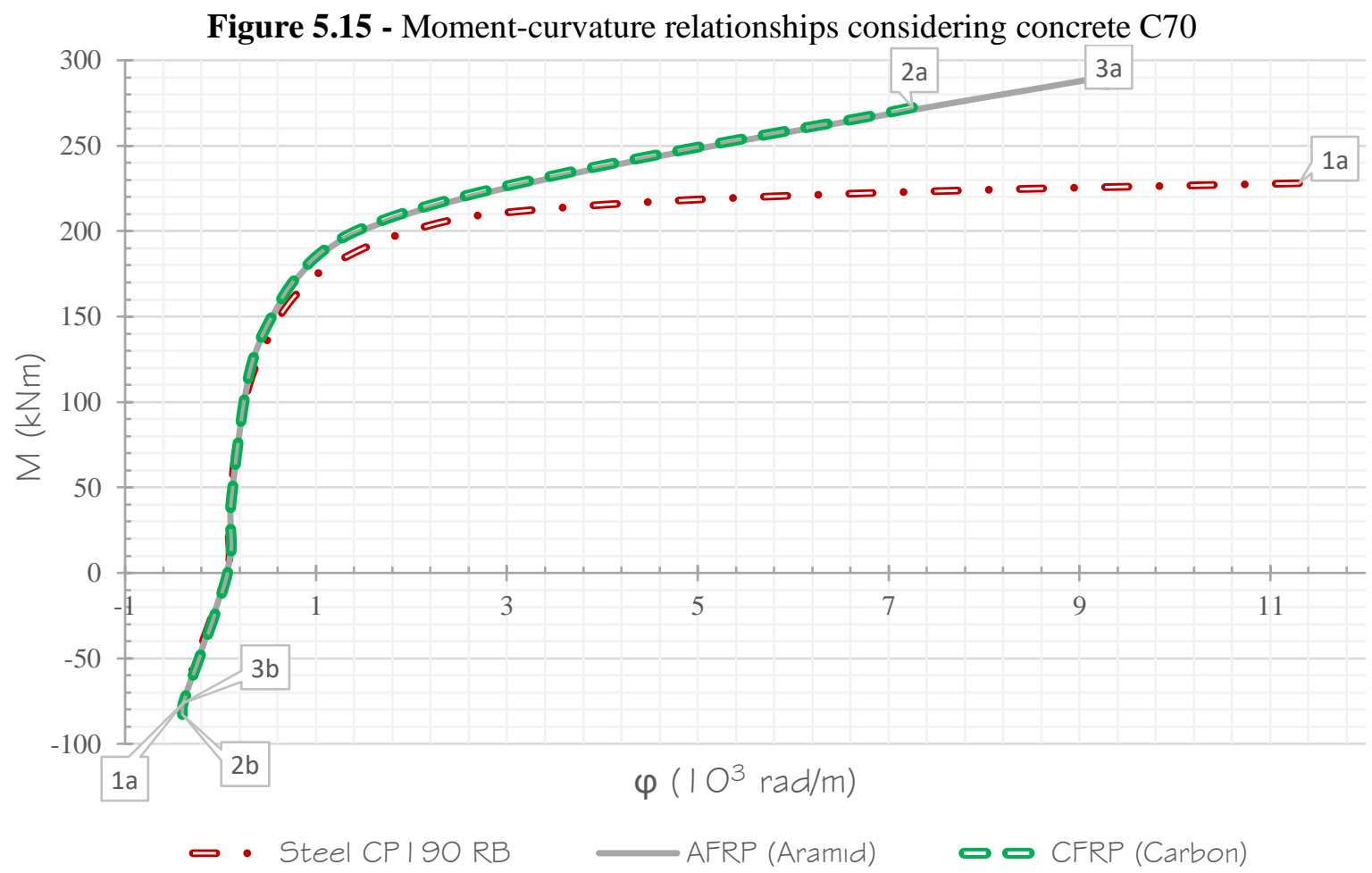

Source: BARBOSA, BITTENCOURT and WELTER, 2019 - Adapted

For the combination of steel and concrete $\mathrm{C} 30$, the cross-section failure is characterized by the crushing of the concrete, which reaches the strain $\varepsilon_{c u}$ of $3.5 \%$. The reinforcement, in turn, yields, exhibiting a strain of $13.7 \%$. For the grade C70, the cross-section is also 
compression-controlled, exhibiting strains in concrete and reinforcement of 2.67 and 11\%o, respectively, which also indicates steel yielding.

Regarding AFRP, the combination with concrete C30 resulted in a tension-controlled cross-section, for which the concrete strain corresponds to 3.38\% and the AFRP strands reach the ultimate strain of $14.3 \%$. The flexural strength $M_{r}$ is $269.7 \mathrm{kNm}$, not close to the value of 232.7 $\mathrm{kNm}$ presented in Table 5.5, for which the cross-section is compression-controlled. This discrepancy is attributed to the fact that the checking for the ultimate limit state considers the prestressing force after all losses $\left|P_{\infty}\right|$ reduced by a safety factor of 0.9 . In contrast, the determination of the moment-curvature relationship was based on the adjusted jacking load $P_{0}$. Consequently, the tensile stress in the reinforcement is higher, which makes the strands reach the ultimate strain $\varepsilon_{p u d}$ prior to concrete, characterizing a tension-controlled cross-section. Moreover, since $P_{0}$ is higher than $\left|P_{\infty}\right|$, the flexural strengths obtained from the procedures to calculate moments and curvatures are also higher.

The same occurred for the combination of AFRP and concrete C70. Although the chart illustrated in Figure 5.15 indicates a flexural strength of $291 \mathrm{kNm}$, close to the value of $M_{r}$ in Table 5.6, the failure modes are different for the same reason as the combination with concrete C30: larger jacking strain to compute the moment-curvature relationships. However, Table 5.6 reports a compressive controlled cross-section with a flexural strength slightly higher than that illustrated in Figure 5.16, fact not observed for the grade C30. Although the strands are subjected to lower stresses in Table 5.6, the better utilization of the high strength concrete properties makes the resulting force become high enough to increase de flexural strength, despite the reduction of the moment arm $d-0.5 \beta x$.

In regard to the combination of CFRP and concrete C30, the cracked cross-section failure is characterized by the rupture of the strands, exhibiting strains of $13.8 \%$. The most compressed fiber, in turn, presents a strain of $2.7 \%$, much lower compared to the other types of reinforcements combined to this concrete grade. This means the concrete properties could be better used if the jacking stress were lower, resulting in a higher flexural strength. Checking for the ultimate limit state, for instance, considered the reduced prestressing strain, which made the cross-section over-reinforced, but with a flexural strength slightly higher. In this particular situation, if the designer wanted to prestress the CFRP strands to the maximum allowed by ACI $4404 \mathrm{R}-04$, it would be better to use a lower strength concrete, so that the cross-section would not be too under-reinforced.

Considering the combination of CFRP and concrete C70, the cross-section is too underreinforced, with the most compressed fiber exhibiting a strain of $1.67 \%$. Since the verification 
of the ultimate limit state accounted for losses in prestressing, the strain at the top $\varepsilon_{t}$ reached $2.26 \%$, which is still smaller than the concrete ultimate strain of $2.67 \%$ as regards the grade C70. As a result, the flexural strength is higher when accounting for prestressing losses, given the better use of the concrete mechanical properties.

The moment curvature-relationships show that the flexural strength of the FRP prestressed members is, in average, 30\% higher than the one as regards conventional steel. Additionally, the required moment to initiate cracking is slightly higher for the two types of non-metallic strands, with a difference of $20 \mathrm{kNm}$ compared to steel (BARBOSA, BITTENCOURT and WELTER, 2019). Figures 5.14 and 5.15 also demonstrate that the failure of the cross-section by virtue of negative bending moments is approximately the same for the three types of reinforcement, relying more on the concrete tensile properties.

Figures 5.16 and 5.17 illustrate the relationships between bending moments and crack widths, considering the grades C30 and C70, respectively. No considerable discrepancies between the three types of reinforcement were observed for service moments up to $190 \mathrm{kNm}$. However, as the bending moment increases, steel starts to yield and the crack widths grow intensively until the cracked cross-section ruptures due to concrete crushing. The crack widths referring to the non-metallic reinforcements, in turn, are less sensitive to the variations in bending moments (BARBOSA, BITTENCOURT and WELTER, 2019).

Figure 5.16 - Relationship between bending moments and crack widths for concrete C30

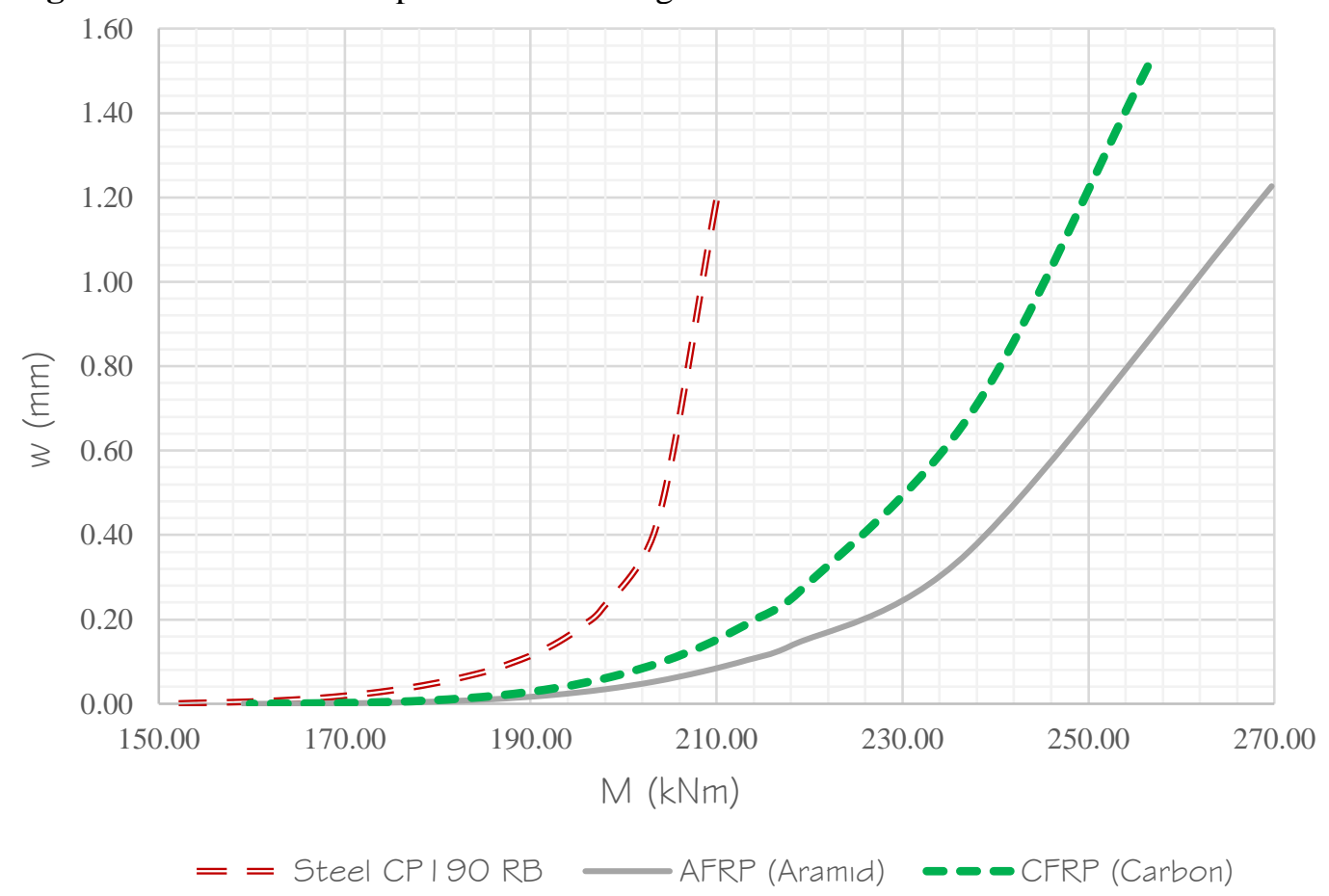

Source: BARBOSA, BITTENCOURT and WELTER, 2019 
Figure 5.17 - Relationship between bending moments and crack widths for concrete C70

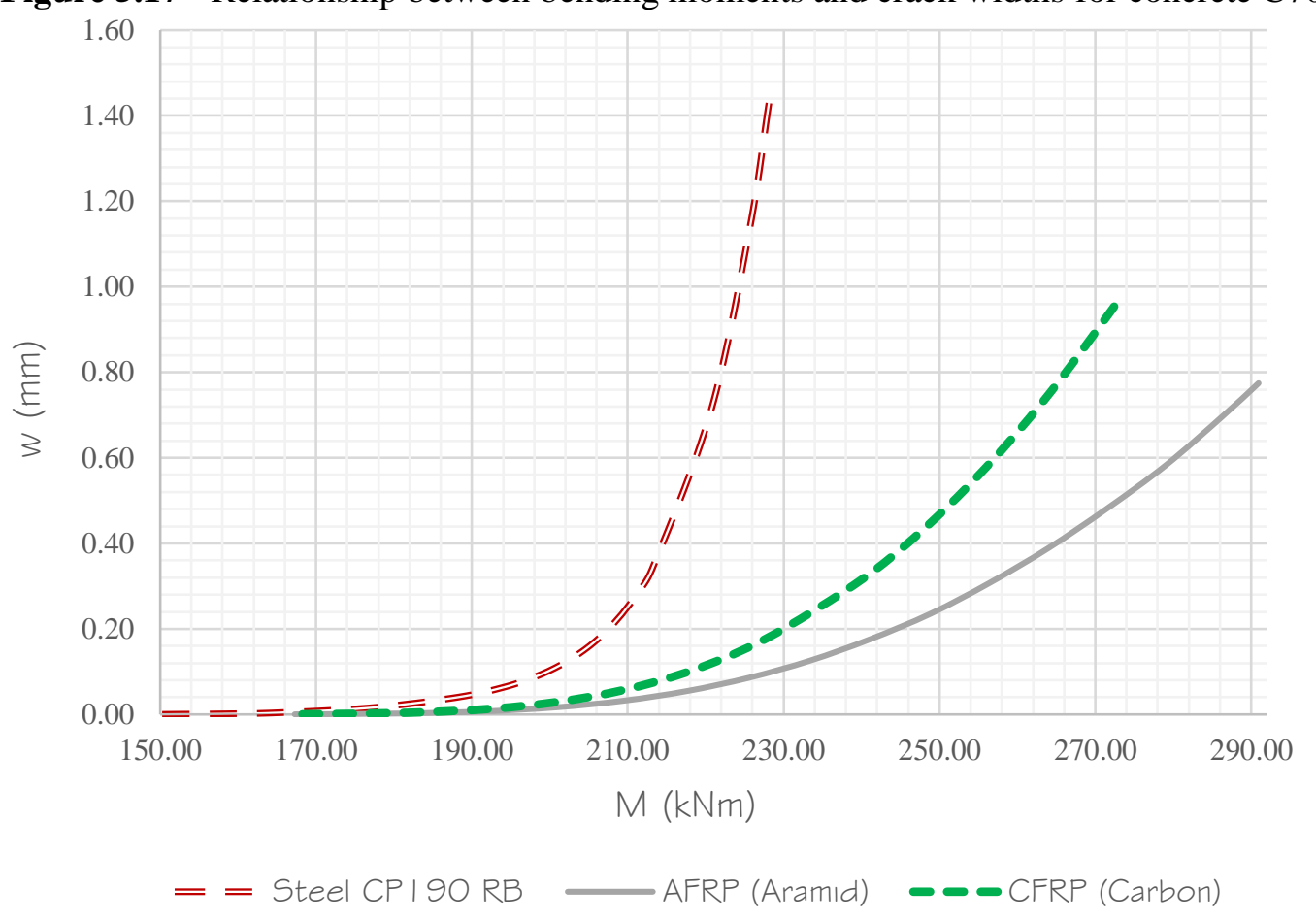

Source: BARBOSA, BITTENCOURT and WELTER, 2019

Unlike the axially loaded members, the simply supported beam prestressed with steel exhibited wider cracks in comparison to the same flexural member prestressed with AFRP and CFRP. Since ACI 440 4R-04 (2004) does not allow high stresses levels in the non-metallic strands, larger areas of FRP are required to reach the same steel jacking load. Consequently, the crack widths are smaller. Moreover, since the amount of reinforcement needs to be adjusted for the strand diameters defined by ABNT NBR 7483 (2008), the adopted areas $A_{p}$ turn out to be larger than those quite necessary, especially for AFRP, resulting in high prestressing forces (BARBOSA, BITTENCOURT and WELTER, 2019).

The distance between the reinforcement position and the superior boundaries illustrated in Figures 5.6 and 5.7 also affects the crack widths. The compressive stress at the cross-section bottom is directly proportional to this distance, suggesting that the steel and AFRP prestressed members would present more intense cracking at mid-span. Indeed, the widest cracks belong to the cross-sections prestressed with steel; however, those with AFRP exhibited the smallest crack widths seeing that the adopted areas are larger than those required. Moreover, the strands were bundled together, resulting in a high reinforcement ratio corresponding to the influence area. Regarding CFRP, in spite of the longest distance between the superior boundary and the position of strands, the cracks were wider compared to AFRP due to its smaller amount of reinforcement. If the reinforcement areas were the same, the difference in crack widths would 
be attributed to the incremental strains $\varepsilon_{p i}$, which depend on the reinforcement elasticity modulus. Therefore, given the low stiffness of AFRP, the cracks would be probably wider if the areas were the same (BARBOSA, BITTENCOURT and WELTER, 2019).

\subsection{Closing Remarks}

This numerical analysis showed that FRP prestressed members present higher strength and less intense cracking compared to those with steel CP190 RB, provided that the prestressing forces $P_{0}$ are the same for all reinforcement types. Conversely, by imposing the same jacking strain $\varepsilon_{p j}$, the FRP prestressed members show lower strength, poor ductility and intense cracking, seeing that this imposition results in low prestressing forces. Therefore, the structural performance of FRP and steel prestressed members depends not only on the material mechanical properties but also on the design and modelling criteria (BARBOSA, BITTENCOURT and WELTER, 2019).

The results also showed that using FRP in pre-tensioning yields better results compared to its use as non-prestressed reinforcement. It is not necessary to over-reinforce the crosssections or increase their dimensions to obtain acceptable curvatures and crack widths at service conditions. As a result, the costs with reinforcement and concrete tends to be lower. Moreover, the analysis of the moment-curvature relationships suggests the utilization of AFRP and CFRP in conjunction with a normal strength concrete to provide greater ductility, since the difference between the curvatures defining the crack formation and the cross-section failure is larger for the grade C30 compared to C70 (BARBOSA, BITTENCOURT and WELTER, 2019). High strength concretes may also result in too under-reinforced cross-sections, for which the stresses in concrete are much lower than its compressive strength, characterizing waste of its mechanical properties.

Finally, it is important to highlight that this numerical analysis considered similar bonding properties for AFRP, CFRP and steel. Additionally, the crack widths were calculated for cross-sections where the shear force is zero. Therefore, this analysis could be reproduced considering the FRP and steel differences in bonding based on other cracking models that account for such differences. The crack widths could also be estimated at other locations of the flexural member, where the shear force is not zero, considering or not the presence of stirrups. 


\section{Chapter 6 - Development of the FRP RC Design Program}

As previously mentioned, the design and verification of FRP reinforced concrete flexural members in real time is paramount. The designer is supposed to understand the crosssection types of failure as well as their behavior under service load conditions. Therefore, this chapter describes the development of the FRP RC Design Program for T/L and rectangular cross-sections, using the VISUAL BASIC.NET@ programming language.

The program code accounts for different scenarios at which a $\mathrm{T} / \mathrm{L}$ cross-section may fail: tension or compression-controlled cross-sections with neutral axis located on the flange or web. Moreover, for under-reinforced cross-sections characterized by the FRP rupture, the code assumes the concrete behaves linear if the stress at the most compressed fiber $f_{c}$ does not exceed $50 \%$ of $0.85 f_{c d}$, as recommended by ABNT NBR 6118 (2014). Once the reinforcement area $A_{f}$ is computed for the design bending moment $M_{d}$, it is necessary to check for creep rupture under service load conditions, adjusting the reinforcement area to also meet this limit state. Consequently, the flexural strength $M_{r}$ becomes higher than $M_{d}$, which means the failure mode may switch from tension to compression-controlled but never the opposite. It is necessary to calculate the new position of the neutral axis for the flexural strength, as well as the strain at the reinforcement $\varepsilon_{f}$ and concrete most compressed fiber $\varepsilon_{t}$. All these calculations were based on assumptions as regards the position of the neutral axis (flange or web), and if the concrete behaves linear for tension-controlled cross-sections.

\subsection{Procedures for the Ultimate Limit State Design}

Initially, the code compares the design bending moment $M_{d}$ to the balanced moment $M_{b}$, for which concrete crushing and FRP rupture occur simultaneously. As previously mentioned, if $M_{d}<M_{b}$, the failure is characterized by FRP rupture, whereas $M_{d} \geq M_{b}$ indicates crushing of the concrete. However, for T/L sections, the neutral axis position $x_{b}$ for the balanced crosssection may be located either on the flange or the web, resulting in two different approaches to calculate $M_{b}$. By imposing the compatibility conditions shown in Figure 2.2, $x_{b}$ is given as follows:

$$
x_{b}=\left(\frac{\varepsilon_{c u}}{\varepsilon_{c u}+\varepsilon_{f u d}}\right) d
$$


The constitutive model illustrated in Figure 2.3 shows that concrete behaves nonlinearly at rupture, which allows using the simplified rectangular block to represent stresses in concrete for the balanced cross-section. If $\beta_{u l s} x_{b}<h_{f}$, the rectangular stress block is distributed on the beam flange, as shown in Figure 6.1:

Figure 6.1 - Balanced cross-section analysis for the stress block located on the flange.
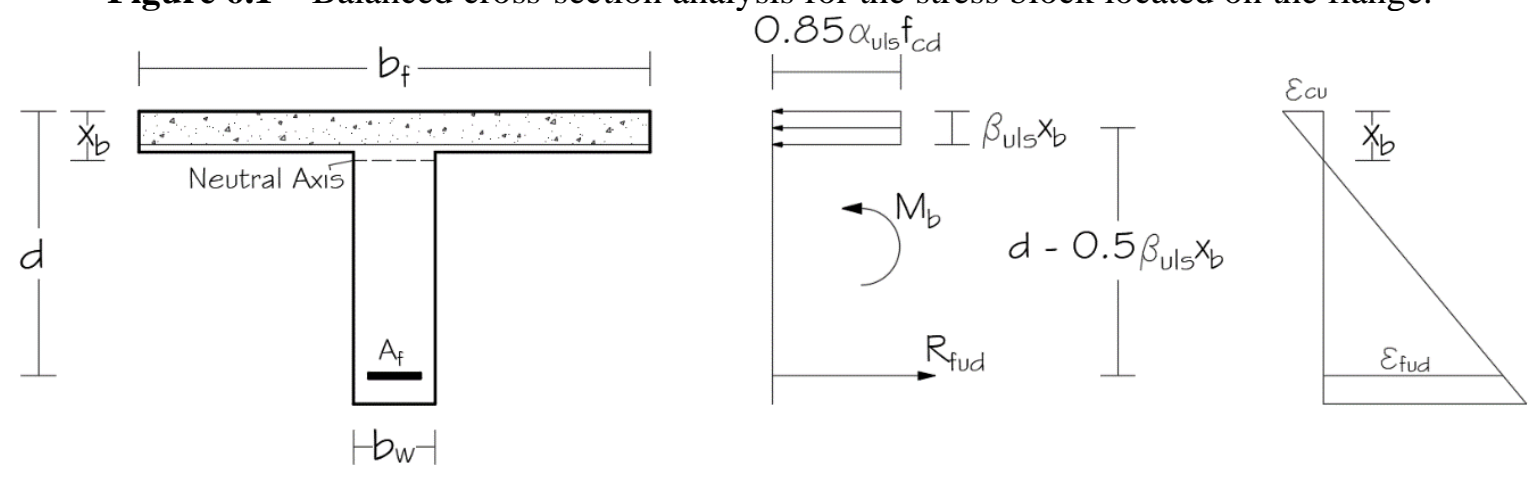

Source: Author

The flange width $\mathrm{b}_{f}$ is used in place of $b$ in Equation 2.9, seeing that only the flange undergoes compressive stresses. Thus, the balanced moment $M_{b}$ is:

$$
M_{b}=0.85 \alpha_{u l s} \beta_{u l s} f_{c d} b_{f} x_{b}\left(d-0.5 \beta_{u l s} x_{b}\right)
$$

In contrast, if $\beta_{u l s} x_{b} \geq h_{f}$, the stress block is distributed both on the flange and web, as shown in Figure 6.2. Thus, the calculation of the balanced moment $M_{b}$ accounts for the contribution of both cross-section elements.

Figure 6.2 - Balanced cross-section analysis for the stress block located on the web
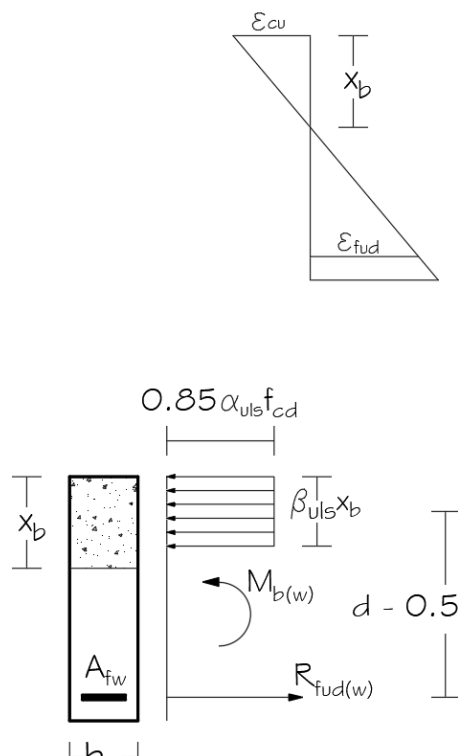

$0.85 \alpha_{\text {us }} f_{c d}$

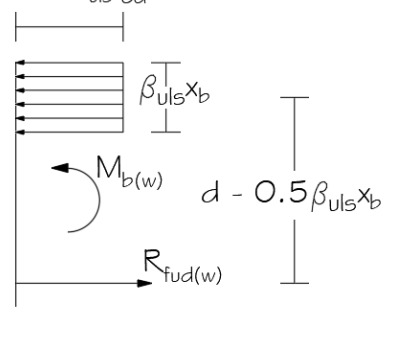

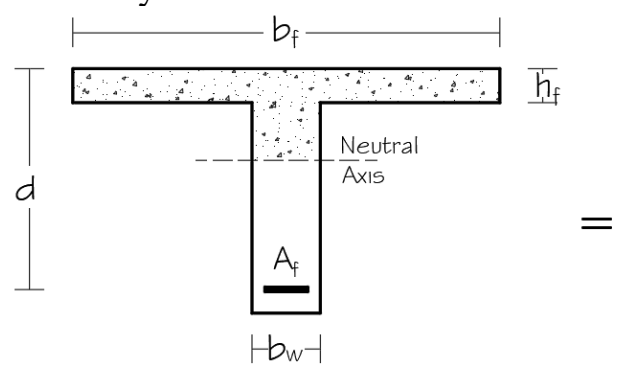

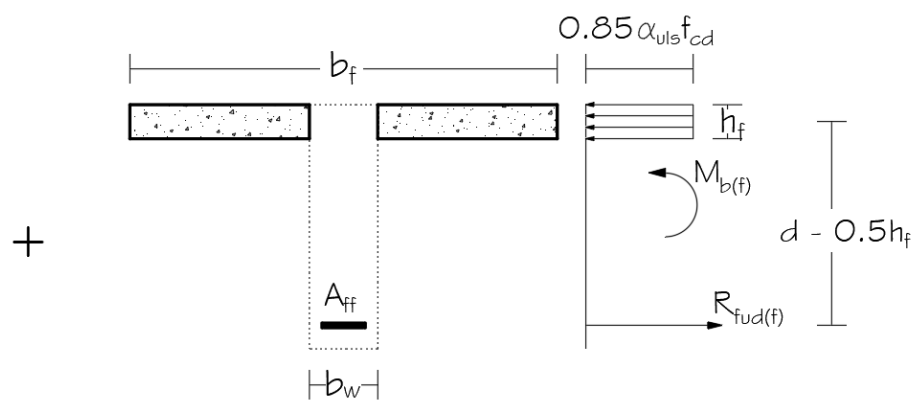

Source: Author 
The web contribution $M_{b(w)}$ to $M_{b}$ depends on the neutral axis $x_{b}$ and is calculated considering a rectangle section with width $b_{w}$ and effective depth $d$. The flange contribution $M_{b(f)}$, in turn, accounts for the compressive force on the rectangle whose width and depth corresponds to $b_{f}-b_{w}$ and $h_{f}$, respectively, as shown in Figure 6.2. Therefore, the total balanced moment $M_{b}$ for $\beta_{u l s} x_{b} \geq h_{f}$ is the sum of $M_{b(w)}$ and $M_{b(f)}$, resulting in:

$$
M_{b}=0.85 \alpha_{u l s} f_{c d}\left[\beta_{u l s} x_{b} b_{w}\left(d-0.5 \beta_{u l s} x_{b}\right)+h_{f}\left(b_{f}-b_{w}\right)\left(d-0.5 h_{f}\right)\right]
$$

Once $M_{b}$ is determined, the code compares it to the design moment $M_{d}$, defining the failure mode of the cross-section. If the balanced neutral axis $x_{b}$ is located on the flange and $M_{d}$ $<\mathrm{M}_{\mathrm{b}}$, the section fails due to the FRP rupture and the actual neutral axis $x$ related to $M_{d}$ is also on the web. However, if $\mathrm{M}_{\mathrm{d}} \geq \mathrm{M}_{\mathrm{b}}$, concrete crushing occurs and the neutral axis $x$ for $M_{d}$ may be located either on the flange or the web. On the other hand, if the balanced neutral axis $x_{b}$ is located on the web and $\mathrm{M}_{\mathrm{d}}<\mathrm{M}_{\mathrm{b}}$, the cross-section is tension controlled and the neutral axis depth $x$ related to $M_{d}$ can be either on the flange or the web. Conversely, if $\mathrm{M}_{\mathrm{d}} \geq \mathrm{M}_{\mathrm{b}}$, the neutral axis is located on the web. Moreover, for under-reinforced cross-sections, the code may consider the concrete behavior as linear, which is further explained in more details. All the procedures concerning each of these scenarios are described as follows:

\subsubsection{Tension-controlled sections and balanced stress block on the flange}

For a balanced cross-section, both strains in the reinforcement and most compressed concrete fiber reach their ultimate values. Regarding a tension-controlled section, the strain $\varepsilon_{t}$ in the most compressed concrete fiber is smaller than the ultimate value $\varepsilon_{c u}$, whereas the reinforcement strain remains equal to its ultimate value $\varepsilon_{f u d}$. Therefore, if the effective depth $d$ does not change, the neutral axis depth $x$ of tension-controlled cross-sections is smaller than that related to $\mathrm{M}_{\mathrm{d}}=\mathrm{M}_{\mathrm{b}}$. Consequently, if the stress block $\beta_{u l s} x_{b}$ is on the flange, so is the one $\beta_{u l s} x$ for the design bending moment.

Because the stresses in concrete may not be linear, the code computes the bending moment $M_{50 \%}$ for which the most compressed concrete fiber stress reaches $50 \%$ of $0.85 f_{c d}$. If $\mathrm{M}_{\mathrm{d}}<\mathrm{M}_{50 \%}$, the concrete constitutive model was assumed as linear elastic. The maximum strain $\varepsilon_{50 \%}$ for the concrete to assume linear behavior is computed by establishing that $\sigma_{\mathrm{cd}}=$ $0.5\left(0.85 \mathrm{f}_{\mathrm{cd}}\right)$ in Equation 2.15 , and isolating $\varepsilon_{c}$, which leads to:

$$
\varepsilon_{50 \%}=\varepsilon_{c 2}\left(1-0.5^{\frac{1}{n}}\right)
$$


The neutral axis $x_{50 \%}$ related to $\varepsilon_{50 \%}$ is found by imposing compatibility conditions, which results in:

$$
x_{50 \%}=\left(\frac{\varepsilon_{50 \%}}{\varepsilon_{50 \%}+\varepsilon_{f u d}}\right) d
$$

Therefore, for T/L sections with neutral axis $x$ located on the flange, the bending moment $M_{50 \%}$ is found from the resulting force on the compressed area times the moment arm, considering that the stress diagram is triangular:

$$
M_{50 \%}=\left(\frac{0.425 f_{c d} x_{50 \%} b_{f}}{2}\right)\left(d-\frac{x_{50 \%}}{3}\right)
$$

Figure 6.3 illustrates the cross-section analysis of an under-reinforced cross-section, for which the FRP reinforcement reaches its design tensile strain $f_{f u d}$ while the concrete stress-strain relationship can still be considered as linear:

Figure 6.3 - Tension-controlled section, neutral axis on the flange and concrete linear behavior
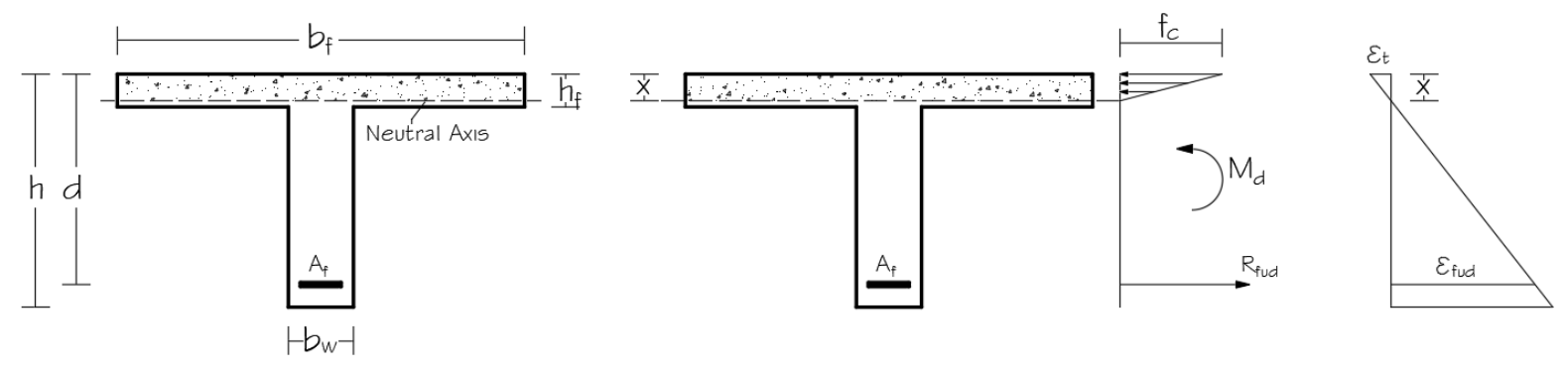

Source: Author

The next step is to compute the neutral axis depth $x$ related to the design bending moment $M_{d}$ under the conditions illustrated in Figure 6.3. First of all, it is necessary to determine the secant elasticity modulus $E_{c s 50 \%}$ for the concrete linear stress-strain relationship, which corresponds to the slope of the line linking the origin to the point $\left(\varepsilon_{50 \%}, 0.425 \mathrm{f}_{\mathrm{cd}}\right)$. Therefore, since $M_{d}$ corresponds to the resulting force times the moment arm, the following cubic equation solution that belongs to the interval $0<\mathrm{x}<\mathrm{d}$ provides the neutral axis depth:

$$
x^{3}-3 d x^{2}+\left(\frac{6 M_{d}}{E_{c s 50 \%} \varepsilon_{f u d} b_{f}}\right)(d-x)=0
$$

The program solves Equation 6.7 through the Newton-Raphson Method. Such equation is defined as a function $f(x)$, whose derivative $f^{\prime}(x)$ exists for a particular interval that contains the equation root. The method requires an initial arbitrated value for $x$ not too close to the 
solution, as a condition for its convergence (ANDRADE, 2012). Therefore, the code initially arbitrates that $\mathrm{x}=1.5 \mathrm{x}$, finding a new value for $x$, according to the method:

$$
x_{i+1}=x_{i}-\frac{f\left(x_{i}\right)}{f^{\prime}\left(x_{i}\right)}
$$

Thenceforth, the code proceeds with the iterative process, stopping as soon as the error defined as $\left|\mathrm{x}_{\mathrm{i}+1}-\mathrm{x}_{\mathrm{i}}\right|$ becomes smaller than $10^{-3}$, which means the neutral axis depth $x$ has been found. Therefore, the reinforcement area $A_{f}$ meeting only the ultimate limit state for flexure is computed through:

$$
A_{f}=\frac{M_{d}}{f_{f u d}\left(d-\frac{x}{3}\right)}
$$

Otherwise, if the design bending moment $M_{d}$ is higher than $M_{50 \%}$, the linear approach no longer applies. ACI 440 1R-15 (2015) allows using the simplified rectangular block for stresses higher than $50 \%$ of the concrete strength. Figure 6.4 illustrates the equilibrium and compatibility conditions for this scenario:

Figure 6.4 - Tension-controlled section with stress block on the flange
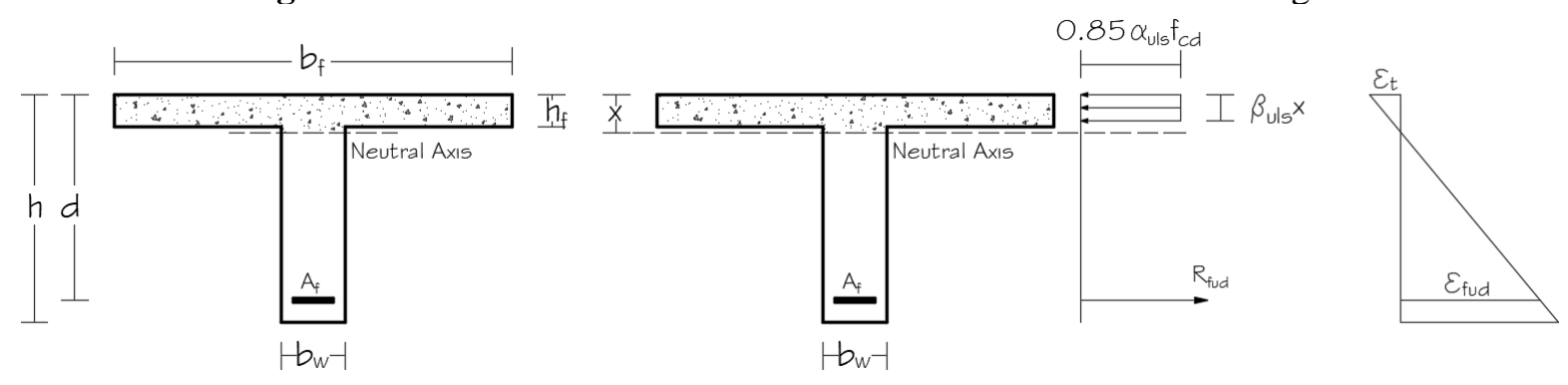

Source: Author

Since the resulting compressive force times the moment arm $d-0.5 \beta_{u l s} x$ corresponds to $M_{d}$, the neutral axis position is:

$$
x=\frac{d}{\beta_{u l s}}\left(1-\sqrt{1-\frac{M_{d}}{0.425 \alpha_{u l s} f_{c d} b_{f} d^{2}}}\right)
$$

The reinforcement area $A_{f}$ to resist $M_{d}$ is computed in the same manner as Equation 6.9, changing only the moment arm:

$$
A_{f}=\frac{M_{d}}{f_{f u d}\left(d-0.5 \beta_{u l s} x\right)}
$$


For both cases, the concrete most compressed concrete fiber $\varepsilon_{t}$ is computed by imposing the compatibility conditions, which leads to:

$$
\varepsilon_{t}=\varepsilon_{f u d}\left(\frac{x}{d-x}\right)
$$

\subsubsection{Tension-controlled sections and balanced stress block on the web}

If the balanced neutral axis $x_{b}$ is located on the web, the actual neutral axis $x$ for an under-reinforced cross-section can be located either on the flange or the web. The code initially assumes that $\beta \mathrm{x}<\mathrm{h}_{\mathrm{f}}$, which means that the depth of the rectangular stress block is smaller than the flange width. Therefore, the neutral axis position is computed through Equation 6.10. If the value found for $x$ confirms the assumption $\beta \mathrm{x}<\mathrm{h}_{\mathrm{f}}$, the code checks whether or not the linear approach can be used to calculate $x$ by comparing $M_{d}$ to $M_{50 \%}$. The code computes the values of $M_{50 \%}, x, A_{f}$ and $\varepsilon_{t}$ the same manner as the previous subsection, with the neutral axis or the actual stress block located on the flange.

However, if the neutral axis $x$ does not confirm the assumption $\beta \mathrm{x}<\mathrm{h}_{\mathrm{f}}$, the code will compute it considering that $\beta \mathrm{x} \geq \mathrm{h}_{\mathrm{f}}$. Since the cross-section is under-reinforced, the possibility of considering the linear approach for the concrete stress-strain relationship exists. To compute the bending moment $M_{50 \%}$, it is necessary to identify the position of $x_{50 \%}$ : flange or web. Thus, if the value of $x_{50 \%}$ found through Equation 6.2 is smaller than $h_{f}, M_{50 \%}$ is computed from Equation 6.6. Thus, if $\beta_{\mathrm{uls}} \mathrm{X} \geq \mathrm{h}_{\mathrm{f}}$ and $\mathrm{x}_{50 \%}<\mathrm{h}_{\mathrm{f}}$, the linear approach does not apply. Figure 6.5 illustrates the cross-section analysis for this situation. The bending moment is composed by the moment $M_{d(w)}$ due to the resulting compressive force on the rectangle with width $b_{w}$ and effective depth $d$, as well as the moment $M_{d(f)}$ caused by the compressive force on the rectangle with $b_{f}-b_{w}$ and $h_{f}$ in width and thickness, respectively, which is directly computed as:

$$
M_{d(f)}=0.85 \alpha_{u l s} f_{c d} h_{f}\left(b_{f}-b_{w}\right)\left(d-0.5 h_{f}\right)
$$

The bending moment, $M_{d(w)}$ is, therefore, equal to $M_{d}-M_{d(f)}$ and the neutral axis position calculated through:

$$
x=\frac{d}{\beta_{u l s}}\left(1-\sqrt{1-\frac{M_{d(w)}}{0.425 \alpha_{u l s} f_{c d} b_{w} d^{2}}}\right)
$$

The FRP areas $A_{f w}$ and $A_{f f}$ illustrated in Figure 6.5 are calculated to resist the bending moments $M_{d(w)}$ and $M_{d(f)}$, respectively. Thus, the total area $A_{f}$ to resist $M_{d}$ is: 


$$
A_{f}=\frac{1}{f_{f u d}}\left(\frac{M_{d(f)}}{d-0.5 h_{f}}+\frac{M_{d(w)}}{d-0.5 \beta_{u l s} x}\right)
$$

Figure 6.5 - Tension-controlled section with stress block on the web
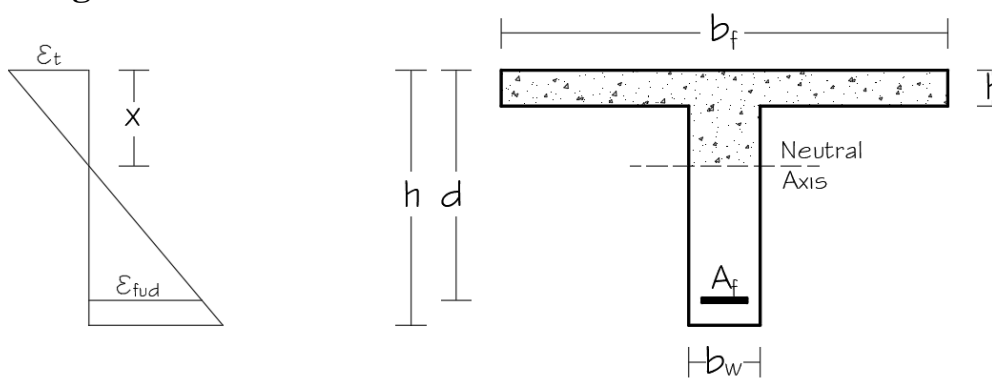

\section{$\overline{h_{f}}$}
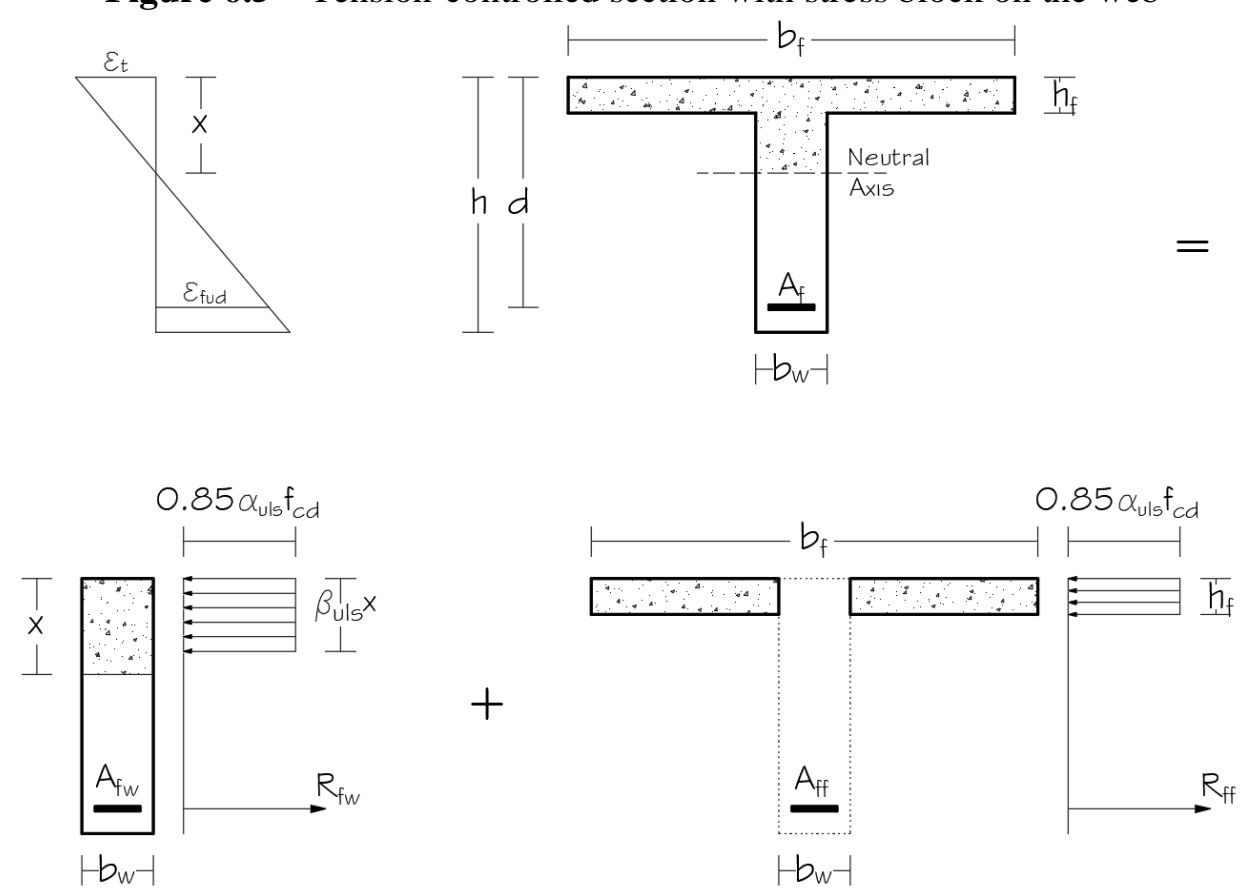

Source: Author

Another scenario is characterized by both neutral axis $x$ and $x_{50 \%}$ locating on the web with $M_{d}<M_{50 \%}$, which means the concrete stress-strain relationship can be considered as linear. Figure 6.6 illustrates the compressive stresses distributed on the flange and web. In order to find $M_{50 \%}$, the code computes the total compressive force $F_{50 \%}$ on the hatched areas, which is:

$$
F_{50 \%}=\frac{1}{2} E_{c s 50 \%} \varepsilon_{c 50 \%}\left[\left(2-\frac{h_{f}}{x_{50 \%}}\right)\left(b_{f}-b_{w}\right) h_{f}+b_{w} x_{50 \%}\right]
$$

Once $F_{50 \%}$ is determined, the program computes its centroid $\bar{y}_{50 \%}$ in relation to the most compressed concrete fiber. Thus, the moment arm defined as the distance between the centers of the compressive and tensile resulting forces is found. Figure 6.6 shows the triangle and trapezium for which their respective centers $\bar{y}_{t r i}$ and $\bar{y}_{t r p}$ are computed through:

$$
\begin{gathered}
\bar{y}_{t r i}=\frac{x_{50 \%}}{3} \\
\bar{y}_{t r p}=h_{f}\left(\frac{1-\frac{2}{3} \frac{h_{f}}{x_{50 \%}}}{2-\frac{h_{f}}{x_{50 \%}}}\right)
\end{gathered}
$$


Therefore, the weighted average of $\bar{y}_{t r i}$ and $\bar{y}_{t r p}$ as regards the triangle and trapezium resulting forces defines the distance $\overline{\mathrm{y}}_{50 \%}$, which is:

$$
\bar{y}_{50 \%}=\frac{b_{w} x_{50 \%} \bar{y}_{t r i}+h_{f}\left(2-\frac{h_{f}}{x_{50 \%}}\right)\left(b_{f}-b_{w}\right) \bar{y}_{t r p}}{b_{w} x_{50 \%}+h_{f}\left(2-\frac{h_{f}}{x_{50 \%}}\right)\left(b_{f}-b_{w}\right)}
$$

The bending moment $M_{50 \%}$ associated to the concrete linear approach limit is:

$$
M_{50 \%}=F_{50 \%}\left(d-\bar{y}_{50 \%}\right)
$$

Figure 6.6 - Tension-controlled section, neutral axis on the web and concrete linear behavior
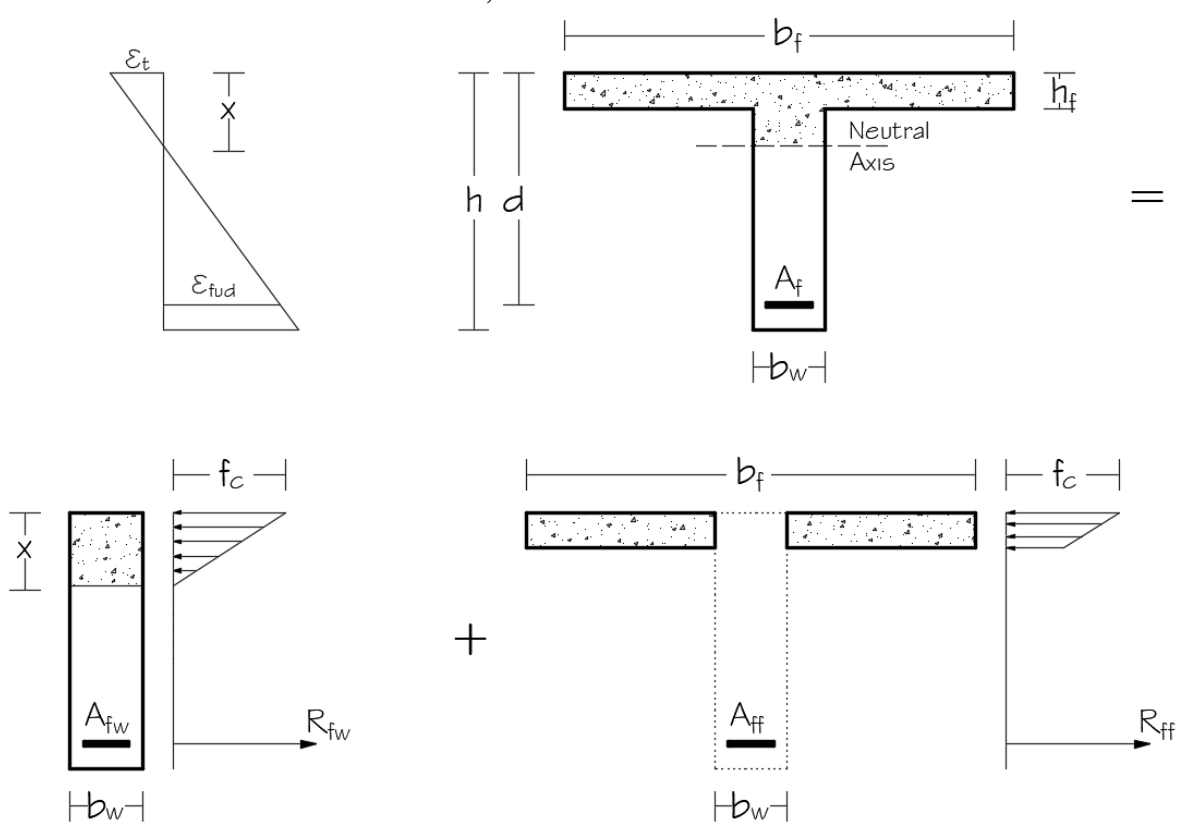

Source: Author

Subsequently, the actual neutral axis $x$ for $\mathrm{M}_{\mathrm{d}}<\mathrm{M}_{50 \%}$ is found through a cubic equation. Since the strain $\varepsilon_{t}$ is unknown, Equation 6.12 allows writing it as a function of $x$. The moment $M_{d}$ results from the total compressive force times the moment arm, which results in:

$$
\begin{gathered}
a_{1}=\frac{6 h_{f}\left(d-0.5 h_{f}\right)\left(b_{f}-b_{w}\right)}{b_{w}} \\
a_{2}=\frac{3 h_{f}^{2}\left(d-h_{f} / 3\right)\left(b_{f}-b_{w}\right)}{b_{w}} \\
a_{3}=\frac{6 M_{d}}{E_{c s 50 \%} \varepsilon_{f u d} b_{w}}
\end{gathered}
$$




$$
x^{3}-3 d x^{2}-\left(a_{1}+a_{3}\right) x+\left(a_{3} d+a_{1} h_{f}-a_{2}\right)=0
$$

Equation 6.24 is solved exactly as Equation 6.7, through the Newton-Hampson Method. The compressive force $F_{c}$ acting on the hatched area is:

$$
F_{c}=\frac{1}{2} E_{c s 50 \%} \varepsilon_{t}\left[\left(2-\frac{h_{f}}{x}\right)\left(b_{f}-b_{w}\right) h_{f}+b_{w} x\right]
$$

Finally, the amount of reinforcement $A_{f}$ to resist the design bending moment $M_{d}$ is:

$$
A_{f}=\frac{F_{c}}{f_{f u d}}
$$

Another scenario is characterized by $\mathrm{M}_{\mathrm{d}} \geq \mathrm{M}_{50 \%}$ and $\beta_{\mathrm{uls}} \mathrm{X} \geq \mathrm{h}_{\mathrm{f}}$, which means the concrete exhibits non-linear behavior and the design must account for the compressive stresses on the flange and web. Therefore, the neutral axis position $x$ and the reinforcement area $A_{f}$ to resist $M_{d}$ are calculated through Equations 6.14 and 6.15, respectively. The strain $\varepsilon_{t}$, in turn, is provided by Equation 6.12 .

\subsubsection{Compression-controlled sections and balanced stress block on the flange}

The failure of compression-controlled cross-sections is characterized by the crushing of the concrete, with the most compressed fiber reaching the ultimate strain $\varepsilon_{c u}$. Additionally, the design bending moment $M_{d}$ is higher than the balanced $M_{b}$. If the balanced stress block $\beta_{u l s} x_{b}$ is located on the flange, the actual stress block $\beta_{u l s} x$ can be located either on the flange or the web. First, the program assumes that $\beta_{\mathrm{uls}} \mathrm{x}<\mathrm{h}_{\mathrm{f}}$, computing the neutral axis depth $x$ through Equation 6.10. If this assumption is correct, the value of $x$ is valid to proceed with the design. Otherwise, the program accounts for the compressive stresses on the flange and web, finding $x$ through Equation 6.14. Therefore, the reinforcement stress $f_{f}$ corresponds to:

$$
f_{f}=E_{f} \varepsilon_{c u}\left(\frac{d-x}{x}\right)
$$

Figures 6.7 and 6.8 illustrate the equilibrium and compatibility conditions to compute the reinforcement areas $A_{f}$ for the scenarios at which the depth of the rectangular stress blocks are smaller and larger than the flange thickness, respectively. Equations 6.28 and 6.29 determine the required areas $A_{f}$ to resist $M_{d}$ considering the scenarios at which $\beta_{\mathrm{uls}} \mathrm{X}<\mathrm{h}_{\mathrm{f}}$ and $\beta_{\mathrm{uls}} \mathrm{X} \geq \mathrm{h}_{\mathrm{f}}$, respectively: 


$$
\begin{gathered}
A_{f}=\frac{M_{d}}{f_{f}\left(d-0.5 \beta_{u l s} x\right)} \\
A_{f}=\frac{1}{f_{f}}\left(\frac{M_{d(f)}}{d-0.5 h_{f}}+\frac{M_{d(w)}}{d-0.5 \beta_{u l s} x}\right)
\end{gathered}
$$

The approach summarized by Figures 6.7 and 6.8, as well as by Equations 6.28 and 6.29 is valid only if $\beta_{\mathrm{uls}} \mathrm{x}_{\mathrm{b}}<\mathrm{h}_{\mathrm{f}}$. The next subsection addresses the design for $\beta_{\mathrm{uls}} \mathrm{x}_{\mathrm{b}} \geq \mathrm{h}_{\mathrm{f}}$.

Figure 6.7 - Compression-controlled section with stress block on the flange

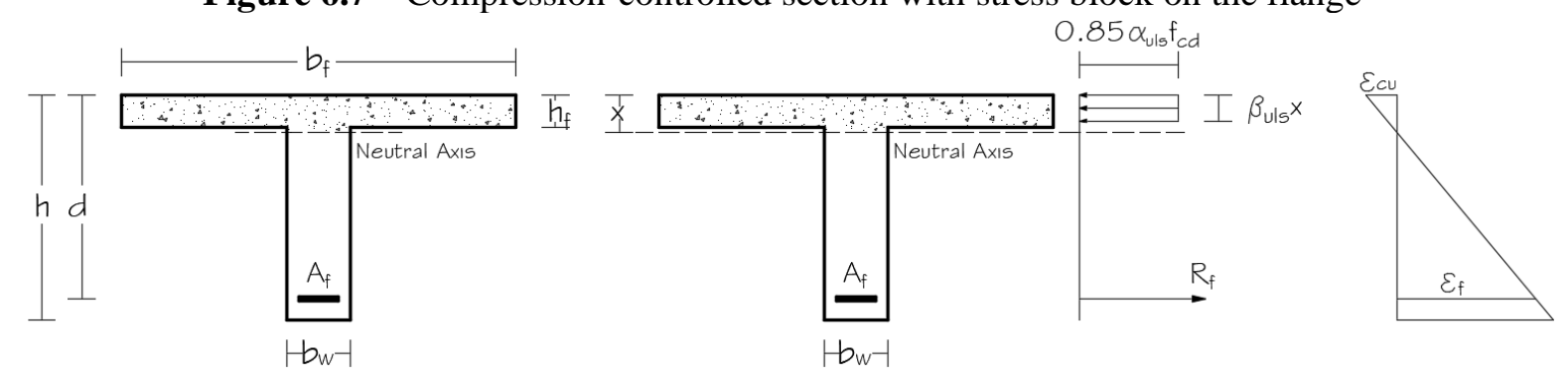

Source: Author

Figure 6.8 - Compressed-controlled section with stress block on the web
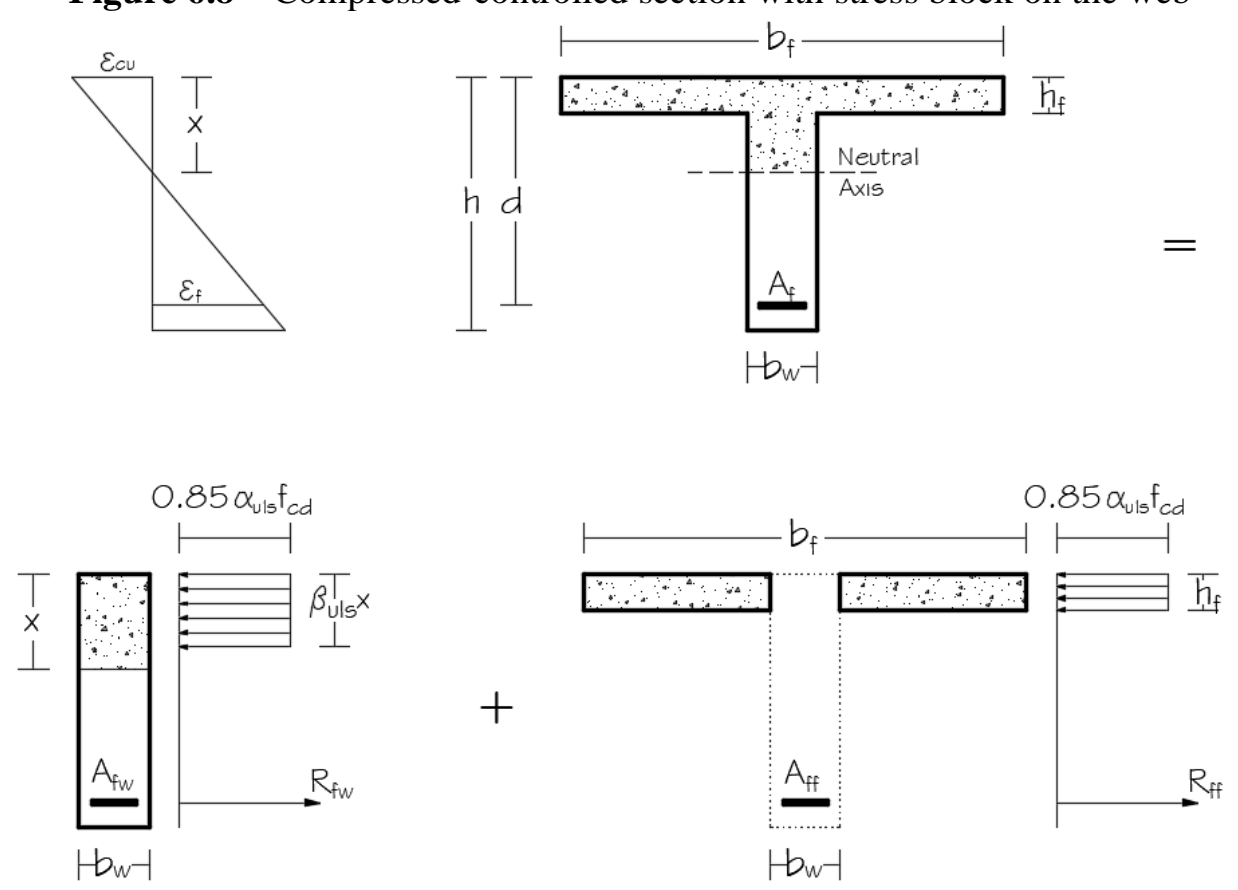

Source: Author

\subsubsection{Compression-controlled sections and balanced neutral axis on the web}

If the balanced stress block $\beta_{u l s} x_{b}$ is located on the web and $\mathrm{M}_{\mathrm{d}} \geq \mathrm{M}_{\mathrm{b}}$, the actual neutral axis $x$ is deeper than $x_{b}$, seeing that the most compressed concrete fiber reaches the ultimate value $\varepsilon_{c u}$ for both the balanced and compression-controlled scenarios. The reinforcement strain 
$\varepsilon f$, in turn, is smaller for the over-reinforced cross-section. Thus, if $x_{b}$ is on the web, so is the actual neutral axis $x$. This scenario is also represented by Figure 6.8, with the neutral axis depth determined by Equation 6.14. Equations 6.27 and 6.29, in turn, compute the tensile stress $f_{f}$ and the required area $A_{f}$, respectively.

\subsection{Checking for FRP creep rupture}

The design comparative analysis described in Chapter 3 showed that the required area $A_{f}$ to resist the design moment $M_{d}$ does not meet the creep rupture limit state under service loading conditions for the majority of AFRP and GFRP RC members. Therefore, the FRP RC Design Program has to adjust the area $A_{f}$ to $A_{a d j}$, so that the limits of 20,30 and $55 \%$ of the nominal tensile strength $f_{f u}$ are not exceeded for GFRP, AFRP and CFRP reinforcement, respectively (ACI 440 1R-15, 2015).

First, it is necessary to calculate the neutral axis $x_{c r}$ under service load conditions through Equations 2.28 to 2.32, as well as, the cracking moment of inertia $I_{c r}$ through Equation 2.33 or 2.34 , depending on the neutral axis depth $x_{c r}$. Thus, considering the bending moment $M_{a p c}$ for almost permanent load combinations, the sustained stress $f_{f s}$ is obtained from Equation 2.27. If the sustained stress exceeds the limits established by ACI 440 1R-15 (2015), the code initiates a loop, by which areas of $0.001 \mathrm{~cm}^{2}$ are added to the initial area $A_{f}$, resulting in $A_{\text {adj }}$. The neutral axis $x_{c r}$ and cracking moment of inertia $I_{c r}$ are recalculated for $A_{a d j}$. The program checks the stress $f_{f s}$ is checked and exits the loop as soon as the sustained stress becomes equal or lower than the maximum allowed. Finally, the reinforcement area $A_{\text {adj }}$ is determined, meeting both limit states.

\subsection{Determination of the Flexural Strength for the Adjusted Area}

Since the reinforcement areas are increased to meet both the limit states for flexure and creep rupture, the flexural strength $M_{r}$ becomes higher than the design bending moment $M_{d}$. As a result, the failure mode may switch from tension to compression-controlled. Even though the cross-sections remain tension-controlled, the linear approach as regards the compressed concrete may no longer apply, which requires the use of the rectangular stress block. Moreover, the neutral axis positions are subject to change from the flange to the web. This section addresses the procedures to compute the flexural strength associated to all these scenarios. 


\subsubsection{FRP rupture and balanced stress block on the flange}

This scenario refers to tension-controlled cross-sections for which the adjusted area $A_{\text {adj }}$ is smaller than the balanced area $A_{b}$ associated to the neutral axis $x_{b}$, for which the concrete and FRP fail simultaneously. Moreover, the depth of the balanced stress block $\beta_{u l s} x_{b}$ is located on the flange, which means that the adjusted stress block depth $\beta_{u l s} x_{a d j}$ related to $A_{\text {adj }}$ is also on the flange, and $x_{a d j}$ is smaller than $h_{f}$.

To verify if the linear concrete behavior applies, the area $A_{50 \%}$ is calculated for the neutral axis $x_{50 \%}$ on the flange. If $\mathrm{A}_{\mathrm{adj}}<\mathrm{A}_{50 \%}$, the linear approach for concrete is used and the area $A_{50 \%}$ for $\mathrm{x}_{50 \%}<\mathrm{h}_{\mathrm{f}}$ is computed through Equation 6.30:

$$
A_{50 \%}=\frac{E_{c s 50 \%} \varepsilon_{c 50 \%} x_{50 \%} b_{f}}{2 f_{f u d}}
$$

The neutral axis position $x_{a d j}$ is calculated by imposing the equilibrium and compatibility conditions shown in Figure 6.3, which leads to:

$$
\begin{gathered}
a_{1}=\frac{E_{c s 50 \%} b_{f}}{2 E_{f} A_{a d j}} \\
x_{a d j}=\frac{\sqrt{1+4 a_{1} d}-1}{2 a_{1}}
\end{gathered}
$$

Therefore, since the neutral axis $x_{a d j}$ is located on the flange and the concrete behaves linearly, the flexural strength $M_{r}$ corresponds to:

$$
M_{r}=A_{a d j} f_{f u d}\left(d-\frac{x_{a d j}}{3}\right)
$$

However, if $\mathrm{A}_{\mathrm{adj}} \geq \mathrm{A}_{50 \%}$, the linear approach no longer applies. Therefore, since the resulting compressive force as regards the rectangular stress block equals the FRP ultimate load, $x_{a d j}$ is computed as follows:

$$
x_{a d j}=\frac{A_{a d j} f_{f u d}}{0.85 \alpha_{u l s} \beta_{u l s} f_{c d} b_{f}}
$$

Subsequently, Equation 6.35 provides the flexural strength $M_{r}$ accounting for the concrete non-linear behavior:

$$
M_{r}=A_{a d j} f_{f u d}\left(d-0.5 \beta_{u l s} x_{a d j}\right)
$$




\subsubsection{FRP Rupture and balanced stress block on the web}

This scenario is similar to the one previously presented; however, the simplified stress block $\beta_{u l s} x_{b}$ reaches the web. Since $\mathrm{A}_{\mathrm{adj}}<\mathrm{A}_{\mathrm{b}}$, the neutral axis positions $x_{a d j}$ and $x_{50 \%}$ may be either on the flange or web. If $\mathrm{x}_{50 \%}<\mathrm{h}_{\mathrm{f}}, \mathrm{A}_{50 \%}$ is determined through Equation 6.30. Furthermore, if $\mathrm{A}_{\mathrm{adj}}<\mathrm{A}_{50 \%}, x_{a d j}$ and $M_{r}$ are obtained from Equations 6.32 and 6.33, respectively.

Conversely, if $\mathrm{x}_{50 \%} \geq \mathrm{h}_{\mathrm{f}}, A_{50 \%}$ corresponds to the ratio between the force $F_{50 \%}$ defined in Equation 6.16 and the FRP design tensile strength $f_{f u d}$. If $\mathrm{A}_{\text {adj }}<\mathrm{A}_{50 \%}$, the neutral axis $x_{a d j}$ can be either on the flange or web. First, it is assumed that it is located on the flange; thus, $x_{a d j}$ is calculated through Equation 6.32. If $\mathrm{x}_{\mathrm{adj}}<\mathrm{h}_{\mathrm{f}}$, the assumption is correct and the flexural strength is obtained from Equation 6.33. Nonetheless, if $\mathrm{x}_{\mathrm{adj}} \geq \mathrm{h}_{\mathrm{f}}$, the linear approach has to consider the compressive stresses on the flange and web. Therefore, the compression force $F_{c}$ provided by Equation 6.25 equals the load at which the FRP rebars rupture. By entering the strain $\varepsilon_{t}$ as a function of $x_{a d j}$, in accordance with Equation 6.12, the neutral axis associated to $A_{\text {adj }}$ is obtained from the following equations:

$$
\begin{gathered}
a_{1}=\frac{2}{b_{w}}\left[\left(b_{f}-b_{w}\right) h_{f}+2 A_{a d j} \frac{E_{f}}{E_{c s 50 \%}}\right] \\
a_{2}=\frac{1}{b_{w}}\left[\left(b_{w}-b_{f}\right) h_{f}^{2}-2 A_{a d j} d \frac{E_{f}}{E_{c s 50 \%}}\right] \\
x_{a d j}=a_{1}\left(\sqrt{\frac{1}{4}-\frac{a_{2}}{a_{1}{ }^{2}}-\frac{1}{2}}\right)
\end{gathered}
$$

Upon finding the neutral axis depth, it is necessary to compute the center $\bar{y}_{c f}$ of the resulting compression force in relation to the most compressed fiber. This parameter is obtained in the same manner as $\bar{y}_{50 \%}$, from Equations 6.17, 6.18 and 6.19, but inserting $x_{a d j}$ instead of $x_{50 \%}$. Finally, the flexural strength is:

$$
M_{r}=A_{a d j} f_{f u d}\left(d-\bar{y}_{c f}\right)
$$

In contrast, if $\mathrm{A}_{\mathrm{adj}} \geq \mathrm{A}_{50 \%}$, the concrete linear approach no longer applies. First, it is assumed that $\beta_{\mathrm{uls}} \mathrm{X}_{\mathrm{adj}}<\mathrm{h}_{\mathrm{f}}$, which allows determining the neutral axis position $x_{a d j}$ through Equation 6.34. If this assumption is correct, the flexural strength $M_{r}$ is obtained from Equation 6.35; otherwise, their values must account for the compressive stresses acting on the flange and 
web. By imposing equilibrium and compatibility conditions, Equations 6.40 and 6.41 determine $x_{a d j}$ and $M_{r}$, respectively, for tension-controlled sections with concrete behaving non-linearly:

$$
\begin{gathered}
x_{a d j}=\frac{A_{a d j} f_{f u d}-0.85 \alpha_{u l s} f_{c d} h_{f}\left(b_{f}-b_{w}\right)}{0.85 \alpha_{u l s} \beta_{u l s} f_{c d} b_{w}} \\
M_{r}=0.85 \alpha_{u l s} f_{c d}\left[\beta_{u l s} b_{w} x_{a d j}\left(d-0.5 \beta_{u l s} x_{a d j}\right)+h_{f}\left(b_{f}-b_{w}\right)\left(d-0.5 h_{f}\right)\right]
\end{gathered}
$$

\subsubsection{Concrete Crushing and balanced stress block on the flange}

If the adjusted area $A_{a d j}$ is larger than the balanced one $A_{b}$, the cross-section fails due to concrete crushing. Additionally, if the balanced stress block depth $\beta_{u l s} x_{b}$ is smaller than the flange thickness $h_{f}$, the actual stress block related to $A_{a d j}$ may be located either on the flange or web. First, the program assumes that $\beta_{\mathrm{uls}} \mathrm{X}_{\mathrm{adj}}<\mathrm{h}_{\mathrm{f}}$, respecting the equilibrium and compatibility conditions shown in Figure 6.7. Since $\varepsilon_{\mathrm{f}}<\varepsilon_{\mathrm{fu}}$, the reinforcement stress is written as a function of the neutral axis depth $x_{a d j}$, in accordance with Equation 6.27. Thus, $x_{a d j}$ is found through:

$$
\begin{aligned}
& a=\frac{0.85 \alpha_{u l s} \beta_{u l s} f_{c d} b_{f}}{E_{f} \varepsilon_{c u} A_{a d j}} \\
& x_{a d j}=\frac{\sqrt{4 a d+1}-1}{2 a}
\end{aligned}
$$

If $\beta_{u l s} x_{a d j}$ is, in fact, smaller than $h_{f}$, the assumption is correct and the flexural strength is determined as follows:

$$
M_{r}=0.85 \alpha_{u l s} \beta_{u l s} f_{c d} b_{f} x_{a d j}\left(d-0.5 \beta_{u l s} x_{a d j}\right)
$$

However, if $\beta_{\mathrm{uls}} \mathrm{X}_{\mathrm{adj}} \geq \mathrm{h}_{\mathrm{f}}$, the assumption is incorrect. Therefore, the equilibrium and compatibility conditions shown in Figure 6.8 allows computing $x_{a d j}$ as follows:

$$
\begin{gathered}
a_{1}=\frac{0.85 \alpha_{u l s} \beta_{u l s} f_{c d} b_{w}}{E_{f} \varepsilon_{c u} A_{a d j}} \\
a_{2}=1+\frac{0.85 \alpha_{u l s} f_{c d}\left(b_{f}-b_{w}\right) h_{f}}{E_{f} \varepsilon_{c u} A_{a d j}} \\
x_{a d j}=\frac{a_{2}}{a_{1}}\left(\sqrt{\frac{1}{4}+\frac{a_{1}}{a_{2}^{2}} d}-\frac{1}{2}\right)
\end{gathered}
$$


Thus, the flexural strength $M_{r}$ is determined through Equation 6.41, in the same manner as for an under-reinforced cross-section whose neutral axis is located on the web and concrete exhibits non-linear behavior.

\subsubsection{Concrete Crushing and balanced stress block on the web}

This scenario is characterized by $A_{a d j} \geq A_{b}$ and $\beta_{u l s} X_{b} \geq h_{f}$. If the balanced stress block reaches the web, so does the actual one $\beta_{u l s} x_{a d j}$. Consequently, $x_{a d j}$ is obtained from Equation 6.47 and the flexural strength $M_{r}$ from Equation 6.41. The only difference from the previous scenario is that no assumptions in regards to the neutral axis position are necessary. It is known for sure that $\beta_{\mathrm{uls}} \mathrm{x}_{\mathrm{adj}}>\mathrm{h}_{\mathrm{f}}$.

\subsection{Interface Program}

Figure 6.9 illustrates the program interface, where the user enters with the cross-section dimensions, concrete grade, type of FRP reinforcement, as well as, its mechanical properties. The applied bending moments as well as the factors for almost permanent, frequent and rare load combinations are inserted according to the structural conditions and design considerations. Nonetheless, the program uses only the moment $M_{a p c}$ regarding the almost permanent combination. Those referring to frequent and rare combinations will be used as the code is optimized to detail cross-sections and estimate crack-widths and deflections.

Moreover, the mechanical properties $f_{f u}$ and $E_{f}$ must be in the intervals defined by Table 4.2.1 of ACI 440 1R-15 (2015) for each type of FRP; otherwise an error message shows up. Additionally, the user reports whether or not the concrete is exposed to earth and weather, so that the environmental reduction factors displayed in Table 6.2 of ACI 440 1R-15 (2015) are properly applied to the FRP tensile strength $f_{f u}$, which is also reduced by the safety factor of 1.25 defined by FIB BULLETIN 40 (2007). The reinforcement grade, in turn, refers to three types of steel with yielding stresses of 250, 500 and $600 \mathrm{MPa}$. The calculations for steel are already implemented in the code, but not in the interface.

The program displays the ultimate bending moment $M_{u d}$ factored by the safety coefficient. However, if it is smaller than the minimum allowed by ABNT NBR 6118 (2014), the bending moment considered for the design is $M_{d, \min }$, determined through Equation 2.26. The program also shows the equilibrium and compatibility conditions, as well as the balanced and actual neutral axis, failure mode and required area $A_{f}$ to resist the design moment $M_{d}$. 
Subsequently, the sustained stress $f_{f s}$ is compared to the maximum allowed by ACI 440 1R-15 (2015). The program will display whether or not the area needs to be adjusted for the creep rupture limit state. Finally, the adjusted reinforcement area $A_{a d j}$, as well as the flexural strength, strains, sustained stress and failure mode are displayed.

Figure 6.9 - Interface of the FRP RC design program

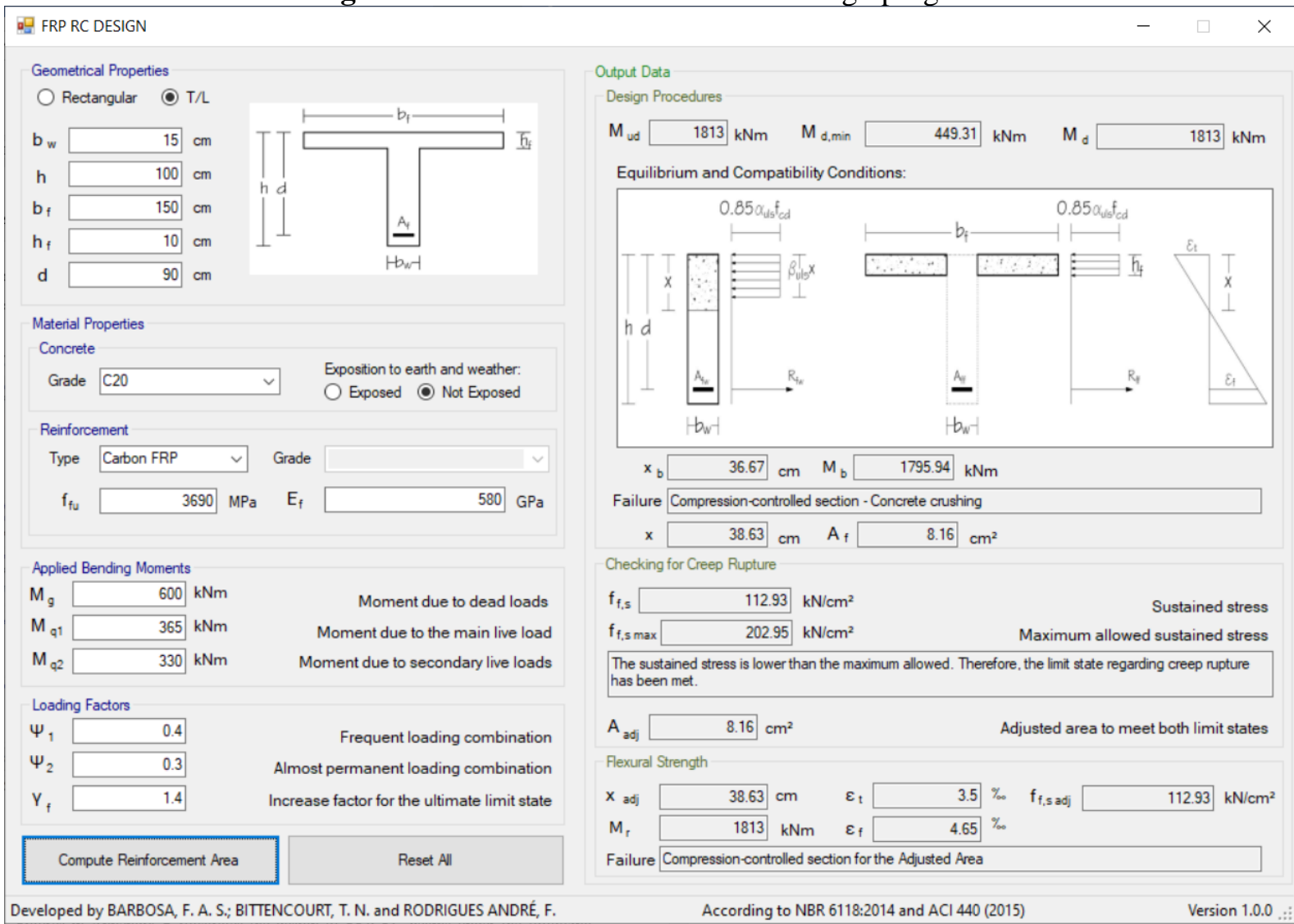

Source: Author

\subsection{Design Examples using the FRP RC Program}

Figures in Appendix B illustrates the design of FRP RC beams under the following circumstances:

a) Balanced stress block on the flange and under-reinforced cross-section with concrete behaving linearly;

b) Balanced stress block on the flange and under-reinforced cross-section with concrete behaving non-linearly;

c) Balanced stress block on the flange and over-reinforced cross-section with actual stress block on the flange; 
d) Balanced stress block on the flange and over-reinforced cross-section with actual stress block on the web;

e) Balanced stress block on the web, under-reinforced cross-section, concrete behaving non-linearly and actual neutral axis on the flange;

f) Balanced stress block on the web, under-reinforced cross-section, concrete behaving non-linearly and actual stress block on the web;

g) Balanced stress block on the web, under-reinforced cross-section, concrete behaving linearly and actual neutral axis on the flange;

h) Balanced stress block on the web, under-reinforced cross-section, concrete behaving linearly and actual neutral axis on the web;

i) Balanced stress block on the web, over-reinforced cross-section and actual stress block on the web.

\subsection{Program Optimization}

The user only enters with loading, material and cross-section parameters, structural systems are not evaluated as a whole. Thus, the program does not compute deflections. Furthermore, once the adjusted area $A_{a d j}$ is found, it is necessary to detail the cross-section in order to evaluate the cracking behavior. However, depending on the cross-section dimensions, diameter of stirrups and concrete cover, the adjusted area may not be accommodated in just one layer. Consequently, if more than one layer is required, the tensile stresses are lower from the second layer onward, leading to the reduction of the flexural strength and the need to redesign the section to, simultaneously, meet all limit states and fit to the commercially available rebars.

However, the comparative design analysis described in Chapter 3 showed that, once the areas are adjusted to meet the creep rupture limit state, the serviceability requirements as regards deflections and cracking are automatically met for the majority of sections. That suggests a future optimization of the design program, which may include the modeling of beams, determination of bending moment diagrams and deflections throughout the flexural member. 


\section{Chapter 7 - Conclusions}

In this dissertation thesis, one can find numerical analyses as regards the behavior of FRP reinforced and prestressed concrete members. The design procedures considering the nonmetallic and conventional steel reinforcements are also presented. Furthermore, an innovative design program for rectangular and T/L cross-section shapes was created so that all steps for the reinforcement area calculation could be displayed.

The design comparative analysis described in Chapter 3 showed that the required FRP reinforcement areas to meet the ultimate limit state for flexure were too small in comparison to those of commercially available rebars. Thus, the areas were readjusted to proper detail the cross-sections. In spite of these adjustments, most AFRP and GFRP RC members still did not meet the creep rupture limit state, which required even more increases in areas. Consequently, the beams became too over-reinforced, with fragile failure characterized by the crushing of the concrete. Regarding the CFRP rebars, ACI 440 1R-15 (2015) allows sustained stresses up to $55 \%$ of the flexural strength. As a result, once the CFRP areas were adjusted for those of commercially available rebars, the creep rupture limit state was directly met. Such need to increase FRP areas may result in very costive solutions, especially for the case in study, for which the design bending moments are considerably lower than the balanced ones. Therefore, it is valid to implement the FRP use in prestressing, taking great advantages of its high strength and capability to elongate.

Perhaps, evaluating the FRP use as non-prestressed reinforcement for situations at which the design bending moment is slightly lower or higher than the balanced moment could yield better results. Since the concrete and FRP strains would be closer to their ultimate values at failure, the mechanical properties of both materials could be proper utilized, resulting in large curvatures that provide some warning as regards the structural conditions prior to failure.

The numerical assessment considering the long-term effects demonstrated that changes in concrete properties affected the structural behavior more than variations in GFRP properties. The cross-sections that were previously designed as compressed-controlled turned out to fail due to the rupture of the non-metallic reinforcement. That occurred because the concrete ultimate strain considerably increased by virtue of the creep effects, especially during the first five years. Even though the long-term effects compromised the structural functionality due to large deflections and intensive cracking, the flexural strength of the cross-sections initially 
defined as tension-controlled considerably increased during the first five years, stabilizing posteriorly. The curvatures, in contrast, continued to increase.

The numerical evaluation described in Chapter 5 showed that using FRP as prestressed reinforcement does not lead to waste of its mechanical properties. The design for the serviceability limit states automatically met the ultimate limit state for flexure, not resulting in too over-reinforced cross-sections for normal strength concretes. High-performance concretes are also suitable; however, the cross-sections became under-reinforced in terms of ultimate limit state, which may indicate some waste of the high strength concrete properties. Moreover, the flexural members prestressed with steel CP 190 RB exhibited intensive cracking and low flexural strength compared to those with FRP. However, it only happened because they were prestressed with the same jacking force. Imposing the same prestressing strain for the axially loaded prismatic members showed totally different results, with the AFRP and CFRP members exhibiting wider cracks for low axial forces compared to the members with steel.

Finally, the procedures for the development of the FRP RC Design Program considered different scenarios as regards the neutral axis position, failure modes and linear or non-linear concrete behavior. The equations developed in Chapter 6 were based on equilibrium and compatibility, assuming that plane cross-sections remain plane and FRP bonds perfectly to concrete. This program is innovative because the main reference codes do not address the design of T/L cross-sections, especially when the ultimate limit state is governed by the FRP rupture instead of concrete crushing. Additionally, it incorporates the concrete constitutive models of ABNT NBR 6118 (2014) into the design of FRP RC beams, suggesting that reinforced concrete courses in Brazil implement the use of FRP, given the need of replacing steel by alternative materials in search for durability. The future optimizations of the program include computation of deflections through matrix analyses, as well as cross-section detailing, not only for FRP but also for steel. Therefore, the user will be able to compare reinforcement area, flexural strengths, deflections and detailing considering steel, AFRP, CFRP and GFRP.

As suggestions for future researches, it is relevant to numerically and experimentally investigate the behavior of flexural members reinforced and prestressed with multiple layers of different FRP types. Implementing sacrificial layers that fail without causing the total structural collapse has the potential to provide valuable information as regards the pseudo-ductility of FRP RC members. Numerical and experimental assessments of FRP RC flexural members strengthened with other innovative materials, such as Ultra High-performance Concrete and different types of non-metallic strengthening are also recommended. 


\section{REFERENCES}

ABNT - Associação Brasileira de Normas Técnicas. ABNT NBR 6118: Projeto de Estruturas de Concreto - Procedimento. $3^{\text {rd }}$ edition, Rio de Janeiro, Brazil, 238 p., 2014.

ABNT - Associação Brasileira de Normas Técnicas. ABNT NBR 6120: Cargas para Cálculo de Estruturas de Edificações - Procedimento, Rio de Janeiro, Brazil, 5 p., 1980.

ABNT - Associação Brasileira de Normas Técnicas. ABNT NBR 7480: Aço destinado a armaduras para estruturas de concreto armado - Especificação. $2^{\text {nd }}$ edition, Rio de Janeiro, Brazil, 13 p., 2007.

ABNT - Associação Brasileira de Normas Técnicas. ABNT NBR 7483: Cordoalhas de Aço para Estruturas de Concreto Protendido - Especificação. $2^{\text {nd }}$ edition, Rio de Janeiro, Brazil, 7 p., 2008.

ACI - American Concrete Institute. ACI 440 1R-06: Guide for the Design and Construction of Structural Concrete Reinforced with FRP Bars. Farm. Hills, MI, USA, 44 p., 2006.

ACI - American Concrete Institute. ACI 440 1R-15: Guide for the Design and Construction of Structural Concrete Reinforced with Fiber-Reinforced Polymer (FRP) Bars. Farm. Hills, MI, USA, 83 p., 2015.

ACI - American Concrete Institute. ACI 440 4R-04: Prestressing Concrete Structures with FRP Tendons - Reapproved 2011. Farm. Hills, MI, USA, 35 p., 2004.

ADHIKARI, S.; Mechanical Properties and Flexural Applications of Basalt FiberReinforced Polymer Bars; Dissertation Thesis, The Graduate Faculty of the University of Akron, Akron, Ohio, 367 p., 2009.

ALY, R. S.; BENMOKRANE, B.; EBEAD, U. A.; Tensile lap splicing of bundled CFRP reinforcing bars in concrete; J. Compos. Constr., Vol. 10, Issue 4, p. 287-294, 2006.

ANDRADE, L. N.; Cálculo Numérico: Introdução à Matemática Computacional, Universidade Federal da Paraíba, João Pessoa - Brazil, 2012. (Handout).

ATUTIS, M.; VALIVONIS, J.; Reinforcement Characteristics of Prestressed Concrete Beams with FRP Tendons; Engineering Structures and Technologies, V.2, p.71-78, 2010. 
BANK, L.C; GENTRY, T.R.; Accelerated Test Methods to Determine the Long-Term Behaviour of FRP Composite Structures: Environmental Effects; Journal of Reinforced Plastic and Composites, Vol. 14, p. 558-587, 1995.

BARBERO, E.J.; Introduction to Composite Materials Design; Taylor \& Francis, Philadelphia, 1999.

BARbOSA, F. A. S.; BITTENCOURT, T. N.; Service Lifetime Assessment of Concrete Reinforced with Glass Fiber-Reinforced Polymer Bars, Proceedings of the $61^{\circ}$ Brazilian Concrete Conference, Fortaleza, Brazil,16 p., 2019.

BARbosA, F. A. S.; BITTEnCOURT, T. N.; WELTER, N. V. C. Structural Behavior Analysis of Prestressed Concrete Reinforced with Fiber-Reinforced Polymer Tendons, Proceedings of the $61^{\circ}$ Brazilian Concrete Conference, Fortaleza, Brazil, 16 p., 2019.

BENMOKRANE, B.; EL-SALAKAWY, E.; EL-RAGABY, A.; DESGAGNE, G.; AND LACKEY, T., Design, Construction and Monitoring of Four Innovative Concrete Bridge Decks Using Non-Corrosive FRP Composite Bars, Annual Conference of the Transportation Association of Canada, Québec City, Québec, Canada, 2004.

BROWN, V.; BARTHOLOMEW, C.; Long-Term Deflections of GFRP-Reinforced Concrete Beams, Proceedings of the First International Conference on Composites in Infrastructure (ICCI-96), H. Saadatmanesh and M. R. Ehsani, eds., Tucson, Ariz., p. 389400, 1996.

BUdelman, H., ROSTASY, F. S., Creep Rupture Behavior of FRP Elements for Prestressed Concrete-Phenomenon, Results and Forecast Models, Proceedings of ACI International Symposium on FRP Reinforcement for Concrete Structures, Vancouver, p. 87$100,1993$.

BURGOYNE C. J. Rational use of advanced composites in concrete; Proceedings of the Institution of Civil Engineers, Structures \& Buildings 146, No 3, p. 253-262, 2001.

CARVALHO, R. C.; FIGUEIREDO FILHO, J. R.; Cálculo e Detalhamento de Estruturas Usuais de Concreto Armado: Segundo a NBR 6118:2014; $4^{\text {th }}$ ed. São Carlos: Edufscar, 415 p., 2014. (ISBN - 978-85-7600-356-4). 
COLLINS, M. P.; MITCHEL. D; Prestressed Concrete Structures; Canadian Prestressed Concrete Structures, Ontario, 1987.

DELla BElla J. C.; Apostila PEF3303 - Estruturas de Concreto 1, Universidade de São Paulo, São Paulo, 2018. (Handout).

DESIMONE, M. V.; Deflections of Continuous GFRP-Reinforced Concrete Beams, MSCE thesis, Department of Civil and Environmental Engineering, Villanova University, Villanova, PA, 2009.

fib International Federation for Structural Concrete, 2001, Externally Bonded FRP Reinforcement for RC Structures, Bulletin $\mathbf{N}^{\mathbf{0}} \mathbf{1 4}$, Fib Task-Group 9.3, Federal Institute of Technology, Lausanne, Switzerland. 138 p. (ISBN - 2-88394-054-1).

fib International Federation for Structural Concrete, 2007, FRP Reinforcement in RC Structures, Bulletin No. 40, Fib Task-Group 9.3, Federal Institute of Technology, Lausanne, Switzerland. 147 p. (ISBN - 978-2-88394-080-2).

fib International Federation for Structural Concrete, 2010, fib Model Code for Concrete Structures, Federal Institute of Technology, Lausanne, Switzerland. 402 p. (ISBN - 978-3433-03061-5).

GRACE, N.; ENOMOTO, T.; ABDELMOHTI, A.; TOKAL, Y.; PURAVANKARA, S.; Flexural behavior of precast concrete box beams post-tensioned with unbonded, carbonfiber-composite cables; PCI Journal, Vol. 53, Issue 4, p. 62-82, 2008.

GHALI, A.; FAVRE, R. Concrete Structures: stresses and deformations, London, UK: Chapman \& Hall, 1986.

HANAI, J. B.; Fundamentos do Concreto Protendido; $1^{\text {st }}$ ed., EESC-USP, São Carlos, Brazil, 110 p, 2005.

HARRIS H. G., SOMBOONSONG W. and KO F. K., New ductile hybrid FRP reinforced bar for concrete structures, Journal of Composites for Construction ASCE 2, No. 1, p. 28-37, 1998.

HAYES, M.D., GARCIA, K., VERGHESE, N.; LESKO, J.J.; The Effects of Moisture on the Fatigue Behavior of a Glass/Vinyl Ester Composite, Proceedings of the 2nd International Conference on Fibre Composites in Infrastructure ICCI'98, Vol. 1, p. 1-13, 1998. 
HOllaway, L., Polymer Composites for Civil and structural Engineering, Blackie Academic \& Professional, Glasgow, 259 p., 1993.

HOLTE, L.E., DOLAN, C.W., SCHMIDT, R.J., Anchorage of non-metallic prestressing tendon, Technical report. University of Wyoming, UWYO-CE93.1, 1993.

HULL, D.; CLYNE, T. W.; An Introduction to Composite Materials; $2^{\text {nd }}$ edition, Cambridge University Press, Cambridge, 1996.

HUSAIN, M.; FAWZY, K.; NADA A.; Performance of prestressed concrete beam with FRP tendons; International Journal of Engineering and Innovative Technology (IJEIT); Vol.5, Issue 2, p. 22-29, 2015.

J.W. SCHMIDT and B. TÄLJSTEN, FRP tendon anchorage in post-tensioned concrete structures, Concrete Repair; Rehabilitation and Retrofitting II -Francis Group, London, ISBN 978-0-415-46850-3, 2009.

KASSEM, C.; FARGHALY, A. S.; BENMOKRANE B.; Evaluation of Flexural Behavior and Serviceability Performance of Concrete Beams Reinforced with FRP Bars, Journal of Composites for Construction, Vol.15, Issue 5, p. 682-695, 2011.

MANDELL, J. F., Fatigue Behavior of Fiber-Resin Composites, Developments in Reinforced Plastics, V. 2, Applied Science Publishers, London, p. 67-107, 1982.

MANDELL, J. F., MEIER, U., Effects of Stress Ratio Frequency and Loading Time on the Tensile Fatigue of Glass-Reinforced Epoxy, Long Term Behavior of Composites, ASTM STP 813, ASTM International, West Conshohocken, PA, p. 55-77, 1983.

MEIER, U.; Carbon Fiber Reinforced Polymers: Modern Materials in Bridge Engineering, Structural Engineering International, Journal of the International Association for Bridge and Structural Engineering, V. 2, No. 1, p. 7-12, 1992.

NANNI, A., BAKIS, C.E., O’NEIL, E.F., DIXON, T.O., Performance of FRP tendon-anchor systems for prestressed concrete structures, Prestressed/Precast Concrete Institute Journal, Vol. 41, No.1, p. 34-43, 1996.

NKURUNZIZA G.; BENMOKRANE, B.; DEBAIKY, A. S.; MASMOUDI, R.; Effect of the Sustained Load and Environment on Long-term Tensile Properties of Glass Fiber- 
Reinforced Polymer Reinforcing Bars, ACI Structural Journal, Vol. 102, No. 4, p. 605-621, 2005.

ODAGIRI, T.; MATSUMOTO, K.; NAKAI H.; Fatigue and Relaxation Characteristics of Continuous Aramid Fiber Reinforced Plastic Rods; Proceedings of the Third International Symposium on Non-Metallic (FRP) Reinforcement for Concrete Structures (FRPRCS-3); V. 2, Japan Concrete Institute, Tokyo, Japan, p. 227-234, 1997.

PILAKOUTAS, K.; GUADAGNINI M., NEOCLEOUS K.; MATTHYS, S. Design Guidelines for FRP Reinforced Concrete Structures, ICE - Institution of Civil Engineers, Structures and Buildings, Vol. 164, Issue SB4, p. 255 - 263, 2009.

RIBEIRO, S. E. C.; Análise de Confiabilidade de Vigas de Concreto Armado com Plástico Reforçado por Fibras. Phd Thesis, Escola de Engenharia da Universidade Federal de Minas Gerais, Belo Horizonte, Brazil, 2009.

RYNGIER, K.; ZDANOWICKZ, L.; Prestressing Concrete Structures with CFRP Composite Tendons; Engineering Transactions, V.63, I.4, p. 407-420, 2015.

SAYED-AHMED, E. Y.; SHRIVE, N. G.; Smart FRP Prestressing Tendons: Properties and Prospects; Proceedings of the Second Middle East Symposium on Structural Composites for Infrastructure Applications, p. 80-93, 1999.

SCHAFF, J. R.; Fatigue and Life Prediction, ASM Handbook Vol. 21 Composites, ASM International, Material Park, Ohio, p. 252-258, 2001.

SLATTERY, K.T., Mechanism model of the creep rupture process in filamentary composites, Proceedings of the $3^{\text {rd }}$ Material and Engineering Conference: Infrastructures: New Materials and Methods of Repair, San Diego, Ca, American Society for Civil Engineering, p. 215-222, 1994.

THOMAZ, E. C. S.; Perdas Imediatas de Protensão - Notas de Aula; IME - Instituto Militar de Engenharia; 2005.

URBANSKI, M.; LAPKO, A.; GARBACZ, A.; Investigation on Concrete Beams Reinforced with Basalt Bars as an Effective Alternative of Conventional R/C Structures; $11^{\text {th }}$ International Conference on Modern Building Materials, Structures and Techniques, MBMST 2013; Vilnius, Lithuania; Procedia Engineering 57, p. 1183 - 1191, 2013. 
YAMAGUCHI, T., KATO, Y., NISHIMURA, T. AND UOMOTO, I., Creep Rupture of FRP

Rods Made of Aramid, Carbon and Glass Fibers, Proceedings of the Third International Symposium on Non-Metallic (FRP) reinforcement for Concrete Structures (FRPRCS-3), Japan Concrete Institute, Sapporo, Japan, Vol. 2, p. 179-186, 1997.

YOUSSEF, T. A.; Time Dependent Behavior of FRP Bars and FRP RC Beams under Sustained Loads, PhD thesis, Université de Sherbrooke, Quebéc, Canada, 250 p., 2010.

YE, L. P.; FENG, P.; ZHANG, K.; LIN, L.; HONG, W. H.; YUE, Q. R.; ZHANG, N.; YANG, T.; FRP in Civil Engineering in China: Research and Applications; Proceedings of the Sixth International Symposium on FRP Reinforcement for Concrete Structures (FRPRCS-6), K. H.Tan, ed., Singapore, 1401 p, 2003. 


\section{Appendix A - Design of FRP and Steel Reinforced Concrete}

Figures A.1 to A.3 illustrate the static schemes of all beams designed in Chapter 3.

Figure A.1 - Structural scheme of Beam 1

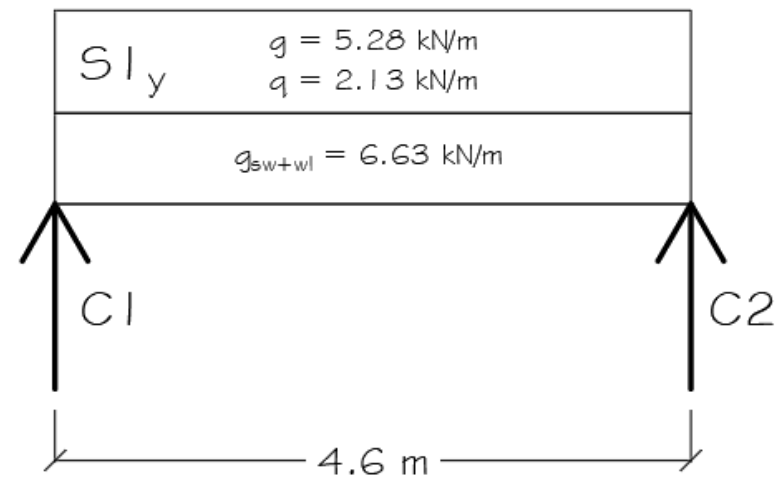

Source: Author

Figure A.2 - Structural scheme of Beam 2

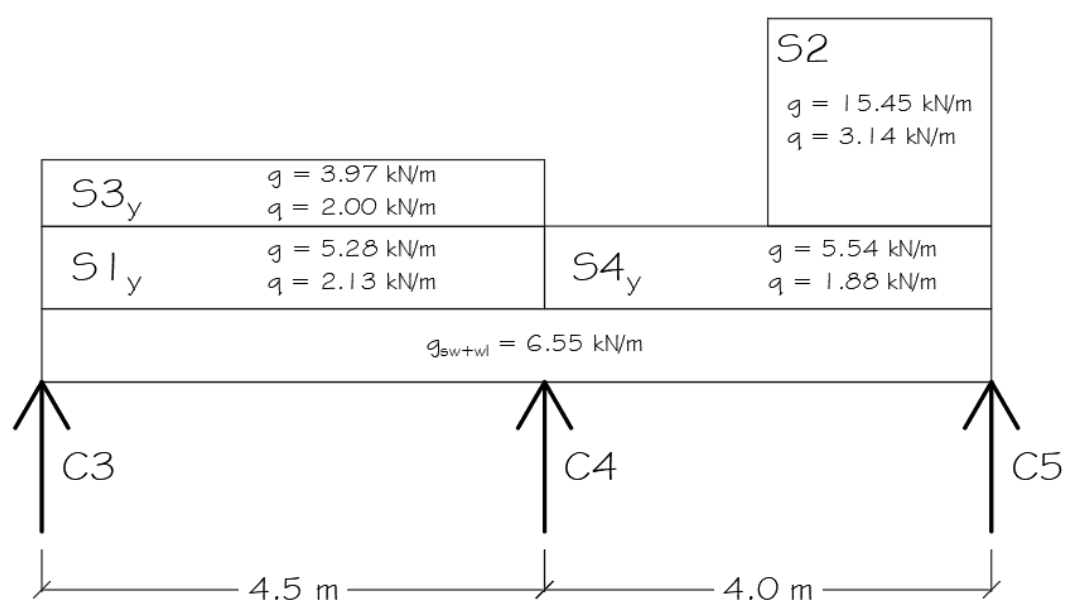

Source: Author

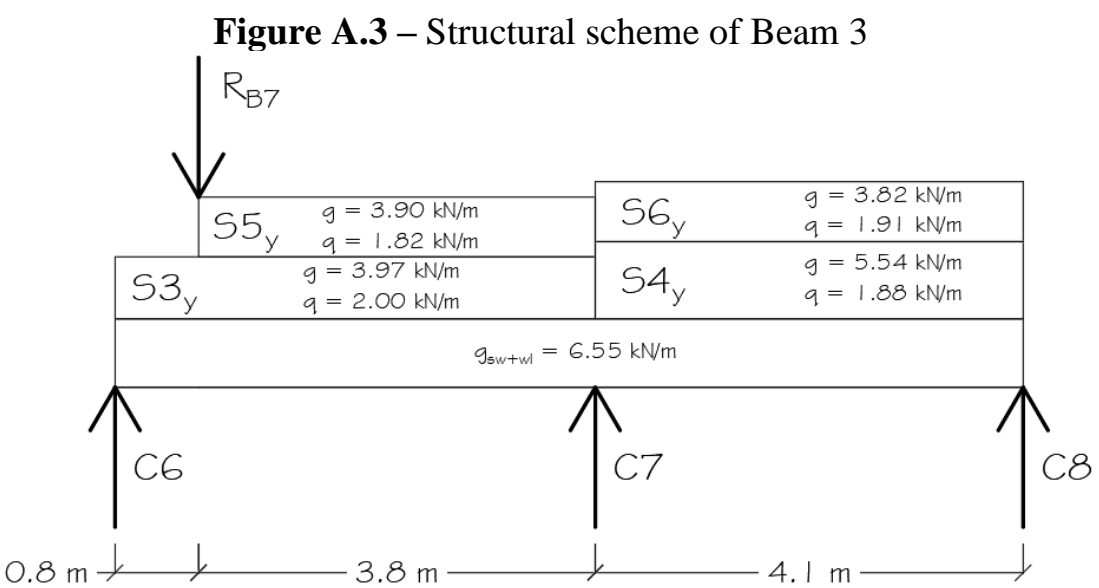

Source: Author 
Figure A.4 - Structural scheme of Beam 4

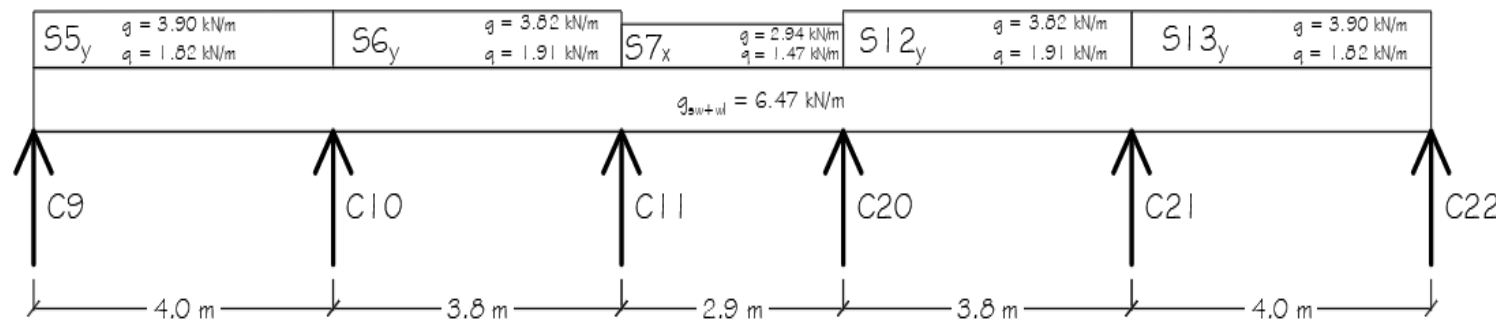

Source: Author

Figure A.5 - Structural scheme of Beam 5

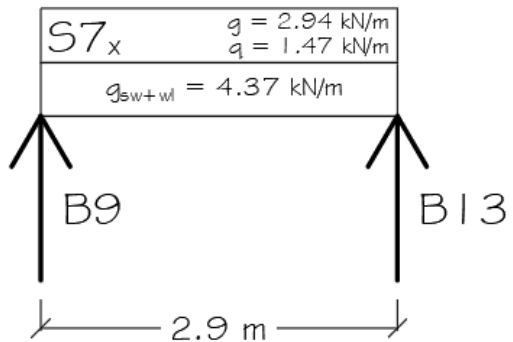

Source: Author

Figure A.6 - Structural scheme of Beam 6

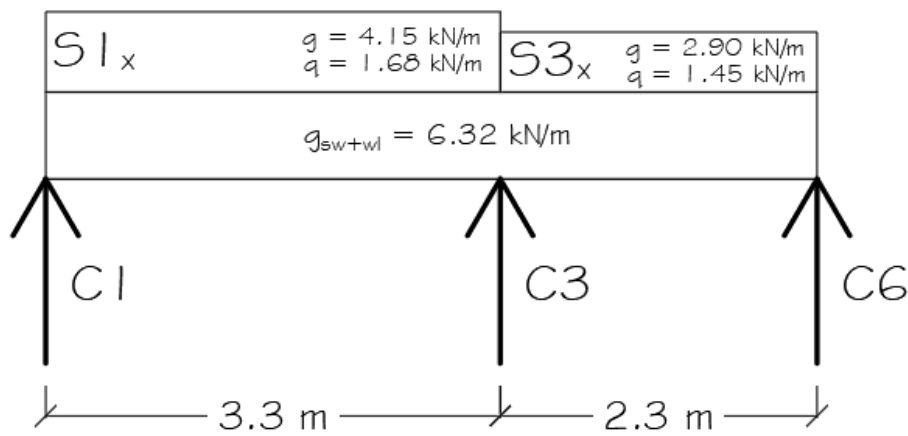

Source: Author

Figure A.7 - Structural scheme of Beam 7

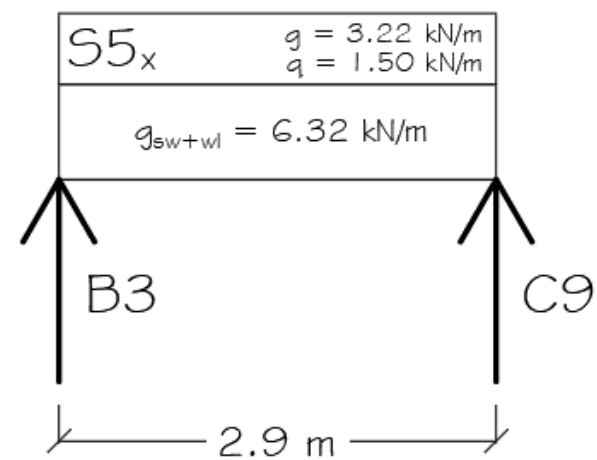

Source: Author 
Figure A.8 - Structural scheme of Beam 8

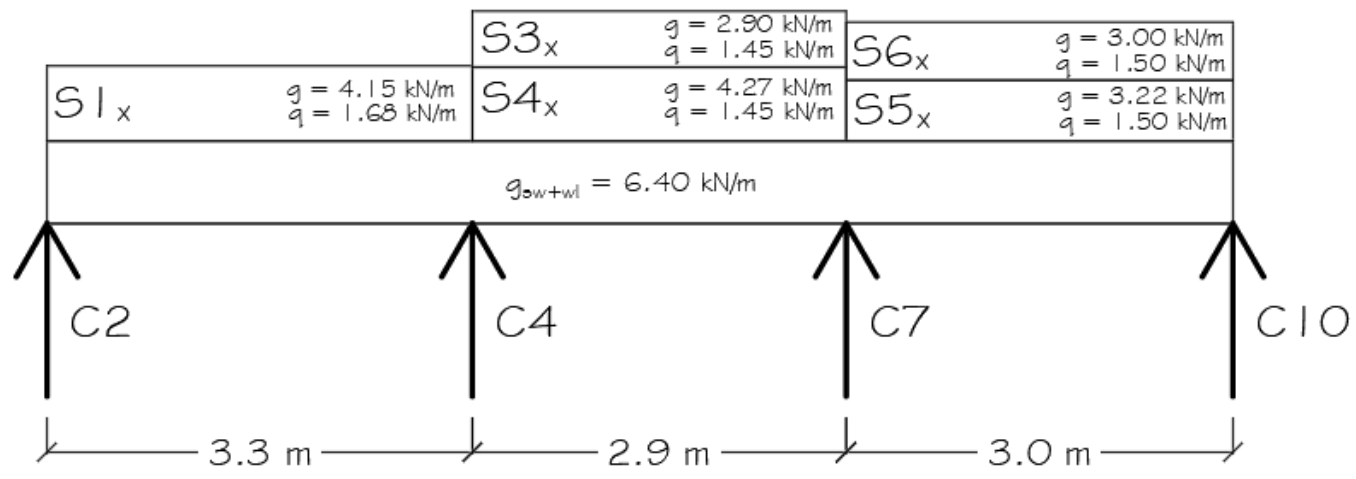

Source: Author

Figure A.9 - Structural scheme of Beam 9

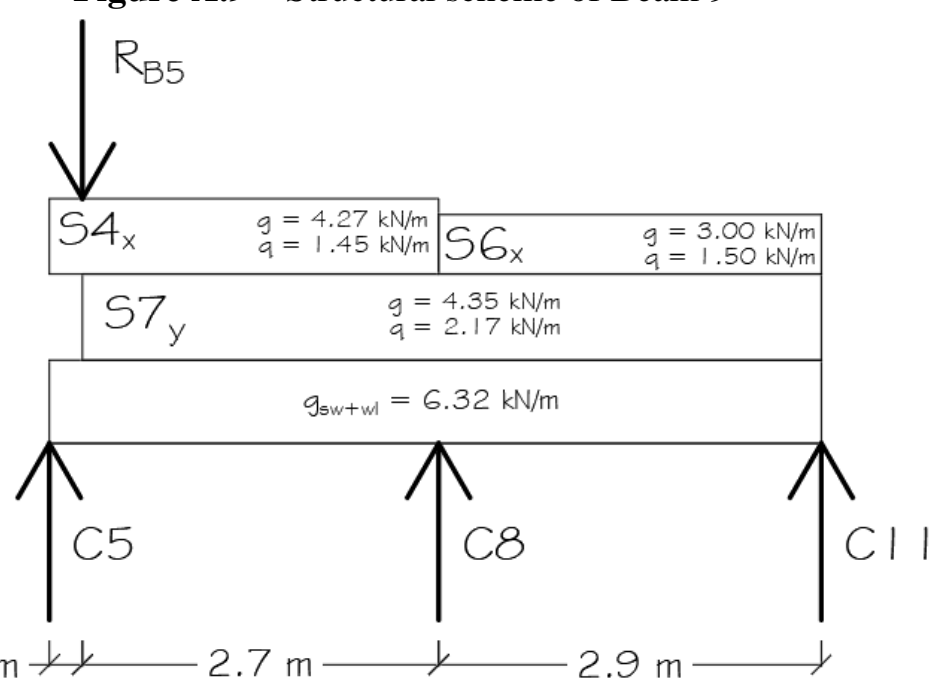

Source: Author

The bending moment diagrams are displayed as follows, by Figures A.10 to A.18:

Figure A.10 - Bending moment diagram of Beam 1

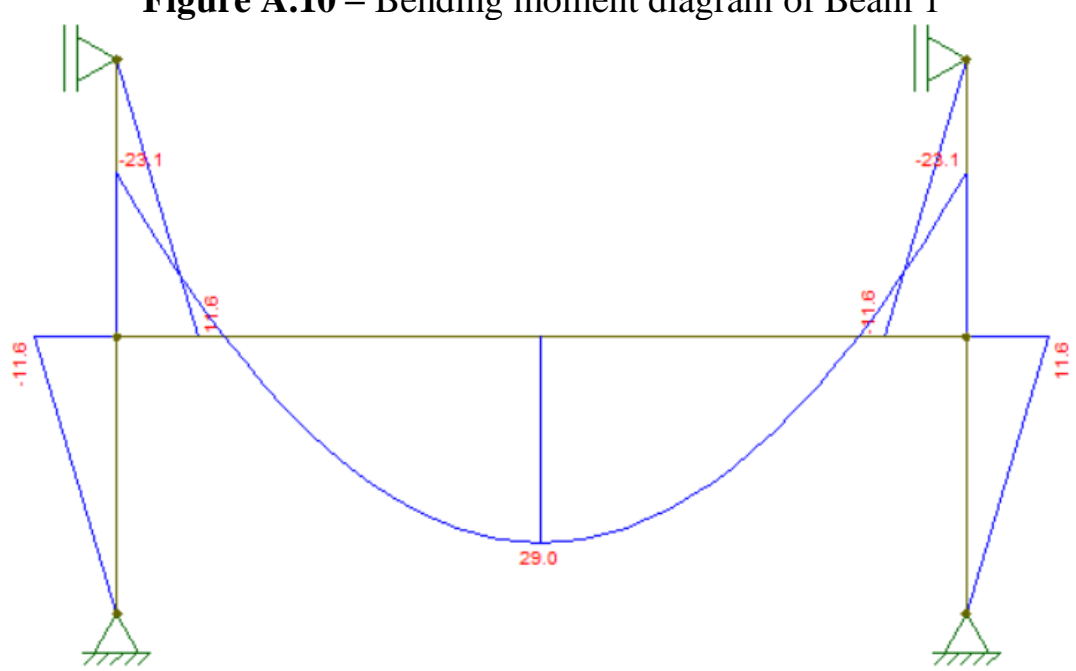

Source: Author 
Figure A.11 - Bending moment diagram of Beam 2

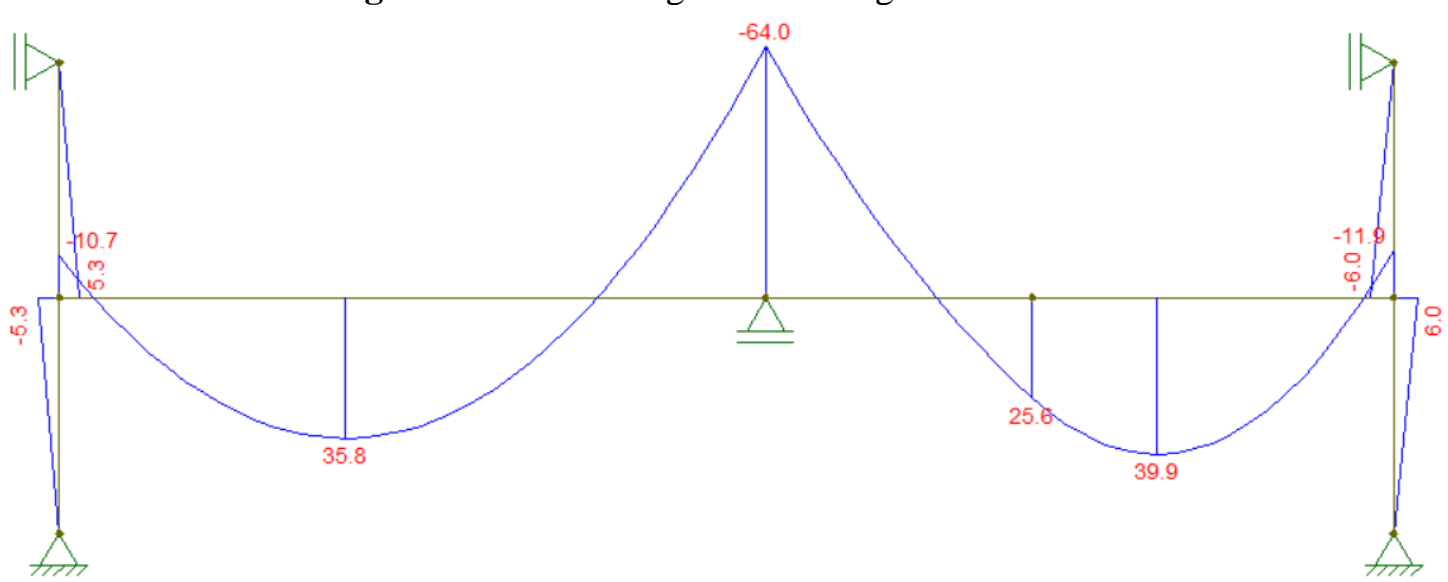

Source: Author

Figure A.12 - Bending moment diagram of Beam 3

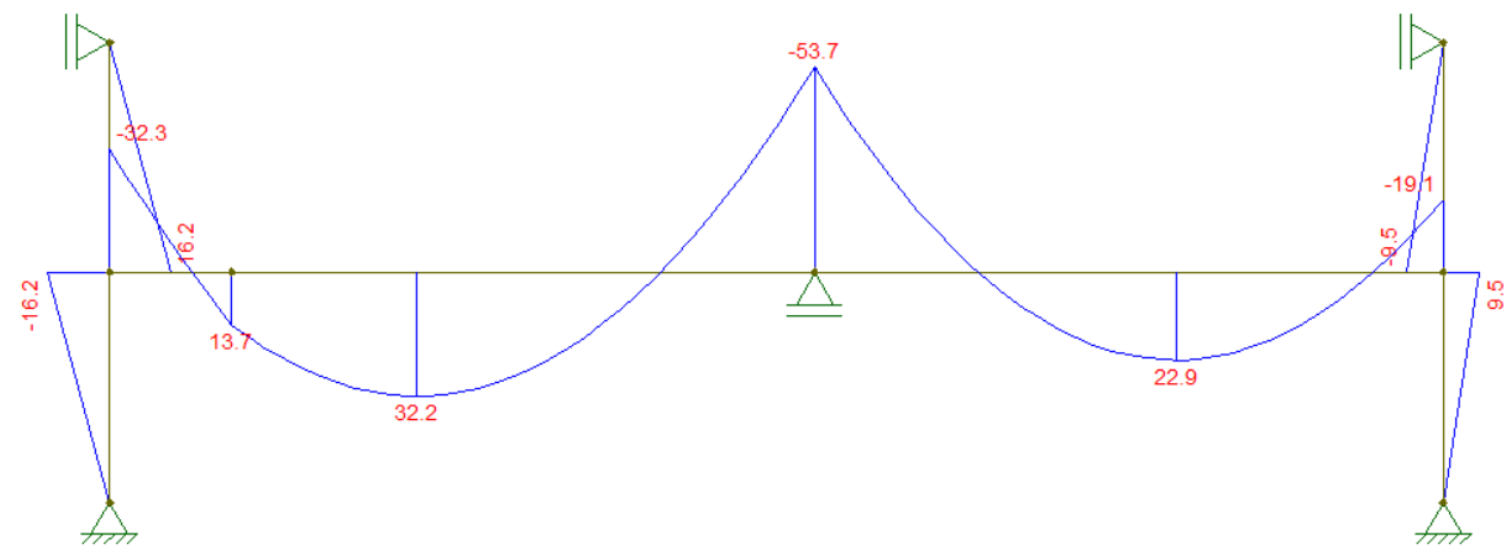

Source: Author

Figure A.13 - Bending moment diagram of Beam 4

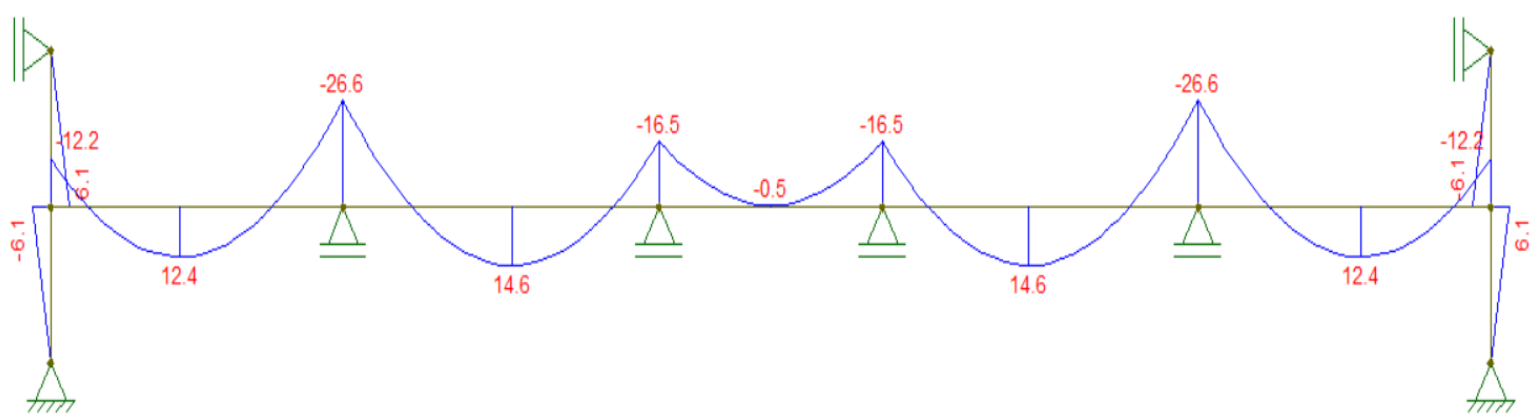

Source: Author

Figure A.14 - Bending moment diagram of Beam 5

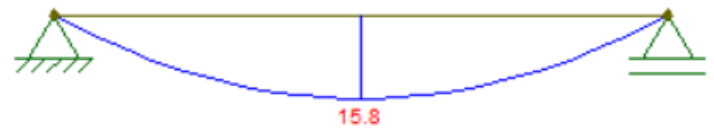

Source: Author 
Figure A.15 - Bending moment diagram of Beam 6

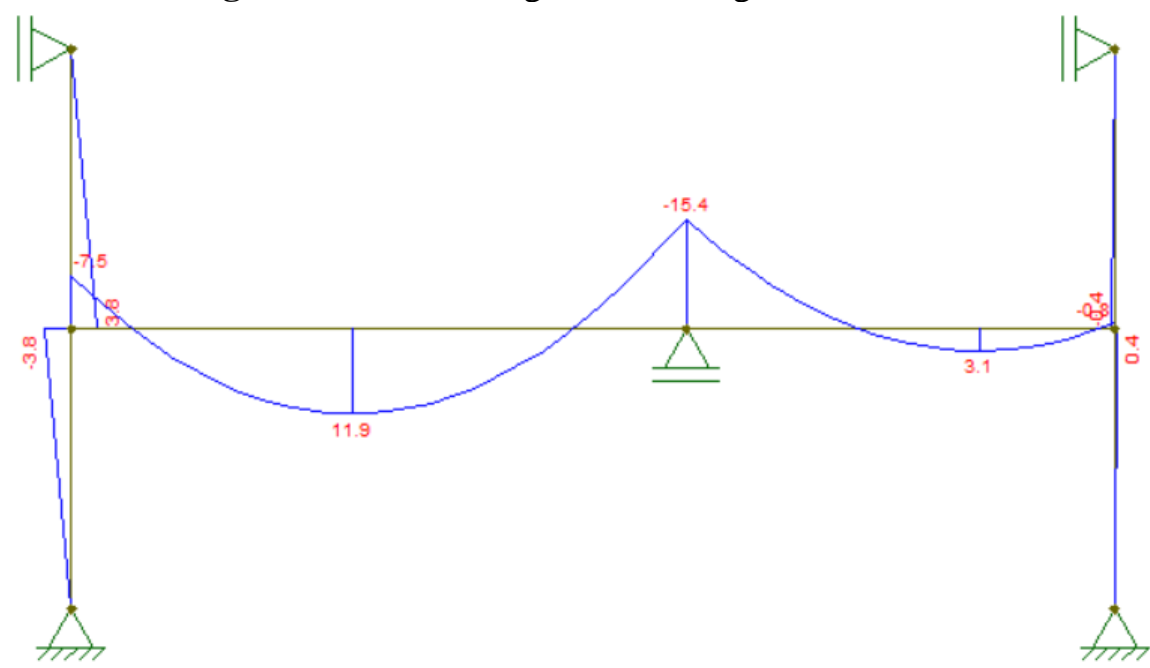

Source: Author

Figure A.16 - Bending moment diagram of Beam 7

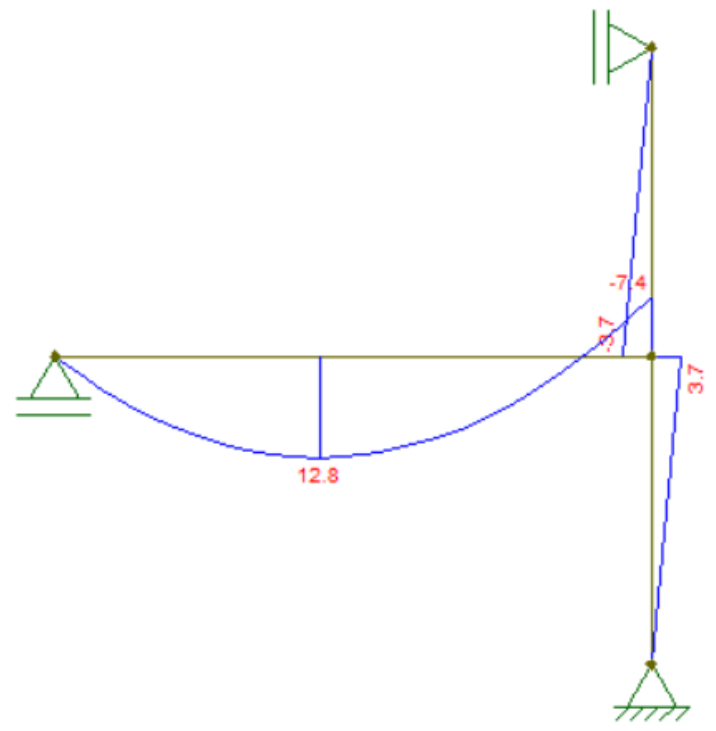

Source: Author

Figure A.17 - Bending moment diagram of Beam 8

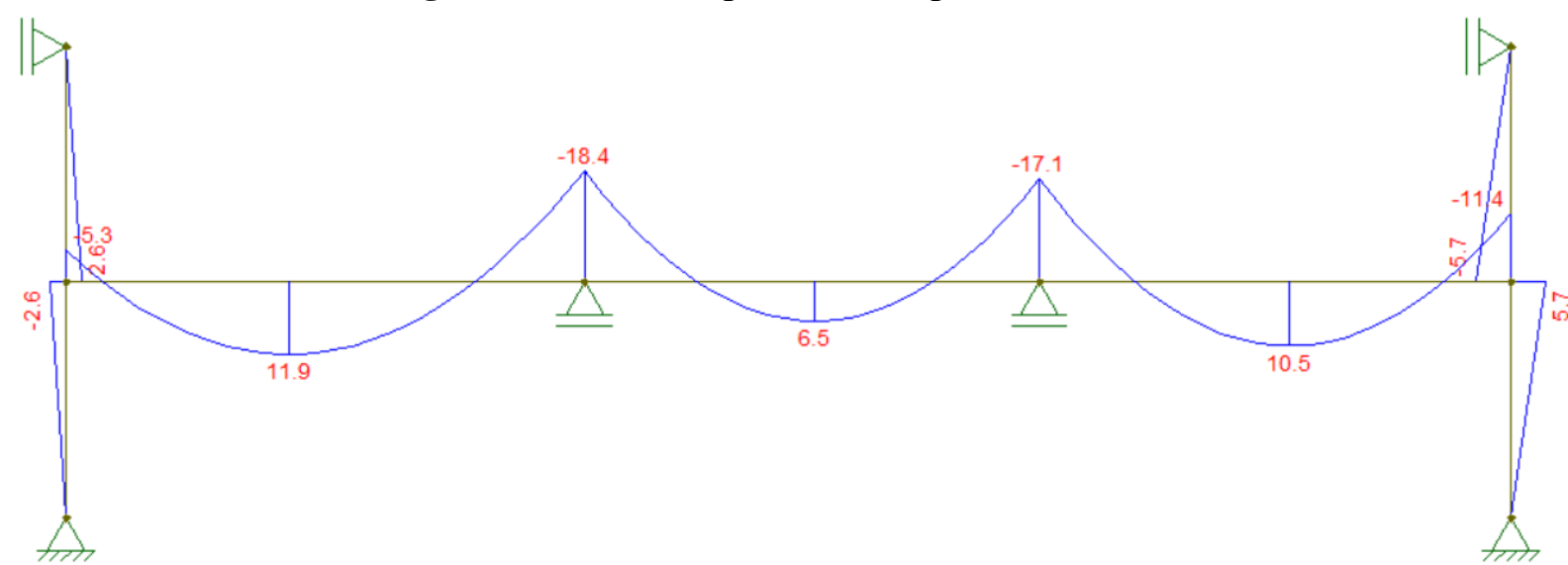

Source: Author 
Figure A.18 - Bending moment diagram of Beam 9

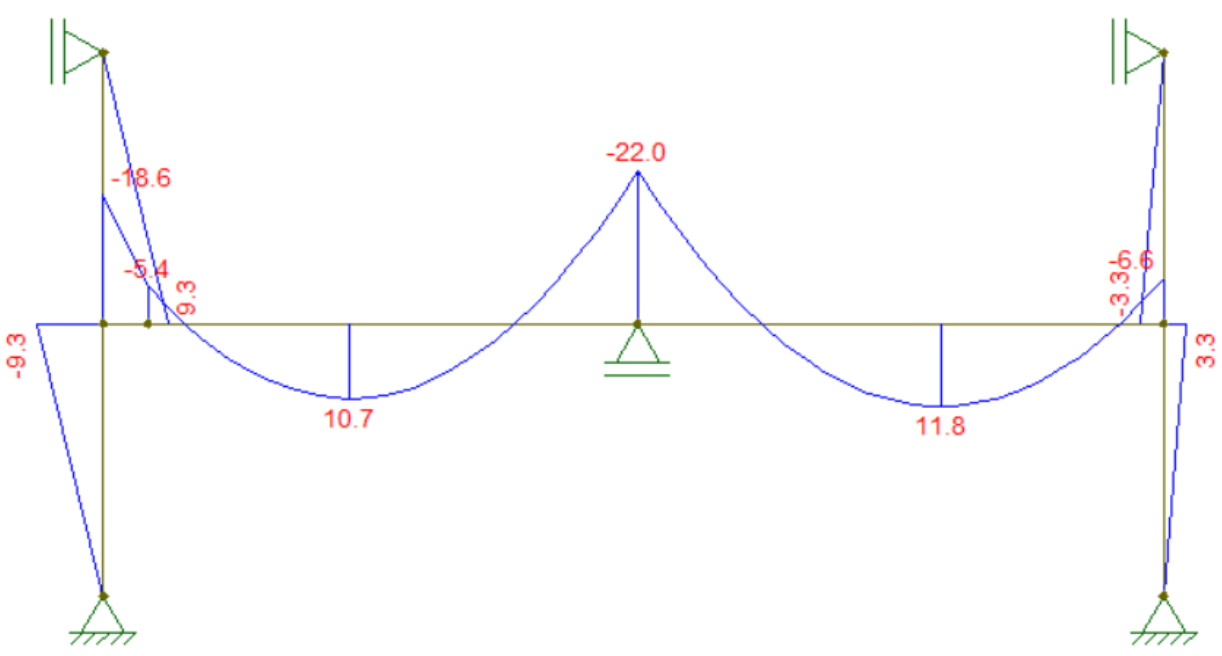

Source: Author

Tables A.1 and A.2 describe the dimensions of the structural elements designed in Chapter 3, as well as the uniformly distributed loads considered for the design:

Table A.1 - Computing of slab distributed dead loads $g$

\begin{tabular}{|c|c|c|c|c|c|c|c|c|c|}
\hline Slab & $\mathbf{l}_{\mathrm{x}}(\mathrm{m})$ & $l_{y}(m)$ & $\underset{\left(\mathbf{k N} / \mathbf{m}^{2}\right)}{\mathbf{g}_{\mathrm{sw}}}$ & $\begin{array}{c}\mathbf{e}_{\mathbf{m w}} \\
(\mathbf{c m})\end{array}$ & $\begin{array}{l}\mathbf{I}_{\mathbf{m w}} \\
(\mathbf{m})\end{array}$ & $\begin{array}{c}\mathbf{h}_{\mathbf{m w}} \\
(\mathbf{m})\end{array}$ & $\begin{array}{c}\mathbf{g}_{\mathrm{wl}} \\
\left(\mathbf{k N} / \mathbf{m}^{2}\right)\end{array}$ & $\underset{\left(\mathbf{k N} / \mathbf{m}^{2}\right)}{\mathbf{g}_{\mathrm{ct}}}$ & $\underset{\left(\mathbf{k N} / \mathbf{m}^{2}\right)}{\mathbf{g}}$ \\
\hline S1 = S9 & 3.4 & 4.6 & 2.25 & 15 & 1.9 & 2.91 & 0.70 & 2.0 & 4.9 \\
\hline $\mathrm{S} 2=\mathrm{S} 8$ & 1.6 & 2.5 & 2.50 & 15 & 3.7 & 2.90 & 5.33 & 2.0 & 9.8 \\
\hline $\mathrm{S3}=\mathrm{S11}$ & 2.9 & 4.6 & 2.00 & - & - & 2.92 & - & 2.0 & 4.0 \\
\hline$S 4=S 10$ & 2.9 & 4.1 & 2.00 & 15 & 4.0 & 2.92 & 1.90 & 2.0 & 5.9 \\
\hline $\mathrm{S5}=\mathrm{S} 12$ & 3.0 & 3.8 & 2.00 & 15 & 0.6 & 2.92 & 0.30 & 2.0 & 4.3 \\
\hline S6 $=$ S13 & 3.0 & 4.1 & 2.00 & - & - & 2.92 & - & 2.0 & 4.0 \\
\hline S7 & 2.9 & 5.7 & 2.00 & - & - & 2.92 & - & 2.0 & 4.0 \\
\hline
\end{tabular}


Table A.2 - Computing of dead $g$ and live $q$ loads on the beams

\begin{tabular}{|c|c|c|c|c|c|c|c|}
\hline Beam & Span & I (m) & $\mathrm{g}_{\mathrm{s}}(\mathrm{kN} / \mathrm{m})$ & $\begin{array}{c}\mathbf{g}_{\text {sw }} \\
(\mathbf{k N} / \mathbf{m})\end{array}$ & $\begin{array}{c}\mathbf{g}_{\mathrm{wl}} \\
(\mathbf{k N} / \mathbf{m})\end{array}$ & $\mathrm{g}(\mathbf{k N} / \mathbf{m})$ & $\mathbf{q}_{\mathrm{s}}(\mathrm{kN} / \mathrm{m})$ \\
\hline \multirow[t]{2}{*}{1} & $1 \mathrm{~A}$ & 4.6 & 5.28 & 1.75 & 4.88 & 11.91 & 2.13 \\
\hline & $2 \mathrm{~A}$ & 4.5 & 9.25 & 1.58 & 4.97 & 15.80 & 4.12 \\
\hline \multirow[t]{3}{*}{2} & $2 B$ & 1.7 & 5.54 & 1.58 & 4.97 & 12.09 & 1.88 \\
\hline & $2 \mathrm{C}$ & 2.3 & 20.99 & 1.58 & 4.97 & 27.54 & 5.02 \\
\hline & $3 \mathrm{~A}$ & 0.8 & 3.97 & 1.58 & 4.97 & 10.52 & 1.99 \\
\hline \multirow[t]{4}{*}{3} & $3 \mathrm{~B}$ & 3.8 & 7.88 & 1.58 & 4.97 & 14.43 & 3.80 \\
\hline & $3 \mathrm{C}$ & 4.1 & 9.35 & 1.58 & 4.97 & 15.90 & 3.79 \\
\hline & $4 \mathrm{~A}$ & 3.8 & 3.97 & 1.40 & 5.07 & 10.44 & 1.99 \\
\hline & $4 B$ & 4.1 & 3.82 & 1.40 & 5.07 & 10.29 & 1.91 \\
\hline \multirow[t]{3}{*}{4} & $4 \mathrm{C}$ & 2.9 & 2.94 & 1.40 & 5.07 & 9.41 & 1.47 \\
\hline & $4 \mathrm{D}$ & 4.1 & 3.82 & 1.40 & 5.07 & 10.29 & 1.91 \\
\hline & $4 \mathrm{E}$ & 3.8 & 3.97 & 1.40 & 5.07 & 10.44 & 1.99 \\
\hline 5 & $5 \mathrm{~A}$ & 2.9 & 2.94 & 1.05 & 5.27 & 9.25 & 1.47 \\
\hline \multirow{2}{*}{6} & $6 \mathrm{~A}$ & 3.3 & 4.15 & 1.05 & 5.27 & 10.47 & 1.68 \\
\hline & $6 \mathrm{~B}$ & 2.3 & 2.90 & 1.05 & 5.27 & 9.21 & 1.45 \\
\hline \multirow[t]{2}{*}{7} & $7 \mathrm{~A}$ & 2.9 & 3.22 & 1.05 & 5.27 & 9.54 & 1.50 \\
\hline & $8 \mathrm{~A}$ & 3.3 & 4.15 & 1.23 & 5.17 & 10.54 & 1.68 \\
\hline \multirow[t]{3}{*}{8} & $8 \mathrm{~B}$ & 2.9 & 7.17 & 1.23 & 5.17 & 13.56 & 2.90 \\
\hline & $8 \mathrm{C}$ & 3.0 & 6.22 & 1.23 & 5.17 & 12.62 & 3.00 \\
\hline & $9 \mathrm{~A}$ & 0.25 & 4.27 & 1.05 & 5.27 & 10.58 & 1.45 \\
\hline \multirow[t]{2}{*}{9} & $9 B$ & 2.7 & 8.62 & 1.05 & 5.27 & 14.93 & 3.62 \\
\hline & $9 \mathrm{C}$ & 2.9 & 7.35 & 1.05 & 5.27 & 13.66 & 3.67 \\
\hline
\end{tabular}


Tables A.3 to A.16 summarize the design of the beams reinforced with FRP and steel combined to concretes C25 and C80 for the comparative analysis described in Chapter 3.

Table A.3 - Design for the ultimate limit state - AFRP and Concrete C25

\begin{tabular}{|c|c|c|c|c|c|c|c|c|c|c|}
\hline B & $\mathbf{S}$ & $M_{d}(k N m)$ & $\mathbf{M}_{\mathrm{b}}(\mathbf{k N m})$ & $\mathbf{F}$ & $\mathbf{x}_{\mathbf{i}}(\mathbf{c m})$ & $A_{f}\left(\mathbf{c m}^{2}\right)$ & $\mathrm{n} \phi_{\mathrm{b}}(\mathbf{m m})$ & $\mathbf{F}_{\mathbf{r}}$ & $\mathbf{x}_{\mathbf{r}}(\mathbf{c m})$ & $M_{r}(k N m)$ \\
\hline \multirow{2}{*}{1} & SP & 28.98 & 73.5 & $\mathrm{~T}$ & 5.5 & 0.72 & $2 \phi 8$ & $\mathrm{~T}$ & 6.7 & 41.08 \\
\hline & SU & 23.10 & 73.5 & $\mathrm{~T}$ & 4.8 & 0.57 & $2 \phi 8$ & $\mathrm{~T}$ & 6.7 & 41.08 \\
\hline \multirow{4}{*}{2} & SP1 & 35.84 & 59.6 & $\mathrm{~T}$ & 6.4 & 1.00 & $2 \phi 8$ & $\mathrm{~T}$ & 6.0 & 36.62 \\
\hline & SP2 & 39.90 & 59.6 & $\mathrm{~T}$ & 6.9 & 1.13 & $3 \phi 8$ & $\mathrm{~T}$ & 6.0 & 54.93 \\
\hline & SU1 & 12.60 & 59.6 & $\mathrm{~T}$ & 3.5 & 0.34 & $2 \phi 8$ & $\mathrm{~T}$ & 6.0 & 36.62 \\
\hline & SU2 & 63.98 & 59.6 & $\mathrm{C}$ & 10.1 & 1.88 & $2 \phi 12.5$ & $\mathrm{C}$ & 11.1 & 69.00 \\
\hline & SU3 & 12.60 & 59.6 & $\mathrm{~T}$ & 3.5 & 0.34 & $2 \phi 8$ & $\mathrm{~T}$ & 6.5 & 36.43 \\
\hline \multirow{5}{*}{3} & SP1 & 32.34 & 59.6 & $\mathrm{~T}$ & 6.0 & 0.90 & $2 \phi 8$ & $\mathrm{~T}$ & 6.5 & 36.43 \\
\hline & SP2 & 22.96 & 59.6 & $\mathrm{~T}$ & 4.9 & 0.63 & $2 \phi 8$ & $\mathrm{~T}$ & 6.5 & 36.43 \\
\hline & SU1 & 32.20 & 59.6 & $\mathrm{~T}$ & 6.0 & 0.90 & $2 \phi 8$ & $\mathrm{~T}$ & 6.5 & 36.43 \\
\hline & SU2 & 53.76 & 59.6 & $\mathrm{~T}$ & 8.7 & 1.55 & $2 \phi 10$ & $\mathrm{~T}$ & 8.8 & 55.09 \\
\hline & SU3 & 19.04 & 59.6 & $\mathrm{~T}$ & 4.4 & 0.52 & $2 \phi 8$ & $\mathrm{~T}$ & 6.5 & 36.43 \\
\hline \multirow{6}{*}{4} & SP1 & 12.32 & 47.1 & $\mathrm{~T}$ & 3.5 & 0.38 & $2 \phi 8$ & $\mathrm{~T}$ & 6.2 & 31.77 \\
\hline & $\mathrm{SP} 2$ & 14.70 & 47.1 & $\mathrm{~T}$ & 3.8 & 0.45 & $2 \phi 8$ & $\mathrm{~T}$ & 6.2 & 31.77 \\
\hline & SP3 & 9.96 & 47.1 & $\mathrm{~T}$ & 3.1 & 0.30 & $2 \phi 8$ & $\mathrm{~T}$ & 6.2 & 31.77 \\
\hline & SU1 & 12.32 & 47.1 & $\mathrm{~T}$ & 3.5 & 0.38 & $2 \phi 8$ & $\mathrm{~T}$ & 6.2 & 31.77 \\
\hline & SU2 & 26.60 & 47.1 & $\mathrm{~T}$ & 5.5 & 0.84 & $2 \phi 8$ & $\mathrm{~T}$ & 6.2 & 31.77 \\
\hline & SU3 & 16.38 & 47.1 & $\mathrm{~T}$ & 4.1 & 0.51 & $2 \phi 8$ & $\mathrm{~T}$ & 6.2 & 31.77 \\
\hline 5 & SP & 15.68 & 26.5 & $\mathrm{~T}$ & 4.2 & 0.66 & $2 \phi 8$ & $\mathrm{~T}$ & 5.6 & 22.43 \\
\hline \multirow{5}{*}{6} & SP1 & 11.90 & 26.5 & $\mathrm{~T}$ & 3.6 & 0.49 & $2 \phi 8$ & $\mathrm{~T}$ & 5.6 & 22.43 \\
\hline & SP2 & 5.60 & 26.5 & $\mathrm{~T}$ & 2.3 & 0.23 & $2 \phi 8$ & $\mathrm{~T}$ & 5.6 & 22.43 \\
\hline & SU1 & 7.56 & 26.5 & $\mathrm{~T}$ & 2.7 & 0.31 & $2 \phi 8$ & $\mathrm{~T}$ & 5.6 & 22.43 \\
\hline & SU2 & 15.40 & 26.5 & $\mathrm{~T}$ & 4.2 & 0.65 & $2 \phi 8$ & $\mathrm{~T}$ & 5.6 & 22.43 \\
\hline & SU3 & 5.60 & 26.5 & $\mathrm{~T}$ & 2.3 & 0.23 & $2 \phi 8$ & $\mathrm{~T}$ & 5.6 & 22.43 \\
\hline \multirow{2}{*}{7} & SP & 12.88 & 26.5 & $\mathrm{~T}$ & 3.7 & 0.54 & $2 \phi 8$ & $\mathrm{~T}$ & 5.6 & 22.43 \\
\hline & SU & 7.28 & 26.5 & $\mathrm{~T}$ & 2.7 & 0.30 & $2 \phi 8$ & $\mathrm{~T}$ & 5.6 & 22.43 \\
\hline \multirow{7}{*}{8} & SP1 & 11.90 & 36.0 & $\mathrm{~T}$ & 3.5 & 0.42 & $2 \phi 8$ & $\mathrm{~T}$ & 5.9 & 27.11 \\
\hline & SP2 & 7.62 & 36.0 & $\mathrm{~T}$ & 2.7 & 0.27 & $2 \phi 8$ & $\mathrm{~T}$ & 5.9 & 27.11 \\
\hline & SP3 & 10.50 & 36.0 & $\mathrm{~T}$ & 3.2 & 0.37 & $2 \phi 8$ & $\mathrm{~T}$ & 5.9 & 27.11 \\
\hline & SU1 & 7.62 & 36.0 & $\mathrm{~T}$ & 2.7 & 0.27 & $2 \phi 8$ & $\mathrm{~T}$ & 5.9 & 27.11 \\
\hline & SU2 & 18.48 & 36.0 & $\mathrm{~T}$ & 4.5 & 0.66 & $2 \phi 8$ & $\mathrm{~T}$ & 5.9 & 27.11 \\
\hline & SU3 & 18.48 & 36.0 & $\mathrm{~T}$ & 4.5 & 0.66 & $2 \phi 8$ & $\mathrm{~T}$ & 5.9 & 27.11 \\
\hline & SU4 & 11.06 & 36.0 & $\mathrm{~T}$ & 3.3 & 0.39 & $2 \phi 8$ & $\mathrm{~T}$ & 5.9 & 27.11 \\
\hline \multirow{5}{*}{9} & SP1 & 10.50 & 26.5 & $\mathrm{~T}$ & 3.3 & 0.43 & $2 \phi 8$ & $\mathrm{~T}$ & 5.6 & 22.43 \\
\hline & SP2 & 11.76 & 26.5 & $\mathrm{~T}$ & 3.5 & 0.49 & $2 \phi 8$ & $\mathrm{~T}$ & 5.6 & 22.43 \\
\hline & SU1 & 18.62 & 26.5 & $\mathrm{~T}$ & 4.8 & 0.79 & $2 \phi 8$ & $\mathrm{~T}$ & 5.6 & 22.43 \\
\hline & SU2 & 21.98 & 26.5 & $\mathrm{~T}$ & 5.4 & 0.94 & $2 \phi 8$ & $\mathrm{~T}$ & 5.6 & 22.43 \\
\hline & SU3 & 7.14 & 26.5 & $\mathrm{~T}$ & 2.6 & 0.29 & $2 \phi 8$ & $\mathrm{~T}$ & 5.6 & 22.43 \\
\hline
\end{tabular}


Table A.4 - Checking for creep rupture, deflections and cracking - AFRP and Concrete C25

\begin{tabular}{|c|c|c|c|c|c|c|c|c|c|c|}
\hline B & $\mathbf{S}$ & $\left(\mathbf{f}_{\mathbf{f}, \mathbf{s}} / \mathbf{f}_{\mathbf{f u}}\right) \%$ & $v_{\text {lt }}(\mathbf{c m})$ & $\mathbf{w}(\mathbf{m m})$ & $\mathbf{n} \varphi_{\mathbf{b}_{\_} \text {adj }}(\mathbf{m m})$ & $\left(\mathbf{f}_{\mathbf{f}, \mathbf{s}} / \mathbf{f}_{\mathbf{f u}}\right) \%$ & $v_{\text {It }}(\mathbf{c m})$ & $\mathbf{w}(\mathbf{m m})$ & $\mathbf{F}_{\mathbf{r}}$ & $M_{r}(k N m)$ \\
\hline \multirow{2}{*}{1} & SP & 35 & 0.20 & 0.7 & $3 \phi 8$ & 24 & 0.20 & 0.4 & $\mathrm{~T}$ & 60.2 \\
\hline & SU & 28 & - & - & $2 \phi 8$ & 28 & - & - & $\mathrm{T}$ & 41.1 \\
\hline & SP1 & 46 & 0.43 & 0.9 & $2 \phi 10$ & 30 & 0.28 & 0.6 & $\mathrm{~T}$ & 55.1 \\
\hline & SP2 & 37 & 2.09 & $\theta .6$ & $2 \phi 12.5$ & 23 & 1.31 & 0.4 & $\mathrm{C}$ & 69.0 \\
\hline 2 & SU1 & 13 & - & - & $2 \phi 8$ & 13 & - & - & $\mathrm{T}$ & 36.4 \\
\hline & SU2 & 36 & - & 0.7 & $2 \phi 16$ & 22 & - & 0.4 & $\mathrm{C}$ & 81.6 \\
\hline & SU3 & 17 & - & - & $2 \phi 8$ & 17 & - & - & $\mathrm{T}$ & 36.4 \\
\hline \multirow{5}{*}{3} & SP1 & 43 & 2.41 & $\theta .8$ & $3 \phi 8$ & 29 & 1.61 & 0.5 & $\mathrm{~T}$ & 53.2 \\
\hline & SP2 & 30 & 0.12 & 0.6 & $3 \phi 8$ & 20 & 0.12 & 0.3 & $\mathrm{~T}$ & 53.2 \\
\hline & SU1 & 43 & - & $\theta .8$ & $3 \phi 8$ & 29 & - & 0.5 & $\mathrm{~T}$ & 53.2 \\
\hline & SU2 & 46 & - & $\theta .9$ & $2 \phi 12.5$ & 30 & - & 0.6 & $\mathrm{C}$ & 69.0 \\
\hline & SU3 & 25 & & - & $2 \phi 8$ & 25 & & - & $\mathrm{T}$ & 36.4 \\
\hline \multirow{6}{*}{4} & SP1 & 19 & 0.09 & - & $2 \phi 8$ & 19 & 0.09 & - & $\mathrm{T}$ & 31.8 \\
\hline & SP2 & 23 & 0.12 & - & $2 \phi 8$ & 23 & 0.12 & - & $\mathrm{T}$ & 31.8 \\
\hline & SP3 & 0 & -0.02 & - & $2 \phi 8$ & 0 & -0.02 & - & $\mathrm{T}$ & 31.8 \\
\hline & SU1 & 19 & - & - & $2 \phi 8$ & 19 & - & - & $\mathrm{T}$ & 31.8 \\
\hline & SU2 & 41 & - & 0.8 & $3 \phi 8$ & 28 & - & 0.5 & $\mathrm{~T}$ & 46.2 \\
\hline & SU3 & 26 & - & 0.5 & $2 \phi 8$ & 26 & - & 0.5 & $\mathrm{~T}$ & 31.8 \\
\hline 5 & SP & 34 & 1.79 & 0.7 & $3 \phi 8$ & 23 & 1.21 & 0.4 & $\mathrm{C}$ & 27.7 \\
\hline \multirow{5}{*}{6} & SP1 & 26 & 0.18 & 0.5 & $3 \phi 8$ & 18 & 0.18 & 0.3 & $\mathrm{C}$ & 27.7 \\
\hline & SP2 & 7 & 0.01 & - & $2 \phi 8$ & 7 & 0.01 & - & $\mathrm{T}$ & 22.4 \\
\hline & SU1 & 17 & - & - & $2 \phi 8$ & 17 & - & - & $\mathrm{T}$ & 22.4 \\
\hline & SU2 & 34 & - & 0.7 & $3 \phi 8$ & 23 & - & 0.4 & $\mathrm{C}$ & 27.7 \\
\hline & SU3 & 2 & - & - & $2 \phi 8$ & 2 & - & - & $\mathrm{T}$ & 22.4 \\
\hline \multirow{2}{*}{7} & SP & 28 & 0.97 & 0.6 & $2 \phi 8$ & 28 & 0.97 & 0.6 & $\mathrm{~T}$ & 22.4 \\
\hline & SU & 16 & - & - & $2 \phi 8$ & 16 & - & - & $\mathrm{T}$ & 22.4 \\
\hline \multirow{7}{*}{8} & SP1 & 22 & 0.11 & 0.4 & $2 \phi 8$ & 22 & 0.11 & 0.4 & $\mathrm{~T}$ & 27.1 \\
\hline & SP2 & 12 & 0.02 & - & $2 \phi 8$ & 12 & 0.02 & - & $\mathrm{T}$ & 27.1 \\
\hline & SP3 & 19 & 0.07 & - & $2 \phi 8$ & 19 & 0.07 & - & $\mathrm{T}$ & 27.1 \\
\hline & SU1 & 10 & - & - & $2 \phi 8$ & 10 & - & - & $\mathrm{T}$ & 27.1 \\
\hline & SU2 & 34 & - & 0.7 & $3 \phi 8$ & 23 & - & 0.4 & $\mathrm{C}$ & 36.9 \\
\hline & SU3 & 33 & - & 0.7 & $3 \phi 8$ & 22 & - & 0.4 & $\mathrm{C}$ & 36.9 \\
\hline & SU4 & 19 & - & - & $2 \phi 8$ & 19 & - & - & $\mathrm{T}$ & 27.1 \\
\hline \multirow{5}{*}{9} & SP1 & 22 & 0.11 & 0.5 & $2 \phi 8$ & 22 & 0.11 & 0.5 & $\mathrm{~T}$ & 22.4 \\
\hline & SP2 & 24 & 0.12 & 0.5 & $2 \phi 8$ & 24 & 0.12 & 0.5 & $\mathrm{~T}$ & 22.4 \\
\hline & SU1 & $4 \theta$ & - & $\theta .8$ & $3 \phi 8$ & 27 & - & 0.5 & $\mathrm{C}$ & 27.7 \\
\hline & SU2 & 46 & - & 1.0 & $2 \phi 10$ & 30 & - & 0.6 & $\mathrm{C}$ & 28.0 \\
\hline & SU3 & 15 & - & - & $2 \phi 8$ & 15 & - & - & $\mathrm{T}$ & 22.4 \\
\hline
\end{tabular}


Table A.5 - Design for the ultimate limit state - AFRP and Concrete C80

\begin{tabular}{|c|c|c|c|c|c|c|c|c|c|c|}
\hline B & $\mathbf{S}$ & $M_{d}(k N m)$ & $M_{b}(\mathbf{k N m})$ & $\mathbf{F}$ & $\mathbf{x}_{\mathbf{i}}(\mathbf{c m})$ & $\mathbf{A}_{\mathbf{f}}\left(\mathbf{c m}^{2}\right)$ & $\mathrm{n} \phi_{\mathrm{b}}(\mathbf{m m})$ & $\mathbf{F}_{\mathbf{r}}$ & $\mathbf{x}_{\mathbf{r}}(\mathbf{c m})$ & $M_{r}(k N m)$ \\
\hline \multirow{2}{*}{1} & SP & 29.35 & 147.7 & $\mathrm{~T}$ & 3.7 & 0.72 & $2 \phi 8$ & $\mathrm{~T}$ & 4.4 & 42.03 \\
\hline & SU & 29.35 & 147.7 & $\mathrm{~T}$ & 3.7 & 0.72 & $2 \phi 8$ & $\mathrm{~T}$ & 4.4 & 42.03 \\
\hline \multirow{5}{*}{2} & SP1 & 35.84 & 119.7 & $\mathrm{~T}$ & 4.1 & 0.98 & $2 \phi 8$ & $\mathrm{~T}$ & 4.2 & 37.40 \\
\hline & SP2 & 39.90 & 119.7 & $\mathrm{~T}$ & 4.3 & 1.09 & $3 \phi 8$ & $\mathrm{~T}$ & 5.1 & 55.63 \\
\hline & SU1 & 23.78 & 119.7 & $\mathrm{~T}$ & 3.3 & 0.64 & $2 \phi 8$ & $\mathrm{~T}$ & 4.2 & 37.40 \\
\hline & SU2 & 63.98 & 119.7 & $\mathrm{~T}$ & 5.5 & 1.77 & $2 \phi 12.5$ & $\mathrm{~T}$ & 6.5 & 88.83 \\
\hline & SU3 & 23.78 & 119.7 & $\mathrm{~T}$ & 3.3 & 0.64 & $2 \phi 8$ & $\mathrm{~T}$ & 4.2 & 37.40 \\
\hline \multirow{5}{*}{3} & SP1 & 32.34 & 119.7 & $\mathrm{~T}$ & 3.9 & 0.88 & $2 \phi 8$ & $\mathrm{~T}$ & 4.2 & 37.40 \\
\hline & SP2 & 23.78 & 119.7 & $\mathrm{~T}$ & 3.3 & 0.64 & $2 \phi 8$ & $\mathrm{~T}$ & 4.2 & 37.40 \\
\hline & SU1 & 32.20 & 119.7 & $\mathrm{~T}$ & 3.9 & 0.88 & $2 \phi 8$ & $\mathrm{~T}$ & 4.2 & 37.40 \\
\hline & SU2 & 53.76 & 119.7 & $\mathrm{~T}$ & 5.0 & 1.48 & $2 \phi 10$ & $\mathrm{~T}$ & 5.2 & 57.75 \\
\hline & SU3 & 23.78 & 119.7 & $\mathrm{~T}$ & 3.3 & 0.64 & $2 \phi 8$ & $\mathrm{~T}$ & 4.2 & 37.40 \\
\hline \multirow{6}{*}{4} & SP1 & 18.79 & 94.6 & $\mathrm{~T}$ & 3.0 & 0.57 & $2 \phi 8$ & $\mathrm{~T}$ & 3.9 & 32.77 \\
\hline & SP2 & 18.79 & 94.6 & $\mathrm{~T}$ & 3.0 & 0.57 & $2 \phi 8$ & $\mathrm{~T}$ & 3.9 & 32.77 \\
\hline & SP3 & 18.79 & 94.6 & $\mathrm{~T}$ & 3.0 & 0.57 & $2 \phi 8$ & $\mathrm{~T}$ & 3.9 & 32.77 \\
\hline & SU1 & 18.79 & 94.6 & $\mathrm{~T}$ & 3.0 & 0.57 & $2 \phi 8$ & $\mathrm{~T}$ & 3.9 & 32.77 \\
\hline & SU2 & 26.60 & 94.6 & $\mathrm{~T}$ & 3.5 & 0.82 & $2 \phi 8$ & $\mathrm{~T}$ & 3.9 & 32.77 \\
\hline & SU3 & 18.79 & 94.6 & $\mathrm{~T}$ & 3.0 & 0.57 & $2 \phi 8$ & $\mathrm{~T}$ & 3.9 & 32.77 \\
\hline 5 & SP & 15.68 & 53.2 & $\mathrm{~T}$ & 2.7 & 0.64 & $2 \phi 8$ & $\mathrm{~T}$ & 3.3 & 23.52 \\
\hline \multirow{5}{*}{6} & SP1 & 11.90 & 53.2 & $\mathrm{~T}$ & 2.4 & 0.48 & $2 \phi 8$ & $\mathrm{~T}$ & 3.3 & 23.52 \\
\hline & SP2 & 10.57 & 53.2 & $\mathrm{~T}$ & 2.2 & 0.43 & $2 \phi 8$ & $\mathrm{~T}$ & 3.3 & 23.52 \\
\hline & SU1 & 10.57 & 53.2 & $\mathrm{~T}$ & 2.2 & 0.43 & $2 \phi 8$ & $\mathrm{~T}$ & 3.3 & 23.52 \\
\hline & SU2 & 15.40 & 53.2 & $\mathrm{~T}$ & 2.7 & 0.63 & $2 \phi 8$ & $\mathrm{~T}$ & 3.3 & 23.52 \\
\hline & SU3 & 10.57 & 53.2 & $\mathrm{~T}$ & 2.2 & 0.43 & $2 \phi 8$ & $\mathrm{~T}$ & 3.3 & 23.52 \\
\hline \multirow{2}{*}{7} & SP & 12.88 & 53.2 & $\mathrm{~T}$ & 2.5 & 0.52 & $2 \phi 8$ & $\mathrm{~T}$ & 3.3 & 23.52 \\
\hline & SU & 10.57 & 53.2 & $\mathrm{~T}$ & 2.2 & 0.43 & $2 \phi 8$ & $\mathrm{~T}$ & 3.3 & 23.52 \\
\hline \multirow{7}{*}{8} & SP1 & 14.38 & 72.4 & $\mathrm{~T}$ & 2.6 & 0.50 & $2 \phi 8$ & $\mathrm{~T}$ & 3.6 & 28.14 \\
\hline & SP2 & 14.38 & 72.4 & $\mathrm{~T}$ & 2.6 & 0.50 & $2 \phi 8$ & $\mathrm{~T}$ & 3.6 & 28.14 \\
\hline & SP3 & 14.38 & 72.4 & $\mathrm{~T}$ & 2.6 & 0.50 & $2 \phi 8$ & $\mathrm{~T}$ & 3.6 & 28.14 \\
\hline & SU1 & 14.38 & 72.4 & $\mathrm{~T}$ & 2.6 & 0.50 & $2 \phi 8$ & $\mathrm{~T}$ & 3.6 & 28.14 \\
\hline & SU2 & 18.48 & 72.4 & $\mathrm{~T}$ & 2.9 & 0.65 & $2 \phi 8$ & $\mathrm{~T}$ & 3.6 & 28.14 \\
\hline & SU3 & 18.48 & 72.4 & $\mathrm{~T}$ & 2.9 & 0.65 & $2 \phi 8$ & $\mathrm{~T}$ & 3.6 & 28.14 \\
\hline & SU4 & 14.38 & 72.4 & $\mathrm{~T}$ & 2.6 & 0.50 & $2 \phi 8$ & $\mathrm{~T}$ & 3.6 & 28.14 \\
\hline \multirow{5}{*}{9} & SP1 & 10.57 & 53.2 & $\mathrm{~T}$ & 2.2 & 0.43 & $2 \phi 8$ & $\mathrm{~T}$ & 3.3 & 23.52 \\
\hline & SP2 & 11.76 & 53.2 & $\mathrm{~T}$ & 2.3 & 0.48 & $2 \phi 8$ & $\mathrm{~T}$ & 3.3 & 23.52 \\
\hline & SU1 & 18.62 & 53.2 & $\mathrm{~T}$ & 3.0 & 0.76 & $2 \phi 8$ & $\mathrm{~T}$ & 3.3 & 23.52 \\
\hline & SU2 & 21.98 & 53.2 & $\mathrm{~T}$ & 3.2 & 0.91 & $2 \phi 8$ & $\mathrm{~T}$ & 3.3 & 23.52 \\
\hline & SU3 & 10.57 & 53.2 & $\mathrm{~T}$ & 2.2 & 0.43 & $2 \phi 8$ & $\mathrm{~T}$ & 3.3 & 23.52 \\
\hline
\end{tabular}


Table A.6 - Checking for creep rupture, deflections and cracking - AFRP and Concrete C80

\begin{tabular}{|c|c|c|c|c|c|c|c|c|c|c|}
\hline B & $\mathbf{S}$ & $\left(\mathbf{f}_{\mathrm{f} . \mathrm{s}} / \mathbf{f}_{\mathrm{fu}}\right) \%$ & $\mathrm{v}_{\mathrm{It}}(\mathbf{c m})$ & $\mathbf{w}(\mathbf{m m})$ & $\mathbf{n} \varphi_{\mathbf{b} \_a d j}(\mathbf{m m})$ & $\left(\mathbf{f}_{\mathrm{f} . \mathrm{s}} / \mathbf{f}_{\mathrm{fu}}\right) \%$ & $\mathrm{v}_{\mathrm{lt}}(\mathrm{cm})$ & $\mathbf{w}(\mathbf{m m})$ & $\mathbf{F}_{\mathbf{r}}$ & $\mathrm{M}_{\mathrm{r}}(\mathbf{k N m})$ \\
\hline \multirow{2}{*}{1} & SP & 35 & 0.11 & - & $3 \phi 8$ & 23 & 0.11 & - & $\mathrm{T}$ & 62.56 \\
\hline & SU & 28 & - & - & $2 \phi 8$ & 28 & - & - & $\mathrm{T}$ & 42.03 \\
\hline \multirow{5}{*}{2} & SP1 & 46 & 0.02 & - & $2 \phi 10$ & 30 & 0.02 & - & $\mathrm{T}$ & 57.75 \\
\hline & SP2 & 37 & 0.12 & $\theta .6$ & $2 \phi 12.5$ & 23 & 0.12 & 0.40 & $\mathrm{~T}$ & 88.83 \\
\hline & SU1 & 13 & - & - & $2 \phi 8$ & 13 & - & - & $\mathrm{T}$ & 37.40 \\
\hline & SU2 & 35 & - & $\theta .7$ & $2 \phi 16$ & 22 & - & 0.40 & $\mathrm{C}$ & 129.57 \\
\hline & SU3 & 16 & - & - & $2 \phi 8$ & 16 & - & - & $\mathrm{T}$ & 37.40 \\
\hline \multirow{5}{*}{3} & SP1 & 42 & 0.13 & - & $3 \phi 8$ & 28 & 0.13 & - & $\mathrm{T}$ & 55.63 \\
\hline & SP2 & 30 & 0.07 & - & $2 \phi 8$ & 30 & 0.07 & - & $\mathrm{T}$ & 37.40 \\
\hline & SU1 & 42 & - & - & $3 \phi 8$ & 28 & - & - & $\mathrm{T}$ & 55.63 \\
\hline & SU2 & 45 & - & $\theta .9$ & $2 \phi 12.5$ & 29 & - & 0.6 & $\mathrm{~T}$ & 88.83 \\
\hline & SU3 & 25 & & - & $2 \phi 8$ & 25 & - & - & $\mathrm{T}$ & 37.40 \\
\hline \multirow{6}{*}{4} & SP1 & 19 & 0.05 & - & $2 \phi 8$ & 19 & 0.05 & - & $\mathrm{T}$ & 32.77 \\
\hline & SP2 & 23 & 0.07 & - & $2 \phi 8$ & 23 & 0.07 & - & $\mathrm{T}$ & 32.77 \\
\hline & SP3 & 0 & -0.01 & - & $2 \phi 8$ & 0 & -0.01 & - & $\mathrm{T}$ & 32.77 \\
\hline & SU1 & 19 & - & - & $2 \phi 8$ & 19 & - & - & $\mathrm{T}$ & 32.77 \\
\hline & SU2 & 41 & - & - & $3 \phi 8$ & 27 & - & - & $\mathrm{T}$ & 48.71 \\
\hline & SU3 & 25 & - & - & $2 \phi 8$ & 25 & - & - & $\mathrm{T}$ & 32.77 \\
\hline 5 & SP & 34 & 0.12 & - & $3 \phi 8$ & 23 & 0.12 & - & $\mathrm{T}$ & 34.89 \\
\hline \multirow{5}{*}{6} & SP1 & 26 & 0.10 & - & $2 \phi 8$ & 26 & 0.10 & - & $\mathrm{T}$ & 23.52 \\
\hline & SP2 & 7 & 0.00 & - & $2 \phi 8$ & 7 & 0.00 & - & $\mathrm{T}$ & 23.52 \\
\hline & SU1 & 16 & - & - & $2 \phi 8$ & 16 & - & - & $\mathrm{T}$ & 23.52 \\
\hline & SU2 & 33 & - & - & $3 \phi 8$ & 22 & - & - & $\mathrm{T}$ & 34.89 \\
\hline & SU3 & 2 & - & - & $2 \phi 8$ & 2 & - & - & $\mathrm{T}$ & 23.52 \\
\hline \multirow{2}{*}{7} & SP & 28 & 0.09 & - & $2 \phi 8$ & 28 & 0.09 & - & $\mathrm{T}$ & 23.52 \\
\hline & SU & 16 & - & - & $2 \phi 8$ & 16 & - & - & $\mathrm{T}$ & 23.52 \\
\hline \multirow{7}{*}{8} & SP1 & 22 & 0.06 & - & $2 \phi 8$ & 22 & 0.06 & - & $\mathrm{T}$ & 28.14 \\
\hline & SP2 & 11 & 0.01 & - & $2 \phi 8$ & 11 & 0.01 & - & $\mathrm{T}$ & 28.14 \\
\hline & SP3 & 18 & 0.04 & - & $2 \phi 8$ & 18 & 0.04 & - & $\mathrm{T}$ & 28.14 \\
\hline & SU1 & 10 & - & - & $2 \phi 8$ & 10 & - & - & $\mathrm{T}$ & 28.14 \\
\hline & SU2 & 33 & - & - & $3 \phi 8$ & 22 & - & - & $\mathrm{T}$ & 41.80 \\
\hline & SU3 & 33 & - & - & $3 \phi 8$ & 22 & - & - & $\mathrm{T}$ & 41.80 \\
\hline & SU4 & 19 & - & - & $2 \phi 8$ & 19 & - & - & $\mathrm{T}$ & 28.14 \\
\hline \multirow{5}{*}{9} & SP1 & 22 & 0.06 & - & $2 \phi 8$ & 22 & 0.06 & - & $\mathrm{T}$ & 23.52 \\
\hline & SP2 & 24 & 0.06 & - & $2 \phi 8$ & 24 & 0.06 & - & $\mathrm{T}$ & 23.52 \\
\hline & SU1 & 39 & - & 0.8 & $3 \phi 8$ & 26 & - & 0.5 & $\mathrm{~T}$ & 34.89 \\
\hline & SU2 & 45 & - & 0.9 & $2 \phi 10$ & 29 & - & 0.6 & $\mathrm{~T}$ & 36.16 \\
\hline & SU3 & 15 & - & - & $2 \phi 8$ & 15 & - & - & $\mathrm{T}$ & 23.52 \\
\hline
\end{tabular}


Table A.7 - Design for the ultimate limit state - CFRP and Concrete C25

\begin{tabular}{|c|c|c|c|c|c|c|c|c|c|c|}
\hline B & $\mathbf{S}$ & $\mathbf{M}_{\mathbf{d}}(\mathbf{k N m})$ & $\mathbf{M}_{\mathbf{b}}(\mathbf{k N m})$ & $\mathbf{F}$ & $\mathbf{x}_{\mathbf{i}}(\mathbf{c m})$ & $A_{\mathbf{f}}\left(\mathbf{c m}^{2}\right)$ & $\mathrm{n} \phi_{\mathrm{b}}(\mathbf{m m})$ & $\mathbf{F}_{\mathbf{r}}$ & $\mathbf{x}_{\mathrm{r}}(\mathbf{c m})$ & $\mathrm{M}_{\mathrm{r}}(\mathrm{kNm})$ \\
\hline \multirow{2}{*}{1} & SP & 28.98 & 75.6 & $\mathrm{~T}$ & 5.6 & 0.41 & $2 \phi 8$ & $\mathrm{~T}$ & 10.0 & 70.0 \\
\hline & SU & 23.10 & 75.6 & $\mathrm{~T}$ & 4.9 & 0.32 & $2 \phi 8$ & $\mathrm{~T}$ & 10.0 & 70.0 \\
\hline \multirow{5}{*}{2} & SP1 & 35.84 & 61.2 & $\mathrm{~T}$ & 6.5 & 0.57 & $2 \phi 8$ & $\mathrm{C}$ & 9.9 & 62.5 \\
\hline & SP2 & 39.90 & 61.2 & $\mathrm{~T}$ & 7.0 & 0.64 & $2 \phi 8$ & $\mathrm{C}$ & 9.9 & 62.5 \\
\hline & SU1 & 12.60 & 61.2 & $\mathrm{~T}$ & 3.5 & 0.19 & $2 \phi 8$ & $\mathrm{C}$ & 9.9 & 62.5 \\
\hline & SU2 & 63.98 & 61.2 & $\mathrm{C}$ & 10.2 & 1.07 & $2 \phi 10$ & $\mathrm{C}$ & 11.9 & 73.6 \\
\hline & SU3 & 12.60 & 61.2 & $\mathrm{~T}$ & 3.5 & 0.19 & $2 \phi 8$ & $\mathrm{C}$ & 9.9 & 62.5 \\
\hline \multirow{5}{*}{3} & SP1 & 32.34 & 61.2 & $\mathrm{~T}$ & 6.1 & 0.51 & $2 \phi 8$ & $\mathrm{C}$ & 9.9 & 62.5 \\
\hline & SP2 & 22.96 & 61.2 & $\mathrm{~T}$ & 4.9 & 0.36 & $2 \phi 8$ & $\mathrm{C}$ & 9.9 & 62.5 \\
\hline & SU1 & 32.20 & 61.2 & $\mathrm{~T}$ & 6.1 & 0.51 & $2 \phi 8$ & $\mathrm{C}$ & 9.9 & 62.5 \\
\hline & SU2 & 53.76 & 61.2 & $\mathrm{~T}$ & 8.8 & 0.88 & $2 \phi 8$ & $\mathrm{C}$ & 9.9 & 62.5 \\
\hline & SU3 & 19.04 & 61.2 & $\mathrm{~T}$ & 4.4 & 0.30 & $2 \phi 8$ & $\mathrm{C}$ & 9.9 & 62.5 \\
\hline \multirow{6}{*}{4} & SP1 & 12.32 & 48.4 & $\mathrm{~T}$ & 3.5 & 0.21 & $2 \phi 8$ & $\mathrm{C}$ & 9.2 & 50.7 \\
\hline & SP2 & 14.70 & 48.4 & $\mathrm{~T}$ & 3.9 & 0.26 & $2 \phi 8$ & $\mathrm{C}$ & 9.2 & 50.7 \\
\hline & SP3 & 9.96 & 48.4 & $\mathrm{~T}$ & 3.1 & 0.17 & $2 \phi 8$ & $\mathrm{C}$ & 9.2 & 50.7 \\
\hline & SU1 & 12.32 & 48.4 & $\mathrm{~T}$ & 3.5 & 0.21 & $2 \phi 8$ & $\mathrm{C}$ & 9.2 & 50.7 \\
\hline & SU2 & 26.60 & 48.4 & $\mathrm{~T}$ & 5.6 & 0.47 & $2 \phi 8$ & $\mathrm{C}$ & 9.2 & 50.7 \\
\hline & SU3 & 16.38 & 48.4 & $\mathrm{~T}$ & 4.1 & 0.29 & $2 \phi 8$ & $\mathrm{C}$ & 9.2 & 50.7 \\
\hline 5 & SP & 15.68 & 27.2 & $\mathrm{~T}$ & 4.3 & 0.37 & $2 \phi 8$ & $\mathrm{C}$ & 7.6 & 29.9 \\
\hline \multirow{5}{*}{6} & SP1 & 11.90 & 27.2 & $\mathrm{~T}$ & 3.6 & 0.28 & $2 \phi 8$ & $\mathrm{C}$ & 7.6 & 29.9 \\
\hline & SP2 & 5.60 & 27.2 & $\mathrm{~T}$ & 2.3 & 0.13 & $2 \phi 8$ & $\mathrm{C}$ & 7.6 & 29.9 \\
\hline & SU1 & 7.56 & 27.2 & $\mathrm{~T}$ & 2.8 & 0.18 & $2 \phi 8$ & $\mathrm{C}$ & 7.6 & 29.9 \\
\hline & SU2 & 15.40 & 27.2 & $\mathrm{~T}$ & 4.2 & 0.37 & $2 \phi 8$ & $\mathrm{C}$ & 7.6 & 29.9 \\
\hline & SU3 & 5.60 & 27.2 & $\mathrm{~T}$ & 2.3 & 0.13 & $2 \phi 8$ & $\mathrm{C}$ & 7.6 & 29.9 \\
\hline \multirow{2}{*}{7} & SP & 12.88 & 27.2 & $\mathrm{~T}$ & 3.8 & 0.30 & $2 \phi 8$ & $\mathrm{C}$ & 7.6 & 29.9 \\
\hline & SU & 7.28 & 27.2 & $\mathrm{~T}$ & 2.7 & 0.17 & $2 \phi 8$ & $\mathrm{C}$ & 7.6 & 29.9 \\
\hline \multirow{7}{*}{8} & SP1 & 11.90 & 37.0 & $\mathrm{~T}$ & 3.5 & 0.24 & $2 \phi 8$ & $\mathrm{C}$ & 8.4 & 39.8 \\
\hline & SP2 & 7.62 & 37.0 & $\mathrm{~T}$ & 2.7 & 0.15 & $2 \phi 8$ & $\mathrm{C}$ & 8.4 & 39.8 \\
\hline & SP3 & 10.50 & 37.0 & $\mathrm{~T}$ & 3.3 & 0.21 & $2 \phi 8$ & $\mathrm{C}$ & 8.4 & 39.8 \\
\hline & SU1 & 7.62 & 37.0 & $\mathrm{~T}$ & 2.7 & 0.15 & $2 \phi 8$ & $\mathrm{C}$ & 8.4 & 39.8 \\
\hline & SU2 & 18.48 & 37.0 & $\mathrm{~T}$ & 4.6 & 0.37 & $2 \phi 8$ & $\mathrm{C}$ & 8.4 & 39.8 \\
\hline & SU3 & 18.48 & 37.0 & $\mathrm{~T}$ & 4.6 & 0.37 & $2 \phi 8$ & $\mathrm{C}$ & 8.4 & 39.8 \\
\hline & SU4 & 11.06 & 37.0 & $\mathrm{~T}$ & 3.4 & 0.22 & $2 \phi 8$ & $\mathrm{C}$ & 8.4 & 39.8 \\
\hline \multirow{5}{*}{9} & SP1 & 10.50 & 27.2 & $\mathrm{~T}$ & 3.3 & 0.25 & $2 \phi 8$ & $\mathrm{C}$ & 7.6 & 29.9 \\
\hline & SP2 & 11.76 & 27.2 & $\mathrm{~T}$ & 3.6 & 0.28 & $2 \phi 8$ & $\mathrm{C}$ & 7.6 & 29.9 \\
\hline & SU1 & 18.62 & 27.2 & $\mathrm{~T}$ & 4.8 & 0.45 & $2 \phi 8$ & $\mathrm{C}$ & 7.6 & 29.9 \\
\hline & SU2 & 21.98 & 27.2 & $\mathrm{~T}$ & 5.5 & 0.53 & $2 \phi 8$ & $\mathrm{C}$ & 7.6 & 29.9 \\
\hline & SU3 & 7.14 & 27.2 & $\mathrm{~T}$ & 2.7 & 0.17 & $2 \phi 8$ & $\mathrm{C}$ & 7.6 & 29.9 \\
\hline
\end{tabular}


Table A.8 - Checking for creep rupture, deflections and cracking - CFRP and Concrete C25

\begin{tabular}{|c|c|c|c|c|c|c|c|c|c|c|}
\hline B & $\mathbf{S}$ & $\left(\mathbf{f}_{\mathbf{f}, \mathbf{s}} / \mathbf{f}_{\mathbf{f u}}\right) \%$ & $v_{I t}(\mathbf{c m})$ & $\mathbf{w}(\mathbf{m m})$ & $\mathbf{n} \varphi_{\mathbf{b} \_a d j}(\mathbf{m m})$ & $\left(\mathbf{f}_{\mathbf{f}, \mathbf{s}} / \mathbf{f}_{\mathbf{f u}}\right) \%$ & $v_{\text {lt }}(\mathbf{c m})$ & $\mathbf{w}(\mathbf{m m})$ & $\mathbf{F}_{\mathbf{r}}$ & $\mathrm{M}_{\mathrm{r}}(\mathbf{k N m})$ \\
\hline \multirow{2}{*}{1} & SP & 20 & 0.20 & 0.3 & $2 \phi 8$ & 24 & 0.20 & 0.3 & $\mathrm{~T}$ & 69.97 \\
\hline & SU & 16 & - & - & $2 \phi 8$ & 28 & - & - & $\mathrm{T}$ & 69.97 \\
\hline \multirow{5}{*}{2} & SP1 & 27 & 0.25 & 0.3 & $2 \phi 8$ & 30 & 0.25 & 0.3 & $\mathrm{C}$ & 62.54 \\
\hline & SP2 & 32 & 1.80 & 0.4 & $3 \phi 8$ & 23 & 1.22 & 0.2 & $\mathrm{C}$ & 72.79 \\
\hline & SU1 & 8 & - & - & $2 \phi 8$ & 13 & - & - & $\mathrm{C}$ & 62.54 \\
\hline & SU2 & 32 & - & 0.4 & $2 \phi 10$ & 22 & - & 0.4 & $\mathrm{C}$ & 73.58 \\
\hline & SU3 & 9 & - & - & $2 \phi 8$ & 17 & - & - & $\mathrm{C}$ & 62.54 \\
\hline \multirow{5}{*}{3} & SP1 & 25 & 1.40 & 0.3 & $2 \phi 8$ & 29 & 1.40 & 0.3 & $\mathrm{C}$ & 62.54 \\
\hline & SP2 & 17 & 0.12 & 0.2 & $2 \phi 8$ & 20 & 0.12 & 0.2 & $\mathrm{C}$ & 62.54 \\
\hline & SU1 & 25 & - & 0.3 & $2 \phi 8$ & 29 & - & 0.3 & $\mathrm{C}$ & 62.54 \\
\hline & SU2 & 41 & - & 0.5 & $2 \phi 8$ & 30 & - & 0.5 & $\mathrm{C}$ & 62.54 \\
\hline & SU3 & 14 & & - & $2 \phi 8$ & 25 & - & - & $\mathrm{C}$ & 62.54 \\
\hline \multirow{6}{*}{4} & SP1 & 11 & 0.09 & - & $2 \phi 8$ & 19 & 0.09 & - & $\mathrm{C}$ & 50.70 \\
\hline & SP2 & 13 & 0.12 & - & $2 \phi 8$ & 23 & 0.12 & - & $\mathrm{C}$ & 50.70 \\
\hline & SP3 & 0 & -0.02 & - & $2 \phi 8$ & 0 & -0.02 & - & $\mathrm{C}$ & 50.70 \\
\hline & SU1 & 11 & - & - & $2 \phi 8$ & 19 & - & - & C & 50.70 \\
\hline & SU2 & 24 & - & 0.3 & $2 \phi 8$ & 28 & - & 0.3 & C & 50.70 \\
\hline & SU3 & 15 & - & 0.2 & $2 \phi 8$ & 26 & - & 0.2 & $\mathrm{C}$ & 50.70 \\
\hline 5 & SP & 20 & 1.04 & 0.3 & $2 \phi 8$ & 23 & 1.04 & 0.3 & $\mathrm{C}$ & 29.88 \\
\hline \multirow{5}{*}{6} & SP1 & 15 & 0.18 & 0.2 & $2 \phi 8$ & 18 & 0.18 & 0.2 & C & 29.88 \\
\hline & SP2 & 4 & 0.01 & - & $2 \phi 8$ & 7 & 0.01 & - & $\mathrm{C}$ & 29.88 \\
\hline & SU1 & 10 & - & - & $2 \phi 8$ & 17 & - & - & $\mathrm{C}$ & 29.88 \\
\hline & SU2 & 20 & - & 0.3 & $2 \phi 8$ & 23 & - & 0.3 & $\mathrm{C}$ & 29.88 \\
\hline & SU3 & 1 & - & - & $2 \phi 8$ & 2 & - & - & $\mathrm{C}$ & 29.88 \\
\hline \multirow{2}{*}{7} & SP & 16 & 0.57 & 0.2 & $2 \phi 8$ & 28 & 0.57 & 0.2 & $\mathrm{C}$ & 29.88 \\
\hline & SU & 9 & - & - & $2 \phi 8$ & 16 & - & - & $\mathrm{C}$ & 29.88 \\
\hline \multirow{7}{*}{8} & SP1 & 13 & 0.11 & 0.2 & $2 \phi 8$ & 22 & 0.11 & 0.2 & $\mathrm{C}$ & 39.79 \\
\hline & SP2 & 7 & 0.02 & - & $2 \phi 8$ & 12 & 0.02 & - & $\mathrm{C}$ & 39.79 \\
\hline & SP3 & 11 & 0.07 & - & $2 \phi 8$ & 19 & 0.07 & - & C & 39.79 \\
\hline & SU1 & 6 & - & - & $2 \phi 8$ & 10 & - & - & $\mathrm{C}$ & 39.79 \\
\hline & SU2 & 19 & - & 0.2 & $2 \phi 8$ & 23 & - & 0.2 & $\mathrm{C}$ & 39.79 \\
\hline & SU3 & 19 & - & 0.2 & $2 \phi 8$ & 22 & - & 0.2 & C & 39.79 \\
\hline & SU4 & 11 & - & - & $2 \phi 8$ & 19 & - & - & $\mathrm{C}$ & 39.79 \\
\hline \multirow{5}{*}{9} & SP1 & 13 & 0.11 & 0.2 & $2 \phi 8$ & 22 & 0.11 & 0.2 & $\mathrm{C}$ & 29.88 \\
\hline & SP2 & 14 & 0.12 & 0.2 & $2 \phi 8$ & 24 & 0.12 & 0.2 & C & 29.88 \\
\hline & SU1 & 23 & - & 0.3 & $2 \phi 8$ & 27 & - & 0.3 & $\mathrm{C}$ & 29.88 \\
\hline & SU2 & 27 & - & 0.4 & $2 \phi 8$ & 30 & - & 0.4 & $\mathrm{C}$ & 29.88 \\
\hline & SU3 & 9 & - & - & $2 \phi 8$ & 15 & - & - & C & 29.88 \\
\hline
\end{tabular}


Table A.9 - Design for the ultimate limit state - CFRP and Concrete C80

\begin{tabular}{|c|c|c|c|c|c|c|c|c|c|c|}
\hline B & $\mathbf{S}$ & $M_{d}(k N m)$ & $\mathbf{M}_{\mathbf{b}}(\mathbf{k N m})$ & $\mathbf{F}$ & $\mathbf{x}_{\mathbf{i}}(\mathbf{c m})$ & $\mathbf{A}_{\mathbf{f}}\left(\mathbf{c m}^{2}\right)$ & $\mathrm{n} \phi_{\mathrm{b}}(\mathbf{m m})$ & $F_{\mathbf{r}}$ & $\mathbf{x}_{\mathbf{r}}(\mathbf{c m})$ & $M_{r}(k N m)$ \\
\hline \multirow{2}{*}{1} & SP & 29.35 & 152.2 & $\mathrm{~T}$ & 3.8 & 0.41 & $2 \phi 8$ & $\mathrm{~T}$ & 6.0 & 73.33 \\
\hline & SU & 29.35 & 152.2 & $\mathrm{~T}$ & 3.8 & 0.41 & $2 \phi 8$ & $\mathrm{~T}$ & 6.0 & 73.33 \\
\hline \multirow{5}{*}{2} & SP1 & 35.84 & 123.3 & $\mathrm{~T}$ & 4.2 & 0.55 & $2 \phi 8$ & $\mathrm{~T}$ & 5.7 & 65.19 \\
\hline & SP2 & 39.90 & 123.3 & $\mathrm{~T}$ & 4.4 & 0.62 & $2 \phi 8$ & $\mathrm{~T}$ & 5.7 & 65.19 \\
\hline & SU1 & 23.78 & 123.3 & $\mathrm{~T}$ & 3.4 & 0.36 & $2 \phi 8$ & $\mathrm{~T}$ & 5.7 & 65.19 \\
\hline & SU2 & 63.98 & 123.3 & $\mathrm{~T}$ & 5.6 & 1.00 & $2 \phi 8$ & $\mathrm{~T}$ & 5.7 & 65.19 \\
\hline & SU3 & 23.78 & 123.3 & $\mathrm{~T}$ & 3.4 & 0.36 & $2 \phi 8$ & $\mathrm{~T}$ & 5.7 & 65.19 \\
\hline \multirow{5}{*}{3} & SP1 & 32.34 & 123.3 & $\mathrm{~T}$ & 4.0 & 0.50 & $2 \phi 8$ & $\mathrm{~T}$ & 5.7 & 65.19 \\
\hline & SP2 & 23.78 & 123.3 & $\mathrm{~T}$ & 3.4 & 0.36 & $2 \phi 8$ & $\mathrm{~T}$ & 5.7 & 65.19 \\
\hline & SU1 & 32.20 & 123.3 & $\mathrm{~T}$ & 4.0 & 0.50 & $2 \phi 8$ & $\mathrm{~T}$ & 5.7 & 65.19 \\
\hline & SU2 & 53.76 & 123.3 & $\mathrm{~T}$ & 5.1 & 0.84 & $2 \phi 8$ & $\mathrm{~T}$ & 5.7 & 65.19 \\
\hline & SU3 & 23.78 & 123.3 & $\mathrm{~T}$ & 3.4 & 0.36 & $2 \phi 8$ & $\mathrm{~T}$ & 5.7 & 65.19 \\
\hline \multirow{6}{*}{4} & SP1 & 18.79 & 97.4 & $\mathrm{~T}$ & 3.0 & 0.32 & $2 \phi 8$ & $\mathrm{~T}$ & 5.3 & 57.05 \\
\hline & SP2 & 18.79 & 97.4 & $\mathrm{~T}$ & 3.0 & 0.32 & $2 \phi 8$ & $\mathrm{~T}$ & 5.3 & 57.05 \\
\hline & SP3 & 18.79 & 97.4 & $\mathrm{~T}$ & 3.0 & 0.32 & $2 \phi 8$ & $\mathrm{~T}$ & 5.3 & 57.05 \\
\hline & SU1 & 18.79 & 97.4 & $\mathrm{~T}$ & 3.0 & 0.32 & $2 \phi 8$ & $\mathrm{~T}$ & 5.3 & 57.05 \\
\hline & SU2 & 26.60 & 97.4 & $\mathrm{~T}$ & 3.6 & 0.46 & $2 \phi 8$ & $\mathrm{~T}$ & 5.3 & 57.05 \\
\hline & SU3 & 18.79 & 97.4 & $\mathrm{~T}$ & 3.0 & 0.32 & $2 \phi 8$ & $\mathrm{~T}$ & 5.3 & 57.05 \\
\hline 5 & SP & 15.68 & 54.8 & $\mathrm{~T}$ & 2.8 & 0.36 & $2 \phi 8$ & $\mathrm{~T}$ & 4.5 & 40.82 \\
\hline \multirow{5}{*}{6} & SP1 & 11.90 & 54.8 & $\mathrm{~T}$ & 2.4 & 0.27 & $2 \phi 8$ & $\mathrm{~T}$ & 4.5 & 40.82 \\
\hline & SP2 & 10.57 & 54.8 & $\mathrm{~T}$ & 2.3 & 0.24 & $2 \phi 8$ & $\mathrm{~T}$ & 4.5 & 40.82 \\
\hline & SU1 & 10.57 & 54.8 & $\mathrm{~T}$ & 2.3 & 0.24 & $2 \phi 8$ & $\mathrm{~T}$ & 4.5 & 40.82 \\
\hline & SU2 & 15.40 & 54.8 & $\mathrm{~T}$ & 2.7 & 0.36 & $2 \phi 8$ & $\mathrm{~T}$ & 4.5 & 40.82 \\
\hline & SU3 & 10.57 & 54.8 & $\mathrm{~T}$ & 2.3 & 0.24 & $2 \phi 8$ & $\mathrm{~T}$ & 4.5 & 40.82 \\
\hline \multirow{2}{*}{7} & SP & 12.88 & 54.8 & $\mathrm{~T}$ & 2.5 & 0.30 & $2 \phi 8$ & $\mathrm{~T}$ & 4.5 & 40.82 \\
\hline & SU & 10.57 & 54.8 & $\mathrm{~T}$ & 2.3 & 0.24 & $2 \phi 8$ & $\mathrm{~T}$ & 4.5 & 40.82 \\
\hline \multirow{7}{*}{8} & SP1 & 14.38 & 74.6 & $\mathrm{~T}$ & 2.6 & 0.28 & $2 \phi 8$ & $\mathrm{~T}$ & 4.9 & 48.93 \\
\hline & SP2 & 14.38 & 74.6 & $\mathrm{~T}$ & 2.6 & 0.28 & $2 \phi 8$ & $\mathrm{~T}$ & 4.9 & 48.93 \\
\hline & SP3 & 14.38 & 74.6 & $\mathrm{~T}$ & 2.6 & 0.28 & $2 \phi 8$ & $\mathrm{~T}$ & 4.9 & 48.93 \\
\hline & SU1 & 14.38 & 74.6 & $\mathrm{~T}$ & 2.6 & 0.28 & $2 \phi 8$ & $\mathrm{~T}$ & 4.9 & 48.93 \\
\hline & SU2 & 18.48 & 74.6 & $\mathrm{~T}$ & 3.0 & 0.37 & $2 \phi 8$ & $\mathrm{~T}$ & 4.9 & 48.93 \\
\hline & SU3 & 18.48 & 74.6 & $\mathrm{~T}$ & 3.0 & 0.37 & $2 \phi 8$ & $\mathrm{~T}$ & 4.9 & 48.93 \\
\hline & SU4 & 14.38 & 74.6 & $\mathrm{~T}$ & 2.6 & 0.28 & $2 \phi 8$ & $\mathrm{~T}$ & 4.9 & 48.93 \\
\hline \multirow{5}{*}{9} & SP1 & 10.57 & 54.8 & $\mathrm{~T}$ & 2.3 & 0.24 & $2 \phi 8$ & $\mathrm{~T}$ & 4.5 & 40.82 \\
\hline & SP2 & 11.76 & 54.8 & $\mathrm{~T}$ & 2.4 & 0.27 & $2 \phi 8$ & $\mathrm{~T}$ & 4.5 & 40.82 \\
\hline & SU1 & 18.62 & 54.8 & $\mathrm{~T}$ & 3.0 & 0.43 & $2 \phi 8$ & $\mathrm{~T}$ & 4.5 & 40.82 \\
\hline & SU2 & 21.98 & 54.8 & $\mathrm{~T}$ & 3.3 & 0.51 & $2 \phi 8$ & $\mathrm{~T}$ & 4.5 & 40.82 \\
\hline & SU3 & 10.57 & 54.8 & $\mathrm{~T}$ & 2.3 & 0.24 & $2 \phi 8$ & $\mathrm{~T}$ & 4.5 & 40.82 \\
\hline
\end{tabular}


Table A.10 - Checking for creep rupture, deflections and cracking - CFRP and Concrete C80

\begin{tabular}{|c|c|c|c|c|c|c|c|c|c|c|}
\hline B & $\mathbf{S}$ & $\left(\mathbf{f}_{\mathbf{f . s}} / \mathbf{f}_{\mathbf{f u}}\right) \%$ & $\mathrm{v}_{\mathrm{It}}(\mathbf{c m})$ & $\mathbf{w}(\mathbf{m m})$ & $\mathbf{n} \varphi_{\mathbf{b} \_ \text {adj }}(\mathbf{m m})$ & $\left(\mathbf{f}_{\mathbf{f . s}} / \mathbf{f}_{\mathbf{f u}}\right) \%$ & $\mathbf{v}_{\mathrm{It}}(\mathbf{c m})$ & $\mathbf{w}(\mathbf{m m})$ & $\mathbf{F}_{\mathbf{r}}$ & $M_{r}(k N m)$ \\
\hline \multirow{2}{*}{1} & SP & 20 & 0.11 & - & $2 \phi 8$ & 20 & 0.11 & - & $\mathrm{T}$ & 73.3 \\
\hline & SU & 16 & - & - & $2 \phi 8$ & 16 & - & - & $\mathrm{T}$ & 73.3 \\
\hline \multirow{5}{*}{2} & SP1 & 26 & 0.02 & - & $2 \phi 8$ & 26 & 0.02 & - & $\mathrm{T}$ & 65.2 \\
\hline & SP2 & 31 & 0.12 & 0.4 & $2 \phi 8$ & 31 & 0.12 & 0.4 & $\mathrm{~T}$ & 65.2 \\
\hline & SU1 & 8 & - & - & $2 \phi 8$ & 8 & - & - & $\mathrm{T}$ & 65.2 \\
\hline & SU2 & 49 & - & 0.6 & $2 \phi 8$ & 32 & - & 0.4 & $\mathrm{~T}$ & 96.6 \\
\hline & SU3 & 9 & - & - & $2 \phi 8$ & 9 & - & - & $\mathrm{T}$ & 65.2 \\
\hline \multirow{5}{*}{3} & SP1 & 24 & 0.13 & - & $2 \phi 8$ & 24 & 0.13 & - & $\mathrm{T}$ & 65.2 \\
\hline & SP2 & 17 & 0.07 & - & $2 \phi 8$ & 17 & 0.07 & - & $\mathrm{T}$ & 65.2 \\
\hline & SU1 & 24 & - & - & $2 \phi 8$ & 24 & - & - & $\mathrm{T}$ & 65.2 \\
\hline & SU2 & 40 & - & 0.5 & $2 \phi 8$ & 40 & - & 0.5 & $\mathrm{~T}$ & 65.2 \\
\hline & SU3 & 14 & & - & $2 \phi 8$ & 14 & - & - & $\mathrm{T}$ & 65.2 \\
\hline \multirow{6}{*}{4} & SP1 & 11 & 0.05 & - & $2 \phi 8$ & 11 & 0.05 & - & $\mathrm{T}$ & 57.1 \\
\hline & SP2 & 13 & 0.07 & - & $2 \phi 8$ & 13 & 0.07 & - & $\mathrm{T}$ & 57.1 \\
\hline & SP3 & 0 & -0.01 & - & $2 \phi 8$ & 0 & -0.01 & - & $\mathrm{T}$ & 57.1 \\
\hline & SU1 & 11 & - & - & $2 \phi 8$ & 11 & - & - & $\mathrm{T}$ & 57.1 \\
\hline & SU2 & 23 & - & - & $2 \phi 8$ & 23 & - & - & $\mathrm{T}$ & 57.1 \\
\hline & SU3 & 15 & - & - & $2 \phi 8$ & 15 & - & - & $\mathrm{T}$ & 57.1 \\
\hline 5 & SP & 20 & 0.12 & - & $2 \phi 8$ & 20 & 0.12 & - & $\mathrm{T}$ & 40.8 \\
\hline \multirow{5}{*}{6} & SP1 & 15 & 0.10 & - & $2 \phi 8$ & 15 & 0.10 & - & $\mathrm{T}$ & 40.8 \\
\hline & SP2 & 4 & 0.00 & - & $2 \phi 8$ & 4 & 0.00 & - & $\mathrm{T}$ & 40.8 \\
\hline & SU1 & 9 & - & - & $2 \phi 8$ & 9 & - & - & $\mathrm{T}$ & 40.8 \\
\hline & SU2 & 19 & - & - & $2 \phi 8$ & 19 & - & - & $\mathrm{T}$ & 40.8 \\
\hline & SU3 & 1 & - & - & $2 \phi 8$ & 1 & - & - & $\mathrm{T}$ & 40.8 \\
\hline \multirow{2}{*}{7} & SP & 16 & 0.09 & - & $2 \phi 8$ & 16 & 0.09 & - & $\mathrm{T}$ & 40.8 \\
\hline & SU & 9 & - & - & $2 \phi 8$ & 9 & - & - & $\mathrm{T}$ & 40.8 \\
\hline \multirow{7}{*}{8} & SP1 & 12 & 0.06 & - & $2 \phi 8$ & 12 & 0.06 & - & $\mathrm{T}$ & 48.9 \\
\hline & SP2 & 7 & 0.01 & - & $2 \phi 8$ & 7 & 0.01 & - & $\mathrm{T}$ & 48.9 \\
\hline & SP3 & 10 & 0.04 & - & $2 \phi 8$ & 10 & 0.04 & - & $\mathrm{T}$ & 48.9 \\
\hline & SU1 & 6 & - & - & $2 \phi 8$ & 6 & - & - & $\mathrm{T}$ & 48.9 \\
\hline & SU2 & 19 & - & - & $2 \phi 8$ & 19 & - & - & $\mathrm{T}$ & 48.9 \\
\hline & SU3 & 19 & - & - & $2 \phi 8$ & 19 & - & - & $\mathrm{T}$ & 48.9 \\
\hline & SU4 & 11 & - & - & $2 \phi 8$ & 11 & - & - & $\mathrm{T}$ & 48.9 \\
\hline \multirow{5}{*}{9} & SP1 & 13 & 0.06 & - & $2 \phi 8$ & 13 & 0.06 & - & $\mathrm{T}$ & 40.8 \\
\hline & SP2 & 14 & 0.06 & - & $2 \phi 8$ & 14 & 0.06 & - & $\mathrm{T}$ & 40.8 \\
\hline & SU1 & 22 & - & 0.3 & $2 \phi 8$ & 22 & - & 0.3 & $\mathrm{~T}$ & 40.8 \\
\hline & SU2 & 26 & - & 0.3 & $2 \phi 8$ & 26 & - & 0.3 & $\mathrm{~T}$ & 40.8 \\
\hline & SU3 & 8 & - & - & $2 \phi 8$ & 8 & - & - & $\mathrm{T}$ & 40.8 \\
\hline
\end{tabular}


Table A.11 - Design for the ultimate limit state - GFRP and Concrete C25

\begin{tabular}{|c|c|c|c|c|c|c|c|c|c|c|}
\hline B & $\mathbf{S}$ & $M_{d}(k N m)$ & $M_{b}(k N m)$ & $\mathbf{F}$ & $\mathbf{x}_{\mathbf{i}}(\mathbf{c m})$ & $\mathbf{A}_{\mathbf{f}}\left(\mathbf{c m}^{2}\right)$ & $\mathrm{n} \phi_{\mathrm{b}}(\mathbf{m m})$ & $\mathbf{F}_{\mathbf{r}}$ & $\mathbf{x}_{\mathbf{r}}(\mathbf{c m})$ & $M_{r}(k N m)$ \\
\hline \multirow{2}{*}{1} & SP & 28.98 & 76.6 & $\mathrm{~T}$ & 5.6 & 1.53 & $2 \phi 10$ & $\mathrm{~T}$ & 5.7 & 30.47 \\
\hline & SU & 23.10 & 76.6 & $\mathrm{~T}$ & 4.9 & 1.21 & $3 \phi 8$ & $\mathrm{~T}$ & 5.6 & 29.35 \\
\hline \multirow{5}{*}{2} & SP1 & 35.84 & 62.1 & $\mathrm{~T}$ & 6.6 & 2.13 & $2 \phi 12.5$ & $\mathrm{~T}$ & 7.2 & 41.30 \\
\hline & SP2 & 39.90 & 62.1 & $\mathrm{~T}$ & 7.1 & 2.39 & $2 \phi 12.5$ & $\mathrm{~T}$ & 7.2 & 41.30 \\
\hline & SU1 & 12.60 & 62.1 & $\mathrm{~T}$ & 3.6 & 0.73 & $2 \phi 8$ & $\mathrm{~T}$ & 4.3 & 17.57 \\
\hline & SU2 & 63.98 & 62.1 & $\mathrm{C}$ & 10.2 & 4.00 & $2 \phi 16$ & $\mathrm{C}$ & 10.2 & 63.61 \\
\hline & SU3 & 12.60 & 62.1 & $\mathrm{~T}$ & 3.6 & 0.73 & $2 \phi 8$ & $\mathrm{~T}$ & 4.3 & 17.57 \\
\hline \multirow{5}{*}{3} & SP1 & 32.34 & 62.1 & $\mathrm{~T}$ & 6.1 & 1.92 & $2 \phi 12.5$ & $\mathrm{~T}$ & 7.2 & 41.30 \\
\hline & SP2 & 22.96 & 62.1 & $\mathrm{~T}$ & 5.0 & 1.34 & $2 \phi 10$ & $\mathrm{~T}$ & 5.5 & 27.06 \\
\hline & SU1 & 32.20 & 62.1 & $\mathrm{~T}$ & 6.1 & 1.91 & $2 \phi 12.5$ & $\mathrm{~T}$ & 7.2 & 41.30 \\
\hline & SU2 & 53.76 & 62.1 & $\mathrm{~T}$ & 8.8 & 3.30 & $2 \phi 16$ & $\mathrm{C}$ & 10.2 & 63.61 \\
\hline & SU3 & 19.04 & 62.1 & $\mathrm{~T}$ & 4.5 & 1.11 & $2 \phi 10$ & $\mathrm{~T}$ & 5.5 & 27.06 \\
\hline \multirow{6}{*}{4} & SP1 & 12.32 & 49.1 & $\mathrm{~T}$ & 3.6 & 0.80 & $2 \phi 8$ & $\mathrm{~T}$ & 4.0 & 15.39 \\
\hline & SP2 & 14.70 & 49.1 & $\mathrm{~T}$ & 3.9 & 0.96 & $2 \phi 8$ & $\mathrm{~T}$ & 4.0 & 15.39 \\
\hline & SP3 & 9.96 & 49.1 & $\mathrm{~T}$ & 3.2 & 0.65 & $2 \phi 8$ & $\mathrm{~T}$ & 4.0 & 15.39 \\
\hline & SU1 & 12.32 & 49.1 & $\mathrm{~T}$ & 3.6 & 0.80 & $2 \phi 8$ & $\mathrm{~T}$ & 4.0 & 15.39 \\
\hline & SU2 & 26.60 & 49.1 & $\mathrm{~T}$ & 5.6 & 1.78 & $2 \phi 12.5$ & $\mathrm{~T}$ & 6.9 & 35.95 \\
\hline & SU3 & 16.38 & 49.1 & $\mathrm{~T}$ & 4.2 & 1.07 & $3 \phi 8$ & $\mathrm{~T}$ & 5.1 & 22.80 \\
\hline 5 & SP & 15.68 & 27.6 & $\mathrm{~T}$ & 4.3 & 1.40 & $3 \phi 8$ & $\mathrm{~T}$ & 4.5 & 16.24 \\
\hline \multirow{5}{*}{6} & SP1 & 11.90 & 27.6 & $\mathrm{~T}$ & 3.6 & 1.05 & $3 \phi 8$ & $\mathrm{~T}$ & 4.5 & 16.24 \\
\hline & SP2 & 5.60 & 27.6 & $\mathrm{~T}$ & 2.4 & 0.48 & $2 \phi 8$ & $\mathrm{~T}$ & 3.5 & 11.02 \\
\hline & SU1 & 7.56 & 27.6 & $\mathrm{~T}$ & 2.8 & 0.66 & $2 \phi 8$ & $\mathrm{~T}$ & 3.5 & 11.02 \\
\hline & SU2 & 15.40 & 27.6 & $\mathrm{~T}$ & 4.3 & 1.37 & $3 \phi 8$ & $\mathrm{~T}$ & 4.5 & 16.24 \\
\hline & SU3 & 5.60 & 27.6 & $\mathrm{~T}$ & 2.4 & 0.48 & $2 \phi 8$ & $\mathrm{~T}$ & 3.5 & 11.02 \\
\hline \multirow{2}{*}{7} & SP & 12.88 & 27.6 & $\mathrm{~T}$ & 3.8 & 1.14 & $3 \phi 8$ & $\mathrm{~T}$ & 4.5 & 16.24 \\
\hline & SU & 7.28 & 27.6 & $\mathrm{~T}$ & 2.7 & 0.63 & $2 \phi 8$ & $\mathrm{~T}$ & 3.5 & 11.02 \\
\hline \multirow{7}{*}{8} & SP1 & 11.90 & 37.6 & $\mathrm{~T}$ & 3.5 & 0.89 & $2 \phi 8$ & $\mathrm{~T}$ & 3.8 & 13.20 \\
\hline & SP2 & 7.62 & 37.6 & $\mathrm{~T}$ & 2.8 & 0.57 & $2 \phi 8$ & $\mathrm{~T}$ & 3.8 & 13.20 \\
\hline & SP3 & 10.50 & 37.6 & $\mathrm{~T}$ & 3.3 & 0.78 & $2 \phi 8$ & $\mathrm{~T}$ & 3.8 & 13.20 \\
\hline & SU1 & 7.62 & 37.6 & $\mathrm{~T}$ & 2.8 & 0.57 & $2 \phi 8$ & $\mathrm{~T}$ & 3.8 & 13.20 \\
\hline & SU2 & 18.48 & 37.6 & $\mathrm{~T}$ & 4.6 & 1.40 & $3 \phi 8$ & $\mathrm{~T}$ & 4.8 & 19.52 \\
\hline & SU3 & 18.48 & 37.6 & $\mathrm{~T}$ & 4.6 & 1.40 & $3 \phi 8$ & $\mathrm{~T}$ & 4.8 & 19.52 \\
\hline & SU4 & 11.06 & 37.6 & $\mathrm{~T}$ & 3.4 & 0.83 & $2 \phi 8$ & $\mathrm{~T}$ & 3.8 & 13.20 \\
\hline \multirow{5}{*}{9} & SP1 & 10.50 & 27.6 & $\mathrm{~T}$ & 3.4 & 0.92 & $2 \phi 8$ & $\mathrm{~T}$ & 3.5 & 11.02 \\
\hline & SP2 & 11.76 & 27.6 & $\mathrm{~T}$ & 3.6 & 1.04 & $3 \phi 8$ & $\mathrm{~T}$ & 4.5 & 16.24 \\
\hline & SU1 & 18.62 & 27.6 & $\mathrm{~T}$ & 4.9 & 1.68 & $2 \phi 12.5$ & $\mathrm{~T}$ & 6.3 & 25.20 \\
\hline & SU2 & 21.98 & 27.6 & $\mathrm{~T}$ & 5.5 & 2.01 & $2 \phi 12.5$ & $\mathrm{~T}$ & 6.3 & 25.20 \\
\hline & SU3 & 7.14 & 27.6 & $\mathrm{~T}$ & 2.7 & 0.62 & $2 \phi 8$ & $\mathrm{~T}$ & 3.5 & 11.02 \\
\hline
\end{tabular}


Table A.12 - Checking for creep rupture, deflections and cracking - GFRP and Concrete C25

\begin{tabular}{|c|c|c|c|c|c|c|c|c|c|c|}
\hline B & $\mathbf{S}$ & $\left(\mathbf{f}_{\mathbf{f . s}} / \mathbf{f}_{\mathbf{f u}}\right) \%$ & $\mathrm{v}_{\mathrm{It}}(\mathbf{c m})$ & $\mathbf{w}(\mathbf{m m})$ & $\mathbf{n} \varphi_{\mathbf{b} \_ \text {adj }}(\mathbf{m m})$ & $\left(\mathbf{f}_{\mathbf{f . s}} / \mathbf{f}_{\mathbf{f u}}\right) \%$ & $\mathbf{v}_{\mathrm{It}}(\mathbf{c m})$ & $\mathbf{w}(\mathbf{m m})$ & $\mathbf{F}_{\mathbf{r}}$ & $M_{r}(k N m)$ \\
\hline \multirow{2}{*}{1} & SP & 48 & 0.20 & 0.7 & $2 \phi 16$ & 19 & 0.20 & 0.3 & $\mathrm{~T}$ & 73.48 \\
\hline & SU & 40 & - & - & $2 \phi 16$ & 15 & - & - & $\mathrm{T}$ & 73.48 \\
\hline \multirow{5}{*}{2} & SP1 & 44 & 0.39 & 0.6 & $2 \phi 20$ & 16 & 0.15 & 0.3 & C & 74.35 \\
\hline & SP2 & 49 & 2.72 & 0.7 & $2 \phi 20$ & 20 & 1.11 & 0.3 & $\mathrm{C}$ & 74.35 \\
\hline & SU1 & 28 & - & - & $3 \phi 8$ & 19 & - & - & $\mathrm{T}$ & 26.07 \\
\hline & SU2 & 47 & - & 0.7 & $2 \phi 25$ & 20 & - & 0.3 & $\mathrm{C}$ & 86.20 \\
\hline & SU3 & 35 & - & - & $2 \phi 12.5$ & 15 & - & - & $\mathrm{T}$ & 41.30 \\
\hline \multirow{5}{*}{3} & SP1 & 38 & 2.17 & 0.6 & $2 \phi 20$ & 15 & 0.85 & 0.2 & $\mathrm{C}$ & 74.35 \\
\hline & SP2 & 42 & 0.12 & 0.6 & $2 \phi 16$ & 17 & 0.12 & 0.2 & $\mathrm{C}$ & 63.61 \\
\hline & SU1 & 38 & - & 0.6 & $2 \phi 20$ & 15 & - & 0.2 & $\mathrm{C}$ & 74.35 \\
\hline & SU2 & 39 & - & 0.6 & $2 \phi 25$ & 16 & - & 0.3 & $\mathrm{C}$ & 86.20 \\
\hline & SU3 & 34 & & - & $2 \phi 16$ & 14 & - & - & $\mathrm{C}$ & 63.61 \\
\hline \multirow{6}{*}{4} & SP1 & 40 & 0.09 & - & $2 \phi 12.5$ & 17 & 0.09 & - & $\mathrm{T}$ & 35.95 \\
\hline & SP2 & 48 & 0.12 & - & $2 \phi 12.5$ & 20 & 0.12 & - & $\mathrm{T}$ & 35.95 \\
\hline & SP3 & 1 & -0.02 & - & $2 \phi 8$ & 1 & -0.02 & - & $\mathrm{T}$ & 15.39 \\
\hline & SU1 & 40 & - & - & $2 \phi 12.5$ & 17 & - & - & $\mathrm{T}$ & 35.95 \\
\hline & SU2 & 37 & - & 0.6 & $2 \phi 20$ & 15 & - & 0.2 & $\mathrm{C}$ & 59.82 \\
\hline & SU3 & 36 & - & 0.5 & $2 \phi 16$ & 14 & - & 0.2 & $\mathrm{C}$ & 51.42 \\
\hline 5 & SP & 49 & 2.57 & $\theta .7$ & $2 \phi 16$ & 19 & 0.99 & 0.3 & $\mathrm{C}$ & 30.03 \\
\hline \multirow{5}{*}{6} & SP1 & 37 & 0.18 & 0.5 & $2 \phi 16$ & 14 & 0.18 & 0.2 & $\mathrm{C}$ & 30.03 \\
\hline & SP2 & 14 & 0.01 & - & $2 \phi 8$ & 14 & 0.01 & - & $\mathrm{T}$ & 11.02 \\
\hline & SU1 & 35 & - & - & $2 \phi 12.5$ & 15 & - & - & $\mathrm{T}$ & 25.20 \\
\hline & SU2 & 48 & - & 0.6 & $2 \phi 16$ & 19 & - & 0.3 & $\mathrm{C}$ & 30.03 \\
\hline & SU3 & 4 & - & - & $2 \phi 8$ & 4 & - & - & $\mathrm{T}$ & 11.02 \\
\hline \multirow{2}{*}{7} & SP & 40 & 1.44 & 0.5 & $2 \phi 16$ & 16 & 0.53 & 0.2 & $\mathrm{C}$ & 30.03 \\
\hline & SU & 34 & - & - & $2 \phi 12.5$ & 14 & - & - & $\mathrm{T}$ & 25.20 \\
\hline \multirow{7}{*}{8} & SP1 & 46 & 0.11 & 0.70 & $2 \phi 12.5$ & 19 & 0.11 & 0.3 & $\mathrm{~T}$ & 30.58 \\
\hline & SP2 & 24 & 0.02 & - & $3 \phi 8$ & 16 & 0.02 & - & $\mathrm{T}$ & 19.52 \\
\hline & SP3 & 39 & 0.07 & - & $2 \phi 12.5$ & 16 & 0.07 & - & $\mathrm{T}$ & 30.58 \\
\hline & SU1 & 21 & - & - & $3 \phi 8$ & 14 & - & - & $\mathrm{T}$ & 19.52 \\
\hline & SU2 & 48 & - & $\theta .6$ & $2 \phi 16$ & 18 & - & 0.3 & $\mathrm{C}$ & 40.20 \\
\hline & SU3 & 47 & - & 0.6 & $2 \phi 16$ & 18 & - & 0.3 & $\mathrm{C}$ & 40.20 \\
\hline & SU4 & 41 & - & - & $2 \phi 12.5$ & 17 & - & - & $\mathrm{T}$ & 30.58 \\
\hline \multirow{5}{*}{9} & SP1 & 47 & 0.11 & 0.7 & $2 \phi 12.5$ & 20 & 0.11 & 0.3 & $\mathrm{~T}$ & 25.20 \\
\hline & SP2 & 34 & 0.12 & 0.5 & $2 \phi 16$ & 13 & 0.12 & 0.2 & $\mathrm{C}$ & 30.03 \\
\hline & SU1 & 35 & - & $\theta .6$ & $2 \phi 20$ & 14 & - & 0.2 & C & 34.47 \\
\hline & SU2 & 44 & - & 0.67 & $2 \phi 20$ & 17 & - & 0.3 & $\mathrm{C}$ & 34.47 \\
\hline & SU3 & 31 & - & - & $2 \phi 10$ & 20 & - & - & $\mathrm{T}$ & 16.81 \\
\hline
\end{tabular}


Table A.13 - Design for the ultimate limit state - GFRP and Concrete C80

\begin{tabular}{|c|c|c|c|c|c|c|c|c|c|c|}
\hline B & $\mathbf{S}$ & $\mathbf{M}_{\mathbf{d}}(\mathbf{k N m})$ & $M_{b}(k N m)$ & $\mathbf{F}$ & $\mathbf{x}_{\mathbf{i}}(\mathbf{c m})$ & $\mathbf{A}_{\mathbf{f}}\left(\mathbf{c m}^{2}\right)$ & $\mathrm{n} \phi_{\mathrm{b}}(\mathbf{m m})$ & $\mathbf{F}_{\mathbf{r}}$ & $\mathbf{x}_{\mathrm{r}}(\mathbf{c m})$ & $\mathrm{M}_{\mathrm{r}}(\mathrm{kNm})$ \\
\hline \multirow{2}{*}{1} & SP & 29.35 & 154.6 & $\mathrm{~T}$ & 3.8 & 1.52 & $2 \phi 10$ & $\mathrm{~T}$ & 3.9 & 31.00 \\
\hline & SU & 29.35 & 154.6 & $\mathrm{~T}$ & 3.8 & 1.52 & $2 \phi 10$ & $\mathrm{~T}$ & 3.9 & 31.00 \\
\hline \multirow{5}{*}{2} & SP1 & 35.84 & 125.3 & $\mathrm{~T}$ & 4.2 & 2.08 & $2 \phi 12.5$ & $\mathrm{~T}$ & 4.6 & 42.60 \\
\hline & SP2 & 39.90 & 125.3 & $\mathrm{~T}$ & 4.4 & 2.32 & $2 \phi 12.5$ & $\mathrm{~T}$ & 4.6 & 42.60 \\
\hline & SU1 & 23.78 & 125.3 & $\mathrm{~T}$ & 3.4 & 1.37 & $2 \phi 10$ & $\mathrm{~T}$ & 3.7 & 27.57 \\
\hline & SU2 & 63.98 & 125.3 & $\mathrm{~T}$ & 5.7 & 3.76 & $2 \phi 16$ & $\mathrm{~T}$ & 5.9 & 68.70 \\
\hline & SU3 & 23.78 & 125.3 & $\mathrm{~T}$ & 3.4 & 1.37 & $2 \phi 10$ & $\mathrm{~T}$ & 3.7 & 27.57 \\
\hline \multirow{5}{*}{3} & SP1 & 32.34 & 125.3 & $\mathrm{~T}$ & 4.0 & 1.87 & $2 \phi 12.5$ & $\mathrm{~T}$ & 4.6 & 42.60 \\
\hline & SP2 & 23.78 & 125.3 & $\mathrm{~T}$ & 3.4 & 1.37 & $2 \phi 10$ & $\mathrm{~T}$ & 3.7 & 27.57 \\
\hline & SU1 & 32.20 & 125.3 & $\mathrm{~T}$ & 4.0 & 1.86 & $2 \phi 12.5$ & $\mathrm{~T}$ & 4.6 & 42.60 \\
\hline & SU2 & 53.76 & 125.3 & $\mathrm{~T}$ & 5.2 & 3.14 & $2 \phi 16$ & $\mathrm{~T}$ & 5.9 & 68.70 \\
\hline & SU3 & 23.78 & 125.3 & $\mathrm{~T}$ & 3.4 & 1.37 & $3 \phi 8$ & $\mathrm{~T}$ & 3.6 & 26.55 \\
\hline \multirow{6}{*}{4} & SP1 & 18.79 & 99.0 & $\mathrm{~T}$ & 3.0 & 1.22 & $3 \phi 8$ & $\mathrm{~T}$ & 3.4 & 23.27 \\
\hline & SP2 & 18.79 & 99.0 & $\mathrm{~T}$ & 3.0 & 1.22 & $3 \phi 8$ & $\mathrm{~T}$ & 3.4 & 23.27 \\
\hline & SP3 & 18.79 & 99.0 & $\mathrm{~T}$ & 3.0 & 1.22 & $3 \phi 8$ & $\mathrm{~T}$ & 3.4 & 23.27 \\
\hline & SU1 & 18.79 & 99.0 & $\mathrm{~T}$ & 3.0 & 1.22 & $3 \phi 8$ & $\mathrm{~T}$ & 3.4 & 23.27 \\
\hline & SU2 & 26.60 & 99.0 & $\mathrm{~T}$ & 3.6 & 1.73 & $2 \phi 12.5$ & $\mathrm{~T}$ & 4.3 & 37.30 \\
\hline & SU3 & 18.79 & 99.0 & $\mathrm{~T}$ & 3.0 & 1.22 & $3 \phi 8$ & $\mathrm{~T}$ & 3.4 & 23.27 \\
\hline 5 & SP & 15.68 & 55.7 & $\mathrm{~T}$ & 2.8 & 1.36 & $3 \phi 8$ & $\mathrm{~T}$ & 2.9 & 16.73 \\
\hline \multirow{5}{*}{6} & SP1 & 11.90 & 55.7 & $\mathrm{~T}$ & 2.4 & 1.03 & $3 \phi 8$ & $\mathrm{~T}$ & 2.9 & 16.73 \\
\hline & SP2 & 10.57 & 55.7 & $\mathrm{~T}$ & 2.3 & 0.91 & $2 \phi 8$ & $\mathrm{~T}$ & 2.4 & 11.23 \\
\hline & SU1 & 10.57 & 55.7 & $\mathrm{~T}$ & 2.3 & 0.91 & $2 \phi 8$ & $\mathrm{~T}$ & 2.4 & 11.23 \\
\hline & SU2 & 15.40 & 55.7 & $\mathrm{~T}$ & 2.8 & 1.34 & $3 \phi 8$ & $\mathrm{~T}$ & 2.9 & 16.73 \\
\hline & SU3 & 10.57 & 55.7 & $\mathrm{~T}$ & 2.3 & 0.91 & $2 \phi 8$ & $\mathrm{~T}$ & 2.4 & 11.23 \\
\hline \multirow{2}{*}{7} & SP & 12.88 & 55.7 & $\mathrm{~T}$ & 2.5 & 1.12 & $3 \phi 8$ & $\mathrm{~T}$ & 2.9 & 16.73 \\
\hline & SU & 10.57 & 55.7 & $\mathrm{~T}$ & 2.3 & 0.91 & $2 \phi 8$ & $\mathrm{~T}$ & 2.4 & 11.23 \\
\hline \multirow{7}{*}{8} & SP1 & 14.38 & 75.8 & $\mathrm{~T}$ & 2.7 & 1.06 & $3 \phi 8$ & $\mathrm{~T}$ & 3.1 & 20.00 \\
\hline & SP2 & 14.38 & 75.8 & $\mathrm{~T}$ & 2.7 & 1.06 & $3 \phi 8$ & $\mathrm{~T}$ & 3.1 & 20.00 \\
\hline & SP3 & 14.38 & 75.8 & $\mathrm{~T}$ & 2.7 & 1.06 & $3 \phi 8$ & $\mathrm{~T}$ & 3.1 & 20.00 \\
\hline & SU1 & 14.38 & 75.8 & $\mathrm{~T}$ & 2.7 & 1.06 & $3 \phi 8$ & $\mathrm{~T}$ & 3.1 & 20.00 \\
\hline & SU2 & 18.48 & 75.8 & $\mathrm{~T}$ & 3.0 & 1.37 & $3 \phi 8$ & $\mathrm{~T}$ & 3.1 & 20.00 \\
\hline & SU3 & 18.48 & 75.8 & $\mathrm{~T}$ & 3.0 & 1.37 & $3 \phi 8$ & $\mathrm{~T}$ & 3.1 & 20.00 \\
\hline & SU4 & 14.38 & 75.8 & $\mathrm{~T}$ & 2.7 & 1.06 & $3 \phi 8$ & $\mathrm{~T}$ & 3.1 & 20.00 \\
\hline \multirow{5}{*}{9} & SP1 & 10.57 & 55.7 & $\mathrm{~T}$ & 2.3 & 0.91 & $2 \phi 8$ & $\mathrm{~T}$ & 2.4 & 11.23 \\
\hline & SP2 & 11.76 & 55.7 & $\mathrm{~T}$ & 2.4 & 1.02 & $3 \phi 8$ & $\mathrm{~T}$ & 2.9 & 16.73 \\
\hline & SU1 & 18.62 & 55.7 & $\mathrm{~T}$ & 3.0 & 1.62 & $2 \phi 12.5$ & $\mathrm{~T}$ & 3.6 & 26.68 \\
\hline & SU2 & 21.98 & 55.7 & $\mathrm{~T}$ & 3.3 & 1.92 & $2 \phi 12.5$ & $\mathrm{~T}$ & 3.7 & 26.68 \\
\hline & SU3 & 10.57 & 55.7 & $\mathrm{~T}$ & 2.3 & 0.91 & $2 \phi 8$ & $\mathrm{~T}$ & 2.4 & 11.23 \\
\hline
\end{tabular}


Table A.14 - Checking for creep rupture, deflections and cracking - GFRP and Concrete C80

\begin{tabular}{|c|c|c|c|c|c|c|c|c|c|c|}
\hline B & $\mathbf{S}$ & $\left(\mathbf{f}_{\mathbf{f} . s} / \mathbf{f}_{\mathbf{f u}}\right) \%$ & $\mathrm{v}_{\mathrm{lt}}(\mathbf{c m})$ & $\mathbf{w}(\mathbf{m m})$ & $\mathbf{n} \varphi_{\mathbf{b}_{\text {_adj }}}(\mathbf{m m})$ & $\left(\mathbf{f}_{\mathbf{f} . s} / \mathbf{f}_{\mathbf{f u}}\right) \%$ & $\mathrm{v}_{\mathrm{lt}}(\mathbf{c m})$ & $\mathbf{w}(\mathbf{m m})$ & $\mathbf{F}_{\mathbf{r}}$ & $M_{r}(k N m)$ \\
\hline \multirow{2}{*}{1} & SP & 47 & 0.11 & - & $2 \phi 16$ & 19 & 0.11 & - & $\mathrm{T}$ & 77.36 \\
\hline & SU & 38 & - & - & $2 \phi 16$ & 15 & - & - & $\mathrm{T}$ & 78.22 \\
\hline & SP1 & 40 & 0.02 & - & $2 \phi 20$ & 16 & 0.02 & - & $\mathrm{T}$ & 105.24 \\
\hline & SP2 & 48 & 0.12 & $\theta .7$ & $2 \phi 20$ & 19 & 0.12 & 0.3 & $\mathrm{~T}$ & 105.24 \\
\hline 2 & SU1 & 18 & - & - & $2 \phi 10$ & 18 & - & - & $\mathrm{T}$ & 27.57 \\
\hline & SU2 & 46 & - & $\theta .7$ & $2 \phi 25$ & 19 & - & 0.3 & $\mathrm{C}$ & 139.30 \\
\hline & SU3 & 22 & - & - & $2 \phi 12.5$ & 14 & - & - & $\mathrm{T}$ & 42.60 \\
\hline \multirow{5}{*}{3} & SP1 & 37 & 0.13 & - & $2 \phi 20$ & 15 & 0.13 & - & $\mathrm{T}$ & 105.24 \\
\hline & SP2 & 41 & 0.07 & - & $2 \phi 16$ & 16 & 0.07 & - & $\mathrm{T}$ & 68.69 \\
\hline & SU1 & 37 & - & - & $2 \phi 20$ & 15 & - & - & $\mathrm{T}$ & 105.24 \\
\hline & SU2 & 38 & - & 0.6 & $2 \phi 25$ & 16 & - & 0.2 & $\mathrm{C}$ & 139.30 \\
\hline & SU3 & 35 & & - & $2 \phi 16$ & 14 & - & - & $\mathrm{T}$ & 68.70 \\
\hline \multirow{6}{*}{4} & SP1 & 27 & 0.05 & - & $2 \phi 12.5$ & 17 & 0.05 & - & $\mathrm{T}$ & 37.30 \\
\hline & SP2 & 32 & 0.07 & - & $2 \phi 12.5$ & 20 & 0.07 & - & $\mathrm{T}$ & 37.30 \\
\hline & SP3 & 1 & -0.01 & - & $3 \phi 8$ & 1 & -0.01 & - & $\mathrm{T}$ & 23.27 \\
\hline & SU1 & 27 & - & - & $2 \phi 12.5$ & 17 & - & - & $\mathrm{T}$ & 37.30 \\
\hline & SU2 & 36 & - & - & $2 \phi 20$ & 14 & - & - & $\mathrm{T}$ & 91.73 \\
\hline & SU3 & 36 & - & - & $2 \phi 16$ & 14 & - & - & $\mathrm{T}$ & 60.02 \\
\hline 5 & SP & 48 & 0.12 & - & $2 \phi 16$ & 19 & 0.12 & - & $\mathrm{T}$ & 42.73 \\
\hline \multirow{5}{*}{6} & SP1 & 36 & 0.10 & - & $2 \phi 16$ & 14 & 0.10 & - & $\mathrm{T}$ & 42.73 \\
\hline & SP2 & 14 & 0.00 & - & $2 \phi 8$ & 14 & 0.00 & - & $\mathrm{T}$ & 11.23 \\
\hline & SU1 & 35 & - & - & $2 \phi 12.5$ & 15 & - & - & $\mathrm{T}$ & 26.68 \\
\hline & SU2 & 47 & - & - & $2 \phi 16$ & 18 & - & - & $\mathrm{T}$ & 42.73 \\
\hline & SU3 & 4 & - & - & $2 \phi 8$ & 4 & - & - & $\mathrm{T}$ & 11.23 \\
\hline \multirow{2}{*}{7} & $\mathrm{SP}$ & 40 & 0.09 & - & $2 \phi 16$ & 15 & 0.09 & - & $\mathrm{T}$ & 42.73 \\
\hline & $\mathrm{SU}$ & 33 & - & - & $2 \phi 12.5$ & 14 & - & - & $\mathrm{T}$ & 26.68 \\
\hline \multirow{7}{*}{8} & SP1 & 31 & 0.06 & - & $2 \phi 12.5$ & 19 & 0.06 & - & $\mathrm{T}$ & 31.98 \\
\hline & SP2 & 16 & 0.01 & - & $3 \phi 8$ & 16 & 0.01 & - & $\mathrm{T}$ & 20.00 \\
\hline & SP3 & 26 & 0.04 & - & $2 \phi 12.5$ & 16 & 0.04 & - & $\mathrm{T}$ & 31.98 \\
\hline & SU1 & 14 & - & - & $3 \phi 8$ & 14 & - & - & $\mathrm{T}$ & 20.00 \\
\hline & SU2 & 47 & - & - & $2 \phi 16$ & 18 & - & - & $\mathrm{T}$ & 51.37 \\
\hline & SU3 & 46 & - & - & $2 \phi 16$ & 18 & - & - & $\mathrm{T}$ & 51.37 \\
\hline & SU4 & 27 & - & - & $2 \phi 12.5$ & 17 & - & - & $\mathrm{T}$ & 31.98 \\
\hline \multirow{5}{*}{9} & SP1 & 46 & 0.06 & - & $2 \phi 12.5$ & 19 & 0.06 & - & $\mathrm{T}$ & 26.68 \\
\hline & SP2 & 34 & 0.06 & - & $2 \phi 16$ & 13 & 0.06 & - & $\mathrm{T}$ & 42.73 \\
\hline & SU1 & 35 & - & 0.5 & $2 \phi 20$ & 14 & - & 0.2 & $\mathrm{C}$ & 55.63 \\
\hline & SU2 & 40 & - & 0.6 & $2 \phi 20$ & 16 & - & 0.3 & $\mathrm{C}$ & 55.63 \\
\hline & SU3 & 31 & - & - & $2 \phi 10$ & 20 & - & - & $\mathrm{T}$ & 17.34 \\
\hline
\end{tabular}


Table A.15 - Design for the ultimate limit state - Steel CA50 and Concrete C25

\begin{tabular}{|c|c|c|c|c|c|c|c|c|c|c|c|}
\hline B & $\mathbf{S}$ & $\mathbf{M}_{\mathrm{d}}(\mathbf{k N m})$ & $\mathbf{M}_{\text {lim }}(\mathbf{k N m})$ & $\mathbf{x}_{\mathbf{i}}(\mathbf{c m})$ & $\mathbf{A}_{\mathbf{f}}\left(\mathbf{c m}^{2}\right)$ & $\mathbf{n} \phi_{\mathrm{b}}(\mathbf{m m})$ & $\mathbf{x}_{\mathbf{r}}(\mathbf{c m})$ & $\varepsilon_{\mathrm{s}}(\%)$ & $\mathbf{M}_{\mathbf{r}}(\mathbf{k N m})$ & $\begin{array}{c}\mathbf{V}_{\text {lt }} \\
(\mathbf{c m})\end{array}$ & $\begin{array}{c}\mathbf{w} \\
(\mathbf{m m})\end{array}$ \\
\hline \multirow{2}{*}{1} & SP & 28.98 & 127.03 & 3.9 & 1.53 & $3 \phi 8$ & 3.9 & 10 & 29.21 & 0.20 & 0.12 \\
\hline & SU & 23.10 & 127.03 & 3.1 & 1.21 & $3 \phi 8$ & 3.9 & 10 & 29.21 & - & - \\
\hline \multirow{5}{*}{2} & SP1 & 35.84 & 102.89 & 5.5 & 2.15 & $2 \phi 12.5$ & 6.3 & 10 & 40.94 & 0.04 & 0.12 \\
\hline & SP2 & 39.90 & 102.89 & 6.2 & 2.41 & $2 \phi 12.5$ & 6.3 & 10 & 40.94 & 0.23 & 0.15 \\
\hline & SU1 & 12.60 & 102.89 & 1.9 & 0.73 & $2 \phi 8$ & 2.6 & 10 & 17.51 & - & - \\
\hline & SU2 & 63.98 & 102.89 & 10.4 & 4.05 & $2 \phi 16$ & 10.3 & 10 & 63.97 & - & 0.15 \\
\hline & SU3 & 12.60 & 102.89 & 1.9 & 0.73 & $2 \phi 8$ & 2.6 & 10 & 17.51 & - & - \\
\hline \multirow{5}{*}{3} & SP1 & 32.34 & 102.89 & 4.9 & 1.93 & $2 \phi 12.5$ & 6.3 & 10 & 40.94 & 0.25 & 0.11 \\
\hline & SP2 & 22.96 & 102.89 & 3.5 & 1.35 & $2 \phi 12.5$ & 6.3 & 10 & 40.94 & 0.12 & 0.08 \\
\hline & SU1 & 32.20 & 102.89 & 4.9 & 1.92 & $2 \phi 12.5$ & 6.3 & 10 & 40.94 & - & 0.11 \\
\hline & SU2 & 53.76 & 102.89 & 8.5 & 3.33 & $2 \phi 16$ & 10.3 & 10 & 63.97 & - & 0.12 \\
\hline & SU3 & 19.04 & 102.89 & 2.8 & 1.11 & $3 \phi 8$ & 3.9 & 10 & 25.94 & - & - \\
\hline \multirow{6}{*}{4} & SP1 & 12.32 & 81.30 & 2.1 & 0.81 & $2 \phi 8$ & 2.6 & 10 & 15.33 & 0.09 & - \\
\hline & SP2 & 14.70 & 81.30 & 2.5 & 0.97 & $2 \phi 8$ & 2.6 & 10 & 15.33 & 0.12 & - \\
\hline & SP3 & 9.96 & 81.30 & 1.7 & 0.65 & $2 \phi 8$ & 2.6 & 10 & 15.33 & 0.02 & - \\
\hline & SU1 & 12.32 & 81.30 & 2.1 & 0.81 & $2 \phi 8$ & 2.6 & 10 & 15.33 & - & - \\
\hline & SU2 & 26.60 & 81.30 & 4.6 & 1.79 & $2 \phi 12.5$ & 6.3 & 10 & 35.60 & - & 0.11 \\
\hline & SU3 & 16.38 & 81.30 & 2.8 & 1.08 & $3 \phi 8$ & 3.9 & 10 & 22.66 & - & 0.09 \\
\hline 5 & SP & 15.68 & 45.73 & 3.6 & 1.41 & $3 \phi 8$ & 3.9 & 10 & 16.10 & 0.23 & 0.13 \\
\hline \multirow{5}{*}{6} & SP1 & 11.90 & 45.73 & 2.7 & 1.06 & $3 \phi 8$ & 3.9 & 10 & 16.10 & 0.18 & 0.10 \\
\hline & SP2 & 5.60 & 45.73 & 1.2 & 0.49 & $2 \phi 8$ & 2.6 & 10 & 10.96 & 0.01 & - \\
\hline & SU1 & 7.56 & 45.73 & 1.7 & 0.66 & $2 \phi 8$ & 2.6 & 10 & 10.96 & - & - \\
\hline & SU2 & 15.40 & 45.73 & 3.5 & 1.38 & $3 \phi 8$ & 3.9 & 10 & 16.10 & - & 0.13 \\
\hline & SU3 & 5.60 & 45.73 & 1.2 & 0.49 & $2 \phi 8$ & 2.6 & 10 & 10.96 & - & - \\
\hline \multirow{2}{*}{7} & SP & 12.88 & 45.73 & 2.9 & 1.15 & $3 \phi 8$ & 3.9 & 10 & 16.10 & 0.17 & 0.10 \\
\hline & $\mathrm{SU}$ & 7.28 & 45.73 & 1.6 & 0.64 & $2 \phi 8$ & 2.6 & 10 & 10.96 & - & - \\
\hline \multirow{7}{*}{8} & SP1 & 11.90 & 62.24 & 2.3 & 0.89 & $2 \phi 8$ & 2.6 & 10 & 13.14 & 0.11 & 0.14 \\
\hline & SP2 & 7.62 & 62.24 & 1.5 & 0.57 & $2 \phi 8$ & 2.6 & 10 & 13.14 & 0.02 & - \\
\hline & SP3 & 10.50 & 62.24 & 2.0 & 0.79 & $3 \phi 8$ & 3.9 & 10 & 19.38 & 0.07 & - \\
\hline & SU1 & 7.62 & 62.24 & 1.5 & 0.57 & $2 \phi 8$ & 2.6 & 10 & 13.14 & - & - \\
\hline & SU2 & 18.48 & 62.24 & 3.6 & 1.41 & $3 \phi 8$ & 3.9 & 10 & 19.38 & - & 0.12 \\
\hline & SU3 & 18.48 & 62.24 & 3.6 & 1.41 & $2 \phi 10$ & 4.0 & 10 & 20.07 & - & 0.13 \\
\hline & SU4 & 11.06 & 62.24 & 2.1 & 0.83 & $2 \phi 8$ & 2.6 & 10 & 13.14 & - & - \\
\hline \multirow{5}{*}{9} & SP1 & 10.50 & 45.73 & 2.4 & 0.93 & $2 \phi 8$ & 2.6 & 10 & 10.96 & 0.19 & 0.14 \\
\hline & SP2 & 11.76 & 45.73 & 2.7 & 1.04 & $3 \phi 8$ & 3.9 & 10 & 16.10 & 0.12 & 0.09 \\
\hline & SU1 & 18.62 & 45.73 & 4.3 & 1.70 & $2 \phi 12.5$ & 6.3 & 10 & 24.93 & - & 0.12 \\
\hline & SU2 & 21.98 & 45.73 & 5.2 & 2.03 & $2 \phi 12.5$ & 6.3 & 10 & 24.93 & - & 0.13 \\
\hline & SU3 & 7.14 & 45.73 & 1.6 & 0.62 & $2 \phi 8$ & 2.6 & 10 & 10.96 & - & - \\
\hline
\end{tabular}


Table A.16 - Design for the ultimate limit state - Steel CA50 and Concrete C80

\begin{tabular}{|c|c|c|c|c|c|c|c|c|c|c|c|}
\hline B & $\mathbf{S}$ & $\mathbf{M}_{\mathrm{d}}(\mathbf{k N m})$ & $\mathbf{M}_{\mathrm{lim}}(\mathbf{k N m})$ & $\mathbf{x}_{\mathbf{i}}(\mathbf{c m})$ & $\mathbf{A}_{\mathbf{f}}\left(\mathbf{c m}^{2}\right)$ & $\mathrm{n} \phi_{\mathrm{b}}(\mathbf{m m})$ & $\mathbf{x}_{\mathrm{r}}(\mathbf{c m})$ & $\varepsilon_{\mathrm{s}}(\%)$ & $\mathrm{M}_{\mathrm{r}}(\mathbf{k N m})$ & $\begin{array}{c}v_{\mathrm{ltt}} \\
(\mathrm{cm})\end{array}$ & $\begin{array}{c}\mathbf{w} \\
(\mathbf{m m})\end{array}$ \\
\hline \multirow{2}{*}{1} & SP & 28.98 & 259.32 & 1.6 & 1.50 & $3 \phi 8$ & 1.6 & 10 & 29.85 & 0.11 & - \\
\hline & SU & 23.1 & 259.32 & 1.2 & 1.19 & $3 \phi 8$ & 1.6 & 10 & 29.85 & - & - \\
\hline \multirow{5}{*}{2} & SP1 & 35.84 & 210.05 & 2.2 & 2.08 & $2 \phi 12.5$ & 2.5 & 10 & 42.63 & 0.02 & - \\
\hline & SP2 & 39.9 & 210.05 & 2.4 & 2.32 & $2 \phi 12.5$ & 2.5 & 10 & 42.63 & 0.12 & 0.13 \\
\hline & SU1 & 10.5 & 210.05 & 0.7 & 0.72 & $2 \phi 8$ & 1.0 & 10 & 17.80 & - & - \\
\hline & SU2 & 63.98 & 210.05 & 3.9 & 3.77 & $2 \phi 16$ & 4.2 & 10 & 68.51 & - & 0.13 \\
\hline & SU3 & 11.9 & 210.05 & 0.7 & 0.72 & $2 \phi 8$ & 1.0 & 10 & 17.80 & - & - \\
\hline \multirow{5}{*}{3} & SP1 & 32.34 & 210.05 & 1.9 & 1.87 & $2 \phi 12.5$ & 2.5 & 10 & 42.63 & 0.13 & - \\
\hline & SP2 & 22.96 & 210.05 & 1.4 & 1.32 & $2 \phi 10$ & 1.6 & 10 & 27.60 & 0.07 & - \\
\hline & SU1 & 32.2 & 210.05 & 1.9 & 1.86 & $2 \phi 12.5$ & 2.5 & 10 & 42.63 & - & - \\
\hline & SU2 & 53.76 & 210.05 & 3.3 & 3.14 & $2 \phi 16$ & 4.2 & 10 & 68.51 & - & 0.11 \\
\hline & SU3 & 19.04 & 210.05 & 1.1 & 1.09 & $3 \phi 8$ & 1.6 & 10 & 26.57 & - & - \\
\hline \multirow{6}{*}{4} & SP1 & 12.32 & 165.96 & 0.8 & 0.79 & $2 \phi 8$ & 1.0 & 10 & 15.61 & 0.05 & - \\
\hline & SP2 & 14.7 & 165.96 & 1.0 & 0.95 & $2 \phi 8$ & 1.0 & 10 & 15.61 & 0.07 & - \\
\hline & SP3 & -0.42 & 165.96 & 0.7 & 0.64 & $2 \phi 8$ & 1.0 & 10 & 15.61 & 0.01 & - \\
\hline & SU1 & 12.32 & 165.96 & 0.8 & 0.79 & $2 \phi 8$ & 1.0 & 10 & 15.61 & - & - \\
\hline & SU2 & 26.6 & 165.96 & 1.8 & 1.73 & $2 \phi 12.5$ & 2.5 & 10 & 37.30 & - & - \\
\hline & SU3 & 16.38 & 165.96 & 1.1 & 1.06 & $3 \phi 8$ & 1.6 & 10 & 23.30 & - & - \\
\hline 5 & SP & 15.68 & 93.36 & 1.4 & 1.36 & $3 \phi 8$ & 1.6 & 10 & 16.74 & 0.12 & - \\
\hline \multirow{5}{*}{6} & SP1 & 11.9 & 93.36 & 1.1 & 1.03 & $3 \phi 8$ & 1.6 & 10 & 16.74 & 0.10 & - \\
\hline & SP2 & 3.08 & 93.36 & 0.5 & 0.48 & $2 \phi 8$ & 1.0 & 10 & 11.24 & 0.00 & - \\
\hline & SU1 & 7.56 & 93.36 & 0.7 & 0.65 & $2 \phi 8$ & 1.0 & 10 & 11.24 & - & - \\
\hline & SU2 & 15.4 & 93.36 & 1.4 & 1.34 & $3 \phi 8$ & 1.6 & 10 & 16.74 & - & - \\
\hline & SU3 & 0.7 & 93.36 & 0.5 & 0.48 & $2 \phi 8$ & 1.0 & 10 & 11.24 & - & - \\
\hline \multirow{2}{*}{7} & SP & 12.88 & 93.36 & 1.2 & 1.11 & $3 \phi 8$ & 1.6 & 10 & 16.74 & 0.09 & - \\
\hline & SU & 7.28 & 93.36 & 0.6 & 0.63 & $2 \phi 8$ & 1.0 & 10 & 11.24 & - & - \\
\hline \multirow{7}{*}{8} & SP1 & 11.9 & 127.07 & 0.9 & 0.88 & $2 \phi 8$ & 1.0 & 10 & 13.43 & 0.06 & - \\
\hline & SP2 & 6.58 & 127.07 & 0.6 & 0.56 & $2 \phi 8$ & 1.0 & 10 & 13.43 & 0.01 & - \\
\hline & SP3 & 10.5 & 127.07 & 0.8 & 0.77 & $2 \phi 8$ & 1.0 & 10 & 13.43 & 0.04 & - \\
\hline & SU1 & 5.32 & 127.07 & 0.6 & 0.56 & $2 \phi 8$ & 1.0 & 10 & 13.43 & - & - \\
\hline & SU2 & 18.48 & 127.07 & 1.4 & 1.37 & $3 \phi 8$ & 1.6 & 10 & 20.02 & - & - \\
\hline & SU3 & 18.48 & 127.07 & 1.4 & 1.37 & $2 \phi 10$ & 1.6 & 10 & 20.77 & - & - \\
\hline & SU4 & 11.06 & 127.07 & 0.8 & 0.82 & $2 \phi 8$ & 1.0 & 10 & 13.43 & - & - \\
\hline \multirow{5}{*}{9} & SP1 & 10.5 & 93.36 & 0.9 & 0.91 & $2 \phi 8$ & 1.0 & 10 & 11.24 & 0.06 & - \\
\hline & SP2 & 11.76 & 93.36 & 1.1 & 1.02 & $2 \phi 8$ & 1.0 & 10 & 11.24 & 0.06 & - \\
\hline & SU1 & 18.62 & 93.36 & 1.7 & 1.62 & $2 \phi 12.5$ & 2.5 & 10 & 26.63 & - & 0.10 \\
\hline & SU2 & 21.98 & 93.36 & 2.0 & 1.92 & $2 \phi 12.5$ & 2.5 & 10 & 26.63 & - & 0.12 \\
\hline & SU3 & 7.14 & 93.36 & 0.6 & 0.61 & $2 \phi 8$ & 1.0 & 10 & 11.24 & - & - \\
\hline
\end{tabular}




\section{Appendix B - Design Examples using the FRP RC Design Program}

Figure B.1 - Example A: Balanced stress block on the flange, under-reinforced cross-section and concrete exhibiting linear behavior

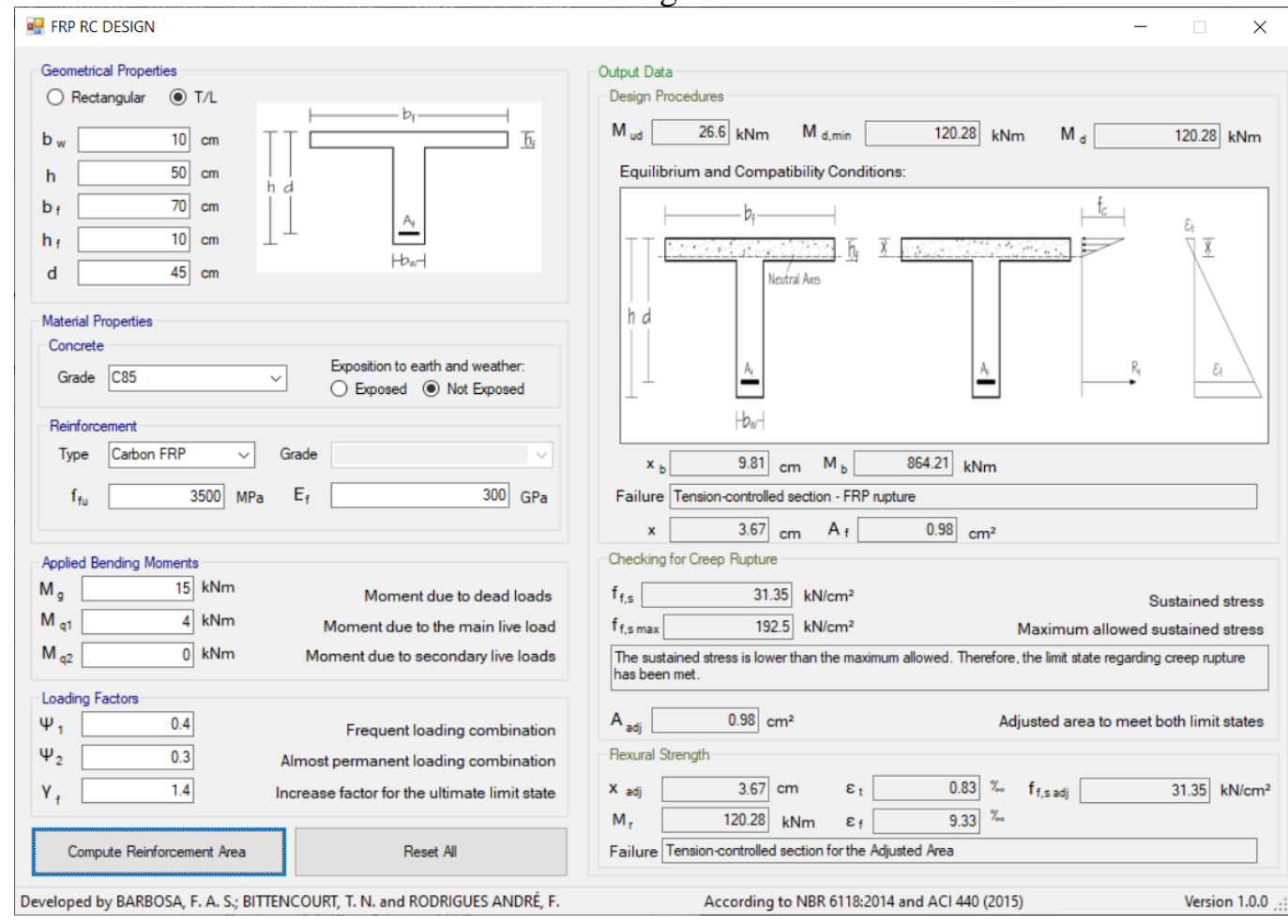

\section{Source: Author}

Figure B.2- Example B: Balanced stress block on the flange, under-reinforced cross-section and concrete exhibiting non-linear behavior
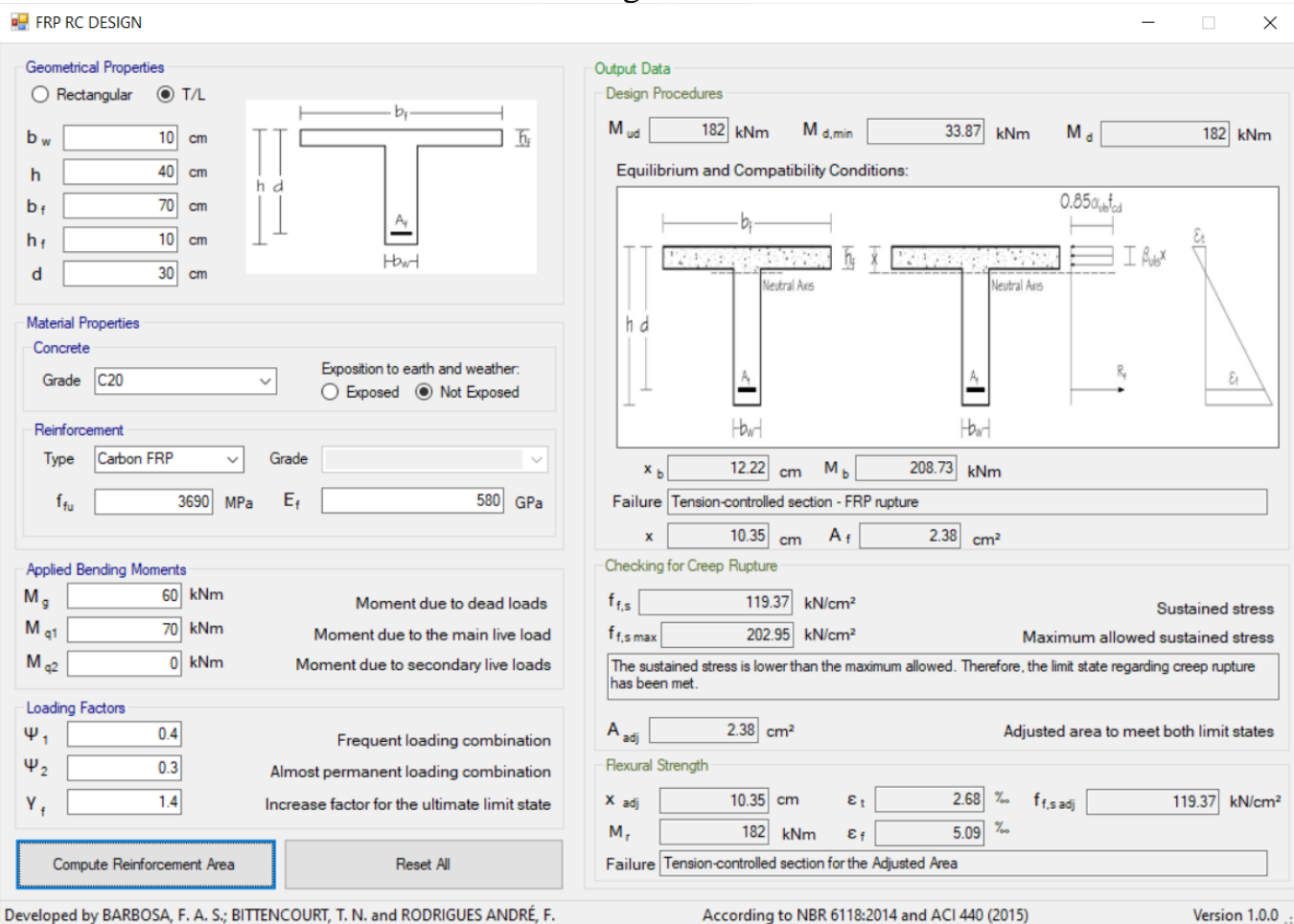
Figure B.3 - Example C: Balanced stress block on the flange, over-reinforced cross-section and actual stress block on the flange

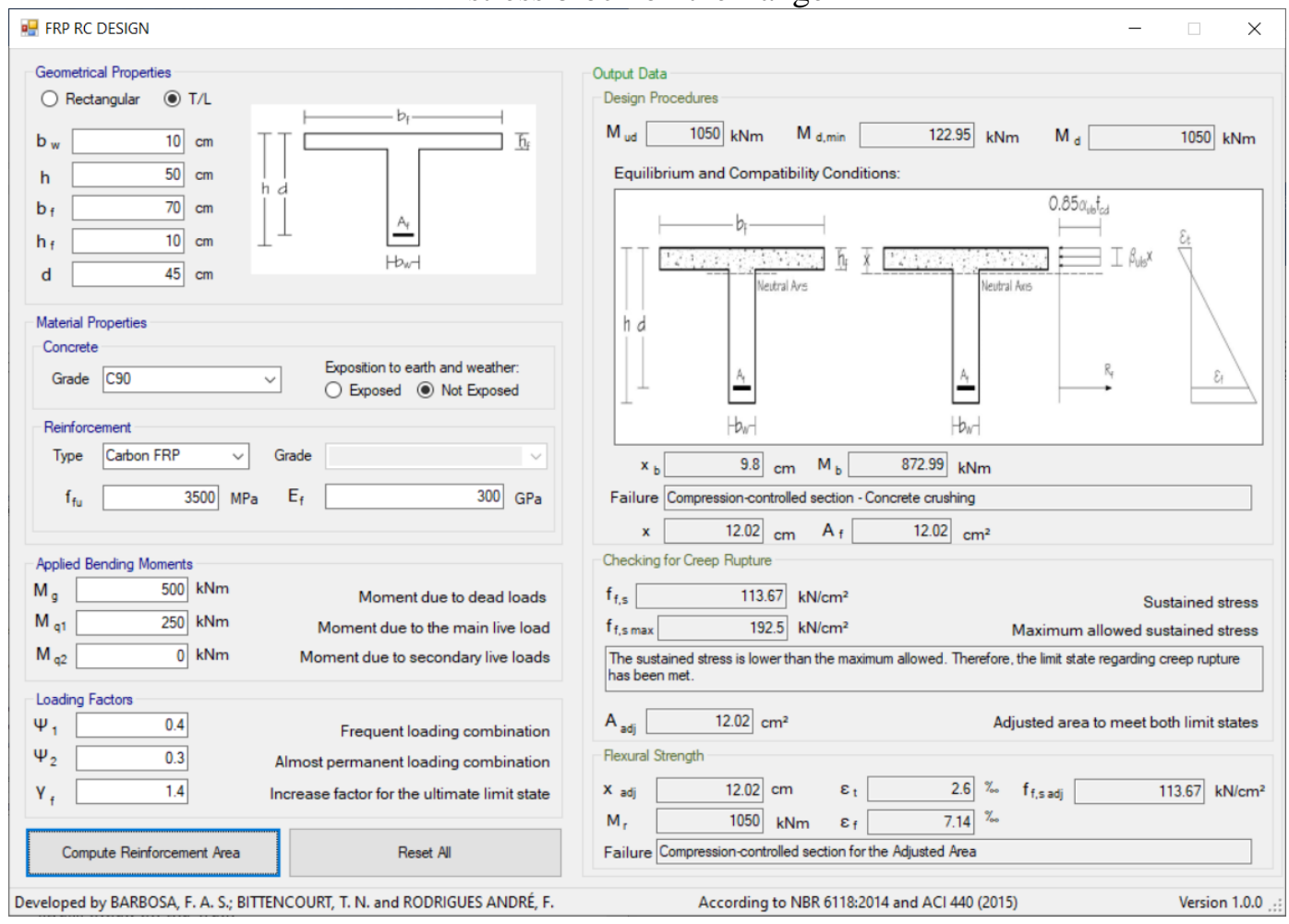

\section{Source: Author}

Figure B.4 - Example D: Balanced stress block on the flange, over-reinforced cross-section and actual stress block on the web.

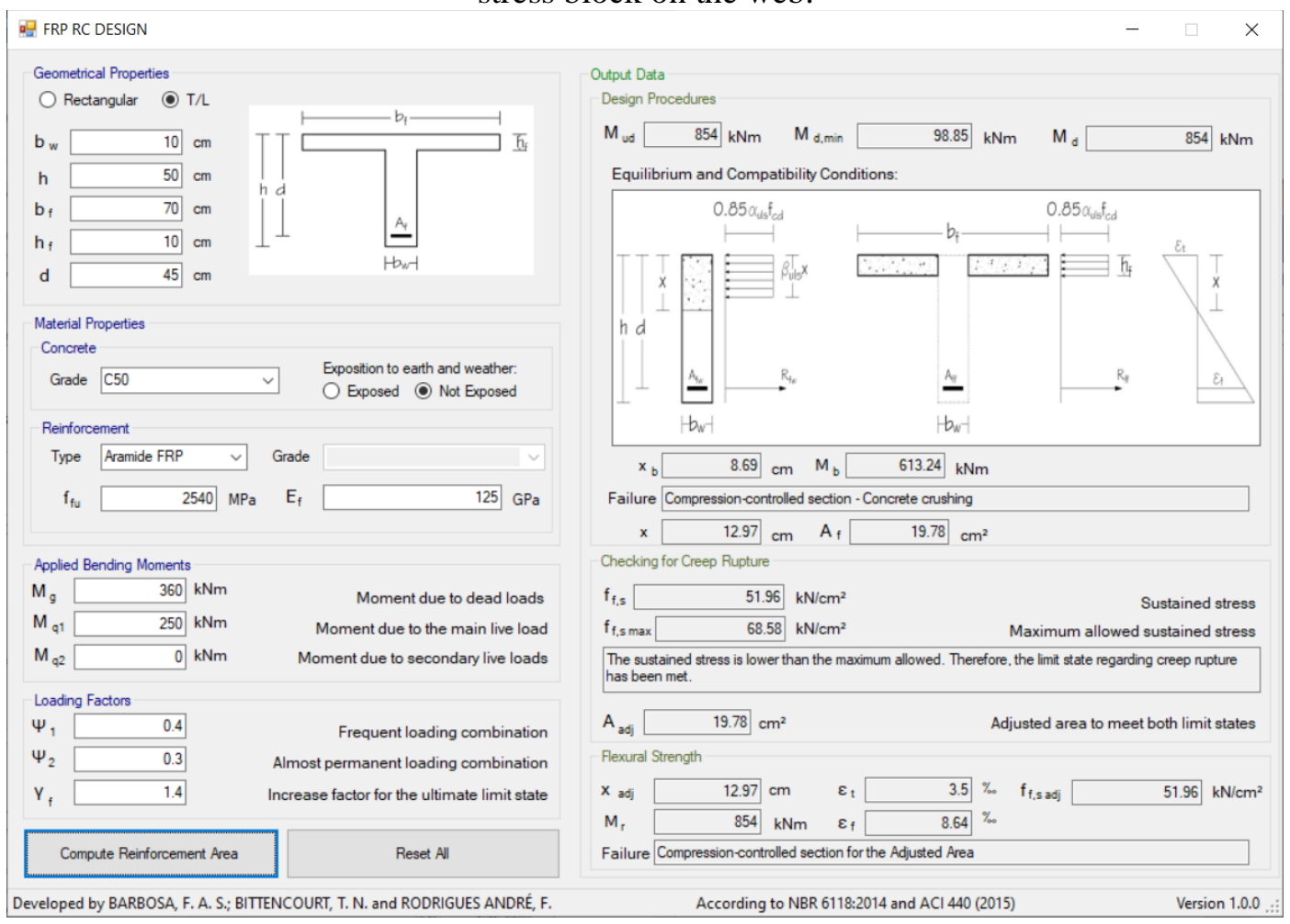

\section{Source: Author}


Figure B.5 - Example E: Balanced stress block on the web, under-reinforced cross-section, concrete exhibiting non-linear behavior and actual stress block on the flange

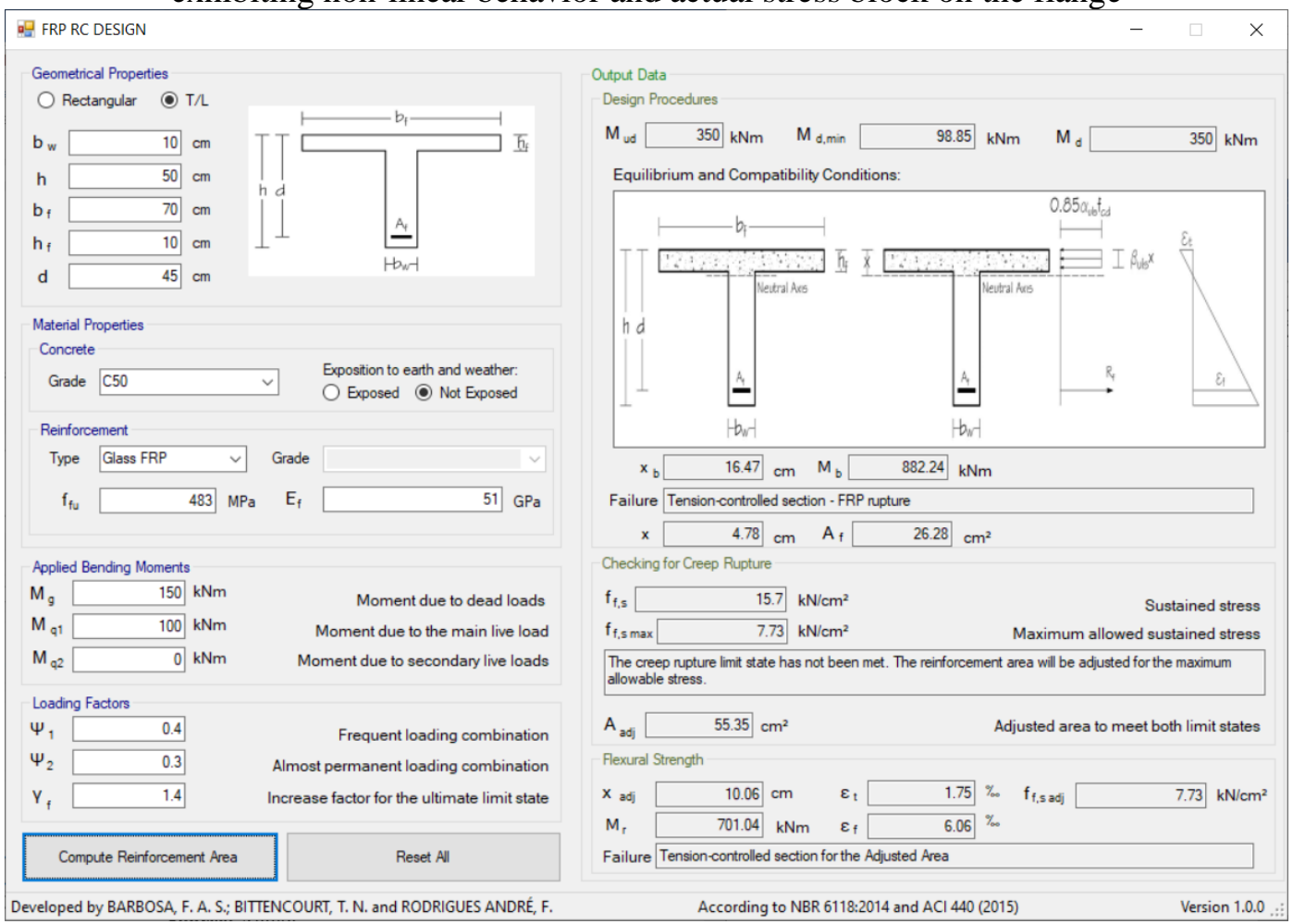

\section{Source: Author}

Figure B.6 - Example F: Balanced stress block on the web, under-reinforced cross-section, concrete exhibiting non-linear behavior and actual stress block on the web.

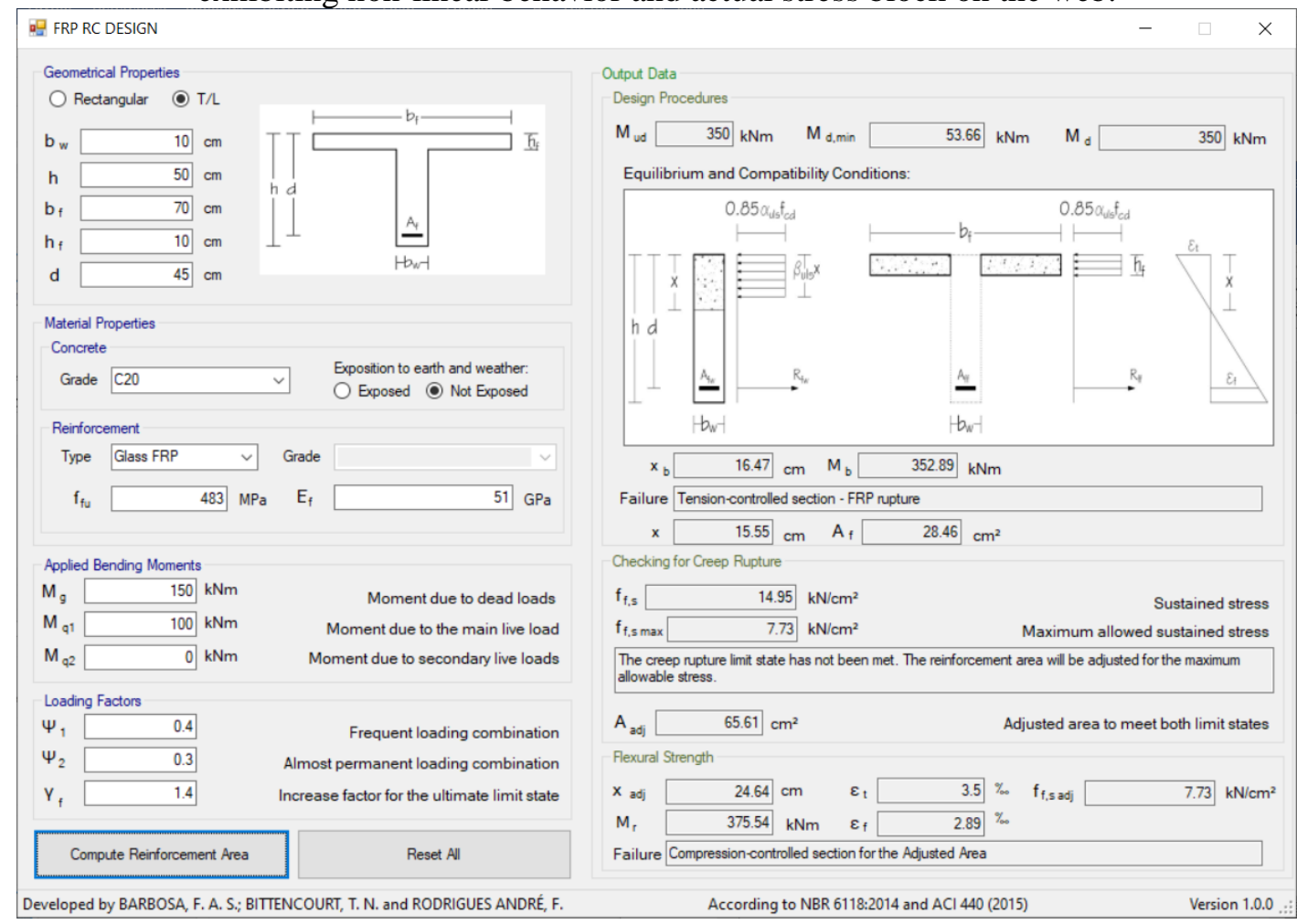

Source: Author 
Figure B.7 - Example G: Balanced stress block on the web, under-reinforced cross-section, concrete exhibiting linear behavior and actual neutral axis on the flange

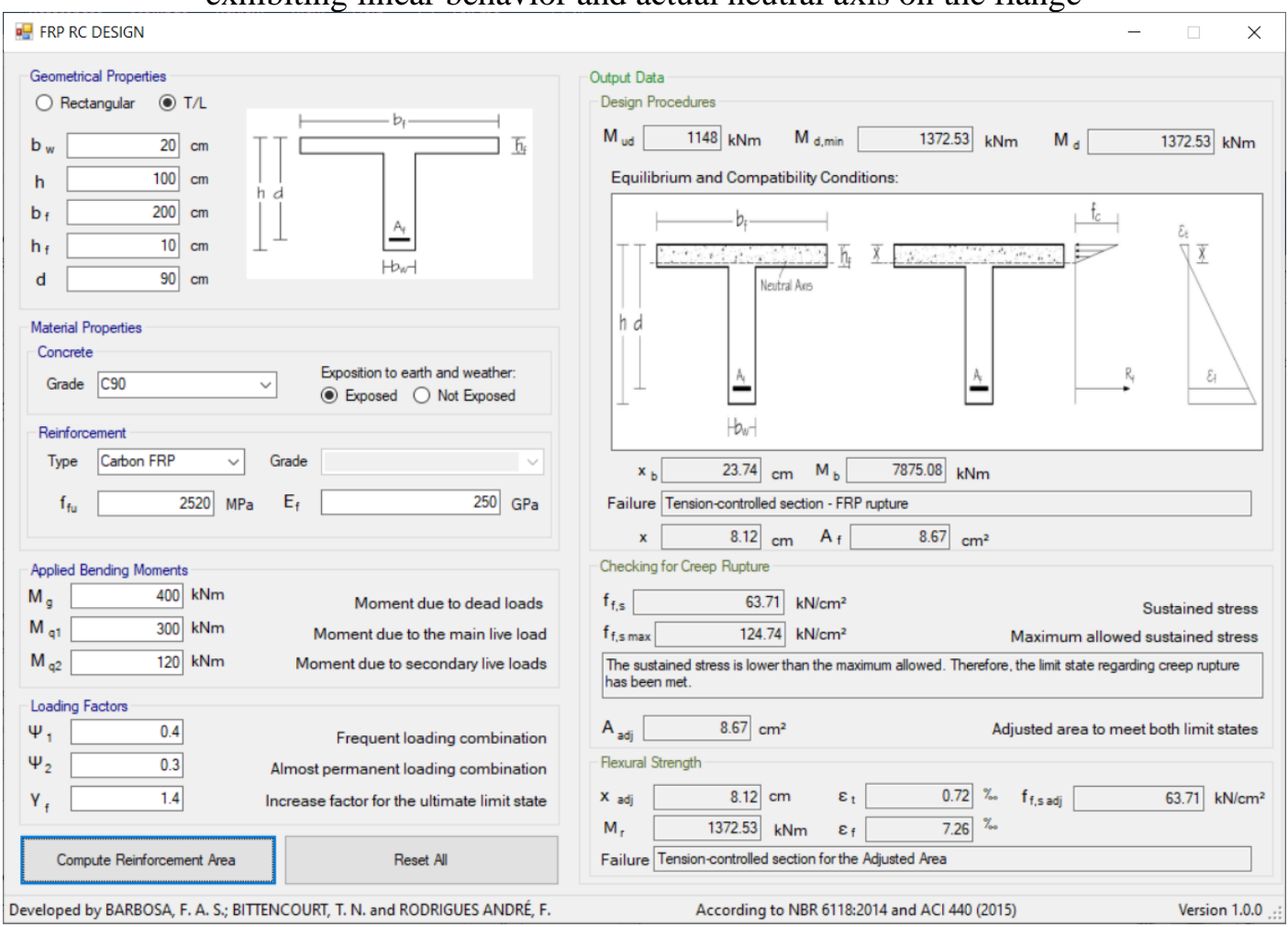

\section{Source: Author}

Figure B.8 - Example H: Balanced stress block on the web, under-reinforced cross-section, concrete exhibiting linear behavior and actual neutral axis on the web.

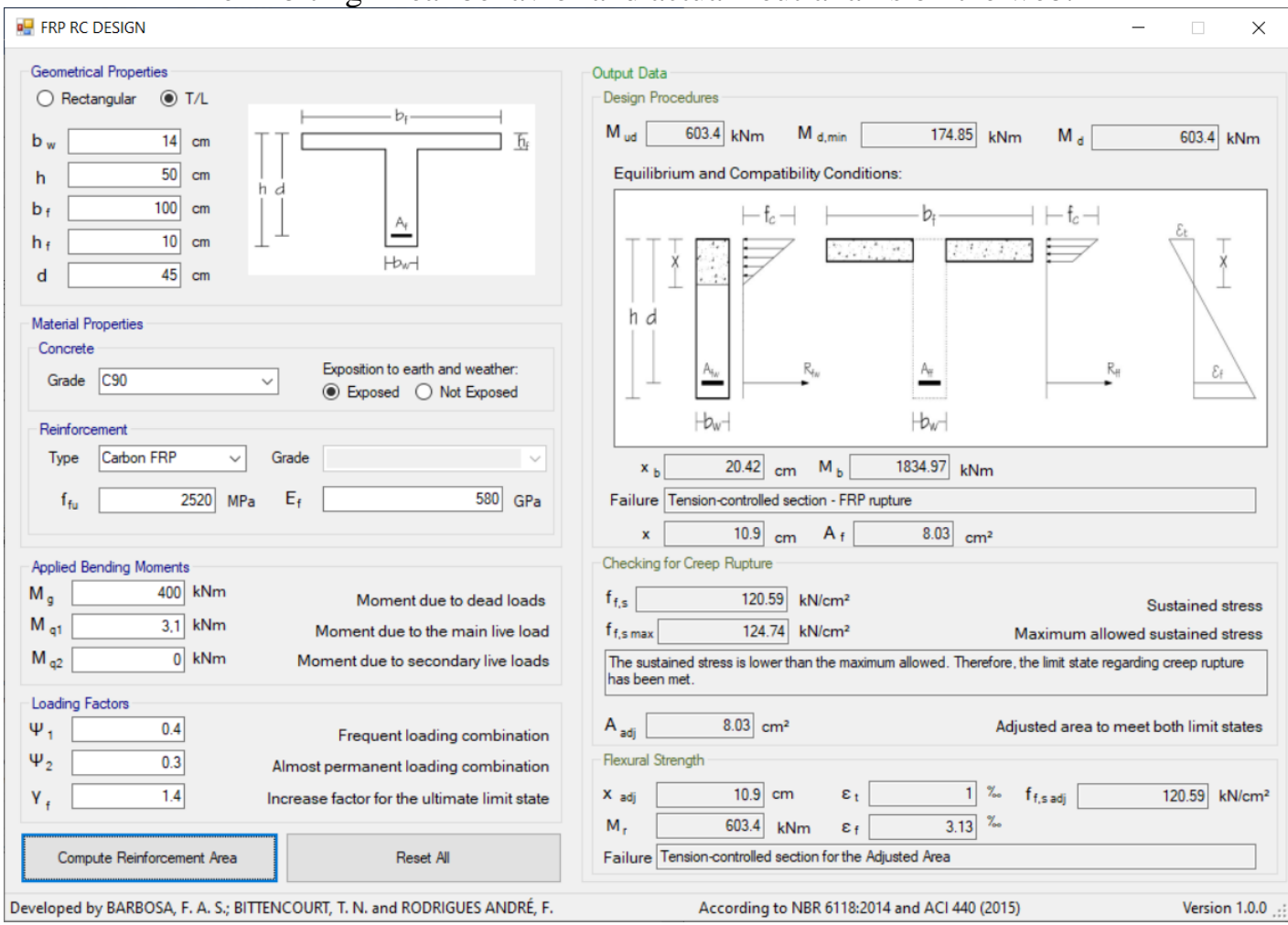


Figure B.9 - Example I: Balanced stress block on the web, over-reinforced cross-section and actual stress block on the web

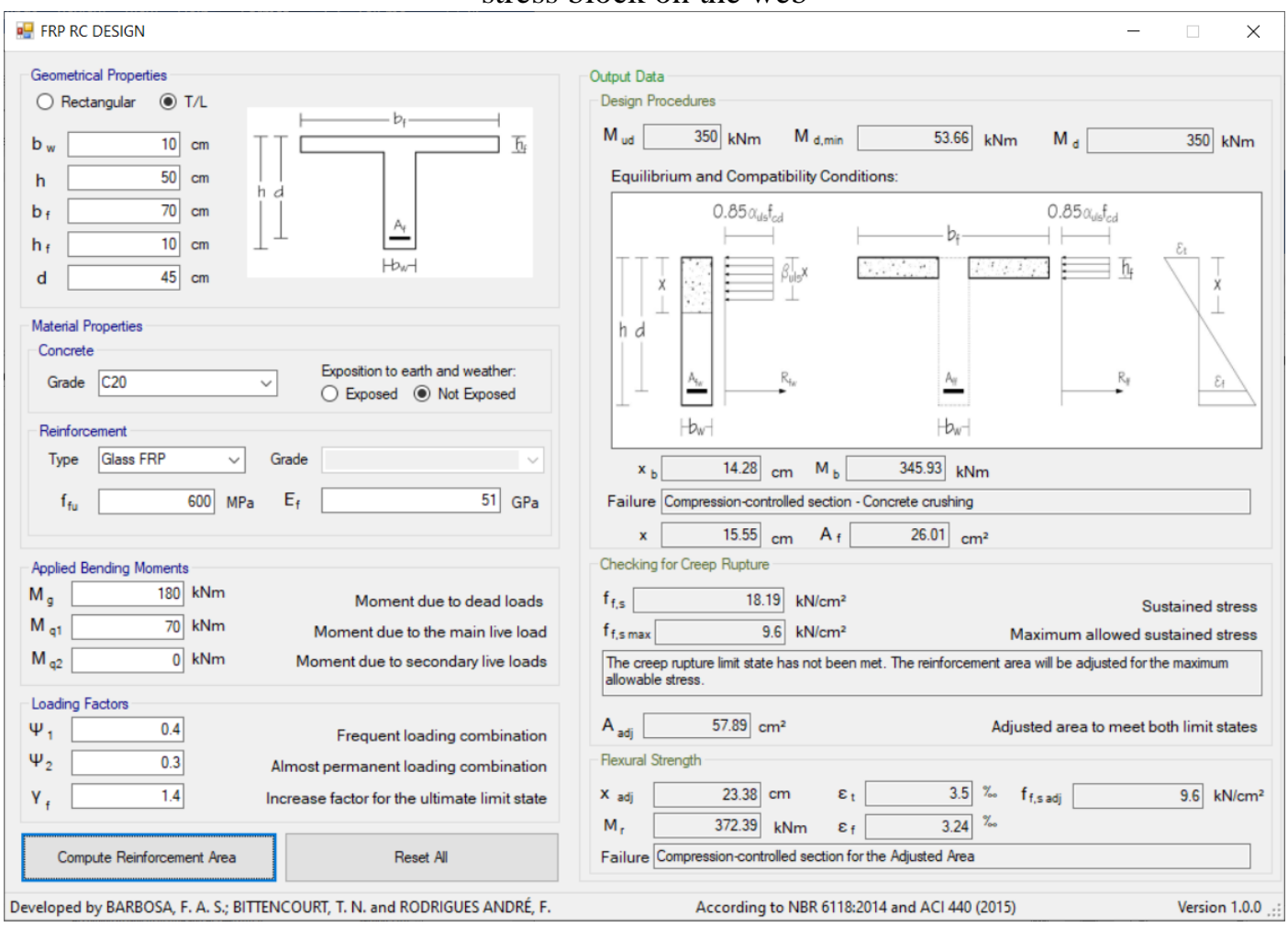

Source: Author 